\title{
Host defense to bacterial endotoxin : role of CD14, LBP and BPI
}

Citation for published version (APA):

Dentener, M. A. (1996). Host defense to bacterial endotoxin : role of CD14, LBP and BPI. [Doctoral Thesis, Maastricht University]. Universiteit Maastricht. https://doi.org/10.26481/dis.19961219md

Document status and date:

Published: 01/01/1996

DOI:

10.26481/dis.19961219md

Document Version:

Publisher's PDF, also known as Version of record

\section{Please check the document version of this publication:}

- A submitted manuscript is the version of the article upon submission and before peer-review. There can be important differences between the submitted version and the official published version of record.

People interested in the research are advised to contact the author for the final version of the publication, or visit the DOI to the publisher's website.

- The final author version and the galley proof are versions of the publication after peer review.

- The final published version features the final layout of the paper including the volume, issue and page numbers.

Link to publication

\footnotetext{
General rights rights.

- You may freely distribute the URL identifying the publication in the public portal. please follow below link for the End User Agreement:

www.umlib.nl/taverne-license

Take down policy

If you believe that this document breaches copyright please contact us at:

repository@maastrichtuniversity.nl

providing details and we will investigate your claim.
}

Copyright and moral rights for the publications made accessible in the public portal are retained by the authors and/or other copyright owners and it is a condition of accessing publications that users recognise and abide by the legal requirements associated with these

- Users may download and print one copy of any publication from the public portal for the purpose of private study or research.

- You may not further distribute the material or use it for any profit-making activity or commercial gain

If the publication is distributed under the terms of Article $25 \mathrm{fa}$ of the Dutch Copyright Act, indicated by the "Taverne" license above, 


\section{Host Defense to Bacterial Endotoxin Role of CD14, LBP and BPI}




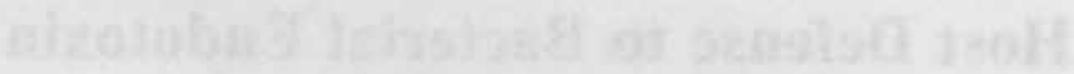

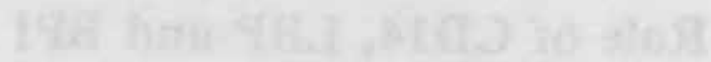




\title{
Host Defense to Bacterial Endotoxin Role of CD14, LBP and BPI
}

\author{
PROEFSCHRIFT
}

ter verkrijging van de graad van doctor aan de Universiteit Maastricht

op gezag van de Rector Magnificus, Prof.mr. M.J. Cohen, volgens het besluit van het College van Decanen, in het openbaar te verdedigen op donderdag 19 december 1996 om 14.00 uur

door

\section{Maria Anna Dentener}

geboren te Mierlo, 7 oktober 1965 


\section{Promotor}

Prof.dr. E.F.M. Wouters

\section{Copromotor}

Dr. W.A. Buurman

\section{Beoordelingscommissie}

Prof.dr. C.A.M.V.A. Bruggeman (voorzitter)

Prof.dr. M.P. van Dieijen-Visser

Prof.dr. J. Kips (Rijksuniversteit Gent. België)

Dr. G. Ramsay

Prof.dr. E.Th. Rietschel (Forschungsinstitut Borstel, Duitsland)

(C) Mieke A. Dentener, Maastricht 1996

ISBN 90-9009815-1

Production: Datawyse, Maastricht/ Krips Repro Meppel

Het verschijnen van dit proefschrift werd mede mogelijk gemaakt door financiele steun van de Stichting Dr.Ir. J.H.J. van de Laar.

( mslag ontwerp door Anita Vreugdenhil, getiteld: Samenspel. 
Opgedragen aan mijn ouders

Voor Johan 


\section{CONTENTS}

\section{CHAPTER 1}

General introduction . . . . . . . . . . . . . . . 9

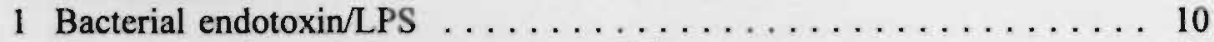

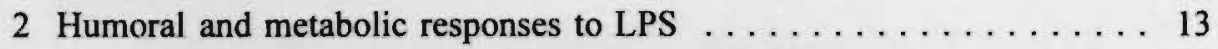

2.1 LPS binding to plasma lipoproteins and clearance . . . . . . 13

2.2 Complement activation .................. 15

2.3 Induction of coagulation $\ldots \ldots \ldots \ldots \ldots \ldots \ldots \ldots \ldots \ldots$

2.4 Neuroendocrine responses and metabolic alterations . . . . . . 17

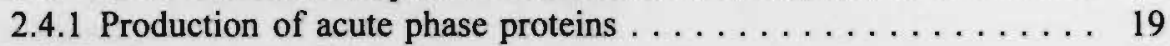

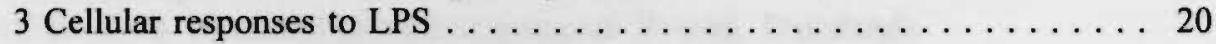

3.1 Cellular receptors for LPS $\ldots \ldots \ldots \ldots \ldots \ldots \ldots \ldots \ldots 20$

3.1.1 Cell surface LPS binding structures $\ldots \ldots \ldots \ldots \ldots \ldots \ldots 20$

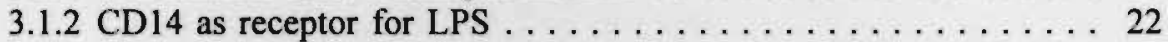

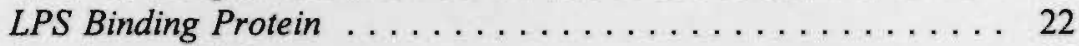

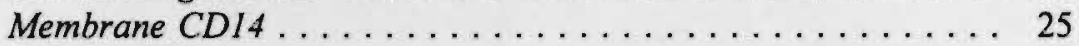

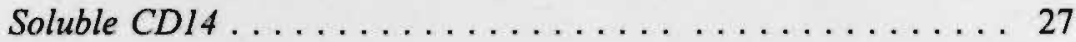

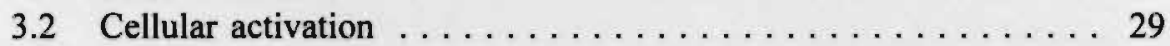

3.2 .1 Monocytes . . . . . . . . . . . . . . . . . . . . 29

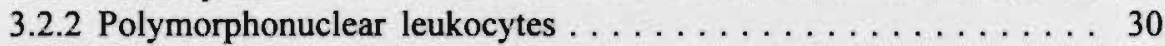

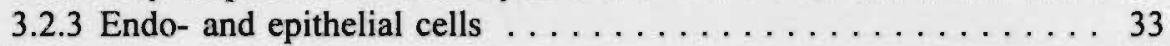

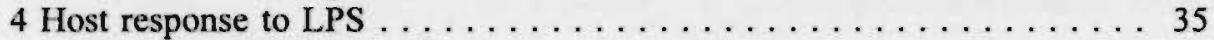

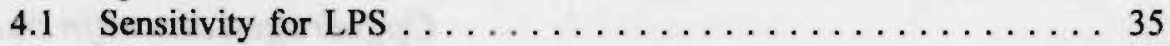

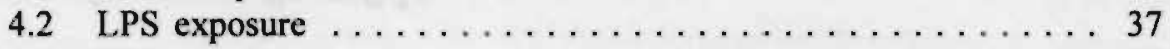

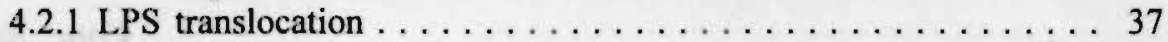

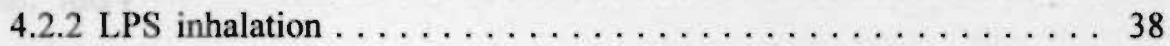

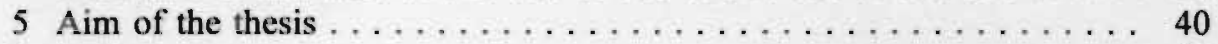

6 References ........................... 41

\section{CHAPTER 2}

Role of tumour necrosis factor in the enhanced sensitivity of mice to endotoxin after exposure to lead . . . . . . . . . . . . . . 55 Immunopharmacol Immunotoxicol 1989:11:321-34

\section{CHAPTER 3}

Involvement of CD14 in lipopolysaccharide-induced tumor necrosis factor- $\alpha$, IL- 6 and IL-8 release by human monocytes and alveolar macrophages

\section{CHAPTER 4}

Anti-CD14 antibodies reduce responses of cultured human endothelial cells to endotoxin 
CHAPTER 5

Lipopolysaccharide LPS-mediated soluble TNF receptor release and TNF receptor expression by monocytes

$J$ Immunol 1994:152:5070-6

\section{CHAPTER 6}

Antagonistic effects of lipopolysaccharide binding protein and bactericidal/permeability-increasing protein on lipopolysaccharideinduced cytokine release by mononuclear phagocytes

J Immunol 1993;151:4258-65

\section{CHAPTER 7}

Characterization of two monoclonal antibodies directed against bactericidal/permeability-increasing protein

J Infect Dis 1994;170:1483-9

\section{CHAPTER 8}

Bactericidal/permeability-increasing protein, a lipopolysaccharide-specific protein on the surface of human peripheral blood monocytes.

$J$ Infect Dis 1996;173:252-5

\section{CHAPTER 9}

Bactericidal/permeability-increasing protein release in whole blood ex vivo: strong induction by lipopolysaccharide and tumor necrosis factor- $\alpha$. 119 $J$ Infect Dis 1997:175:108-17

\section{CHAPTER 10}

Presence of bactericidal/permeability-increasing protein in disease: detection by ELISA . . J Infect Dis 1995;171:739-43

\section{CHAPTER 11}

Lipopolysaccharide toxicity-regulating proteins in bacteremia

$J$ Infect Dis 1995:171:1250-7

\section{CHAPTER 12}

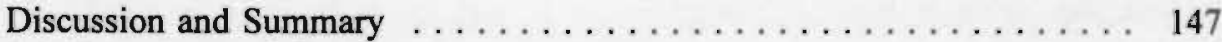

1 Discussion and Summary $\ldots \ldots \ldots \ldots \ldots \ldots \ldots \ldots \ldots \ldots \ldots$

2 References .......................... 156

NEDERLANDSE SAMENVATTING VOOR NIET-INGEWIJDEN $\ldots \ldots \ldots 160$

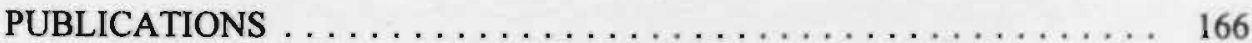

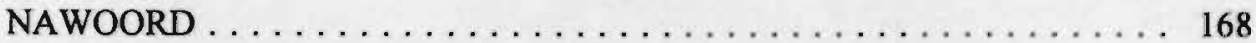

CURRICULUM VITAE $\ldots \ldots \ldots \ldots \ldots \ldots \ldots \ldots \ldots \ldots \ldots \ldots \ldots$ 
BPI bactericidal/permeability-increasing protein

$\mathrm{CD} \quad$ cluster of differentiation

CR complement receptor

CRP $\quad \mathrm{C}$-reactive protein

ELISA enzyme linked immunosorbent assay

FMLP formyl-methionyl-leucyl-phenylalanine

GPI glycosyl-phosphatidyl inositol

HDL high density lipoprotein

HUVEC human umbicial vein endothelial cell(s)

IFN interferon

IL interleukin

ICAM intercellular adhesion molecule

Kdo 2-keto-3-deoxyoctonic acid

LBP LPS Binding Protein

LDL low density lipoproteins

LPS lipopolysaccharide

LTA lipoteichoic acid

$\mathrm{mAb}$ monoclonal antibody

PAF platelet activating factor

$\mathrm{PGE}_{2}$ prostaglandin $\mathrm{E}_{2}$

PMA phorbol myristate acetate

PMN polymorphonuclear leukocytes

$r$

S

recombinant

soluble

STZ

TNF serum treated zymosan

TNFR TNF receptor

VCAM vascular cell adhesion molecule

VLDL very low density lipoprotein 
Chapter 1

\section{General Introduction}




\section{BACTERIAL ENDOTOXIN/LPS}

Bacterial endotoxin was first described about a century ago by R. Pfeiffer who observed that the Vibro cholerae bacterium synthesizes not only a heat-labile toxin, but also a heat resistant toxic substance that was not secreted by the bacterial cell. To distinguish this toxic compound bound to the bacteria from the toxic compounds secreted (exotoxins), it was called endotoxin (1). Now it is known that endotoxin is present in the cell wall of all gram-negative bacteria, and that this glycolipid is responsible for many of the pathological effects of these microorganisms (2).

The gram-negative bacterial cell wall is composed of three layers consisting of an inner membrane, a peptidoglycan layer and an outer membrane $(2,3)$. Endotoxin comprises the major component of the outer membrane (4)(Figure 1) and is essential for viability of bacteria. Since endotoxin has low fluidity, the outer membrane is an effective permeation barrier against hydrophobic and other agents $(2,3)$. Endotoxin, which is localized at the outer surface of all gram-negative bacteria, can be considered as a primary signal used by the host to detect and react to a wide range of microorganisms (5).

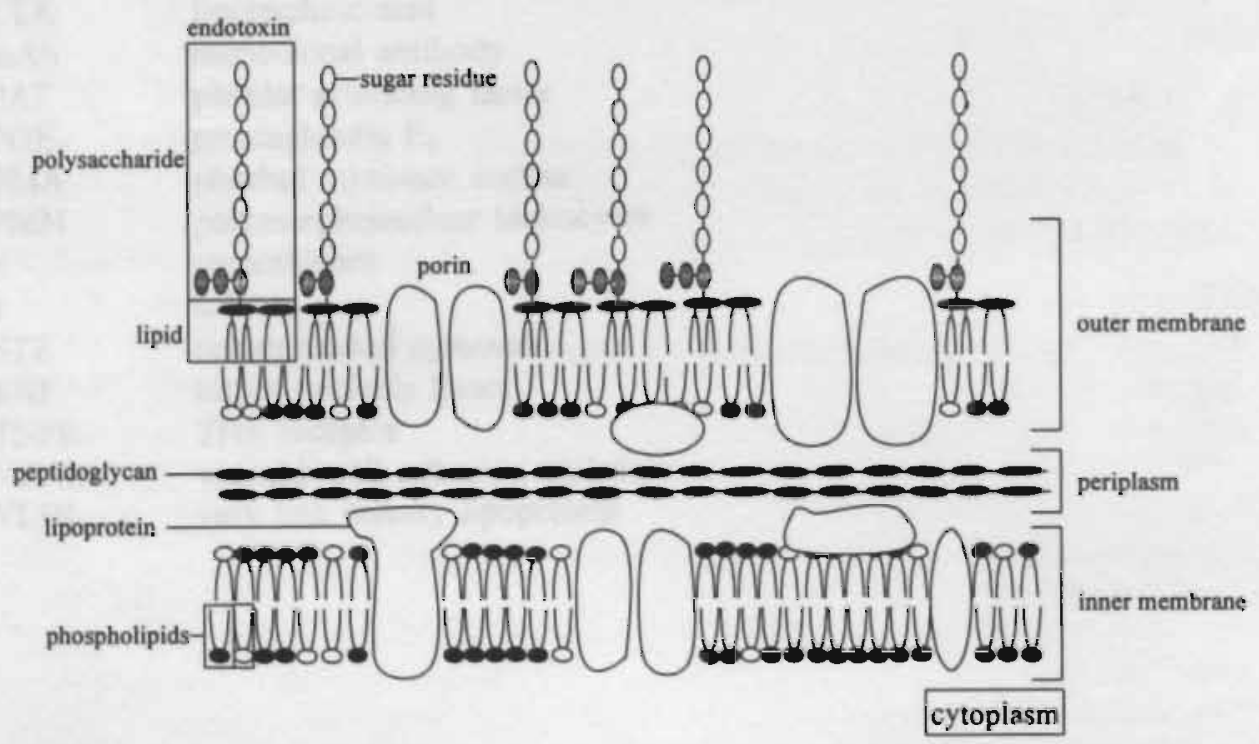

Figure 1: Schematic presentation of the Escherichia Coli envelope; figure modified after Raetz (3).

Endotoxins of all gram-negative bacteria have a common structure. They are amphiphilic molecules, consisting of a hydrophilic polysaccharide and a covalently bound hydrophobic lipid compound (lipid A), see Figure 2, and hence are chemically lipopolysaccharide (L.PS) $(2,3)$. The terms endotoxin and LPS will therefore be used interchangeable in the remainder of the chapter. 
The polysaccharide chain of LPS consists of two regions namely an O-specific chain and a core oligosaccharide, connecting the $\mathrm{O}$-antigen to the lipid $\mathrm{A}$ part. The $\mathrm{O}$-specific chain is the most variable region of the LPS molecule, consisting of a polymer of repeating oligosaccharide units which contain up to 8 different sugar residues interlinked by glycosidic bonds. Due to the diversity of constituents and their linkages, an enormous number of structures of O-specific chains is present. These structures determine the serological specificity of LPS and of the parental bacterial strain. A specific immune reaction can be evoked against the O-chain, resulting into the production of antibody molecules of the IgM isotype (6).

The core segment of LPS consists of an O-chain proximal outer core and a lipid A proximal inner core. The structural variability of the core within a bacterial species is limited. Hexoses commonly present in the outer core of LPS are Dglucose, $\mathrm{D}$-galactose, $\mathrm{N}$-acetyl-D-glucosamine and $\mathrm{N}$-acetyl-l-galactosamine, whereas the inner core region is characterized by the sugars heptose, and 2-keto-3deoxyoctonic acid (Kdo).

Lipid A, the most conserved part of LPS is linked to Kdo in the inner core via a ketosidic linkage. Unique for lipid $A$ is the presence of a backbone of biphosphorylated $\beta(1-6)$ linked disaccharides of D-glucosamines. (R)-3 hydroxy fatty acid chains are attached to this backbone, both via hydroxyl groups and via amino groups. Part of these fatty acid chains have saturated fatty acids linked to their 3hydroxy groups. LPS of distinct bacteria differ in the length, and the attachment sites of their fatty acid chains.

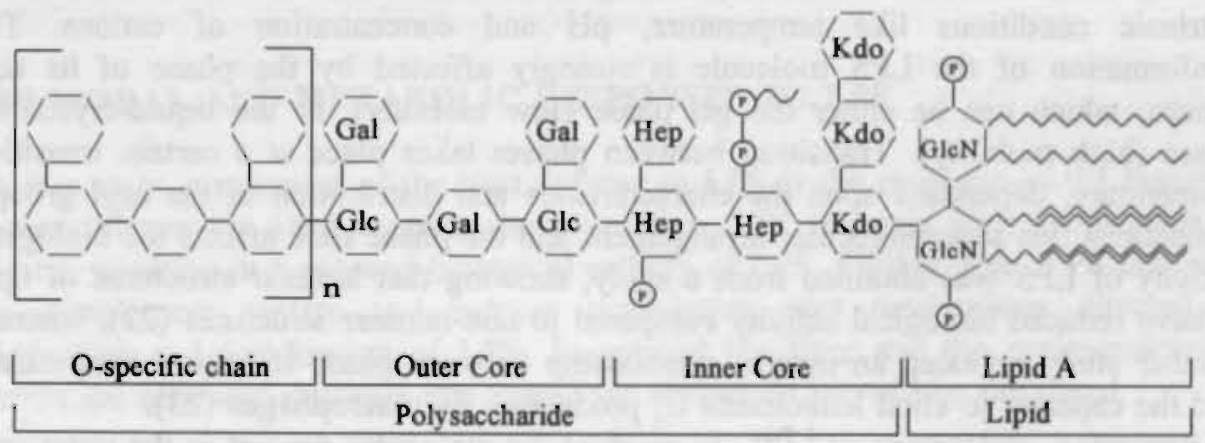

Figure 2: Schematic chemical structure of lipopolysaccharide; figure modified after Raetz (3). GIcN, N-acetyl glucosamine; Kdo, 2-keto-3-deoxyoctonic acid; Hep, heptose; Gal, D-galactose; Glc, D-glucose; P, phosphate. ethanolamine; $M$, fatty acid chain

A variety of wild type bacteria form LPS lacking the O-specific chain, called rough mutants, since they form rough colonies, in contrast to bacteria with complete LPS, which form smooth colonies, and are called smooth mutants. In addition, rough mutants missing parts of the core exist, which are designated by the nomenclature $\mathrm{Ra}$ to $\mathrm{Re}(3)$. The minimal LPS structure required for growing and multiplying of bacteria consists of one Kdo residue linked to lipid A (7).

Using purified and synthetic preparations of lipid $\mathrm{A}$, it was demonstrated that 
lipid $\mathrm{A}$ is responsible for most of the biological effects of LPS $(8,9)$. The minimal structure of Lipid A required for endotoxic activity is a molecule containing two $\beta(1-6)$-linked-D-glucosamine residues, two phosphoryl groups and 6 fatty acids in a defined arrangement (10). The binding of lipid $\mathrm{A}$ to a recognition molecule on macrophages is largely mediated via the hydrophilic backbone. However, the hydrophobic region of lipid A (fatty acid chains) was shown to be essential for the activation of these cells $(10,11)$.

Although as reported, the majority of the biological activities exhibited by LPS resides in the lipid A portion of the molecule, the polysaccharide part also affects host responses. Several studies indicate the requirement of the Kdo containing inner core for biological activity $(12,13)$. Besides, the polysaccharide chain modulates in vivo interactions of LPS with host systems, as shown by a very rapid clearance of rough LPS, as compared with smooth LPS (14). In addition, the O-antigen was demonstrated to exert directly several biological activities, like induction of interleukin (IL)-1 and interferon (IFN) $\gamma$ release, and activation of the alternative pathway of the complement cascade (15-17). However, most importantly the Ospecific chain confers the serological specificity of LPS, as described above.

LPS is released from the bacterial cell wall during growth and replication of bacteria (18). After killing of bacteria by treatment with antibiotics, or under the influence of the lytic action of complement, the amount of free LPS is strongly enhanced $(19,20)$. Since LPS is an amphiphilic molecule above a critical concentration, it forms noncovalent aggregates, that may adopt different supramolecular structures (reviewed in 21). The physical structure formed depends on the conformation of the contributing LPS molecules, and is influenced by extrinsic conditions like temperature, $\mathrm{pH}$ and concentration of cations. The conformation of the LPS molecule is strongly affected by the phase of its acyl groups, which can be either the gel phase (low mobility), or the liquid-crystalline phase (high mobility). Transition between phases takes place at a certain transition temperature, dependent upon the characteristics and distribution of the acyl groups. Indications that supramolecular arrangement and the phase state affects the biological activity of LPS was obtained from a study, showing that laminar structures of lipid A have reduced biological activity compared to non-laminar structures (22), whereas another study revealed an inverse relationship between phase transition temperature and the capacity to elicit leukotriene $\mathrm{C}_{4}$ production by macrophages (23).

Resuming, endotoxins or LPS are amphiphilic molecules present in the outer wall of gram-negative bacteria. Lipid A, which is highly conserved among LPS of different bacteria, contains most of the biological activity, whereas the polysaccharide chain confers the serological specificity of LPS. Since endotoxins are present in all gram-negative bacteria the host recognition of and response to this glycolipid provides protection against a wide range of microorganisms. In response to LPS a broad range of physiological responses is induced, as shown in Figure 3, all contributing to the defense against LPS and gram-negative bacteria, as will be discussed further in this chapter. 


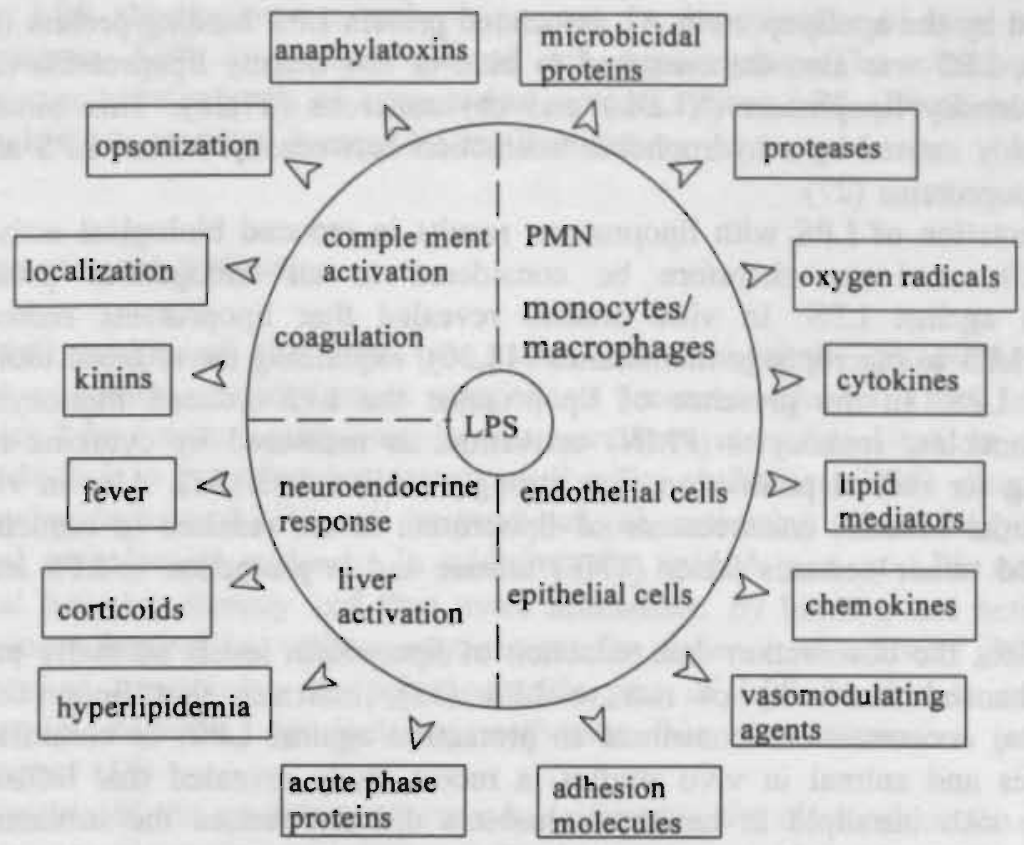

Figure 3: Scheme of the diversity of host reactions, both of cellular and humoral origin, in response to LPS, as will be discussed further in the text.

\section{HUMORAL AND METABOLIC RESPONSES TO LPS}

An important component of the host defense to LPS is the response of the humoral system (Figure 3). After entering the circulation, LPS interacts with lipoproteins in plasma, resulting in a reduced biological activity of LPS. Furthermore, LPS activates the complement system and induces coagulation, two mechanisms directed at elimination and localization of LPS. In parallel the liver and the neuro-endocrine system are activated resulting into metabolic alterations, as will be discussed.

\subsection{LPS Binding to Plasma Lipoproteins and Clearance}

After entering the blood $80-90 \%$ of the LPS is present in the plasma compartment, whereas only a minor part is cell associated (24). Several plasma proteins are able to bind LPS, like albumin, transferrin and lipoproteins, of which the latter are a major LPS binding components in plasma. Ulevitch et al were the first to demonstrate that the reduction of buoyant density of LPS, which is observed after interaction of LPS with plasma, was caused by complex forming of LPS with high density lipoprotein (HDL) and associated apolipoprotein A1 $(25,26)$. It was observed that for interaction with HDL, disaggregation of LPS is required, which, as will be discussed below, can 
be mediated by the apolipoprotein Al associated protein LPS binding protein (LBP). In addition, LPS was also demonstrated to bind to low density lipoproteins (LDL), very low density lipoprotein (VLDL) and chylomicrons $(27,28)$. This binding is most probably caused by a hydrophobic interaction between lipid A of LPS and the lipids of lipoproteins (27).

The interaction of LPS with lipoproteins results in reduced biological activity of LPS $(25,29)$, and can therefore be considered as an endogenous protection mechanism against LPS. In vitro studies revealed that lipoproteins reduce the binding of LPS to macrophage membranes $(14,30)$, explaining the reduced biological activity of LPS. In the presence of lipoproteins the LPS-induced monocyte and polymorphonuclear leukocytes $(\mathrm{PMN})$ activation, as measured by cytokine release and priming for radical production, was strongly inhibited $(30,31)$. Also in vivo, in several animal models, enhancement of lipoprotein levels resulted in reduction of LPS-induced tumor necrosis factor (TNF) release and in protection to LPS lethality $(28,32)$.

In addition, the observation that reduction of lipoprotein levels normally present, greatly enhanced sensitivity of rats to LPS (33), indicates that lipoproteins at physiological concentrations contribute to protection against LPS. In contrast to in vitro studies and animal in vivo studies, a recent study revealed that infusion of triglyceride rich intralipid in healthy volunteers did not reduce the inflammatory responses to LPS (34). The cause for this discrepancy is not yet clear. In addition, not all biological functions of LPS are blocked by lipoporoteins. For instance the LPS mitogenicity for splenocytes is not affected by lipoproteins (30).

Interaction of LPS with lipoproteins not only affects the biological activity but also the clearance rate of LPS. Intravenously injected LPS is cleared from the blood in a biphasic way. Part of LPS is rapidly taken up by organs rich in phagocytes, like the liver and spleen, whereas the part of LPS bound to HDL is taken up more slowly into tissues by HDL mediated mechanisms $(14,35,36)$. In contrast to the reduced clearance due to HDL binding, chylomicrons were reported to enhance the clearance rate of LPS. In an experimental rat model, addition of chylomicrons increased the rate of clearance of LPS from plasma and doubled the amount of LPS eleared by the liver. Furthermore. LPS was directed from kupffer cells to chylomicron clearing hepatocytes, resulting in reduced cytokine production and reduced mortality (28).

As indicated above. LPS not bound to lipoproteins is mainly associated with tissue phagocytes, namely the macrophages and PMN (14,35). These phagocytic cells are able to internalize LPS and to detoxify it, as will be described later. The complete removal of LPS from tissues requires several weeks, as was demonstrated in a rat model, in which small amounts of LPS were still detectable in liver, spleen and lungs after a four week study period (37).

These data indicate that after it enters the circulation the fraction of LPS that is not associated with lipoproteins is cleared rapidly from the circulation and becomes asseciated with tissue phagocytes. This results into cell activation, uptake and detoxification of LPS. Besides, part of LPS will interact with HDL resulting in reduced biological activity and in a reduced clearance rate of LPS. Enhancement of the level of HDL protects against LPS lethality, most probably by reducing the 
amount LPS able to interact with phagocytes. In the presence of large amounts of chylomicrons LPS is rapidly cleared via hepatocytes. The observations that enhancement of the levels of lipoproteins protects against LPS effects, indicates that this could have potential therapeutic implications.

\subsection{Complement Activation}

It is well established that LPS is a potent activator of the complement system, through activation of complement components present in plasma. Three mechanisms by which LPS interacts with complement have been identified. First, in response to LPS, which is a polyclonal activator of B-cells, antibodies (IgM) directed at the polysaccharide part of LPS will be produced (6), activating the antibody dependent classical complement pathway. In addition, the lipid A part of L.PS activates the classical pathway directly and thus more immediate, by binding and activating the complement factor $\mathrm{Clq}$, without requirement for presence of antibody (38). Thirdly, as described previously, the polysaccharide part of LPS is able to activate the complement cascade, by inducing activation via the alternative pathway of complement (17).

Activation of the complement cascade (either via the classical or the alternative pathway) results in the formation of $\mathrm{C} 3$ convertases, which converts complement factor $\mathrm{C} 3$ to $\mathrm{C} 3 \mathrm{~b}$. The formed $\mathrm{C} 3 \mathrm{~b}$ has strong opsonic activity, resulting in the enhanced phagocytosis of LPS or gram-negative bacteria by PMN or monocytes/macrophages, via complement receptor (CR)l or CR3 (39). After phagocytosis LPS is neutralized, or bacteria are killed by microbicidal proteins or reactive oxygen radicals, as will described below.

Also, activation of complement will induce destruction of intact gram-negative bacteria by the membrane attack complex. Binding of $\mathrm{C} 3 \mathrm{~b}$ to bacterial surfaces leads to activation of complement components $\mathrm{C} 5-\mathrm{C}$. These activated components form the membrane attack complex which is plugged into the membrane, resulting in lysis of bacteria (39). Indications that bacterial killing or LPS detoxification in normal human plasma is mediated by complement components were provided by studies showing a reduced killing and detoxifying potential of complement deficient plasma, or of plasma with inactivated complement components $(20,40)$.

Moreover, as a consequence of complement activation the anaphylatoxins $\mathrm{C} 3 \mathrm{a}$ and C5a, derived from activated complement factors C3 and C5, are formed (41). These low-molecular weight peptides induce vasodilatation of small blood vessels and contraction of smooth muscles. Furthermore, these anaphylatoxins, principally C5a, have chemoattractive capacity for PMN and monocytes, resulting into attraction of these phagocytic cells to the site of infection. In parallel, C5a directly activates phagocytic cells, as demonstrated by enhanced adhesion to surfaces, by the secretion of lysosomal enzymes and eicosanoids, by increased oxidative metabolism, and by enhanced expression of CR3 and Fc receptors (41). These cell activation processes will result in enhanced phagocytosis, and neutralization of microorganisms and LPS.

Activation of complement is thus one of the many facets of host response to LPS. The complement system contributes to the defense against LPS and gram-negative 
bacteria via several pathways, namely by inducing lysis of bacteria, by opsonization of LPS and bacteria for phagocytosis, and by attraction and activation of phagocytic cells. The protective capacity of complement against LPS was confirmed by studies showing that animals genetically deficient for complement factor C3 or C6, exerted decreased L.PS clearance and had increased organ damage (42) or were more sensitive to lethal activities of LPS (43).

However, other studies revealed that LPS-induced complement activation could have detrimental effects for the host. In patients with sepsis syndrome, activation of the complement system was observed, which was related to the severity of shock and death $(44,45)$. Furthermore, antibodies directed against C5a could attenuate the systemic manifestations of experimental sepsis in nonhuman primates (46). These data indicate that under certain conditions, inappropriate activation of this protective system occurs, resulting in adverse effects for the host.

\subsection{Induction of Coagulation}

LPS activates also other humoral response factors in blood, such as coagulation factors (47). Morrison et al. demonstrated that LPS was directly able to activate coagulation factor XII (Hageman factor) which is present in plasma at levels of approximately $30 \mu \mathrm{g} / \mathrm{ml}(48,49)$. In parallel, factor XII can indirectly be activated by LPS, as LPS-induced cell damage results in exposure of collagen, another trigger for factor XII activation (49). Stimulation of factor XII is the initiating step of a cascade of reactions, called the intrinsic coagulation pathway, resulting in the formation of a blood clot, consisting of insoluble fibrin. This blood clot is considered to contribute to the localization of the infection (5).

In addition to initiating the intrinsic coagulation pathway, activated factor XII also activates the plasma protein prekallikrein. Activated kallikrein in turn cleaves kinins, which have strong vasodilatory and permeability enhancing effects, from plasma kininogen. This process forms part of the contact activation pathway (49). Indications that LPS activates the contact activation system in vivo are obtained from studies showing that patients with sepsis have enhanced levels of the $\alpha_{2}$ macroglobulin-kallikrein complexes (50). Furthermore, LPS administration to healthy volunteers resulted in activation of the kallikrein-kinin systems (51).

Another pathway of L.PS activated coagulation is by inducing tissue factor expression on monocytes and endothelial cells $(52,53)$, the initiating step of the extrinsic pathway of coagulation. The importance of the extrinsic pathway in LPSinduced coagulation was derived from a study showing that antibodies directed against tissue factor blocked coagulation in experimental endotoxemia in baboons (54).

Plasma and tissues contain besides procoagulant factors, also anticoagulant factors, which inhibit coagulation, or contribute to lysis of the formed blood clot. Next to enhancing the procoagulation as described above, LPS also blocks anticoagulation processes. The main step in the fibrinolytic pathway, namely the conversion of plasminogen to plasmin, which degrades fibrin, is mediated by plasminogen activator, and can be blocked by plasminogen activator inhibitor, both 
produced by endothelial cells (55). In vitro studies demonstrated that LPS enhanced activity of the plasminogen activator inhibitor, and did not affect the plasminogen activator activity, thus inhibited fibrinolysis (55). In vivo studies however revealed that LPS administration in healthy volunteers resulted in activation of both proteins. An early upregulation in plasminogen activator, concomitantly with fibrinolytic activity, was followed by upregulation of plasminogen activator inhibitor levels (56).

In addition, LPS downmodulates the expression of the anticoagulant molecule thrombomodulin on endothelial cell surface (53). Thrombomodulin binds thrombin, resulting in reduced ability of thrombin to convert fibrinogen to fibrin. In parallel, the formation of the thrombomodulin-thrombin complex activates protein $\mathrm{C}$, which function as anticoagulant factor by degrading the activated coagulant factors $\mathrm{V}$ and VIII (47). Reducing the expression of thrombomodulin therefore inhibits anticoagulant capacity of endothelium.

Resuming, LPS is able to activate coagulation, both via induction of coagulation pathways, and via inhibition of anticoagulation processes. The coagulation is another approach by which the host protects itself against LPS, by localizing the infection. Furthermore, coagulation contributes to restoring the LPS-induced vessel wall damage. The observation that the horseshoe crab uses a similar mechanism for protection (57) indicates that coagulation is evolutionary well conserved as defense against LPS, and emphasizes its importance in defense. However, to much of a good thing as coagulation, for instance due to high systemic levels of L.PS, can result in disseminated intravascular coagulation and is thus deleterious for the host.

\subsection{Neuroendocrine Responses and Metabolic Alterations}

A generalized host response to infection is the induction of fever and a strongly altered metabolism of lipids, proteins and carbohydrates, resulting in hyperlipidemia, protein catabolism and hyperglycemia (58). These metabolic alterations are largely mediated by neuroendocrine hormones and by cytokines released in response to LPS.

Alteration of the temperature set point in the hypothalamus, and the induction of fever in response to LPS is caused by cytokines like IL-1, TNF and IL-6. These cytokines induce a febrile response through the induction of prostaglandin $\mathrm{E}_{2}\left(\mathrm{PGE}_{2}\right)$ (59). This enhanced body temperature, contributes to hypermetabolism and requires enhanced energy supply. Fever is considered beneficial for the host by increasing the resistance to microorganisms, due to restriction of replication of the infectious reagent, and by enhancement of several aspects of the host resistance, like phagocytic capacity of PMN, the stimulation of T-cells, and T-cell dependent reactions $(60)$.

A striking metabolic alteration in bacteremic patients or LPS treated animals, is hyperlipidemia. This hyperlipidemia is characterized by increased concentrations of triglycerides, VLDL, and LDL and a decreased concentration of HDL $(29,58,61)$. The increase in lipids can be speculated to be useful as supply in order to fulfill the enhanced energy requirements observed during infection status. In addition, since lipoproteins could protect against biological effects of LPS as described in paragraph 2.1, this hyperlipoproteinemia could be considered an physiological defense 
mechanism of the host. The mechanism of LPS-induced hyperlipidemia is not completely defined, although it is clear that cytokines like TNF may be involved in this metabolic condition. TNF affects serum triglyceride levels by stimulating hepatic lipid synthesis and secretion of VLDL. Furthermore, TNF suppresses levels of lipoprotein lipase, the enzyme responsible for metabolism of triglyceride rich lipoproteins, thus preventing removal of lipoproteins from the circulation $(61,62)$. In addition, LPS directly induces hyperlipidemia by suppression of LDL clearance, most probably due to the reduction of LDL receptor expression on hepatocytes $(61,63,64)$.

Another important metabolic consequence of endotoxemia is the wasting of body tissues $(58,65)$. Endotoxemia is related to catabolism of muscle proteins due to an increase in protein breakdown, resulting into peripheral release of amino acids, and in parallel to a decrease in amino acid uptake and reduced protein synthesis. Concomitantly, a large portion of these amino acids are used for the hepatic acute phase protein response, which will be discussed in the next section. Despite the fact that both anabolic (the production of acute phase proteins) and catabolic processes (wasting of muscle protein) are occurring simultaneously, nitrogen balances become negative, indicative for protein wasting (58). This catabolic response is accompanied by a diminished uptake of food and other nutrients, an effect largely attributed to the cytokine TNF (62).

Although some indications for TNF and IL-1 in the breakdown of muscle proteins were obtained (65), counterregulatory hormones, especially glucocorticoid are strongly involved in this catabolic response (65-67). Glucocorticoids present in enhanced levels during infection are produced in response to LPS, and to its mediators TNF and IL-1, either by a direct activation of the adrenal, or by activation of the hypothalamus-pituitary-adrenal axis $(65,68)$. Glucocorticoids further strengthen the muscle-hepato-axis, by enhancing the cytokine-induced production of acute phase proteins in the liver $(65,68)$.

In addition to these changes in lipid and protein metabolism, alterations in carbohydrate metabolism are also observed during infections (58). Described alterations are elevated blood glucose levels, altered insulin levels, increased endogenous glucose production and profound insulin resistance. Comparable metabolic alterations were obtained by combined infusion of cortisol, glucagon and epinephrine, further stressing the role of these hormones in the metabolic derangements occurring during infection $(67,69)$.

Besides affecting metabolism, glucocorticoids have suppressive effects upon inflammation and immune responses $(68,70)$. Corticosteroids inhibit the production of pro-inflammatory cytokines and lipid metabolites, and downregulate the function of cellular components of inflammation, as phagocytic cells, lymphocytes and platelets. Therefore, glucocorticoids provide a negative feedback signal in order to reduce the inflammatory cascade. Consequently, reduced cytokine release will attenuate the production of this adrenal hormone.

Summarizing. the induction of fever, leading to enhanced resistance to microorganisms, contributes to hypermetabolism resulting from endotoxemia. The concomitant metabolic alterations consist of an altered glucose metabolism and an increased production of lipids. The enhanced lipoprotein levels could serve to 
provide energy and furthermore contribute directly to protection against LPS, by blocking its biological effects. Besides, muscle proteins are degraded in order to provide amino acids, which are (partially) used for production of acute phase proteins required for protection against microorganism. Some neuro-endocrine hormones especially glucocorticoids, play an important role in these metabolic responses. Furthermore, glucocorticoids contribute to controlling the inflammatory response, by blocking production of cytokines and other pro-inflammatory processes.

\subsubsection{Production of Acute Phase Proteins}

As discussed in the previous section, as a consequence of endotoxemia the liver produces enhanced levels of a group of proteins, which under normal conditions are produced at steady state levels, called the acute phase proteins. In parallel, other liver proteins are produced at lower levels, like albumin, transferrin, and ApoA1, the so called negative acute phase proteins. Although most acute phase proteins are produced by hepatocytes, some are synthesized by other cells including monocytes, endothelial cells, fibroblasts and adipocytes $(65,68,71,72)$.

During acute phase response levels of most acute phase proteins are induced several fold over normal levels, whereas the concentration of some acute phase proteins, like C-reactive protein (CRP), can increase 1000 -fold over normal levels $(71,73)$. Therefore, CRP levels are often used as marker for monitoring the inflammatory response (73).

The main stimuli for acute phase protein production by the liver are cytokines (74). Depending upon the stimulus specific induction, acute phase proteins can be divided into two groups. The type I acute phase proteins, like complement component 3, CRP and LBP, are produced in response to IL-1 type cytokines (including IL-1 $\alpha$, IL-1 $\beta$, TNF $\alpha$ and TNF $\beta$ ). The type II acute phase proteins, as fibrinogen and $\alpha_{1}$-antitrypsin, are produced in response to IL-6 type cytokines (including Il-6, IL-11, leukemia inhibitory factor, oncostatin $\mathrm{M}$ and ciliary neutrotrophic factor). The IL-6 type cytokines can synergistically enhance the production of the type I acute phase proteins. Production of acute phase proteins is also modulated by other factors like glucocorticoids which synergistically enhance the production of these proteins $(68,74)$.

Acute phase proteins have a wide range of activities, all contributing to the removal of micro-organisms and repair of damaged tissues. The acute phase proteins can be dived into subgroups based on their actions $(68,71)$, and consist of complement compounds, including $\mathrm{C} 3$ and factor B, coagulation components, as fibrinogen and von Willebrand factor, proteinase inhibitors like $\alpha_{1}$-antitrypsin, and $\alpha_{1}$-antichymotrypsin, and metal-binding proteins as haptoglobin and hemopexin. However, several acute phase proteins can not be classified into a subgroup, including LBP which will be discussed thoroughly later in this chapter.

CRP, as indicated above a prototypic acute phase protein, plays an important role in the nonspecific host defense against invading microorganisms $(71,73)$. CRP binds to the nucleus compounds chromatin, histones and small nuclear ribonucleoprotein particles. Additional ligands for CRP are phosphocholine containing molecules, 
which are frequently present on the surface of bacteria, fungi, parasites and on damaged cells. After binding to ligand, CRP activates the complement by the classical pathway, resulting in phagocytosis and destruction of microorganisms and of cellular debris. In parallel, CRP activates neutrophils, macrophages, natural killer cells and platelets.

The production of acute phase proteins is one of the many responses of the host. to LPS. As a result of LPS-induced cytokine release the liver is activated, and produces a range of acute phase proteins. These acute phase proteins contribute to neutralization of LPS (bacteria), help to minimize the extent of local tissue damage, and participate in tissue repair and regeneration.

\section{CELLULAR RESPONSES TO LPS}

Besides activation of the humoral defense system, LPS is a well known activator of a variety of cells, like monocytes, PMN, endothelial and epithelial cells (Figure 3). Cell activation requires two steps, specific interaction of LPS with a cell surface receptor and transduction of cell activating signals. In this section first the cell surface structures known to interact with LPS will be discussed, whereas in the second part of this section the cellular responses to LPS will be reported.

\subsection{Cellular Receptors for LPS}

LPS interacts with several structures on cell membranes. These structures function either as receptor for LPS, or in binding and internalization of LPS. However, of several of the identified LPS binding structures, the function has not yet been revealed. Since the membrane antigen CD14 is the most important LPS receptor known so far, this antigen will be discussed in detail.

\subsubsection{Cell Surface LPS Binding Structures}

Due to its lipid part, LPS is able to interact aspecifically with cell surfaces via hydrophobic interactions $(75,76)$. However, also specific interactions of LPS with several structures on the cell membrane are reported, which will be discussed here shortly.

Wright et al. described that CD18, a member of the integrin family of adhesion molecules, interacts with LPS on the surface of gram-negative bacteria, and LPS coated erythrocytes $(77,78)$. However, leukocytes obtained from patients deficient from CD18 did not show a reduced response to LPS (79), and treatment of mononuclear cells with anti-CD18 antibody did not interfere with LPS-induced TNF $\alpha$ release $(80)$, indicating that CD18 is not essential for cellular responses to LPS. CD18 is most probably involved in uptake and clearance of LPS (78). However, recently also indications for a functional role of $\mathrm{CD} 18 / \mathrm{CD} 11 \mathrm{c}$ were 
obtained, since transfection of LPS unresponsive $\mathrm{CHO}$ cells with $\mathrm{CD} 1 \mathrm{lc} / \mathrm{CD} 18$ induced a serum-independent response to LPS (81).

In addition, LPS was demonstrated to be a ligand for the scavenger receptor on macrophages. Hampton et al. demonstrated that binding of lipid IVa (the bioactive precursor of lipid A) by the macrophage like cell line RA.W264.7, and subsequently metabolism into a less active form was mediated via the scavenger receptor (82). No indication for involvement of this receptor concerning lipid IVa or LPS-induced stimulation of macrophages was obtained $(82,83)$. The scavenger receptor is found in large amounts in the liver (on kupffer cells and on sinusoidal endothelial cells) and appears to be well placed there to remove LPS entering the circulation from the gut (82).

Using a radio-iodinated, disulfide-reducible, photoactivatable LPS derivative Morrison et al demonstrated a $73 \mathrm{kDa}$ LPS binding protein specifically interacting with the lipid A part of LPS, on the membrane of murine splenic lymphocytes, and macrophages (84-86). Further evidence for a functional role of this LPS recepior was obtained by studies showing that an antibody directed against this LPS receptor, functioned as an agonist for LPS biological activity in vitro and protected mice against the lethal effects of L.PS in vivo $(87,88)$. However, Dziarski et al demonstrated that this $70-\mathrm{kDa}$ protein was a broadly reactive protein, interacting with other structures like bacterial peptidoglycan, lipoteichic acid, and heparin (89). Studies have now demonstrated that this $70-\mathrm{kDa}$ protein was cell bound albumin, which originated from tissue culture medium, or from serum, and was not required for cell activation (90).

Another approach to study LPS binding and cell activation is the development of cell lines deficient in LPS binding $(91,92)$. The LPS resistant mutant of the macrophage-like mouse cell line J774.1 was reported to miss, as compared to the parent cell, two distinct binding proteins of about 55 and $65 \mathrm{kDa}$, indicating that these proteins are involved in LPS-induced macrophage activation (91). The 55-kDa protein could be identical to CD14 which will be described in the next paragraph.

Furthermore, using different techniques, several lipid A binding proteins are identified for which so far no function is described. By photo-affinity cross-linking, lipid A binding proteins of 18 and $25 \mathrm{kDla}$ were demonstrated on the $70 \mathrm{Z} / 3 \mathrm{pre} \mathrm{Bi}$ cell line (93), whereas using a ligand blot assay a LPS binding protein of $40 \mathrm{kDa}$ on murine-lymphocyte-cell lines and proteins of 40 and $80 \mathrm{kDa}$ on murine-macrophagelike cell line were detected (94). Recently, a 80-kDa membrane protein on monocytes and endothelial cells was identified, capable of binding lipid $\mathrm{A}$. in the presence of serum-components (95). Furthermore, binding of L.PS to monocytes and PMN, mediated by membrane proteins other than CDI4 and CDI8 was reported, although these structures were not yet characterized $(96,97)$.

Besides specific receptors for the lipid A part of LPS, Cavaillon et al also demonstrated that the polysaccharide part of L.PS interacts specifically with a lectin like receptor on the monocyte/macrophage mernbrane $(76,98)$. In accordance, the lectin galectin-3, which is expressed by activated macrophages and epithelial cells was described recently to bind the polysaccharide chain of LPS via its carbohydrate binding site in the C-terminal domain (99). Moreover, galectin 3 also bound the lipid A part of LPS via a site within the N-terminal part. Also a p38 LPS binding 
protein on mouse splenocyte, on the J774.1 macrophage-like cell line and on the $70 \mathrm{Z} / 3$ pre B-cell line, was hypothesized to be specific for the inner core oligosaccharide part of LPS (100).

These studies reveal that several LPS binding structures on cell membranes exist. CD18 and the scavenger receptor are generally accepted to play a role in binding, internalization and detoxification of LPS. However, the exact function of the other LPS binding structures has not been fully elucidated, and requires further study. In contrast, the CD14 antigen, as present on monocytes/macrophages and PMN, has convincingly been shown to function as a receptor for LPS. This antigen was demonstrated to be an important LPS binding protein, and also to be involved in LPS-induced cell activation, as will be discussed in the next section.

\subsubsection{CD14 as receptor for LPS}

As indicated in the previous section, so far only the $55-\mathrm{kDa}$ glycoprotein $\mathrm{CD} 14$ has definitely been shown to be involved in the LPS-induced cell activation. This antigen is present as a membrane bound form and as soluble antigen, both involved in cell stimulation by LPS. Furthermore, the plasma protein LBP plays an important role in this LPS-CD14 mediated cell activation, as will be discussed first.

\section{LPS Binding Protein}

In normal plasma the amphiphilic molecule LPS is present as aggregate or bound to circulating lipids like HDL as discussed before. Tobias et al observed that in acute phase serum the interaction of LPS with HDL was changed, and identified the acute phase reactant responsible for this altered interaction as a protein of $60 \mathrm{kDa}$. This acute phase protein was shown to bind LPS directly and was therefore called LPS binding protein: LBP (101). Further studies showed that LBP binds smooth LPS, rough LPS and the lipid A part of LPS with high affinity ( $\mathrm{kDa}$ of $\left.10^{-9} \mathrm{M}\right)(102)$. Although LBP was discovered in rabbit acute phase plasma, this protein was thereafter also identified in human, mouse rat and bovine plasma (103-106).

LBP is constitutively synthesized by hepatocytes in the form of a single $50 \mathrm{kDa}$ polypeptide and is released after glycosylation into the plasma in the form of a 60 $\mathrm{kDa}$ protein (107). In plasma of healthy individuals LBP is present at levels of approximately $10 \mu \mathrm{g} / \mathrm{ml}$, which increase approximately 10 -fold during acute phase responses $(103,108)$. Studies in the HepG2 hepatoma cell line revealed that LBP is a type 1 acute phase protein (109). Indications for extrahepatic production of LBP were obtained in rat models of sepsis (105), whereas in concert, IL-1 $\beta$ induced LBP mRNA expression in cultured rat pulmonary artery smooth muscle cells (110). However, no LBP mRNA was detected in lung homogenate of rabbits in which an acute phase response was induced (111).

LBP has high sequence homology with the lipid transporting proteins cholesteryl ester transfer protein (103), and phospholipid transfer protein (112), whereas also functional homology with these proteins exist, since LBP functions as a transporting 
molecule specific for the lipid LPS, as discussed below. Also sequence homology between LBP and the PMN protein bactericidal/ permeability-increasing protein (BPI) was reported (103). Our studies revealed that these proteins, which both bind to the lipid A part of LPS $(102,113)$, exert antagonistic effects (114).

So far, several functions of LBP, all affecting LPS-induced host responses, are known (Figure 4). First, it was demonstrated that LBP binds to LPS and facilitates the interaction of LPS to membrane CDI4, resulting in strongly enhanced cell activation. Wright et al. very elegantly showed that CD 14 binds the complex of LPS and LBP (80). Antibody directed against CD14 blocked binding of the L.PS-LBP complex to macrophages, whereas enzymatic removal of $\mathrm{CD} 14$ from macrophage surface strongly reduced LPS-LBP complex binding. Also others showed that serum, as a source of LBP, or LBP enhanced the binding of LPS to monocytes as mediated via CD14 $(115,116)$.

Evidence for a functional role of LBP-LPS interaction with CD14 was obtained from several studies showing that the presence of LBP greatly enhanced sensitivity of monocytes for LPS, whereas immunodepletion of LBP from plasma markedly inhibited LPS-induced monocyte activation as measured by TNFa production $(103,111,115,117)$. The LPS binding site of LBP is located in its amino terminal half, whereas the CDI4 binding site is indicated to reside within its carboxylterminal half (118). It was reported that LBP remains associated with LPS bound to the cell membrane (119).

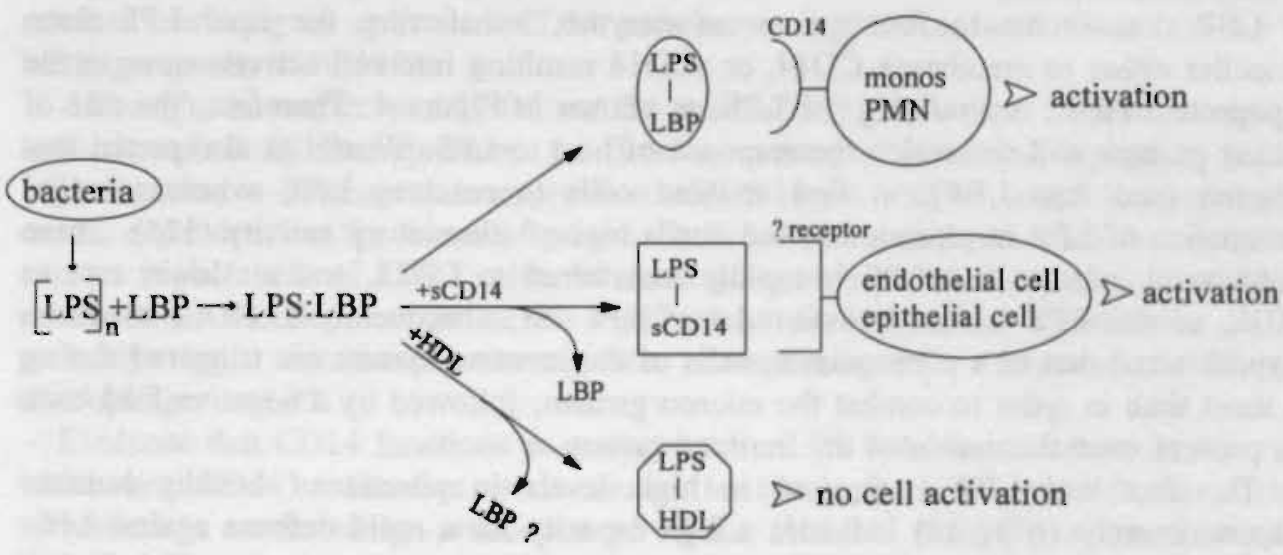

Figure 4: Schematic model of current view on functions of LBP. LBP monomerizes LPS out of LPS aggregates, which can be followed by three different processes namely: 1. the LB.P-LPS complex activates monocytes and PMN via membrane CD14; 2 . LBP transfers LPS to SCD14. The resulting sCD14-LPS complex, which does not contain $\mathrm{LBP}_{\text {, }}$ activates cells lacking membrane CD14 like endo- or epithelial cells, via a so far unknown receptor, 3. LBP transfers LPS to the lipoprotein HDL, resulting into neutralization of LPS.

Besides facilitating the binding of LPS to membrane CD14, LBP also accelerates the binding of L.PS to the soluble form of CD14 ( $\mathrm{sCD} 14$ ), present in the plasma of 
healthy individuals (120). The formed sCD14-LPS complexes are able to activate cells that are membrane CD14 negative, like endothelium, epithelium and astrocytes $(121,122)$. In addition, also activation of membrane CD14 positive cells by the LPSsCD14 complex was indicated (123). In contrast to the stable interaction of LBP to LPS and membrane CD14 (119), LBP does not stay associated with the LPS-sCD14 complex and is not necessary for LPS-sCD14 induced cell activation. Rather, LBP is considered to function catalytically, as a lipid transfer protein, mediating the movement of LPS from LPS aggregates to SCD14 (123).

In contrast to the two described functions of LBP, resulting in cell activation, the third known activity of LBP results in the neutralization of LPS. From the group of $\mathrm{S}$. Wright it was reported that LBP mediates a direct transfer of LPS from micelles to the lipoprotein HDL (124). In addition, LPS which is transferred to SCD14 can subsequently be transferred by LBP to HDL, a pathway that is strongly favored over the direct transfer of LPS to HDL (125). Moreover, as reported previous, LBP was observed to be associated with apoprotein A1, present in HDL (125). As described in paragraph 2.1 the interaction of LPS with HDL strongly reduces its biological activity.

Furthermore, LBP contributes to the clearance of bacteria by interacting with LPS at the surface of bacteria, and thus opsonizing bacteria for interaction with macrophages (126). In addition, the LBP mediated binding of LPS to membrane CD14 results not only in cell activation, but also in internalization of I.PS. This process is not mediated via CD14 but possibly via a membrane structure interacting with L.BP $(119,127)$.

LBP thus seems to function as an enzyme, transferring the lipid LPS from micelles either to membrane CD14, or sCD14 resulting into cell activation, or to the lipoprotein HDL, neutralizing the LPS, as shown in Figure 4. Therefore, the rate of either process will determine the response of host to LPS. Wurfel et al reported that plasma (and thus L.BP), at first enabled cells to react to LPS, whereas longer incubation of LPS in plasma resulted into a loss of stimulatory activity (125). These data could indicate that LPS is rapidly transferred to CD14, and at slower rate to HDL, or that LPS is first transferred to CD14 and subsequently to HDL. It can be hypothesized that as a consequence, cells of the immune system are triggered during a short time in order to combat the microorganism, followed by a negative feed back to prevent overstimulation of the immune system.

The fact that LBP is present in high levels in plasma of healthy humans (approximately $10 \mu \mathrm{g} / \mathrm{ml}$ ) indicates a high capacity for a rapid defense against LPS. The functional consequence of the increase in LBP levels observed during disease however, has not been elucidated. The observation that antibodies directed against LBP prevented LPS lethality in D-galactosamine sensitized mice (128) indicates that in this model of vigorously LPS exposure, LBP has detrimental effects for the host. Further studies are required to elucidate the role of LBP in the defense to LPS. 
CD14, the membrane antigen known to function as a receptor for LPS is expressed mainly on the surface of monocytes/macrophages, and PMN, the cells responsible for scavenging of LPS and bacteria. The number of CD14 molecules on peripheral blood monocytes has been estimated at 50.000 per cell, whereas the level of expression on PMN is approximately 10 -fold less $(129,130)$. CD14 is anchored to both cell types via a glycosyl-phosphatidyl inositol (GPI) linkage $(131,132)$. The gene encoding human $\mathrm{CD} 14$ has been cloned and maps to the long arm of chromosome 5 , in a region containing many genes for growth factors and growth factor receptors (133).

During the process of monocyte differentiation the CD14 expression is markedly increased. The enhancement of CDI4 expression as induced by vitamin D3, is paralleled by increased mRNA levels, a process in which the transcription factor $\mathrm{Spl}$ seems to play a critical role (134). In response to the cytokines IL-4, IL-13 and IFN $\gamma$, expression of monocyte membrane CD14 is reduced $(135,136)$, whereas other cytokines such as granulocyte monocyte colony stimulating factor, IL-1 $\beta$, IL-2, IL-3, IL-5, IL-6, and transforming growth factor- $\beta$ do not seem to affect CD14 expression on monocytes (135). Data concerning the effect of LPS on membrane CD14 are conflicting since an upregulation (137), downregulation (138), or unchanged expression (139) of CD14 were reported. PMN contain an intracellular pool of $\mathrm{CD} 14$, which is stored in the secretory vesicles. After stimulation with agonists like formyl-methionyl-leucyl-phenylalanine (FMLP), or TNF these vesicles are rapidly released resulting in enhanced CD14 membrane expression, with functional LPS binding capacity $(130,140)$.

Although monocytes and PMN are the main CD14 expressing cells few reports have described CD14 expression on B-cells, mesangial cells and basophils (141143). In vivo a heterogenous expression of $\mathrm{CD} 14$ on mature tissue macrophages exists, dependent on the tissue of origin. Peritoneal macrophages were described to express high levels of $\mathrm{CDI4}$, alveolar macrophages moderate levels, and intestine macrophages are deficient in CD14 expression $(144,145)$. These differences, most probably have functional consequence, determining the response of these macrophages to LPS.

Evidence that CD14 functions as a receptor for LPS was obtained from studies in which anti-CD14 antibodies were shown to block the LPS-induced monocyte activation as measured by production of TNF $\alpha(103,111,115,117)$, as we showed, IL-6 and IL-8 (146), or tissue factor expression (147). Similar to monocytes, LPSinduced neutrophil activation, as the expression of CD18/CD11b (130), priming for oxidative burst $(31,148)$ or priming for synthesis of 5-lipoxygenase products (149), was shown to be mediated via LBP-LPS interaction with membrane CD14.

The role of CDI4 as a receptor for LPS was further confirmed by studies showing that transfection of CD14 negative cells with CD14 greatly enhanced sensitivity to LPS $(83,150)$, and similarly the differentiation of THP-1 cells resulted in enhanced CD14 levels and increased responsiveness to L.PS (151). In addition, transgenic mice expressing human CD14 are hypersensitive to LPS (152), whereas knock-out CD14 deficient mice are hyporesponsive to LPS (153). Analysis of LPS 
binding to CD14 revealed that the dissociation constant of CD14 for LPS is approximately $3^{*} 10^{-8} \mathrm{M}$. Furthermore, in this study was found that membrane CD14 binds more than one LPS molecule (154).

Because CD14 is linked to the membrane via GPI, and does not transverse the membrane, it is not clear how the intracellular signal after LPS binding is initiated. Indications that CD14 plays a pivotal role in LPS-induced monocyte and PMN activation was obtained from studies showing that cross-linking of membrane CD14 directly activated cells (155). Stefanova et al demonstrated a critical role for protein tyrosine kinases in LPS-CD14 induced cell activation, since CD14 coprecipitated with protein tyrosine kinase, whereas LPS induced activation of protein tyrosine kinase (156). In line with these observations, blocking of protein tyrosine kinase activity inhibited LPS-induced TNF and IL-1 production (156). Additionally, several groups have demonstrated a role for protein tyrosine kinases, mitogen activated protein kinases, and protein kinase $\mathrm{C}$ in LPS-induced cell activation via CD14 $(157,158)$. Also, involvement of protein $G$ translocation and for $N f K \beta$ activation in LPS cell activation via CDI4 was reported $(159,160)$.

However, several lines of evidence indicate that membrane CDI4 is not directly responsible for signal transduction in response to LPS. Kitchens et al described that deacetylated LPS, which antagonizes LPS-induced cell activation, did not block LPS binding to CD14 on THP-1 cells (161), indicating that binding of LPS to CDI4 is not sufficient to induce cell stimulation. Similarly, a group of anti-CD14 antibodies was described to block monocyte activation by LPS, whereas they did not affect LPS binding to monocytes (129). This indicates that at least two epitopes on membrane CD14 are involved in the monocyte response to LPS: one involved in binding of LPS, and the second in the interaction with other structures, resulting in signalling. The observation that CD14 linked to the cell membrane either via a GPI linkage, or as integral membrane protein, mediated identical cellular responses to LPS (162), further suggested that CD14 is not the signalling molecule. In addition, several studies have shown that blocking of LPS-induced cell activation with antiCD14 antibody can be overcome with high concentrations of LPS, indicating the existence of additional low affinity LPS receptors $(115,146)$.

The result of these studies support a model on LPS-induced monocyte activation as shown in Figure 5 (163). In this model it is assumed that binding of LPS to high affinity cell surface CD14, mediated by LBP, is followed by interaction of the LPSCD14 complex with additional low affinity membrane components, the putative LPS receptor, enabling trans-membrane signalling. High LPS concentrations will directly activate this signaling receptor. Because CD14 is a GPI linked protein, it should possess adequate mobility in the membrane, allowing LPS to associate with other membrane components. The membrane structures which, as described in section 3.1.1, bind LPS could be candidates for this hypothetic low affinity signaling molecule, although this has not been confirmed.

In addition to function as receptor for LPS, several other functions have been ascribed to CD14. This membrane antigen was proposed to be a pattern recognition receptor, since it is also involved in the cell stimulation induced by cell wall preparations of gram-positive bacteria and by mycobacterial lipoarabinomannan $(164,165)$. These data confirm the importance of CD14 in the recognition of 
microorganisms by the innate immune system.

Next, also indications for a role of CD14 in cell-cell interactions is obtained from several studies. Anti-CD14 antibody was reported to induce CD11/CD18intercellular adhesion molecule (ICAM) mediated homotypic adhesion of monocytes, independently of FcR activation or CD14 cross-linking (166). In addition, some antiCD14 antibodies induced monocyte mediated inhibition of T-cell proliferation by a mechanism that required cell-cell interaction (167). Recently, it was described that anti-CD14 antibody blocked B cell Ig production, an effect that was exerted at the B cell level, and was speculated to depend on interaction between CD14 and a putative CD14-ligand at B cells (168). In addition, anti-CD14 antibody inhibited monocyte adhesion to cytokine activated endothelial cells (169), an interaction which was demonstrated to be CD11/CD18-ICAM dependent (170). These data indicate that CD14 has broad activities, however, in the remainder of this chapter, CD14 will be only considered as receptor for LPS.

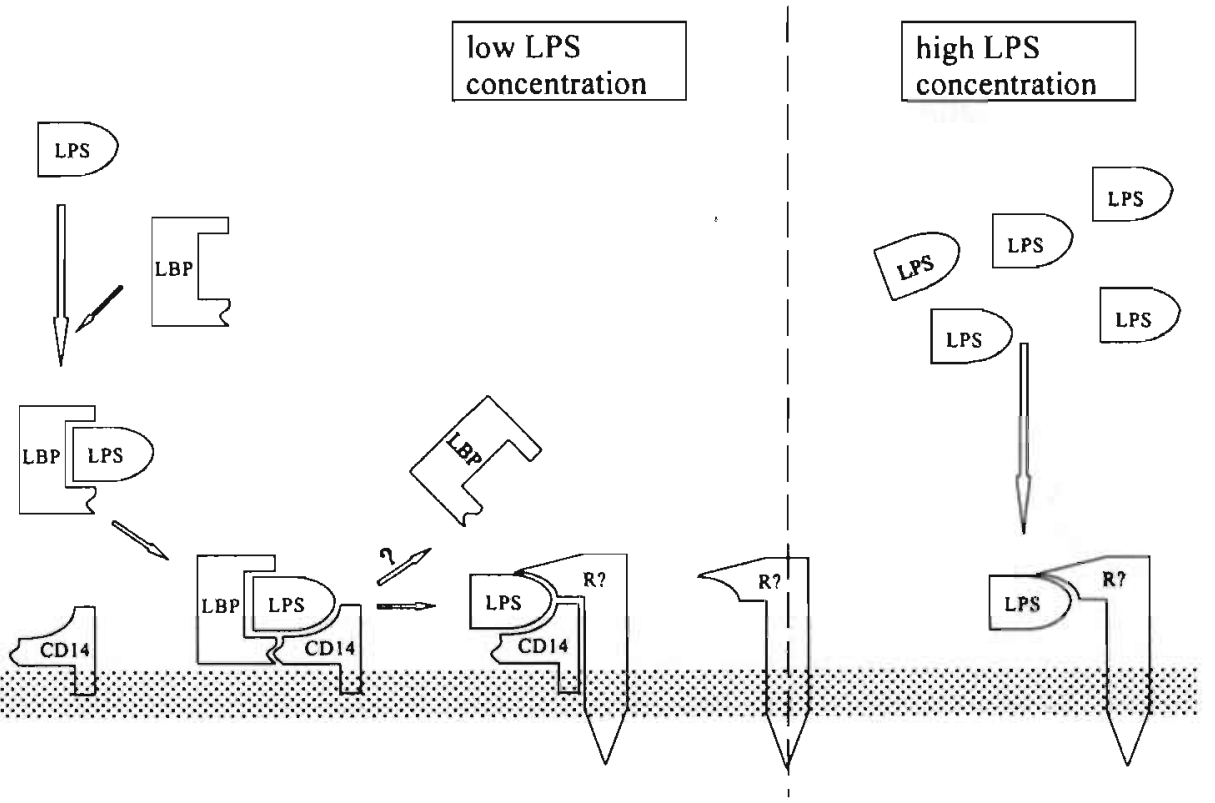

Figure 5: Proposed model of LPS stimulation of monocytes, see text for details. R? denotes the putative LPS receptor.

\section{Soluble CDI4}

Besides the membrane bound form of $\mathrm{CD} 14$ also the soluble form of $\mathrm{CD} 14, \mathrm{sCD} 14$, is involved in LPS-induced cell activation. A soluble form of $\mathrm{CD} 14$ was first identified in HL-60 culture medium, since such medium prevented the binding of anti-CD14 antibody to myeloid cells (171). Subsequently, sCD14, which lacks the 
GPI anchor (131), was demonstrated to be present in plasma of humans, in levels from $2-4 \mu \mathrm{g} / \mathrm{ml}(108,120)$. Two forms of sCD14, of approximately $48 \mathrm{kDa}$, derived from monocytes membrane $\mathrm{CD} 14$, and of $56 \mathrm{kDa}$, speculated to be directly released in plasma or supernatant after processing $(138,172,173)$ are now known to exist.

Indications for a role of $\mathrm{sCD} 14$ in LPS-induced activation of cells lacking membrane CD14 were obtained from a study of our group, showing that anti-CD14 antibody blocked LPS-induced activation of endothelial cells (174). Other studies revealed that LBP mediates binding of LPS to sCD14, and that the LPS-sCD14 complex activates membrane CD14 negative cells, like endothelial, epithelial cells, astrocytes and dendritic cells $(121,122)$. These cells are activated by the sCD14-LPS complex, via an so far unidentified surface structure. Despite the facilitating role of sCD14, cells lacking membrane CD14 are less sensitive to LPS, thus require higher concentrations of LPS for cell activation, as compared to monocytes, which express membrane CD14 and respond to very low LPS concentrations (175).

Besides mediating LPS-induced activation of CD14 negative cells, sCD14 can also antagonize LPS-LBP induced activation of membrane CD14 positive cells, by competing with membrane CD14 for LPS binding. SCD14 was demonstrated to block LPS-induced oxidative burst by monocytes, and TNF $\alpha$ production in whole blood $(176,177)$. Rather high concentrations of $20-30 \mu \mathrm{g} / \mathrm{ml} \mathrm{sCD14}$ were required for blocking the LPS mediated monocyte activation, which are approximately 10 times higher than levels present in blood of healthy individuals. However, in a model of experimental endotoxemia in mice, the TNF release and LPS lethality was inhibited by $\mathrm{sCD} 14$ at far lower concentrations, of approximately $10 \mu \mathrm{g} / \mathrm{ml}(178)$. The observation that sCD14 protected against LPS lethality, despite the fact that sCD14 enhances LPS-induced endothelial activation, is in line with the observation that the indirect pathway of endothelial cell activation, via IL-1 and TNF released by LPS activated monocytes, is more efficient than the direct endothelial activation pathway via SCD14 and LPS (175).

In vitro studies revealed that LPS, and TNF enhance shedding of CD14 resulting in increased sCD14 levels $(138,176)$, whereas in presence of IL-4 and IFN $\gamma$ reduced levels of sCD14 are observed $(176,179)$. Although in our study no enhancement of sCD14 levels in bacteremic patients were detected (108), Landman et al. described enhanced sCDI4 levels in patients with gram-negative shock, which correlated with mortality (180). However, as the authors reported, the functional consequence of the elevated SCD14 levels should be further analyzed (180).

Summarizing, sCD14 affects LPS actions via several pathways. As indicated previous, $\mathrm{SCD} 14$ is an intermediate in the transfer of LPS to $\mathrm{HDL}$, resulting into neutralization of LPS. Besides, $\mathrm{SCD} 14$ facilitates LPS activation of CD14-membrane negative cells like endo- and epithelium. Besides, high concentrations of SCD14 were shown to block LPS-induced activation of monocytes. SCD14 thus both enhances and reduces cellular responses to LPS, indicating that the physiologic function of this soluble antigen in the defense against LPS or gram-negative bacteria has to be further elucidated. 


\subsection{Cellular Activation}

A wide variety of cells will be stimulated after LPS exposure, including, monocytes/macrophages, endothelial and epithelial cells, platelets, B-cells, mast cells, fibroblasts, dendritic cells, astrocytes, smooth muscle cells etc. In this section the response of monocytes and PMN, cells that are most sensitive to LPS and important in defense against LPS, will be presented. Furthermore, the activation of endothelial and epithelial cells, which perform a barrier function and contribute greatly to the inflammatory response to LPS will be discussed.

\subsubsection{Monocytes}

Peripheral blood monocytes belong to the mononuclear phagocytic system and are derived from the bone-marrow. Monocytes circulate in the blood for one to two days, and differentiate into tissue macrophages after entering tissues, where they can stay for months. Subpopulations of tissue macrophages differ widely in their sensitivity to stimuli and the responses they exert after activation (181).

Monocytes respond to LPS with a range of activities, at very low LPS concentrations, due to the high membrane expression of the LPS receptor CD14. A series of cytokines, either with pro-inflammatory capacity or with anti-inflammatory activity, are released by the monocytes. Furthermore, monocytes are primed by LPS to produce arachidonic acid metabolites, which can enhance (leukotrienes) or inhibit $\left(\mathrm{PGE}_{2}\right)$ the inflammatory response (182). Also, LPS primes monocytes for production of oxygen radicals contributing to destruction of phagocytized microbial agents (182). Besides, the expression of adhesion molecules on cell surface of monocytes is enhanced, essential for the recruitment of monocytes to the site of infection (183).

In this section the cytokines released by monocytes in response to LPS will be shortly discussed. Two important pro-inflammatory cytokines, with greatly overlapping actions, are TNF and IL-1 $(184,185)$. Both cytokines have pleiotropic effects, including activation of leukocytes, enhancement of adherence of PMN and monocytes to endothelium, and triggering of local production of other proinflammatory cytokines. These cytokines are important mediators of LPS responses, since injection of TNF, or IL-1 in experimental animals resulted into responses comparable to those observed after LPS injection $(186,187)$. Furthermore, blocking these cytokines prevents LPS lethality $(188,189)$.

Besides TNF and IL-1 production in response to LPS IL-6 is released, a cytokine well known for its ability to induce proliferation and antibody production by B-cells. Furthermore, in common with TNF and IL-1, IL- 6 induces the production of a series of acute phase proteins (190). Another pro-inflammatory cytokine produced is IL-12. This heterodimeric cytokine exerts a broad range of actions, including the regulation of cytokine synthesis and proliferation of $T$ and NK cells, the promotion of Thl development, the differentiation of CD8+ cells and effects on hematopoiesis (191).

In addition to the release of pro-inflammatory cytokines, anti-inflammatory cytokines are produced by monocytes in response to LPS. A cytokine with strong 
immunosuppressive activity is IL-10, due to its downregulatory effects on monocyte activities. IL-10 inhibits the production of cytokines like IL-1 $\beta$, IL-6, IL-8 and TNF $\alpha$, reduces the expression of MHCII on monocytes, and prevents production of reactive nitrogen oxide (192). This indicates that the release of IL-10 (or other antiinflammatory cytokines) result into a negative-feedback, controlling the inflammatory reaction evolving after LPS exposure.

The activity of pro-inflammatory cytokines is also counterbalanced by naturally occurring cytokine inhibitors (193). The two membrane associated receptors for TNF, namely $\mathrm{TNFR}_{55}$ and $\mathrm{TNFR}_{75}$, are both present in plasma in soluble form. We demonstrated that LPS induced shedding of TNFR by monocytes (194), whereas also enhanced levels of sTNR were detected in disease state (195). The biological role of these soluble receptors seems to be dose dependent. At high concentrations sTNFR prevent TNF activities, due to competition for binding to membrane TNFR, whereas at lower concentrations, they stabilize the trimeric structure of TNF, slowing its decay of bioactivity (196). In addition, for the pro-inflammatory cytokine IL-1 several natural IL-1 inhibitors are known, like the $\mathrm{LL}-1$ receptor antagonist, and the soluble forms of both IL-1R $(185,193)$.

Another class of cytokines produced in response to LPS are chemokines, which are cytokines with chemotactic activity. The chemokines can be divided into two groups, the CC-chemokines specifically attracting and activating monocytes, and the CXC chemokines with chemotactic activity for PMN (197). In response to LPS, monocytes will produce several chemokines, most importantly IL-8, a well studied CXC chemokine $(197,198)$.

Although LPS has no direct effect upon T-cell responses, the cytokines produced by monocytes in response to LPS affect differentiation of Th0 towards Th1 or Th2 cells (199). IL-12 induces differentiation of Thl cells, which produce IFN $\gamma$, resulting into macrophage activation (191). In contrast, IL-10 inhibits the Thl response, possibly due to its inhibitory capacity on IL-12 production (192). As a result, the T cell response is dominated by Th2 cells, which produce IL- 4 and IL-10, thus blocking monocyte activities.

Therefore, the cytokines released in response to LPS importantly regulates the response of the host to LPS. The pro-inflammatory cytokines and chemokines induce an inflammatory response directed at attraction of immune cells to the site of infection and at elimination of the microorganism. By the production of antiinflammatory cytokines and cytokine inhibitors, the inflammatory response is regulated, preventing a noncontrollable inflammatory cascade. Furthermore, the cytokines released in response to LPS affect the $T$ cell development, further directing immune responses evolving in response to LPS. Since the Th1/Th2 balance seems to be involved in several chronical immune diseases, this fact has to be considered in studying these diseases.

\subsubsection{Polymorphonuclear Leukocytes}

PMN, comprising the majority of circulating leukocytes, form the first line of defense against invading microorganisms and LPS (200). In response to 
inflammatory stimuli a rapid and often massive influx of PMN in the inflamed tissue occurs. The most important function of PMN is to phagocytize and kill microorganisms. LPS or bacteria opsonized by antibodies or complement components interact with PMN via Fc-receptors or via complement receptors, and are subsequently phagocytized (201). In addition, LPS opsonized with LBP binds CD14, resulting into internalization (119), whereas LPS can bind directly to CD18 on PMN (77). For neutralizing LPS or killing the microorganism a phagocytic vesicle (also phagosome) has to fuse with a cytoplasmic granule, containing digestive enzymes and microbicidal proteins, $(202,203)$. The reactive oxygen metabolites formed as a result of respiratory burst activity further contribute to microbial killing (204). In parallel, PMN will produce inflammatory mediators in response to LPS like IL-8 (205), thereby inducing an inflammatory cascade. PMN have a short life span in circulation (4-8 h) and stay 4-5 days in tissues, and are disposed of by the process of apoptosis (206).

This section will further be focussed on BPI, one of the microbicidal proteins present in PMN, specifically directed against LPS, and with possible therapeutic potential (Figure 6). BPI was purified from the granule of human PMN, and characterized as a potent bactericidal protein in 1978 by Weiss et al. (207). This 55 $\mathrm{kDa}$ protein is highly cytotoxic towards gram-negative bacteria, but not towards gram-positive bacteria, fungi or mammalian cells. The target specificity is due to the strong attraction of the cationic BPI for the negatively charged LPS, present in the outer membrane of all gram-negative bacteria (208). BPI competes with the divalent cations $\left(\mathrm{Ca}^{2+}\right.$, or $\left.\mathrm{Mg}^{2+}\right)$, normally occupying the anion site of LPS, located in the inner core and lipid A part, thereby allowing a tight LPS packing. Since increasing length of the polysaccharide part of LPS impedes access of BPI to the anion site of LPS, the susceptibility of bacteria to BPI is determined by the polysaccharide chain length of LPS. In accordance, rough bacteria are more sensitive to BPI as compared to smooth bacteria $(207,208)$.

The cytotoxic action of BPI on bacteria can be divided into two stages (209). Binding of BPI to the outer membrane induces immediate growth arrest and outer membrane alterations like increased permeability, and selective activation of envelope enzymes degrading phospholipids and peptidoglycans. These first effects can be reversed when bound BPI is removed by addition of high $\left[\mathrm{Mg}^{2+}\right]$, or albumin. However, after more prolonged exposure to BPI, alterations of the cytoplasmatic membrane are produced, resulting in impaired energy metabolism, irreversible growth arrest, and thus in killing of bacteria.

First studies analyzing blood cells revealed that BPI is present in PMN, located in the azurophilic (also primary) granules (210). Since only small amounts of BPI are released after stimulation, or could be extracted from isolated granules, it was hypothesized that BPI is membrane associated. This was later confirmed by ultrastructural methods (211). Furthermore, BPI was reported to be present on cell surface of PMN (212,213) (Figure 6). We observed that monocytes also express BPI on their cell surface, although no indications for BPI production by these cells were obtained (214). The total amount of BPI as present in PMN was found to be approximately $200 \mathrm{ng} / 10^{6} \mathrm{PMN}$ (our data;215) or $650 \mathrm{ng}$ per $10^{6} \mathrm{PMN}$ according to others $(210)$. 
Further studies on BPI release, as induced by microbial agents, confirmed that, although LPS and TNF are relatively potent inducers of BPI release, major part of BPI remains inside PMN (215). These data support the study of Weiss et al. describing that BPI functions primarily intracellular (216). The actions of BPI, which is one of the most potent bactericidal proteins of PMN (217) can synergistically be enhanced by extracellular host defense systems like complement (218).

Molecular cloning of BPI revealed that this protein consists of a highly cationic lysine-rich amino (N)-terminal half, and a very hydrophobic, much less charged carboxyl (C)-terminal half. A relatively hydrophilic proline-rich protease sensitive region separates the two halves (219). Limited proteolysis, or incubation at $37^{\circ} \mathrm{C}$ resulted in the formation of a N-terminal $25 \mathrm{kDa}$ and $30 \mathrm{kDa}$ C-terminal fragment of BPI. The $25 \mathrm{kDa}$ N-terminal half was demonstrated to exhibit all the antibacterial activities of the holo protein (219). The hydrophobic C-terminal part could account for the association of BPI with the granule membrane.

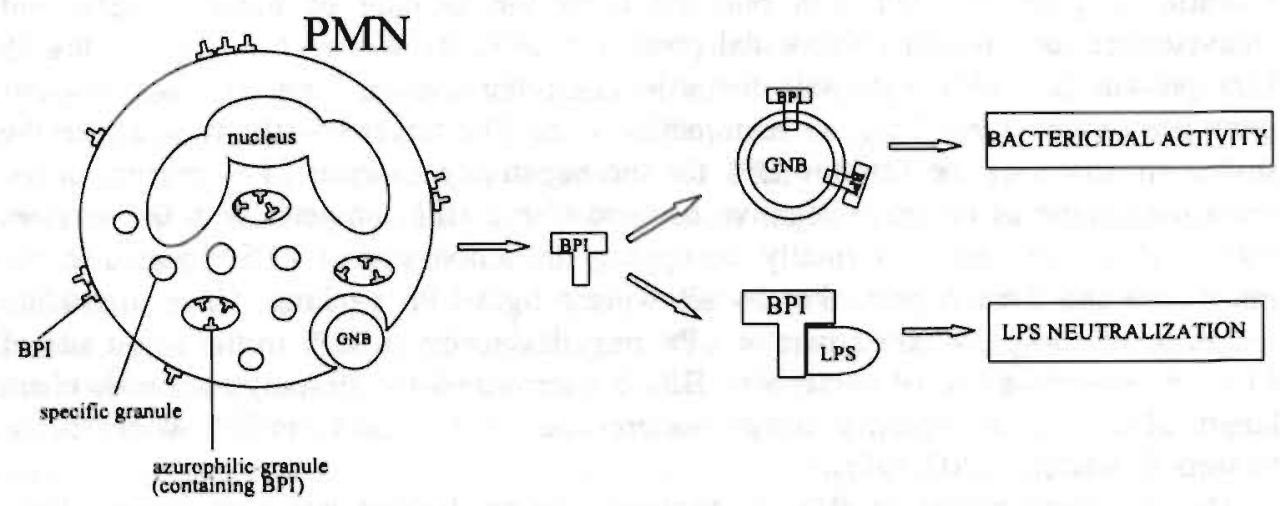

Figure 6. Localization of BPI in PMN and mode of its action. BPI is stored in the azurophilic granule, but also present on cell surface of PMN. Due to its specific interaction with LPS, BPI neutralizes LPS and kills gram-negative bacteria (GNB), actions that can be exerted inside PMN, and by BPI present in extracellular environment.

BPI, which binds isolated LPS with high affinity $(113,212)$, was furthermore shown to inhibit biological actions of LPS, like PMN priming, cytokine production by monocytes, and activation of procoagulant proteases in Limulus amebocyte lysates $(212,218,221,222)$. Moreover, we demonstrated that BPI, with a high LBP sequence homology, antagonizes the capacity of LBP to enhance LPS cell activation (114). These antagonistic properties were due to competition of BPI and LBP for binding to LPS, as was confirmed in other studies (223).

In plasma of healthy individuals none (224) or very low (225) BPI levels are present, whereas BPI levels are enhanced in biological fluids of several patient groups $(108,224,226,227)$. A study from our group revealed that in bacteremic patients the $\mathrm{BPI} /$ neutrophil ratio, reflecting neutrophil activation, was significantly associated with sepsis state and mortality, and could thus be useful in monitoring 
infectious diseases (108). In addition, Opal et al. reported that levels of BPI in abscess fluids exeded LBP levels, in contrast to levels in non-infectious fluids. indicating that BPI in these conditions could exert biological activity to L.PS (227).

Furthermore, BPI as present in glycogen-induced sterile inflammatory rabbit peritoneal exudate, was shown to exhibit bactericidal activity, indicating that extracellular BPI has biological capacity (228). In line herewith, various reports have described that exogenous recombinant (r)BPI (either the $23 \mathrm{kDa} \mathrm{N}$-terminal fragment or the holo protein) has protective capacity in models of experimental endotoxemia and bacteremia $(212,229,230)$. These data indicate that rBPI has been able to overcome the actions of other plasma proteins like LBP, and could have therapeutic potential (231).

BPI is thus a very potent endogenous LPS neutralizing and bactericidal protein, contributing significantly to the microbicidal potential present inside PMN. In infectious lesions, possibly large amounts of BPI are released as a result of PMN disrupture, contributing to fluid phase protection to LPS. The observation that BPI has high structural and functional homology with rabbit and bovine BPI (232), indicates that BPI is a highly conserved component of the antimicrobial arsenal of the mammalian PMN, further stressing its important role in defense.

\subsubsection{Endo- and Epithelial Cells}

Endothelial cells lining the vasculature have an important barrier function (233). Exposure to LPS can result in disturbance of the endothelial cell layer, as was demonstrated in animal models, resulting into leakage and oedema formation (234). In vitro models showed that LPS did not directly cause human umbicial vein endothelium cells (HUVEC) injury (235), suggesting that the in vivo endothelium damage is induced by mediators released in response to LPS. However, a direct role for LPS in endothelium damage can not be excluded, since in the presence of inhibitors of protein or RNA synthesis LPS exposure lead to detachment and lysis of the endothelium (236).

After exposure to LPS, the endothelium acquires several functional properties contributing to the defense against LPS/microorganism $(233,237)$. As described in paragraph 2.3 LPS-induced activation of the endothelium promotes coagulation by increasing the activity of the extrinsic pathway and by decreasing fibrinolytic activity (47). The blood clot formed as a result of coagulation contributes to localization of LPS and to repair of damaged vessels.

Besides, the endothelium has an important function in directing immune cells to the site of infection. Due to LPS (or inflammatory mediators) different sets of adhesion molecules are expressed, which mediate discrete steps in the process of leukocyte recruitment (as reviewed in ref 183,238). The interaction between Pselectin (early expression) and E-selectin (expression after a few hours) on endothelium, and their ligands sialylated oligosaccharide SLex and L-selectin on leukocytes, is crucial for the initial rolling interaction of leukocytes to endothelial cells. After several hours, expression of the selectins is downregulated, whereas expression of ICAM-1 and vascular cell adhesion molecule (VCAM)-1, members of 
the immunoglobulin family is strongly upregulated. Due to interaction of activated $\beta_{2}$-integrins on leukocytes with ICAM-1 and VCAM-1, leukocytes become firmly attached to endothelium, and subsequently migrate into the tissues.

By releasing chemokines the endothelium further contributes to attraction of leukocytes to site of infection. As indicated previous, the type of chemokine released determines which subgroup of leukocytes is attracted to the site of infection. Endothelial cells are known to release IL-8, specifically chemoattractive for PMN's, whereas also the monocyte chemoattractant MCP-1 can be released $(197,239)$. Besides, LPS activated endothelium will also release other inflammatory mediators like IL-6 and platelet activating factor (PAF) (237).

In addition, endothelial cells control vasomotor tone, by synthesis and secretion of vasoactive mediators including nitric oxide (NO), prostacyclin (both vasodilatory), endothelin and thromboxane (both vasoconstrictory) $(233,240)$. As a result of LPS exposure the potent vasodilatory agent NO is produced, the reaction product of nitric oxide synthase on L-arginine (241). NO formed in endothelial cells diffuses into the vascular smooth muscle cell and reduces $\left[\mathrm{Ca}^{2+}\right]$, resulting into muscle cell relaxation and vasodilation. Consequently, the rate of blood flow is reduced, facilitating the adherence of leukocytes to endothelium. Therefore, regulation of the vasomotor tone is a contributing factor for leukocyte recruitment to the site of inflammation.

Comparable to endothelial cells, epithelial cells have, besides their tissue specific function, a barrier function. The epithelium separates tissues from the outer environment, and protects in that way against macromolecules or infectious agents. The last few years information has emerged that epithelial cells play an important role in inflammatory processes. Epithelium was demonstrated to express adhesion molecules and to release different inflammatory mediators in response to appropriate stimuli, as nicely reviewed recently for lung epithelium $(242,243)$.

Endo- and epithelial cells therefore seem to protect the host against LPS by two ways. First, by providing a barrier function, and second by participating in the inflammatory response, resulting into recruitment of immune cells to the site of infection. The observation that rather high concentrations of LPS are required for stimulation of these barrier cells (as indicated previous), whereas low concentrations of TNF and IL-1 also activate these cells (175), suggest that endo- epithelial cells are activated subsequently to the monocyte activation, and represent thus a late response to LPS. The contribution of the different cells present in organs, in the defense against LPS however, is not yet clarified. For instance, it was recently shown that the mast cells play an important role in the local defense against bacterial infection, mediated through TNF $\alpha$ (244). Therefore, further studies on this subject are required. 


\section{HOST RESPONSE TO LPS}

After exposure to LPS a range of physiological responses is induced. The effect of these responses can either be beneficial or detrimental for the host (Table 1). The result of the responses to LPS depends amongst other factors, on the concentration and the localization of the LPS. In the following section two main entrance routes of LPS, namely translocation of gut derived LPS, and inhalation of air-borne LPS, and the concomitant host responses will be discussed. Since in addition the response to LPS depends on sensitivity of host to LPS, this will be discussed first.

Table 1: Beneficial and toxic effects of LPS

\begin{tabular}{ll}
\hline Beneficial & Toxic \\
\hline Enhanced resistance to infection & Tissue necrosis \\
Antitumor effects & High fever \\
Protection from lethal irradiation & Disseminated intravascular coagulation \\
Resistance to endotoxin & Generalized hypotension \\
Adjuvanticity & Multiple organ failure \\
& Shock \\
& Death \\
\hline
\end{tabular}

Table adapted from Vogel et al. (245)

\subsection{Sensitivity for LPS}

The sensitivity for LPS varies considerably among animal species. Mice and rats are relatively resistant to LPS, whereas rabbits, pigs and humans are very sensitive to LPS (246). The reasons for these differences are not yet unravelled. It has been demonstrated that resistance to endotoxin is genetically determined. The $\mathrm{C} 3 \mathrm{H} / \mathrm{HeJ}$ mouse exhibits a marked insensitivity to LPS as compared to other mouse strains, due to a defect in a single autosomal gene termed Lps, located on chromosome 4 $(247,248)$. Further studies revealed that a defective response of $\mathrm{C} 3 \mathrm{H} / \mathrm{HeJ}$ macrophages to LPS is the cause for this LPS resistance $(249,250)$.

A similar genetic trait is not known for man. However, recently data have become available that a polymorphism in the TNF gene (a $G$ to A transmission at position -238) reduced the release of this pro-inflammatory cytokine in response to LPS (251). Furthermore, this polymorphism was associated with increased risk for fatal meningococcal disease and reduced risk for autoimmune disease (251). Besides, another TNF gene polymorphism (at position -308) was reported to be associated with susceptibility to cerebral malaria (252). This indicates that genetic alterations on different genes (Lps gene versus TNF gene) can affect susceptibility for I.PS. Similarly, genetic variations in other genes coding for proteins involved in the response to LPS, could affect sensitivity of host to LPS, although this hypothesis has to be further investigated.

The sensitivity for LPS can be strongly enhanced under experimental conditions 
by treatment with agents as $\mathrm{D}$-galactosamine. $\mathrm{D}$-galactosamine is metabolized in the liver, resulting in a selective depletion of uridine nucleotides in hepatocytes and thus in blockade of hepatic transcription and consequently protein biosynthesis in these cells (253). Although D-galactosamine itself is not toxic, it enhances sensitivity of animals for LPS several thousand fold (254). Further studies revealed that the enhanced sensitivity was mediated by TNF $\alpha$ produced by monocytes/macrophages in response to LPS (255). Recently it was shown that the liver damage observed in Dgalactosamine sensitized mice is the result of TNF-induced apoptosis of hepatocytes with transcriptional arrest (256).

Similarly, exposure to lead also enhances sensitivity to LPS (257). We showed that, comparable to D-galactosamine, this effect is mediated via TNF $\alpha$ (258). Since exposure to lead and LPS or TNF, induces strong hepatoxicity (259), lead most probably induces sensitization via the same processes as D-galactosamine, although this had not yet been confirmed.

Infection with gram-negative bacteria also increases sensitivity of the host for LPS (260). A key role for IFN $\gamma$ in this hypersensitivity was demonstrated, since antibodies directed against IFN $\gamma$ blocked the bacteria induced sensitization (260). This indicates that in response to bacteria monocytes are triggered to release IL-12, which in turn activates T cells to produce IFN $\gamma$ (191). Due to the presence of IFN which is known to enhance the responses of macrophages to LPS (261), the sensitivity for LPS is enhanced.

Furthermore, some tumors enhance the susceptibility of the host to LPS (262). This indicates that these tumors produce a factor, or stimulate other cells to release a soluble mediator (possibly IL-12 or IFNy) resulting in this enhanced sensitivity. However, the mechanism underlying this process have not yet been unravelled. In addition, it was demonstrated that some groups of tumors are extremely sensitive to LPS or TNF, resulting in hemorrhagic necrosis inside the tumor, whereas the host is not affected (263). These data are in line with production of a locally acting factor enhancing sensitivity.

On the contrary, enhanced resistance to LPS can be induced, which is due to repeated exposure to LPS, a process known as tolerance. After primary exposure the host is temporarily insensitive for LPS, and hardly responds to additional LPS exposure (264). This tolerance was demonstrated to be mediated by macrophages (265), but is not caused by a reduced expression of the LPS receptor CD14 (266). Although the production of pro-inflammatory cytokines like TNF $\alpha$ and IL-1 is clearly diminished, enhanced levels of anti-inflammatory mediators sTNFR 75 and IL10 are reported after secondary LPS exposure $(267,268)$. In addition, IL-10 was shown to play an important role in the phenomenon of LPS tolerance (269).

The process of tolerance was demonstrated to occur also in humans like cancer patients repeatedly injected with LPS (270), and in sepsis patients (269). This induction of tolerance could be beneficial, since it prevents excessive inflammatory reactions in response to long-term or repeated LPS exposure. However, when tolerance results in inability of the host to combat the infection, the tolerant state will become deleterious for the host.

Since IL-10 is involved in induction of tolerance for LPS, whereas IL-12 as reported above is involved in the enhanced sensitivity to LPS, it can be speculated 
that $\mathrm{T}$ helper subsets affect sensitivity of the host to LPS. Thl response (induced by IL-12) result in increased sensitivity for LPS, due to INF $\gamma$ production enhancing macrophage responses to LPS. In contrast, Th2 response (induced by IL-10) lead to production of IL-10 and IL-4 which block macrophage activation and in this way induce tolerance for LPS.

In conclusion, sensitivity of the host to LPS seems to be genetically determined. This sensitivity can be enhanced by hepatotoxic agents, rendering the liver sensitive for TNF-induced apoptosis, indicating that patients with liver disorder have increased risk for LPS toxicity. Furthermore, also a (latent) infection with gramnegative bacteria or the presence of a tumor can be considered as a cause of enhanced sensitivity to LPS. However, after a first LPS exposure the host is temporarily unresponsive to LPS, which seems to be a protective mechanism directed at prevention of an excessive inflammatory cascade.

\subsection{LPS Exposure}

The host can be exposed to LPS via several ways. As a result of translocation of bacteria normally present in the gut of the host, LPS will appear in circulation. Besides, the host is exposed to air-borne LPS continuously. These two main routes of LPS exposure and the concomitant host responses will be discussed in the next section.

\subsubsection{LPS Translocation}

A major part of the gut flora of healthy individuals consists of gram-negative bacteria. As a consequence large amounts of LPS are present inside the gut. Since no signs of inflammation are present in the gastro-intestinal tract of healthy individuals, whereas also orally administrated LPS does not induce toxic symptoms (271), it can be concluded that the inner milieu of the gut is resistant to LPS.

The mechanisms underlying this phenomenon of LPS resistance inside the gut are not fully elucidated. One of the components possibly contributing to resistance to LPS are bile acids, which inactivate LPS due to their detergent effects (272). In addition, as a result of the repeated exposure to LPS, a state of local tolerance can have been evolved. Furthermore, the resident macrophages in normal intestine express low amounts of the LPS receptor CD14 (145), indicating that these cells are LPS insensitive. Besides, it can be speculated that the mucus layer covering the epithelium, provides protection, by preventing a direct interaction of LPS with the epithelial cells.

Small amounts of LPS derived from the gut can be adsorbed and detoxified by the liver (273). However, as shown in animal models, severe trauma, as hemorrhagic shock, multi-trauma or hypoxy-reperfusion injury, leads to translocation of large amounts of bacteria and induces endoxemia $(274,275)$. Furthermore, as a result of a single physiological insult the susceptibility for second otherwise subinjurious stress can be increased resulting in large bacterial translocation, which is called the two-hit 
theory $(276,277)$. LPS translocation is also reported in man. In patients with inflammatory bowel disease increased systemic LPS levels are present, due to mucosal barrier dysfunction $(278,279)$. Also in sepsis patients, gut derived endotoxin secondary to failure of hepatic filtration, was indicated to play a central role in the syndrome of multiple organ failure (280).

High levels of LPS in the circulation will result in derangement of host physiology, like induction of hypotension, metabolic acidosis, and leukopenia. In addition, organs like lung, gut and kidney are damaged, as reflected by inflammation and necrosis. Eventually, these systemic levels of LPS lead to multi-organ failure, shock and dead (281).

Such detrimental effects of LPS are mediated by cytokines released in response to LPS, since blocking the biological activity of pro-inflammatory cytokines like TNF and IL-1 prevented toxic effects of LPS $(188,189)$. In addition, the induction of coagulation and the complement activation, which appear mechanisms directed to localize and eliminate LPS, were shown to contribute to these adverse effects $(44,46,50,54)$.

However, in localized or compartmentalized infections, the inflammatory cascade in response to LPS is beneficial. For instance in a model of peritonitis, as induced by cecal duct ligation and puncture, it was shown that administration of TNF prevented hypotension, hypothermia and lethality (282). Furthermore, a beneficial role of endogenous TNF was demonstrated, since neutralizing antibodies against this cytokine enhanced lethality in this model (283). This indicates that where local cytokine production is required for adequate defense, the host has no appropriate defense against high levels of systemic LPS, due to the generalized non-controllable response.

\subsubsection{LPS Inhalation}

The lung is one of the main organs in direct contact with the outer environment. On a daily basis a healthy individual inhales approximately 10.000 littre air, containing many contaminating agents. Airborne LPS is present in a variety of environmental conditions, very often attached to organic dust as particles of animal, vegetable and microbial origin (284).

Lungs have, under normal conditions, an very efficient defense system against these invading agents (285). First, the epithelium lining of the airways forms an impermeable barrier. Due to exogenous triggers like mechanical irritation or dust particles, the nerve system is activated resulting into coughing and sneezing, thereby eliminating the contaminants, whereas bronchoconstriction will prevent the penetration of agents into the lower airways. Furthermore, trapping of particles in mucus and subsequent clearance of mucus by ciliary activity and cough, forms an other efficient clearance mechanism against inhaled or aspirated particles.

In addition, a diversity of factors is present in the epithelial lining fluid which contributes to the local defense $(242,243,285)$. These include antimicrobial compounds like lysozyme and lactoferrine acting directly on bacteria, whereas complement components function as opsonins for microorganisms. In addition, 
secretory IgA contributes to the defense against bacteria and viruses. Also antioxidants as glutathione and catalase, and antiproteases including $\alpha_{1}$-protease inhibitor secretory leucoprotease inhibitor, $\alpha_{1}$-antitrypsin and elafin are present in the epithelial lining fluid.

In the alveoli, the alveolar macrophages form the first line of defense against invading particles. These cells have strong phagocytic capacity, and in response to activation will secrete a series of inflammatory mediators, including chemokines. As a result PMN present in the lung capillaries, will be attracted to the site of injury thereby amplifying the defense against the invading agent $(285,286)$.

Similarly as described for the inner milieu of the gut, the airways, and especially the epithelium are continuously exposed to LPS, but do not exert signs of inflammation. As hypothesized previous, this could be due to a state of local tolerance, or to the presence of the mucus layer covering the epithelium, preventing the interaction of LPS with the epithelial cells.

However, especially after different occupational exposure, LPS-induced pulmonary disorders have been described, as after exposure to grain dust, animal feed mills dust and swine dust (284,287-289). Inhalation of organic dust, contaminated with LPS, was shown to result in increased cytokine levels, both in animal models and in man, $(289,290)$, which could mediate some of the peripheral symptoms associated with dust inhalation. The physiological response to dust varies widely among the exposed workers, suggesting a genetic variability as discussed above. For instance the Pi-Mz phenotype of the $\alpha$-1-antitrypsin gene was found associated with family allergy and could possibly predispose to the development of byssinosis (291).

Furthermore, epithelial cell damage, frequently present in different lung disorders can attenuate the barrier function. Besides, the underlying lung pathology can affect the function of immune cells important in defense to LPS: these cells can either be sensitized, resulting in enhanced response to LPS, or they can have become tolerant, due to repeated exposure to LPS, leading to an incomplete defense $(292,293)$.

Thus, although the airways are continuously exposed to airborne LPS, under normal circumstances this organ has a very efficient defense system, and is not affected by LPS. However, under conditions of high exposure to LPS, or due to a reduced defense capacity caused by underlying lung disorder, the exposure to LPS could become detrimental for the lungs, and thus for the host. 


\section{AIM OF THE THESIS}

As discussed in this chapter, in response to LPS a wide range of humoral and cellular systems are activated in order to eliminate free LPS and gram-negative bacteria, and to induce subsequently tissue repair and regeneration. However, when these activation processes are not well controlled, for instance due to generalized responses to LPS, or as a result of enhanced sensitivity for LPS, they can be detrimental to the host.

The aim of this thesis is to obtain more insight in the pathways of LPS-induced action, which could help to develop therapeutic strategies directed against LPS mediated pathology. To this end several aspects of host response to LPS were studied. First, the mechanism of the enhanced sensitivity for LPS after exposure to lead was analyzed, by studying the role of the pro-inflammatory cytokine TNF $\alpha$ in this process. Furthermore, a series of studies was performed in order to investigate the responses, both of pro-inflammatory and anti-inflammatory nature, of monocytes and endothelial cells to LPS. The role of the endogenous LPS binding proteins CD14, LBP and BPI in these cellular activation processes was analyzed. Additional studies were performed on the PMN protein BPI, a very potent LPS neutralizing and bactericidal agent. An assay was developed to the measure this protein and subsequently its presence in health and disease was studied. 


\section{REFERENCES}

1. Pfeiffer R. Untersuchungen über das choleragift. Z Hyg Infektionskr 1892;11:393-412.

2. Rietschel ET, Brade H. Bacterial endotoxins. Sci Am 1992;267:26-33.

3. Raetz CRH. Biochemisty of endotoxins. Annu Rev Biochem 1990;59:129-70.

4. Shands JW. Localization of somatic antigen on gram-negative bacteria by electron microscopy. J Bacteriol 1965;90:266-70.

5. Legrand EK, An evolutionary perspective of endotoxin: a signal for a well-adapted defense system. Med Hypothesis 1990;33:49-56.

6. Möller G, Michael G. Frequency of antigen-sensitive cells to thymus-independent antigens. Cell Immunol 1971;2:309-16.

7. Helander IM, Lindner B, Brade H, Altmann K, Lindberg AA, Rietschel ET, Zahhringer U. Chemical structure of the lipopolysaccharide of Haemophilus influenzae stain $1-69 \mathrm{Rd} / \mathrm{b}^{+}$: description of a novel deep-rough chemotype. Eur J Biochem 1988;177:483-92.

8. Galanos C, Lüderitz O, Rietschel ET, et al. Synthetic and natural Escherichia coli free lipid A express identical endotoxic activities. Eur J Biochem 1985;148:1-5.

9. Kotani S, Takada H, Tsujimoto $M$, et al. Synthetic lipid A with endotoxic and related biological activities comparable to those of a natural lipid A from an Escherichia coli Remutant. Infect Immun 1985:49:225-37.

10. Rietschel ET, Kirikae T, Schade FU, et al. Bacterial endotoxin: molecular relationships of structure to activity and function. FASEB J 1994;8:217-25.

11. Kirikae T, Schade FU, Zähringer U, et al. The significance of the hydrophilic backbone and the hydrophobic fatty acid regions of lipid $A$ for macrophage binding and cytokine induction. FEMS Immunol Med Microbiol 1994;8:13-26.

12. Haeffner-Cavaillon $\mathbf{N}$, Caroff $\mathbf{M}$, Cavaillon $\mathbf{J}-\mathbf{M}$. Interleukin-1 induction by lipopolysaccharides: structural requirements of the 3-deoxy-d-manno-2-octulosonic acid (KDO). Mol Immunol 1989;26:485-94.

13. Männel DN, Falk W. Optimal induction of tumor necrosis factor production in human monocytes requires complete S-form lipopolysaccharide. Infect Immun 1989;57:1953-8.

14. Freudenberg MA, Galanos $C$. The metabolic fate of endotoxins. In: Levin J. Bacterial endotoxins: pathophysiological effects, clinical significance and pharmacological control. New York: Alan R. Llss, Inc, 1988:63-75.

15. Haeffner-Cavaillon N, Cavaillon J-M, Moreau M, Szabó L. Interleukin 1 secretion by human monocytes stimulated by the isolated polysaccharide region of the Bordetella periussis endotoxin. Mol Immunol 1984;21:389-95.

16. Nowotny A, Blanchard DK, Newton C, Klein T, Stewart II W, Szentivanyi A, Friedman H. Interferon induction by endotoxin-derived nontoxic polysaccharides. J Interferon Res 1987;7:371-8.

17. Morrison DC, Kline LF. Activation of the classical and properdin pathways of complement by bacterial lipopolysaccharides (LPS). J Immunol 1977;1 18:362-8.

18. Russell RRB. Free endotoxin - a review. Microbios Letters 1976;2:125-35.

19. Evans ME, Pollack $M$. Effect of antibiotic class and concentration on the release of lipopolysaccharide from Escherichia coli. J Infect Dis 1993;167:1336-43.

20. Tesh VL, Duncan RL, Morrison DC. The interaction of Escherichia coli with normal human serum: the kinetics of serum-mediated lipopolysaccharide release and its dissociation from bacterial killing. J Immunol 1986;137:1329-35.

21. Seydel U, Labischinski H, Kastowsky M, Brandenburg K. Phase behavior, supramolecular structure, and molecular conformation of lipopolysaccharide. Immunobiology 1993;187:191211.

22. Brandenburg K, Mayer H, Koch MH, Weckesser J, Rietschel ET, Seydel U. Influence of the supramolecular structure of free lipid A on its biological activity. Eur J Biochem 1993;218:555-63.

23. Lüderitz T, Brandenburg K, Seydel U, Roth A, Galanos C, Rietschel ET. Structural and 
physicochemical requirements of endotoxin for the activation of arachidonic acid metabolism in mouse peritoneal macrophages in vitro. Eur J Biochem 1989;179:11-6.

24. Roth RI, Levin FC, Levin J. Distributin of bacterial endotoxin in human and rabbit blood and effects of stroma-free hemoglobin. Infect Immun 1993;61:3209-15.

25. Ulevitch RJ, Johnston AR. The modification of biophysical and endotoxic properties of bacterial lipopolysaccharides by senum. J Clin Invest 1978;62:1313-24.

26. Ulevitch RJ, Johnston AR, Weinstein DB. New function for high density lipoproteins: isolation and characterization of a bacterial lipopolysaccharide-high density lipoprotein complex formed in rabbit plasma. J Clin Invest 1981;67:827-37.

27. Van Lenten BJ, Fogelman AM, Haberland ME, Edwards PA. The role of lipoproteins and receptor-mediated endocytosis in the transport of bacterial lipopolysaccharide. Proc Natl Acad Sci U S A 1986;83:2704-8.

28. Harris HW, Grunfeld C, Feingold KR, et al. Chylomicrons alter the fate of endotoxin, decreasing tumor necrosis factor release and preventing death. J Clin Invest 1993;91:1028-34.

29. Liao W, Florén C-H. Hyperlipidemic response to endotoxin - a part of the host-defence mechanism. Scand J Infect Dis 1993;25:675-82.

30. Cavaillon J-M, Fitting C, Haeffner-Cavaillon N, Kirsch SJ, Warren HS. Cytokine response by monocytes and macrophages to free and lipoprotein-bound lipopolysaccharide. Infect Immun 1990;58:2375-82.

31. Vosbeck K, Tobias P, Mueller H, Allen RA, Arfors K-E, Ulevitch RJ, Sklar LA. Priming of polymorphonuclear granulocytes by lipopolysaccharides and its complexes with lipopolysaccharide binding protein and high density lipoprotein. J Leukoc Biol 1990;47:97104.

32. Levine DM, Parker TS, Donnelly TM, Walsh A, Rubin AL. In vivo protection against endotoxin by plasma high density lipoprotein. Proc Natl Acad Sci U S A 1993;90;12040-4.

33. Feingold KR, Funk JL, Moser AH, Shigenaga JK, Rapp JH, Grunfeld C. Role of circulating lipoproteins in protection form endotoxin toxicity. Infect Immun. 1995;63:2041-6.

34. Van Der Poll T, Braxton CC, Coyle SM, et al. Effect of hypertriglyceridemia on endotoxin responsiveness in humans. Infect Immun 1995;63:3396-400.

35. Mathison JC, Ulevitch RJ. The clearance, tissue distribution, and cellular localization of intravenously injected lipopolysaccharide in rabbits. J Immunol 1979;123:2133-43.

36. Munford RS, Dietschy JM. Effects of specific antibodies, hormones and lipoproteins on bacterial lipopolysaccharides injected into the rat. J Infect Dis 1985;152:177-84.

37. Ge Y, Ezzell RM, Tompkins RG, Warren HS. Cellular distribution of endotoxin after injection of chemically purified lipopolysaccharide differs from that after injection of live bacteria. J Infect Dis 1994;169:95-104.

38. Cooper NR, Morrison DC. Binding and activation of the first component of human complement by the lipid A region of lipopolysaccharides. J Immunol 1978;120:1862-8.

39. Abbas AK, Lichtman AH, Pober JS. Cellular and molecular immunology. 2nd ed. Philadelphia: W.B. Saunders company,1994:293-316.

40. Johnson $\mathrm{KJ}$, Ward PA. The requirement for serum complement in the detoxification of bacterial endotoxin. J Immunol 1972;108:611-6.

41. Goldstein IM. Complement: biologically active products. In: Gallin JI, Goldstein IM, Snyderman R. Inflammation: basic principles and clinical correlates. 2ng ed. New York: Raven Press, 1992:63-80.

42. Quezado ZMN, Hoffman WD, Winkelstein JA, et al. The third component of complement protects against Escherichia coli endotoxin-induced shock and multiple organ failure. J Exp Med 1994;179:569-78.

43. Johnson $\mathrm{KJ}$, Ward PA. Protective function of $\mathrm{C} 6$ in rabbits treated with bacterial endotoxin. J lmmunol 1971;106: I125-7.

44. Fust G, Petrás G, Ujhelyi E. Activation of the complement system during infections due to gram-negative bacteria. Clin Immunol Immunopathol 1976;5:293-302.

45. Hack CE, Nuijens JH, Felt-Bersma RJF, Schreuder WO, Eerenberg-Belmer AJM, Paardekooper J, Bronsveld W, Thijs LG. Elevated plasma levels of the anaphylatoxins C3a 
and 4a are associated with a fatal outcome in sepsis. Am J Med 1989;86:20-6.

46. Stevens JH, O'Hanley P, Shapiro JM, Mihm FG, Satoh PS, Collins JA, Raffin TA. Effects of anti-C5a antibodies on the adult respiratory distress syndrome in septic primates. $\mathrm{J}$ Clin Invest 1986;77:1812-6.

47. Pearson JD. Vessel wall interactions regulating thrombosis. Br Med Bull 1994;50:776-88.

48. Morrison DC, Cochrane CG. Direct evidence for hageman factor (factor XII) activation by bacterial lipopolysaccharides (endotoxins) J Exp Med 1974;140:797-811.

49. Kozin F, Cochrane CG. The contact activation system of plasma: biochemistry and pathophysiology. In: Gallin J, Goldstein IM, Snyderman R. Inflammation: basic principles and clinical correlates. 2nd ed. New York: Raven Press, 1992:103-21.

50. Kaufman N, Page JD, Pixley RA, Schein R, Schmaier AH, Colman RW. $\alpha_{2}$-macroglobulinkallikrein complexes detect contact system activation in hereditary angioedema and human sepsis. Blood 1991;77:2660-7.

51. Dela Cadena RA, Suffredini AF, Page JD, Pixley RA, Kaufman N, Parrillo JE, Colman RW. Activation of the kallikrein-kinin system after endotoxin administration to normal human volunteers. Blood 1993;81:3313-7.

52. Gregory SA, Morrissey JH, Edgington TS. Regulation of tissue factor gene expression in the monocyte procoagulant response to endotoxin. Mol Cell Biol 1989;9:2752-5.

53. Moore KL, Andreoli SP, Esmon NL, Esmon CT, Bang NU. Endotoxin enhances tissue factor and suppresses thrombomodulin expression of human vascular endothelium in vitro. $\mathrm{J}$ Clin Invest 1987;79:124-30.

54. Levi $\mathrm{M}$, Ten Cate $\mathrm{H}$, Bauer $\mathrm{KA}$, et al. Inhibition of endotoxin-induced activation of coagulation and fibrinolysis by pentoxifylline or by a monoclonal anti-tissue factor antibody in chimpanzees. J Clin Invest 1994;93:114-20.

55. Hanss $M$, Collen $D$. Secretion of tissue-type plasminogen activator and plasminogen activator inhibitor by cultured human endothelial cells: modulation by thrombin, endotoxin, and histamine. J Lab Clin Med 1987;109:97-104.

56. Suffredini AF, Harpel PC, Parrillo JE. Promotion and subsequent inhibition of plasminogen activation after administration of intravenous endotoxin to normal subjects. $\mathrm{N}$ Engl $\mathrm{J}$ Med 1989;320:1165-72.

57. Levin J, Bang FB. Clottable protein in limulus: its localization and kinetics of its coagulation by endotoxin. Thromb Diath Haemorrh 1968;19:186-97.

58. Beisel WR. Metabolic response to infection. Annu Rev Med 1975;26:9-20.

59. Dinarello CA, Cannon JG, Mancilla J, Bishai I, Lees J, Coceani F. Interleukin-6 as an endogenous pyrogen: induction of prostanglandin $E_{2}$ in brain but not in peripheral blood mononuclear cells. Brain Res 1991;562:199-206.

60. Ashman RB, Müllbacher A. Infectious disease, fever, and the immune response. Immunol Today 1984;5:268-71.

61. Liao W, Floren $\mathrm{CH}$. Endotoxin, cytokines, and hyperlipidemia. Scand J Gastroenterol 1993;28:97-103.

62. Grunfeld C, Palladino MA. Tumor necrosis factor: immunologic, antitumor, metabolic and cardiovascular activities. Adv Intern Med 1990;35:45-72.

63. $\mathrm{Xu} \mathrm{N}$, Nilsson A. Endotoxin inhibits catabolism of low density lipoproteins in vivo: an experimental study in the rat. Scand J Clin Lab Invest 1996;56:53-61.

64. Liao W, Rudling M, Angelin B. Endotoxin suppresses rat hepatic low-density lipoprotein receptor expression. Biochem J 1996;313:873-8.

65. Fischer JE, Hasselgren P-O. Cytokines and glucocorticoids in the regulation of the "hepatoskeletal muscle axis" in sepsis. Am J Surg 1991;161:266-71.

66. Simmons PS, Miles JM, Gerich JE, Haymond MW. Increased proteolysis: an effect of increases in plasma cortisol within the physiologic range. J Clin Invest 1984;73:412-20.

67. Gelfand RA, Matthews DE, Bier DM, Sherwin RS. Role of counterregulatory hormones in the catabolic response to stress. J Clin Invest 1984;74:2238-48.

68. Berczi I. Neuroendocrine defence in endotoxin shock (a review). Acta Microbiol Hung 1993;40:265-302. 
69. Bessey PQ, Watters JM, Aoki TT, Wilmore DW. Combined hormonal infusion simulates the metabolic response to injury. Ann Surg 1984;200:264-81.

70. Goldstein RA, Bowen DL, Fauci AS. Adrenal corticosteroids. In: Gallin J, Goldstein IM, Snyderman R. Inflammation: basic principles and clinical correlates. 2nd ed. New York: Raven Press, 1992:1061-81.

71. Steel DM, Whitehead AS. The major acute phase reactants: C-reactive protein, serum amyloid $\mathrm{P}$ component and serum amyloid A protein. Immunol Today 1994;15;81-8.

72. Gewurz H, Zhang X-H, Lint TF. Structure and function of the pentraxins. Curr Opin Immunol 1995;7:54-64.

73. Young B, Gleeson M, Cripps AW. C-reactive protein: a critical review. Pathology $1991 ; 23: 118-24$.

74. Baumannn H, Gauldie J. The acute phase response. Immunol Today 1994;15:74-80.

75. Tahri-Jouti M-A, Chaby R. Specific binding of lipopolysaccharides to mouse macrophages-1. characteristics of the interaction and inefficiency of the polysaccharide region. Mol Immunol 1990;27:751-61.

76. Couturier $\mathrm{C}$, Haeffner-Cavaillon N, Caroff $M$, Kazatchkine MD. Binding sites for endotoxins (lipopolysaccharides) on human monocytes. J Immunol 1991;147:1899-1904.

77. Wright SD, Jong MTC. Adhesion-promoting receptors on human macrophages recognize Escherichia coli by binding to lipopolysaccharide. J Exp Med 1986;164:1876-88.

78. Wright SD. Multiple receptors for endotoxin. Curr Opin Immunol 1991;3:83-90.

79. Wright SD, Detmers PA, Aida Y, et al. CD-18 deficient cells respond to lipopolysaccharide in vitro. J Immunol 1990; |44:2566-71.

80. Wright SD, Ramos RA, Tobias PS, Ulevitch RJ, Mathison JC. CD14, a receptor for complexes of lipopolysaccharide (LPS) and LPS binding protein. Science 1990;249:1431-3.

81. Ingalls $\mathrm{RR}$, Golenbock DT. CDIlc/CD18, a transmembrane signaling receptor for lipopolysaccharide. J Exp Med 1995;181:1473-9.

82. Hampton RY, Golenbock DT, Penman M, Krieger M, Raetz CRH. Recognition and plasma clearance of endotoxin by scavenger receptors. Nature 1991:352:342-4.

83. Goldenbock DT, Liu Y, Millham FH, Freeman MW, Zoeller RA. Surface expression of human $\mathrm{CD} 14$ in chinese hamster ovary fibroblasts imparts macrophage-like responsiveness to bacterial endotoxin. J Biol Chem 1993;268:22055-9.

84. Lei M-G, Morrison DC. Specific endotoxic lipopolysaccharide-binding proteins on murine spenocytes: I. Detection of lipopolysaccharide-binding sites on splenocytes and splenocyte subpopulations. J Immunol 1988;141:996-1005.

85. Lei M-G, Morrison DC. Specific endotoxic lipopolysaccharide-binding proteins on murine spenocytes: II. Membrane localization and binding characteristics. J Immunol 1988;141:100611.

86. Lei M-G, Stimpson SA, Morrison DC. Specific endotoxic lipopolysaccharide-binding proteins on murine spenocytes: III. Binding specificity and characterization. J Immunol 1991;147:1925-32.

87. Chen T-Y, Bright SW, Pace $\mathrm{L}$, Russell SW, Morrison DC. Induction of macrophagemediated tumor cytotoxicity by a hamster monoclonal antibody with specificity for lipopolysaccharide receptor. J Immunol 1990;145:8-12.

88. Morrison DC, Silverstein R, Bright SW, Chen T-Y, Flebbe LM, Lei M-G. Monoclonal antibody to mouse lipopolysaccharide receptor protects mice against the lethal effects of endotoxin. J Infect Dis 1990;162:1063-8.

89. Dziarski R, Gupta D. Heparin, sulfated heparinoids, and lipoteichoic acids bind to the 70-kDa peptidoglycan/lipopolysaccharide receptor protein on lymphocytes. J Biol Chem 1994;269:2100-10.

90. Dziarski R. Cell-bound albumin is the $70-\mathrm{kDa}$ peptidoglycan-, lipopolysaccharide-, and lipoteichoic acid-binding protein on lymphocytes and macrophages. $\mathrm{J}$ Biol Chem 1994:269:20431-6.

91. Hara-Kuge S, Amano F, Nishijima M, Akamatsu Y. Isolation of a lipopolysaccharide (LPS)resistant mutant, with defective LPS binding, of cultured macrophage-like cells. J Biol Chem 
1990;265:6606-10.

92. Kirikae T, Schade FU, Kirikae F, Rietschel ET, Morrison DC. Isolation of a macrophage-like cell line defective in binding of lipopolysaccharide: influence of serum and lipopolysaccharide chain length on macrophage activation. J Immunol 1993;151:2742-52.

93. Kirkland TN, Virca GD, Kuus-Reichel T, Multer FK, Kim SY, Ulevitch RJ, Tobias PS. Identification of lipopolysaccharide-binding proteins in $70 \mathrm{Z} / 3$ cells by photoaffinity crosslinking. J Biol Chem 1990;265:9520-5.

94. Kirikae T, Kirikae F, Schade FU, et al. Detection of lipopolysaccharide-binding proteins on membranes of murine lymphocyte and macrophage-like cell lines. FEMS Microbiol Immunol 1991;76:327-36.

95. Schletter J, Brade H, Brade L, et al. Binding of lipopolysaccharide (LPS) to an 80-Kilodalton membrane protein of human cells is mediated by soluble CD14 and LPS-binding protein. Infect Immun 1995;63:2576-80.

96. Corrales I, Weersink AJL, Verhoef J, Van Kessel KPM. Serum-independent binding of lipopolysaccharide to human monocytes is trypsin sensitive and does not involve CDI4. Immunology 1993;80:84-9.

97. Weersink AJL, Van Kessel KPM, Van Der Tol ME, Verhoef J. Modulation of lipopolysaccharide binding to human granulocytes. Immunology 1994;83:617-23.

98. Haeffner-Cavaillon N, Cavaillon J-M, Etievant M, Lebbar S, Szabó L. Specific binding of endotoxin to human monocytes and mouse macrophages; serum requirement. Cell Immunol 1985;91:119-31.

99. Mey A, Leffler $\mathrm{H}$, Hmama Z, Normier G, Revillard J-P. The animal lectin galectin-3 interacts with bacterial lipopolysaccharide via two independent sites. J Immunol 1996;156:1572-7.

100. Lei M-G, Quereshi N, Morrison DC. Lipopolysaccharide (LPS) binding to 73-kDa and 38$\mathrm{kDa}$ surface proteins on lymphoreticular cells: preferential inhibition of LPS binding to the former by Rhodopseudomonas sphaeroides lipid A. Immunol Lett 1993;36:245-50.

101. Tobias PS, Soldau K, Ulevitch RJ. Isolation of a lipopolysaccharide-binding acute phase reactant from rabbit serum. J Exp Med 1986;164:777-93.

102. Tobias PS, Soldau K, Ulevitch RJ. Identification of a lipid A binding site in the acute phase reactant lipopolysaccharide binding protein. J Biol Chem 1989;264:10867-71.

103. Schumann RR, Leong SR, Flaggs GW, et al. Structure and function of lipopolysaccharide binding protein. Science 1990;249:1429-31.

104. Gallay P, Carrel S, Glauser MP, et al. Purification and characterization of murine lipopolysaccharide-binding protein. Infect Immun 1993;61:378-83.

105. Su GL, Freeswick PD, Geller DA, et al. Molecular cloning, characterization, and tissue distribution of rat lipopolysaccharide binding protein: evidence for extrahepatic expression. J Immunol 1994; 153:743-52.

106. Khemlani LS, Yang Z, Bochsler PN. Identification and characterization of a bovine lipopolysaccharide-binding protein. J Leukoc Biol. 1994;56:784-91.

107. Ramadori G, Meyer zum Buschenfelde K-H, Tobias PS, Mathison JC, Ulevitch RJ. Biosynthesis of lipopolysaccharide-binding protein in rabbit hepatocytes. Pathobiology 1990;58:89-94.

108. Froon AHM, Dentener MA, Greve JWM, Ramsay G, Buurman WA. Lipopolysaccharide toxicity-regulating proteins in bacteremia. J Infect Dis 1995;171:1250-7.

109. Grube BJ, Cochane CG, Ye RD, Green CE, McPhail ME, Ulevitch RJ, Tobias PS. Lipopolysaccharide binding protein expression in primary human hepatocytes and HepG2 hepatoma cells. J Biol Chem 1994;269:8477-82.

110. Wong HR, Pitt BR, Su GL, Rossignol DP, Steve AR, Billiar TR, Wang SC. Induction of lipopolysaccharide-binding protein gene expression in cultured rat pulmonary artery smooth muscle cells by interleukin 1 $\beta$. Am J Respir Cell Mol Biol 1995;12:449-54.

111. Martin TR, Mathison JC, Tobias PS, Leturcq DJ, Moriarty AM, Maunder RJ, Ulevitch RJ. Lipopolysaccharide binding protein enhances the responsiveness of alveolar macrophages to bacterial lipopolysaccharide: implications for cytokine production in normal and injured 
lungs. J Clin Invest 1992;90:2209-19.

112. Day JR, Albers JJ, Lofton-Day CE, et al. Complete cDNA encoding human phopholipid transfer protein from human endothelial cells. J Biol Chem 1994;269:9388-91.

113. Gazzano-Santoro H, Parent JB, Grinna L, et al. High-affinity binding of the bactericidal/permeability-increasing protein and a recombinant amino-terminal fragment to the lipid A region of lipopolysaccharide. Infect Immun 1992;60:4754-61.

114. Dentener MA, Von Asmuth EJU, Francot GJM, Marra MN, Buurman WA. Antagonistic effects of lipopolysaccharide binding protein and bactericida/permeability-increasing protein on lipopolysaccharide-induced cytokine release by mononuclear phagocytes: competition for binding to lipopolysaccharide. J Immunol 1993;151:4258-65.

115. Heumann D, Gallay P, Barras C, et al. Control of lipopolysaccharide (LPS) binding and LPSinduced tumor necrosis factor secretion in human peripheral blood monocytes. J Immunol 1992;148:3505-12.

116. Tobias PS, Soldau K, Kline L, Lee J-D, Kato K, Martin TP, Ulevitch RJ. Cross-linking of lipopolysaccharide (LPS) to CD14 on THP-1 cells mediated by LPS-binding protein. J Immunol 1993;150:3011-21.

117. Mathison JC, Tobias PS, Wolfson E, Ulevitch RJ. Plasma lipopolysaccharide (LPS)-binding protein: a key component in macrophage recognition of gram-negative LPS. J Immunol 1992;149:200-6.

118. Han J, Mathison JC, Ulevitch RJ, Tobias PS. Lipopolysaccharide (LPS) binding protein, truncated at Ile-197, binds LPS but does not transfer LPS to CD14. J Biol Chem 1994;269:8172-5.

119. Gegner JA, Ulevitch RJ, Tobias PS. Lipopolysaccharide (LPS) signal transduction and clearance: dual roles for LPS binding protein and membrane CD14. J Biol Chem 1995;270:5320-5.

120. Grunwald U, Krliger C, Westermann J, Lukowsky A, Ehlers M, Schütt C. An enzyme-linked immunosorbent assay for the quantification of solubilized CD14 in biological fluids. J Immunol Methods 1992;155:225-32.

121. Frey EA, Miller DS, Jahr TG, Sundan A, Bažil V, Espevik T, Finlay BB, Wright SD. Soluble CDI4 participates in the response of cells to lipopolysaccharide. J Exp Med 1992;176:1665-71.

122. Pugin J, Schilrer-Maly C-C, Leturcq D, Moriarty A, Ulevitch RJ, Tobias PS. Lipopolysaccharide activation of human endothelial and epithelial cells is mediated by lipopolysaccharide-binding protein and soluble CD14. Proc Natl Acad Sci U S A. 1993;90:2744-8.

123. Hailman E, Lichenstein HS, Wurfel MM, et al. Lipopolysaccharide (LPS)-binding protein accelerates the binding of LPS to CD14. J Exp Med 1994;179:269-77.

124. Wurfel MM, Kunitake ST, Lichenstein H, Kane JP, Wright SD. Lipopolysaccharide (LPS)binding protein is carried on lipoproteins and acts as a cofactor in the neutralization of LPS. J Exp Med 1994;180:1025-35.

125. Wurfel MW, Hailman E, Wright SD. Soluble CD14 acts as a shuttle in the neutralization of lipopolysaccharide (LPS) by LPS-binding protein and reconstituted high density lipoprotein. $\mathrm{J}$ Exp Med 1995; 181:1743-54.

126. Wright SD. Tobias PS, Ulevitch RJ, Ramos RA. Lipopolysaccharide (LPS) binding protein opsonizes LPS-bearing particles for recognition by a novel receptor on macrophages. J Exp Med 1989;170:1231-41.

127. Luchi $M$, Munford RS. Binding, internalization, and deacetylation of bacterial lipopolysacchaide by human neutrophils. J Immunol 1993;151:959-69.

128. Gallay P, Heumann D, Le Roy D, Barras C, Glauser MP. Lipopolysaccharide-binding protein as a major plasma protein responsible for endotoxemic shock. Proc Natl Acad Sci U S A 1993:90:9935-8.

129. Goyert SM, Haziot A, Jiao D, Katz IR, Kruger C, Ross J, Schütt C. CD14 cluster workshop report. In: Schlossman SF. Boumsell L, Gilks W. et al. Leucocyte typing V: white cell differentiation antigens. Oxford: Oxford University Press, 1995:778-90. 
130. Wright SD, Ramos RA, Hermanowski-Vosatka A, Rockwell P, Detmers PA. Activation of the adhesive capacity of CR3 on neutrophils by endotoxin: dependence on lipopolysaccharide binding protein and CD14. J Exp Med 1991;173:1281-6.

131. Haziot A, Chen S, Ferrero E, Low MG, Silber R, Goyert SM. The monocyte differentiation antigen, $\mathrm{CD} 14$, is anchored to the cell membrane by a phosphatidylinositol linkage. $\mathrm{J}$ Immunol 1988;141:547-52.

132. Haziot A, Tsuberi B-Z, Goyert SM. Neutrophil CD14: biochemical properties and role in the secretion of tumor necrosis factor- $\alpha$ in response to lipopolysaccharide. J Immunol 1993;150:5556-65.

133. Goyert SM, Ferrero E, Rettig WJ, Yenamandra AK, Obata F, Le Beau MM. The CD14 monocyte differentiation antigen maps to a region encoding growth factors and receptors. Science $1988 ; 239: 497-500$.

134. Zhang DE, Hetherington CJ, Gonzales DA, Chen H-M, Tenen DG. Regulation of CD14 expression during monocytic differentiation induced with $1 \alpha, 25$-dihydroxyvitamin D3. J Immunol 1994;153:3276-84.

135. Landmann $\mathbf{R}$, Wesp $M$, Obrecht JP. Cytokine regulation of the myeloid glycoprotein CDI4. Pathobiology 1991;59:131-5.

136. Cosentino G, Soprana E, Thienes CP, Siccardi AG, Viale G, Vercelli D. IL-13 downregulates CD14 expression and TNF- $\alpha$ secretion in normal human monocytes. J Immunol 1995;155:3145-51.

137. Marchant A, Duchow J, Delville I-P, Goldman M. Lipopolysaccharide induces up-regulation of CD14 molecule on monocytes in human whole blıod. Eur J Immunol 1992;22:1663-5.

138. Bažil V, Strominger $\mathrm{L}$, Shedding as a mechanism of down-modulation of CD14 on stimulated human monocytes. J Immunol 1991;147:1567-74.

139. Smith PD, Suffredini AF, Allen JB, Wahl LM, Parrillo JE, Wahl SM. Endotoxin administration to humans primes alveolar macrophages for increased production of inflammatory mediators. J Clin Immunol 1994;14:141-8.

140. Detmers PA, Zhou D, Powell D, Lichenstein H, Kelley M, Pironkova R. Endotoxin receptors (CD14) are found with CD16 (FcyRIII) in an intracellular compartment of neutrophils that contains alkaline phosphatase J Immunol 1995;155:2085-95.

141. Ziegler-Heitbrock HWL, Pechumer H, Petersmann I, Durieux J-J, Vita N, Labeta MO, Ströbel M. CD14 is expressed and functional in human B cells. Eur J Immunol 1994;24:1937-40.

142. Camussi G, Mariano F, Biancone L, De Martino A, Bussolati B, Montrucchio G, Tobias PS. Lipopolysaccharide binding protein and CD14 modulate the synthesis of platelet-activating factor by human monocytes and mesangial and endothelial cells stimulated with lipopolysaccharide. J Immunol 1995;155:316-24.

143. Lida M, Hirai K, Shinohara S, et al. Lipopolysaccharide primes human basophils for enhanced mediator release: requirement for plasma co-factor and CD14. Biochem Biochys Res Commun 1994:203:1295-1301.

144. Andreesen R, Brugger W, Scheibenbogen C, Kreutz M, Leser H-G, Rehm A, Lobr GW. Surface phenotype analysis of human monocyte to macrophage maturation. $J$ Leukoc Biol 1990;47:490-7.

145. Grimm MC, Pavli P, Van De Pol E Doe WF. Evidence for a CD14 $4^{+}$population of monocytes in inflammatory bowel disease mucosa-implications for pathogenesis. Clin Exp Immunol 1995; 100:291-7.

146. Dentener MA, Bažil V, Von Asmuth EJU, Ceska M, Buurman WA. Involvement of CDI4 in lipopolysaccharide-induced tumor necrosis factor- $\alpha$, IL-6 and IL-8 release by human monocytes and alveolar macrophages. J Immunol 1993;150:2885-2891.

147. Steinemann S, Ulevitch RJ, Mackman N. Role of the lipopolysaccharide (LPS)-binding protein/CD14 pathway in LPS induction of tissue factor expression in monocytic cells. Arterioscler Thromb 1994;14:1202-9.

148. Shapira L, Champagne C, Gordon B, Amar S, Van Dyke TE. Lipopolysaccharide priming of superoxide release by human neutrophils: role of membrane CD14 and serum LPS binding 
protein. Inflammation 1995;19:289-95.

149. Surette ME, Palmantier R, Gosselin J, Borgeat P. Lipopolysaccharides prime whole human blood and isolated neutrophils for the increased synthesis of 5-lipoxygenase products by enhancing arachidonic acid availability: involvement of the CD14 antigen. J Exp Med 1993;178:1347-55.

150. Lee J-D, Kato K, Tobias PS, Kirkland TN, Ulevitch RJ Transfection of CD14 into 70Z/3 cells dramatically enhances the sensitivity to complexes of lipopolysaccharide (LPS) and LPS binding protein. J Exp Med 1992;175:1697-1705.

151. Martin TR, Mongovin SM, Tobias PS, Mathison JC, Moriarty AM, Leturcq DJ, Ulevitch RJ. The CD14 differentiation antigen mediates the development of endotoxin responsiveness during differentiation of mononuclear phagocytes. J Leukoc Biol 1994;56:1-9.

152. Ferrero E, Jiao D, Tsuberi BZ, Tesio L, Rong GW, Haziot A, Goyert SM. Transgenic mice expressing human CDI4 are hypersensitive to lipopolysaccharide. Proc Natl Acad Sci U S A 1993;90:2380-4.

153. Haziot A, Ferrero E, Lin XY, Stewart CL, Goyert SM. CD-14 deficient mice are exquisitely insensitive to the effects of LPS. In: Levin J, Alving CR, Munford RS, Redl H. Bacterial endotoxins: lipopolysaccharides from genes to therapy. New York: Wiley-Liss, Inc., 1995:349-63.

154. Kirkland TN, Finley F, Leturcq D, Moriarty A, Lee J-D, Ulevitch RJ, Tobias PS. Analysis of lipopolysaccharide binding by CD14. J Biol Chem 1993;268:24818-23.

155. Lund-Johansen F, Olweus J, Symington FW, Arli A, Thompson JS, Vilella R, Skubitz K, Horesji V. Activation of human monocytes and granulocytes by monoclonal antibodies to glycosylphosphatidylinositol-anchored antigens. Eur J Immunol 1993;23:2782-91.

156. Štefanová I, Corcoran ML, Horak EM, Wahl LM, Bolen JB, Horak ID. Lipopolysaccharide induces activation of $\mathrm{CD} 14$-associated protein tyrosine kinase $\mathrm{p} 53 / 56^{\mathrm{lym}} \mathrm{J}$ Biol Chem 1993;268:20725-8.

157. Weinstein SL, June CH, DeFranco AL. Lipopolysaccharide-induced protein tyrosine phosphorylation in human macrophages is mediated by CD14. J Immunol 1993;151:3829-38.

158. Shapira L, Takashiba S, Champagne C, Amar S, Van Dyke TE. Involvement of protein kinase $C$ and protein tyrosine kinase in lipopolysaccharide-induced TNF- $\alpha$ and ILI- $\beta$ production by human monocytes J Immunol 1994;153:1818-24.

159. Jakway JP, DeFranco AL. Pertussis toxin inhibition of B cell and macrophage responses to bacterial lipopolysaccharide. Science 1986;234:743-6.

160. Muller JM, Ziegler-Heitbrock HWL, Baeuerle PA. Nuclear factor kappa B, a mediator of lipopolysaccharide effects. Immunobiology 1993;187:233-56.

161. Kitchens RL, Ulevitch RJ, Munford RS. Lipopolysaccharide (LPS) partial structures inhibit responses to LPS in a human macrophage cell line without inhibiting LPS uptake by a CD14mediated pathway. J Exp Med 1992;176:485-94.

162. Lee J-D, Kravchenko V, Kirkland TN, et al. Glycosyl-phosphatidylinositol-anchored or integral membrane forms of CD14 mediate identical cellular responses to endotoxin. Proc Natl Acad Sci U S A 1993:90:9930-4.

163. Ulevitch RJ, Tobias PS. Receptor-dependent mechanisms of cell stimulation by bacterial endotoxin. Annu Rev Immunol 1995; 13:437-57.

164. Puging J, Heumann D, Tomasz A, et al. CD14 is a pattern recognition receptor. Immunity 1994;1:509-16.

165. Wright SD. CD14 and innate recognition of bacteria. J Immunol 1995;155:6-8.

166. Lauener RP, Geha RS, Vercelli D. Engagement of the monocyte surface antigen CD14 induces lymphocyte function-associated antigen-1/intercellular adhesion molecule-1dependent homotypic adhesion. J Immunol 1990;145:1390-4.

167. Lue K-H, Lauener RP, Winchester RJ, Geha RS, Vercelli D. Engagement of CD14 on human monocytes terminates $T$ cell proliferation by delivering a negative signal to cells. I Immunol 1991;147:1134-8.

168. Jabara HH, Vercelli D. Engagement of CD14 on monocytes inhibits the synthesis of human Igs, including IgE. J Immunol 1994;153:972-8 
169. Beekhuizen H, Blokland I, Corsèl-Van Tilburg AJ, Koning F, Van Furth R. CD14 contributes to the adherence of human monocytes to cytokine-stimulated endothelial cells. J Immunol $1991 ; 147: 3761-7$.

170. Beekhuizen H, Blokland I, Van Furth R. Cross-linking of CD14 molecules on monocytes results in a CDI1/CD18-and ICAM-1-dependent adherence to cytokine-stimulated human endothelial cells. J Immunol 1993;150:950-9.

171. Maliszewski CR, Ball ED, Graziano RF, Fanger MW. Isolation and characterization of My23, a myeloid cell-derived antigen reactive with the monoclonal antibody AML-2-23. J Immunol 1985; 135:1929-36.

172. Bažil V, Hořejł̌i V, Baudys M, Krištofová H, Strominger JL, Kostka W, Hilgert I. Biochemical characterization of a soluble form of the $53-\mathrm{kDa}$ monocyte surface antigen. Eur J Immunol 1986;16:1583-9.

173. Durieux J-J, Vita N, Popescu O, et al. The two soluble forms of the lipopolysaccharide receptor, CD14: characterization and release by normal human monocytes. Eur J Immunol 1994;24:2006-12.

174. Asmuth Von EJU, Dentener MA, Bažil V, Bouma MG, Leeuwenberg JFM, Buurman WA Anti-CD14 antibodies reduce responses of cultured human endothelial cells to endotoxin. Immunology 1993;80:78-83.

175. Pugin J, Ulevitch RJ, Tobias PS. Tumor necrosis factor-alpha and interleukin-1-beta mediate human endothelial cell activation in blood at low endotoxin concentrations. J Inflamm 1995;45:49-55.

176. Schütt C, Schilling T, Grunwald U, Schönfeld W, Krüger C. Endotoxin-neutralizing capacity of soluble CD14. Res Immunol 1992;143:71-8.

177. Haziot A, Rong G-W, Bażil V, Silver J, Goyert SM. Recombinant soluble CDI4 inhibits LPS-induced tumor necrosis factor- $\alpha$ production by cells in whole blood. J Immunol 1994;152:5868-76.

178. Haziot A, Rong GW, Lin X-Y, Silver J, Goyert SM. Recombinant soluble CD14 prevents mortality in mice treated with endotoxin (lipopolysaccharide). J Immunol 1995; 154:6529-32.

179. Landmann R, Fisscher AE, Obrecht J-P. Interferon- $\gamma$ and interleukin-4 down-regulate soluble CD14 release in human monocytes and macrophages. J Leukoc Biol 1992;52:323-30.

180. Landmann R, Zimmerli W, Sansano S, Link S, Hahn A, Glauser MP, Calandra T. Increased circulating soluble CD14 is associated with high mortality in gram-negative septic shock. J Infect Dis 1995;171:639-44.

181. Van Furth R. Development and distribution of mononuclear phagocytes. In: Gallin Jl, Goldstein IM, Snyderman R. Inflammation: basic principles and clinical correlates. 2nd ed. New York: Raven Press, 1992:325-339.

182. Watson RWG, Redmond HP, Bouchier-Hayes D. Role of endotoxin in mononuclear phagocyte-mediated inflammatory responses. J Leukoc Biol 1994;56:95-103.

183. Beekhuizen H, Van Furth R. Monocyte adherence to human vascular endothelium. J Leukoc Biol 1993;54:363-78.

184. Tracey KJ, Cerami A. Tumor necrosis factor: a pleiotropic cytokine and therapeutic target. Annu Rev Med 1994;45:491-503.

185. Dinarello CA. Biologic basis for interleukin-1 in disease. Blood 1996;87:2095-2147.

186. Tracey KJ, Beutler B, Lowry SF, et al. Shock and tissue injury injuced by recombinant human cachectin. Science 1986;234:470-3.

187. Okusawa S, Gelfand JA, Ikejima $\mathrm{T}$, Connolly RJ, Dinarello CA. Interleukin 1 induces a shock-like state in rabbits: synergism with tumor necrosis factor and the effect of cyclooxygenase inhibition. J Clin Invest 1988;81:1162-72.

188. Beutler B, Milsark IW, Cerami AC. Passive immunization against cachectin/tumor necrosis factor protects mice from lethal effect of endotoxin. Science 1985;229:869-71.

189. Li $\mathrm{P}$, Allen H, Banerjee $\mathrm{S}$, et al. Mice deficient in IL-1ß-converting enzyme are defective in production of mature IL-1 $\beta$ and resistant to endotoxic shock. Cell 1995;80:401-11.

190. Hirano T, Akira S, Taga T, Kishimoto T. Biological and clinical aspects of interleukin 6. Immunol Today 1990;11:443-9. 
191. Lamont AG, Adorini L. IL-12: a key cytokine in immune regulation. Immunol Today 1996;17:214-7.

192. Mosmann TR. Properties and functions of interleukin-10. Adv Immunol 1994;56:1-26.

193. Burger D, Dayer J-M. Inhibitory cytokines and cytokine inhibitors. Neurology 1995;45(suppl 6):S39-S43.

194. Leeuwenberg JFM, Dentener MA, Buurman WA. Lipopolysaccharide LPS-mediated soluble TNF receptor release and TNF receptor expression by monocytes: role of CD14, LPS binding protein and bactericidal/permeability-increasing protein. J Immunol 1994;152:5070-6.

195. Froon AHM, Bemelmans MHA, Greve JW, Van Der Linden CJ, Buurman WA. Increased plasma concentrations of soluble tumor necrosis factor receptors in sepsis syndrome: correlation with plasma creatinine levels. Crit Care Med 1994;22:803-9.

196. Mohler KM, Torrance DS, Smith CA. et al. Soluble tumor necrois factor (TNF) receptors are effective therapeutic agents in lethal endotoxemia and function simultaneously as both TNF carriers and TNF antagonists. J Immunol 1993;151:1548-61.

197. Graves DT, Jiang Y. Chemokines, a family of chemotactic cytokines. Crit Rev Oral Biol Med 1995;6:109-18.

198. Bickel $M$. The role of interleukin-8 in inflammation and mechanisms of regulation. $J$ Periodontol 1993;64:456-60.

199. Belardelli F. Role of interferons and other cytokines in the regulation of the immune response. AMPIS 1995;103:161-79.

200. Jandl JH. Granulocytes. In: Jandl JH. Blood: textbook of hematology. Boston: Little, Brown and Company, 1989:441-71.

201. Wright SD. Receptors for complement and the biology of phagocytosis. In: Gallin $\pi$, Goldstein IM, Snyderman R. Inflammation: basic principles and clinical correlates. 2nd ed. New York: Raven Press, 1992:477-95.

202. Elsbach P, Weiss J. Oxygen-independent antimicrobial systems of phagocytes. In: Gallin JI, Goldstein IM, Snyderman R. Inflammation: basic principles and clinical correlates. 2nd ed. New York: Raven Press, 1992:603-36.

203. Munford RS, Hall CL. Detoxification of bacterial lipopolysaccharides (endotoxins) by a human neutrophil enzyme. Science 1986;234:203-5.

204. Klebanoff SJ. Oxygen metabolites from phagocytes In: Gallin JI, Goldstein IM, Snyderman R. Inflammation: basic principles and clinical correlates. 2nd ed. New York: Raven Press, 1992:541-88.

205. Strieter RM, Kasahara K, Allen RM, et al. Cytokine-induced neutrophil-derived interleukin-8. Am J Pathol 1992;141:397-407.

206. Savill JS, Wyllie AH, Henson JE, Walport MJ, Henson PM, Haslett C. Macrophage phagocytosis of aging neutrophils in inflammation: programmed cell death in the neutrophil leads to its recognition by macrophages. J Clin Invest 1989;83:865-75.

207. Weiss J, Elsbach P, Olsson I, Odeberg H. Purification and characterization of a potent bactericidal and membrane active protein from the granules of human polymorphonuclear leukocytes. J Biol Chem 1978;253:2664-72.

208. Weiss J, Muello K, Victor M, Elsbach P. The role of lipopolysaccharides in the action of the bactericidal/permeability-increasing neutrophil protein on the bacterial envelope. J Immunol 1984;132:3109-15.

209. Mannion BA, Weiss J, Elsbach P. Separation of sublethal and lethal effects of the bactericidal/permeability increasing protein on Escherichia coli. J Clin Invest 1990;85:853-60.

210. Weiss $\mathrm{J}$, Olsson 1 . Cellular and subcellular localization of the bactericidal/permeabilityincreasing protein of neutrophils. Blood 1987;69:652-9.

211. Egesten A, Breton-Gorius J, Guichard J, Gullberg U, Olsson I. The heterogeneity of azurophil granules in neutrophil promyelocytes: immunogold localization of myeloperoxidase, cathepsin $G$, elastase, proteinase 3, and bactericidal/permeability-increasing protein. Blood 1994:83:2985-94.

212. Marra MN, Wilde CG, Collins MS, Snable JL, Thomton MB, Scott RW. The role of bactericidal/permeability-increasing protein as a natural inhibitor of bacterial endotoxin. $\mathrm{J}$ 
Immunol 1992;148:532-7.

213. Weersink AJL, Van Kessel KPM, Van den Tol ME, et al. Human granulocytes express a 55$\mathrm{kDa}$ lipopolysaccharide-binding protein on the cell surface that is identical to the bactericidal/permeability-increasing protein. J Immunol 1993;150:253-63.

214. Dentener MA, Francot GJM, Buurman WA. Bactericidal/permeability-increasing protein, a lipopolysaccharide-specific protein on the surface of human peripheral blood monocytes. J Infect Dis 1996;173:252-5.

215. Dentener MA, Francot GJM, Hiemstra PS, Tool ATJ, Verhoeven AJ, Vandenabeele P, Buurman WA. Bactericidal/permeability-increasing protein release in whole blood ex vivo: strong induction by lipopolysaccharide and turnor necrosis factor- $\alpha$. J Infect Dis 1997; 175:108- 17.

216. Weiss J, Kao L, Victor M, Elsbach P. Oxygen-independent intracellular and oxygendependent extracellular killing of Escherichia coli $\mathrm{S} 15$ by human polymorphonuclear leukocytes. J Clin Invest 1985;76:206-12.

217. Mannion BA, Kalatzis ES, Weiss J, Elsbach P. Preferential binding of the neutrophil cytoplasmic granule-derived bactericidal/permeability increasing protein to target bacteria: implications and use as a means of purification. J Immunol 1989;142:2807-12.

218. Weiss J, Elsbach P, Shu C, Castillo J, Grinna L, Horwitz A, Theofan G. Human bactericidal/permeability-increasing protein and a recombinant $\mathrm{NH}_{2}$-terminal fragment cause killing of serum-resistant gram-negative bacteria in whole blood and inhibit tumor necrosis factor release induced by the bacteria. J Clin Invest 1992;90:1122-30.

219. Gray, PW, Flaggs G, Leong SR, Gumina RJ, Weiss J, Ooi CE, Elsbach P. Cloning of the cDNA of a human neutrophil bactericidal protein: structural and functional correlations. J Biol Chem 1989;264:9505-9.

220. Ooi CE, Weiss J, Elsbach $\mathrm{P}$, Frangione B, Mannion B. A $25-\mathrm{kDa} \mathrm{NH}_{2}$-terminal fragment carries all the antibacterial activities of the human neutrophil $60-\mathrm{kDa}$ bactericidal/permeability-increasing protein. J Biol Chem 1987;262:14891-4.

221. Marra MN, Wilde CG, Griffith JE, Snable JL, Scon RW. Bactericidal/permeability-increasing protein has endotoxin-neutralizing activity. J Immunol 1990;144:662-6.

222. Ooi CE, Weiss J, Doerfler ME, Elsbach P. Endotoxin neutralizing properties of the $25 \mathrm{kD} \mathrm{N}$ terminal fragement and a newly isolated $30 \mathrm{kD}$ C-terminal fragment of the $55-60 \mathrm{kD}$ bactericidal/permeability-increasing protein of human neutrophils. J Exp Med 1991;174:64955.

223. Heumann D, Gallay P, Betz-Corradin S, Barras C, Baumgartner J-D, Glauser MP. Competition between bactericidal/permeability-increasing protein and lipopolysaccharidebinding protein for lipopolysaccharide binding to monocytes. J Infect Dis 1993;167:1351-7.

224. Dentener MA, Francot GJM, Smit FT, Froon AHM, Pennings H-J, Wouters EFM, Buurman WA. Presence of bactericidal/permeability-increasing protein in disease: detection by ELISA. J Infect Dis 1995; 171:739-43.

225. White ML, Ma JK, Birt CA, Trown PW, Carroll SF. Measurement of bactericidal/permeability-increasing protein in human body fluids by sandwich ELISA. J Immunol Methods 1994;167:227-35.

226. Calvano SE, Thompson WA, Marra MN, et al. Changes in polymorphonuclear leukocyte surface and plasma bactericidal/ permeability-increasing protein and plasma lipopolysaccharide binding protein during endotoxemia or sepsis. Arch Surg 1994;129:220-6.

227. Opal SM, Palardy JE, Marra MN, Fisher Jr CJ, McKelligon BM,Scott RW. Relative concentrations of endotoxin-binding proteins in body fluids during infection. Lancet 1994;344:429-31.

228. Weinrauch Y, Foreman A, Shu C, Zarember K, Levy O, Elsbach P. Weiss J. Extracellular accumulation of potently microbicidal bactericidal/permeability-increasing protein and pl $5 \mathrm{~s}$ in an evolving sterile rabbit peritoneal inflammatory exudate. J Clin Invest 1995;95:1916-24.

229. Fisher CJ, Marra MN, Palardy JE, Marchbanks CR, Scott RW, Opal SW.Human neutrophil bactericidal/permeability-increasing protein reduces mortality rate from endotoxin challenge: a placebo-controlled study. Crit Care Med 1994;22:553-8. 
230. Ammons WS, Kohn FR, Kung AHC. Protective effects of an N-terminal fragment of bactericidal/permeability-increasing protein in rodent models of gram-negative sepsis: role of bactericidal properties. J Infect Dis 1994;170:1473-82.

231. Elsbach P, Weiss J. Prospects for use of recombinant BPI in the treatment of gram-negative bacterial infections. Infect Agents Dis 1995;4:102-9.

232. Leong SR. Camerato $T$. Nucleotide sequence of the bovine bactericidal/permeability increasing protein (BPI). Nucleic Acids Res 1990;18:3052.

233. Shireman PK, Pearce WH. Endothelial cell function: biologic and physiologic functions in health and disease. AJR Am J Roentgenol 1996;166:7-13.

234. Reidy MA, Bowyer DE. Scanning electron microscopy: morphology of aortic endothelium following injury by endotoxin and during subsequent repair. Atherosclerosis 1977:26:319-28.

235. Harlan JM, Harker LA, Reidy MA, Gajdusek CM, Schwartz SM, Striker GE. Lipopolysaccharide-mediated bovine endothelial cell injury in vitro. Lab Invest 1983;48:26974.

236. Pohiman TH, Harlan JM. Human endothelial cell response to lipopolysaccharide, interleukin1 , and tumor necrosis factor is regulated by protein synthesis. Cell Immunol 1989;1 19:41-52.

237. Pohlman TH, Harlan JM. Endotoxin-endothelial cell interactions. In: Morrison DC, Ryan JR. Bacterial endotoxic lipopolysaccharides vol 1: Molecular biochemistry and cellular biology. Boca Raton: CRC Press, 1992:347-71.

238. Stad RK, Buuman WA. Current views on structure and function of endothelial adhesion molecules. Cell Adhes Commun 1994;2:261-8.

239. Seino Y, Ikeda U, Takahashi M, Hojo Y, Irokawa M, Kasahara T, Shimada K. Expression of monocyte chemoattractant protein-l in vascular tissue. Cytokine 1995;7:575-9.

240. Vane JR, Änggárd EE, Botting RM. Regulatory functions of the vascular endothelium. N Engl J Med 1990;323:27-36.

24I. Fleming I, Gray GA, Julou-Schaeffer G, Parratt JR, Stoclet J-C. Incubation with endotoxin activates the L-arginine pathway in vascular tissue. Biochem Biophys Res Commun $1990 ; 171: 562-8$.

242. Thompson AB, Robbins RA, Romberger DJ, Sisson JH, Spurzem JR, Teschler H, Rennard SI. Immunological functions of the pulmonary epithelium. Eur Respir J 1995;8:127-49.

243. Simon RH, Paine III R. Participation of pulmonary alveolar epithelial cells in lung inflammation. J Lab Clin Med 1995; 126:108-18.

244. Malaviya R, IKeda T, Ross E, Abraham SN. Mast cell modulation of neutrophil influx and bacterial clearance at sites of infection through TNF- $\alpha$. Nature 1996;381:77-80.

245. Vogel SN, Hogan MM. Role of cytokines in endotoxin-mediated host responses. In: Oppenheim JJ, Shevach EM. Immunophysiology: the role of cells and cytokines in immunity and inflammation. New York: Oxford University Press, 1990:238-58.

246. Berczi I, Bertók L, Bereznai T. Comparative studies on the toxicity of Escherichia coli lipopolysaccharide endotoxin in various animal species. Can J Microbiol 1966;12:1070-1.

247. Watson J, Riblet R. Genetic control of responses to bacterial lipopolysaccharides in mice I. Evidence for a single gene that influences mitogenic and immunogenic responses to lipopolysaccharides. J Exp Med 1974; 140:1147-61.

248. Watson J, Kelly K, Largen $M$, Taylor BA. The genetic mapping of a defective LPS response gene in $\mathrm{C} 3 \mathrm{H} / \mathrm{HeJ}$ mice. J Immunol 1978;120:422-4.

249. Freudenberg MA, Keppler D, Galanos C. Requirement for lipopolysaccharide-responsive macrophages in galactosamine-induced sensitization to endotoxin. Infect Immun 1986;51:8915 .

250. Beutler B, Krochin N, Milsark IW, Luedke C, Cerami A. Control of cachectin (tumor necrosis factor) synthesis: mechanisms of endotoxin resistance. Science 1986;232:977-80.

251. Huizinga TWJ, Westendorp R, Brinkman BMN, Breedveld FC, Verweij CL. Disease susceptibility related to the $-238 \mathrm{TNF} \alpha \mathrm{G}$ to A promotor polymorphism. Eur Cytokine Netw 1996; 7:259 (Abstract).

252. McGuire W, Hill AVS, Allsopp CEM, Greenwood BM, Kwjatkowski D. Variation in the TNF- $\alpha$ promotor region associated with susceptibility to cerebral malaria. Nature 
1994;371:508-11.

253. Decker K, Keppler D. Galactosamine hepatitis: key role of the nucleotide deficiency period in the pathogenesis of cell injury and cell death. Rev Physiol Biochem Pharmacol 1974;71:77106.

254. Galanos C, Freudenberg MA, Reutter W. Galactosamine-induced sensitization to the lethal effects of endotoxin. Proc Natl Acad Sci U S A 1979;76:5939-43.

255. Lehmann V, Freudenberg MA, Galanos C. Lethal toxicity of lipopolysaccharide and tumor necrosis factor in normal and D-galactosamine-treated mice. J Exp Med 1987; 165:657-63.

256. Leist M, Gantner F, Bohlinger I, Tiegs G, Germann PG, Wendel A. Tumor necrosis factorinduced hepatocyte apoptosis precedes liver failure in experimental murine shock models. Am J Pathol 1995;146:1220-34.

257. Seyle H, Tuchweber B, Bertók L. Effect of lead acetate on the susceptibility of rats to bacterial endotoxins. J Bacteriol 1966;91:884-90.

258. Dentener MA, Greve JW, Maessen JG, Buurman WA. Role of tumour necrosis factor in the enhanced sensitivity of mice to endotoxin after exposure to lead. Immunopharmacol Immunotoxicol 1989;11:321-34.

259. Honchel R, Marsano L, Cohen D, Shedlofsky S, McClain JC. Lead enhances lipopolysaccharide and tumor necrosis factor liver injury. J Lab Clin Med 1991;117:202-8.

260. Galanos C, Freudenberg MA. Mechanisms of endotoxin shock and endotoxin hypersensitivity. Immunobiololgy 1993;187:346-56.

261. Young HA, Hardy KJ. Role of interferon- $\gamma$ in immune cell regulation. J Leukoc Biol 1995;58:373-81.

262. Bartholeyns J, Freudenberg M, Galanos C. Growing tumors induce hypersensitivity to endotoxin and tumor necrosis factor. Infect Immun 1987;55:2230-3.

263. Carswell EA, Old LJ, Kassel RL, Green S, Fiore N, Wiliamson B. An endotoxin-induced serum factor that causes necrosis of tumors. Proc Natl Acad Sci U S A 1975;72:3666-70.

264. Ziegler-Heitbrock HWL. Molecular mechanism in tolerance to lipopolysaccharide. J Inflamm 1995;45:13-26.

265. Freudenberg MA, Galanos C. Induction of tolerance to lipopolysaccharide (LPS)-Dgalactosamine lethality by pretreatment with LPS is mediated by macrophages. Infect Immun 1988;56:1352-7.

266. Mathison J, Wolfson E, Steinemann S, Tobias P, Ulevitch R. Lipopolysaccharide (LPS) recognition in macrophages: participation of LPS-binding protein and CD14 in LPS-induced adaptation in rabbit peritoneal exudate macrophages. J Clin Invest 1993;92:2053-9.

267. Henricson BE, Manthey CL, Perera PU, Hamilton TA, Vogel SN. Dissociation of lipopolysaccharide (LPS)-inducible gene expression in murine macrophages pretreated with smooth LPS versus monophosphoryl lipid A. Infect Immun 1993;61:2325-33.

268. Frankenberger $M$, Pechumer $\mathrm{H}$, Ziegler-Heitbrock HWL. Interleukin-10 is upregulated in LPS tolerance. J Inflamm 1995;45:56-63.

269. Randow F, Syrbe U, Meisel C, Krausch D, Zuckermann H, Platzer C, Volk H-D. Mechanism of endotoxin desensitization: involvement of interleukin 10 and transforming growth factor $\beta$. J Exp Med 1995;181:1887-92.

270. Mackensen A, Galanos C, Wehr U, Engelhardt R. Endotoxin tolerance: regulation of cytokine production and cellular changes in response to endotoxin application in cancer patients. Eur Cytokine Netw 1992;3:571-9.

27l. Berczi I, Bertók L, Baintner Jr K, Veress B. Failure of oral Escherichia coli endotoxin to induce either specific tolerance or toxic symptoms in rats. J Pathol Bacteriol 1968;96:481-6.

272. Bertók L. Physico-chemical defense of vertebrate organisms: the role of bile acids in defense against bacterial endotoxins. Perspect Biol Med 1977;21:70-6.

273. Nolan JP. Endotoxin, reticuloendothelial function, and liver injury. Hepathology 1981;1:45865.

274. Yao Y-M, Sheng Z-Y, Tian H-M, et al. Gut-derived endotoxemia and multiple system organ failure following gutshot wounds combined with hemorrhagic shock: an experimental study in the dog. J Trauma 1995;38:742-6. 
275. Jiang J, Bahrami S, Leichtfried G, Redl H, Öhlinger W, Schlag G. Kinetics of endotoxin and tumor necrosis factor appearance in portal and systemic circulation after hemorrhagic shock in rats. Ann Surg 1995;221:100-6.

276. Deitch EA, Berg RD. Endotoxin but not malnutrition promotes bacterial translocation of the gut flora in burned mice. J Trauma 1987;27:161-6.

277. Tumbull RG, Talbot JA, Hamilton SM. Hemodynamic changes and gut barrier function in sequential hemorrhagic and endotoxic shock. J Trauma 1995;38:705-12.

278. Gardiner KR, Anderson NH, Rowlands BJ, Barbul A. Colitis and colonic mucosal barrier dysfunction. Gut 195;37:530-5.

279. Gardiner KR, Halliday MI, Barclay GR, et al. Significance of systemic endotoxaemia in inflammatory bowel disease. Gut 1995;36:897-901.

280. Ramsay G, Newman PM, McCartney AC, Ledingham IM. Endotoxaemia in multiple organ failure due to sepsis. Prog Clin Biol Res 1988;272:237-46.

281. Heumann and Glauser MP. Pathogenesis of sepsis. Sci Am 1994;271:28-37.

282. Alexander HR, Sheppard BC, Jensen JC, et al. Treatment with recombinant human tumor necrosis factor-alpha protects rats against the lethality, hypotension, and hypothermia of gram-negative sepsis. J Clin Invest 1991;88:34-9.

283. Echtenacher B, Falk W, Männel DN, Krammer PH. Requirement of endogenous tumor necrosis factor/cachectin for recovery from experimental peritonitis. J Immunol 1990; 145:3762-6.

284. Raylander R. Endotoxins in the environment. In: Levin J, Alving CR, Munford RS, Redl H. Bacterial endotoxins: lipopolysaccharides from genes to therapy. New York: Wiley-Liss, Inc., 1995:79-90.

285. Clarke S. Respiratory defences. In: Brewis RAL, Gibson GJ, Geddes DM. Respiratory Medicine. London: Ballière Tindall, 1990:176-203.

286. Sibille Y, Machandise F-X. Pulmonary immune cells in health and disease: polymorphonuclear neutrophils. Eur Respir J 1993;6:1529-43.

287. Schwartz DA, Thorne PS, Yagla SJ, Burmeister LF, Olenchock SA, Watt JL, Quinn TJ. The role of endotoxin in grain dust-induced lung disease. Am J Respir Crit Care Med 1995;152:603-8.

288. Smid T, Heederik D, Houba R, Quanjer PH. Dust- and endotoxin-related respiratory effects in the animal feed industry. Am Rev Respir Dis 1992;146:1474-9.

289. Wang Z, Malmberg P, Larsson P, Larsson B-M, Larsson K. Time course of interleukin-6 and tumor necrosis factor- $\alpha$ increase in serum following inhalation of swine dust. Am $J$ Respir Crit Care Med 1996;153:147-52.

290. Schwartz DA, Thorne PS, Jagielo PJ, White GE, Bleuer SA, Frees KL. Endotoxin responsiveness and grain-dust induced inflammation in the lower respiratory tract. Am $J$ Physiol 1994;267:L609-17.

291. Sigsgaard T, Brandslund I, Rasmussen JB, Lund ED, Varming H. Low normal $\alpha-1$ antitrypsin serum concentrations and MZ-phenotype are associated with byssinosis and familial allergy in cotton mill workers. Pharmacogenetics 1994;4:135-41.

292. Jansen HM, Sachs APE, Van Alphen L. Predisposing conditions to bacterial infections in chronic obstructive pulmonary disease. Am J Respir Crit Care Med 1995;151:2073-80.

293. Shelhamer JH, Levine SJ, Wu T, Jacoby DB, Kaliner MA, Rennard SI. NIH conference: Airway inflammation. Ann Intern Med 1995;123:288-304. 
Chapter 2

Role of Tumour Necrosis Factor in the Enhanced Sensitivity of Mice to Endotoxin after Exposure to Lead 


\title{
ROLE OF TUMOUR NECROSIS FACTOR IN THE ENHANCED SENSITIVITY OF MICE TO ENDOTOXIN AFTER EXPOSURE TO LEAD.
}

\author{
M.A. Dentener, J.W. Greve, J.G. Maessen and W.A. Buurman* \\ Department of Surgery, Biomedical Center, University \\ of Limburg P.O. Box 616, 6200 MD Maastricht, \\ The Netherlands
}

\begin{abstract}
Heavy metals administered to animals at doses which appear relatively innoxious by themselves enhance susceptibility to endotoxin. The mechanisms which underly this phenomenon are not yet fully understood. In this study we investigated the role of the cytokine Tumour Necrosis Factor (TNF), an important mediator of the effects of endotoxin, in this phenomenon.

First it was studied whether lead enhances sensitivity of mice to endotoxin and to TNF. Lead appeared to enhance sensitivity to both endotoxin and TNF resulting in mortality of mice at low endotoxin and TNF doses. Next we studied the influence of lead on serum TNF levels after stimulation by endotoxin. Lead treated mice showed lower TNF blood levels two hours after injection of endotoxin and lead. Six and eight hours after injection TNF levels of lead treated mice were higher compared to those of mice injected with endotoxin only. In the last part of our investigation we studied the influence of a monoclonal hamster anti TNF antibody on the effect of combined lead-endotoxin exposure. Administration of the antibody prevents lethality completely.

Our data indicate that TNF plays a central role in the phenomenon of the enhanced susceptibility of animals to endotoxin after exposure to lead. The enhanced susceptibility to endotoxin is caused by an enhanced susceptibility to TNF and possibly by a prolonged exposure to a higher level of TNF.
\end{abstract}

Copyright $(1989$ by Marcel Dekker, Inc 


\section{INTRODUCTION}

Lead enhances sensitivity of animals to endotoxin (1). Administration of non lethal lead and endotoxin doses causes lethality of the organism. This originally by Selye observed phenomenon can be elicited in a variety of animals like rats $(1,2)$, mice $(3,4)$, baboons (5) and chickens (6). Lead is an ubiquitous agent $(7,8)$ and the sensitization to endotoxin at levels which appear not toxic by themselves emphasizes the need to obtain more insight in this phenomenon.

Endotoxemia, due to gram negative infections is frequently observed $(9,10)$. High systemic endotoxin levels can cause shock $(10,11)$, multiple-organ-failure (12) and ultimately death (10). The cytokine TNF is an important mediator of the effects of endotoxin (13-15). Administration of antibodies directed against TNF, reduces endotoxin induced lethality of mice (15). TNF is produced by mononuclear phagocytes in response to endotoxin and other bacterial toxins (16), it is a mediator of inflammation and has profound effects on host metabolism $(17,18)$.

In this study, we investigated the role of TNF in the mechanism of the enhanced sensitivity of animals to endotoxin, after exposure to lead. We first studied whether lead enhances sensitivity of mice to endotoxin and to TNF. Next the influence of lead on serum TNF levels after stimulation by endotoxin was studied. In the last part we investigated the influence of a monoclonal antibody directed against murine TNF on the effect of combined lead-endotoxin exposure.

\section{MATERIALS AND METHODS}

\section{Animals}

Female Swiss mice, weighing between 27.5 - $30.5 \mathrm{~g}$ were purchased from Charles River Breeding Company (Heidelberg, FRG). They were given free access to standard laboratory diet and water. 


\section{$\underline{\text { Reagents }}$}

Lead acetate $(\mathrm{Pb})^{\prime}($ Merck; Darmstadt, FRG) was dissolved in distilled water at a concentration of $25.0 \mathrm{mg} / \mathrm{ml}$. Filter sterilized lead solution was injected intraperitoneally (i.p.) $5.0 \mathrm{mg}$ per mouse in a volume of $0.2 \mathrm{ml}$. Endotoxin from Escherichia coli (055:B5 phenol extracted Sigma; St-Louis, M.O.) was suspended in sterile pyrogenfree saline. A stock solution of $100 \mu \mathrm{g} / \mathrm{ml}$ was made and kept frozen at $-20{ }^{\circ} \mathrm{C}$. Before use, the endotoxin solution was thawn at $37{ }^{\circ} \mathrm{C}$ and vortexed for three minutes. Endotoxin was injected i.p. $50 \mu \mathrm{g}$ per mouse in a volume of $0.5 \mathrm{ml}$. Human recombinant tumour necrosis factor (TNF) (kindly provide by Celltech; Slough, U.K.) was diluted in phosphate buffered saline at a concentration of 200 $\mu \mathrm{g} / \mathrm{ml}$ and $100 \mu \mathrm{g}$ was injected i.p. A hamster anti-mouse TNF monoclonal antibody (Mab) (TN3; kindly provided by Dr. B. Schreiber, St. Louis M.O. via Celltech) made by fusion of hyper immunized chinese hamster spleen cells with murine myeloma cells, was used. This antibody inhibits the biological activity of murine TNF. TN3 was injected i.p. in a volume of $0.5 \mathrm{ml}(175 \mu \mathrm{g}$ or 500 $\mu \mathrm{g} \mathrm{Ig} /$ mouse).

\section{Mortality of Mice}

Groups of mice were exposed to lead, endotoxin or TNF or combinations thereof. Lead and endotoxin were administered simultaneously. TNF was injected simultaneously or two hours after lead administration. Further groups of mice were exposed to lead, endotoxin and the hamster monoclonal antibody TN3 directed against murine TNF. The TN3 was administered in a dose of $175 \mu \mathrm{g} \mathrm{24,7}$, and $O$ hours before simultaneously administered lead and endotoxin. TN3 in a dose of $500 \mu \mathrm{g}$ was administered 7 hours before combined lead-endotoxin exposure. 
Mortality of the mice was recorded at 24 hours intervals until day seven.

The Influence of Lead on Serum TNF Levels after Stimulation by Endotoxin

Mice were injected with endotoxin with or without lead simultaneously. Two, four, six and eight hours after the injections blood was collected by orbital puncture from a group of mice (6-14 per point). TNF concentrations in serum which was once diluted with RPMI-1640 (Gibco; Paisley, Scotland), were determined with a murine TNF specific enzyme linked immunosorbent assay (ELISA).

\section{$\underline{\text { ELISA }}$}

Immuno assay plates (96-well plates) (Greiner; Nurtingen, FRG) were coated overnight at $4^{\circ} \mathrm{C}$ with TN3 $(5 \mu \mathrm{g} / \mathrm{ml})$. Plates were blocked with $1 \%(w t / v o l)$ BSA in PBS for one hour at room temperature. After four washes with washing buffer (WB, consisting of PBS, $0.1 \%$ BSA, $0.1 \%$ Tween 20 ) test samples were added to the plate for one hour at room temperature. A standard titration curve was obtained by making serial dilutions of a known sample of mouse TNF (Genzyme; Cambridge, M.A.) in a solution consisting of $50 \%$ murine serum and $50 \%$ RPMI-1640. Next the plates were washed four times with WB and incubated with rabbit anti mouse TNF immune serum (Genzyme) and peroxidase conjugated goat anti-rabbit IgG (Jackson; WestGrove, P.A.). After adding the substrate $O$ phenylenediamine $(0.43 \mathrm{mg} / \mathrm{ml}$ ) (Sigma) to the plates for $5-10$ minutes, the colour reaction was stopped with $1.0 \mathrm{M} \mathrm{H}_{2} \mathrm{SO}_{4}$ and light absorption was measured with a micro ELISA autoreader (Flow; Irvine, U.K.) with a $492 \mathrm{~nm}$ filter. The ELISA has a lower detection limit of $150 \mathrm{pg} / \mathrm{ml}$. 


\section{$\underline{\text { Statistics }}$}

Measurements of TNF levels were statistically analyzed with the Wilcoxon test. The statistical significance of the mortality data was determined by the test of Fisher. A p-value less than 0.05 was considered to be significant.

\section{RESULTS}

The Influence of Lead on the Sensitivity of Mice to Endotoxin and TNF.

First we studied whether lead changes the sensitivity of mice to endotoxin and to TNF. Simultaneous administration of lead and endotoxin resulted in mortality of 9 mice of a total of 12 (see fig 1). Single injections of lead and endotoxin in the concentrations used did not cause mortality. Concentrations of $1 \mathrm{mg}$ of endotoxin and 10 $\mathrm{mg}$ of lead were necessary to induce mortality of a low proportion of the mice (data not given).

Further we determined whether lead enhances sensitivity of mice to TNF. TNF was administered two hours after lead injection. This schedule of administration is used because it is known that maximal sensitivity is reached when lead and endotoxin are administered simultaneously (1) and that TNF production is maximal two hours after endotoxin stimulation (9) see also below. Single injections of lead and TNF did not cause mortality and simultaneous administration of lead and TNF also failed to induce mortality (data not shown). The injection of TNF 2 hours after lead injection caused death of 5 mice out of 8 . 

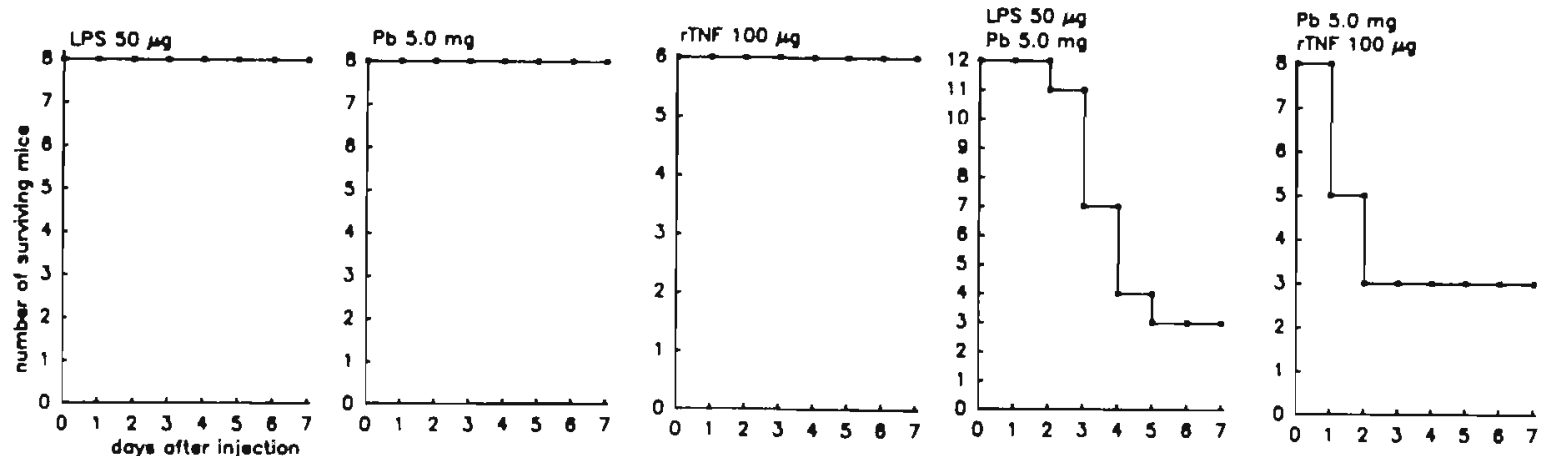

FIG. 1 Mortality of mice treated with lead, endotoxin and combination thereof. lead and endotoxin were administered simultaneously, TNF was given 2 hours after administration of lead.

Lead, endotoxine and TNF were injected i.p. 


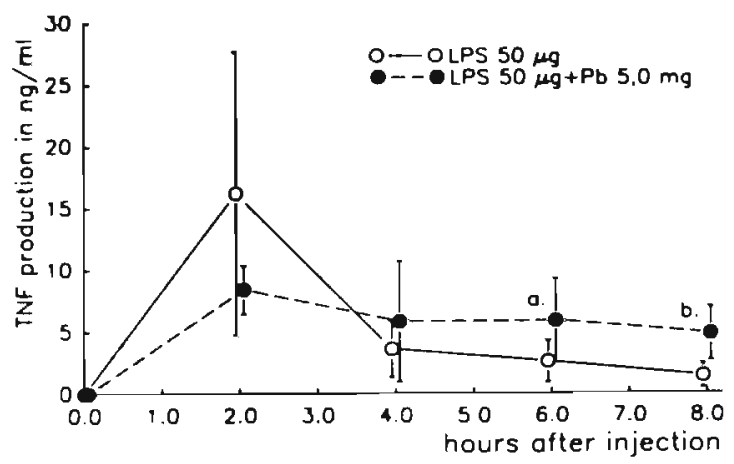

FIG. 2 The influence of lead on serum TNF levels after stimulation by endotoxin. Lead and endotoxin were simultaneously injected i.p.. Each point represents values of 6-14 mice.The mean value and SD are given.

a. $\mathrm{p}=0.01$ b. $\mathrm{p}=0.08$

The Influence of Lead on Serum TNF levels after Stimulation by Endotoxin.

To study the influence of lead on serum TNF levels after stimulation by endotoxin we injected mice with endotoxin with or without lead simultaneously. TNF levels of mice reached two hours after exposure to endotoxin a peak level and dropped thereafter rapidly (fig 2). Lead treated mice showed a lower TNF blood level two hours after injection of endotoxin and lead although this difference was not significant. At six and eight hours after injection, TNF levels of lead treated mice were higher than those of mice treated with endotoxin only, although significance was marginally reached $p=0.01$ and $p=0.08$ resp. at 6 and 8 hours after injection. 

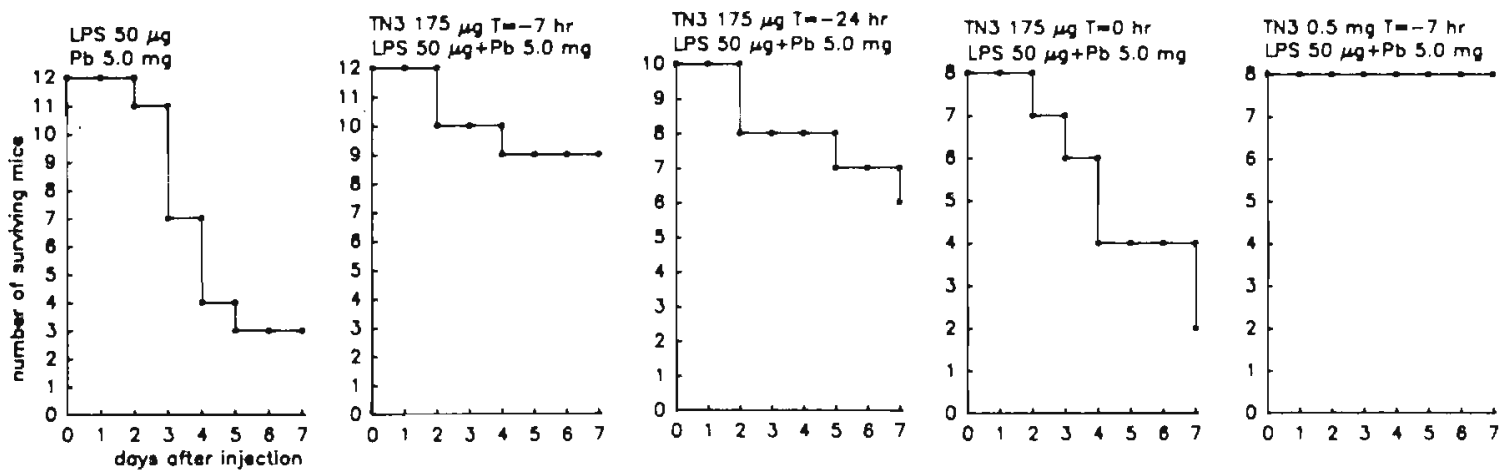

FIG. 3 The influence of the anti-murine TNF monoclonal antibody TN3 on the effect of the combined lead-endotoxin exposure on the mortality of mice. Lead and endotoxin were administered simultaneously whereas TN3 was given at the indicated time related to the moment of administration of lead and endotoxin. 
The Influence of the anti-TNF Mab TN3 on the Effect of Combined Exposure to Lead and Endotoxin.

To further investigate the role of TNF in the mechanism of the enhanced sensitivity of animals to endotoxin after exposure to lead, mice were exposed to lead, endotoxin and the anti murine TNF Mab TN3. TN3 in a dose of $175 \mu \mathrm{g}$ was administered 24,7 , and 0 hours before simultaneously administered lead and endotoxin. Administration of TN3 7 hours before lead and endotoxin reduced mortality significantly $(p<0.05$ ) (see fig 3 ). TN3 administered 24 hours before lead and endotoxin administration also reduced mortality but this reduction was not significant. When TN3 lead and endotoxin were administered simultaneously no change in mortality occurred. The administration of $500 \mu \mathrm{g}$ TN3 prevented lethality that resulted from combined lead endotoxin exposure $(p<0.01)$

\section{DISCUSSION}

Endotoxins have multiple pathological effects. High systemic endotoxin levels can cause shock $(10,11)$ multi-organ-failure(12) and ultimately death (10). Organisms may get exposed to endotoxin after infection with gram-negative bacteria (10). Susceptibility to endotoxin can be enhanced by many agents like glucan (20) BCG (21) actinomycin D (22) and heavy metals $(2,9)$. The heavy metal lead is an agent that strongly enhances this sensitivity (1).

TNF is an important mediator of the effects of endotoxin(13-15). Antibodies directed against TNF protect mice against the lethal effects of endotoxin (15). TNF is a cytokine produced by macrophages (16) and lymphocytes (23) which is involved in inflammation reactions, shock and death $(17,18)$. 
In this study we provide evidence that TNF plays an important role in the mechanism of the enhanced sensitivity of animals to endotoxin after exposure to lead. We have shown that mice after exposure to lead become more sensitive to TNF in a similar way as to endotoxin. Exposure to lead affected serum TNF levels in mice stimulated with endotoxin. Serum TNF levels of mice exposed to lead were lower at two hours after injection of the compounds whereas they stayed longer at a higher level than TNF levels of mouse exposed to endotoxin only. Finally we observed that a monoclonal antibody directed against TNF prevented lethality after the combined administration of lead and endotoxin.

The combination of a non lethal dose of both lead and endotoxin caused mortality, which lead us to the conclusion that lead enhances sensitivity to endotoxin. This is in agreement with the results of other investigators (1-6,9). Further it was shown that the combination of a non lethal dose of lead and a non lethal dose of TNF caused mortality of mice. This means that lead also enhances sensitivitY to TNF. It is possible that the enhanced sensitivity to TNF, which is an important mediator of endotoxin toxicity, accounts for the enhanced sensitivity to endotoxin.

Our observation that lead enhances sensitivity to endotoxin and to TNF is analogous to the observation of Lehmann,who reported that D-galactosamine enhanced sensitivity of mice to endotoxin and also to TNF (24). This suggests that lead and D-galactosamine, which are both hepatotoxic agents $(24,25)$ might exert their effects in a similar way.

The data presented indicate that lead alters the kinetics plasma TNF levels after endotoxin administration. The profile of TNF levels in circulation of mice injected with endotoxin are similar to the serum TNF levels in rabbits injected with endotoxin (19). The lower TNF levels of mice injected with lead observed in our study at two hours after stimulation, although it did not reach statistical significance, suggests that lead inhibits TNF production. Lead may inhibit TNF 
production in a way similar to the inhibition of MlF production by lead (26). In disagreement with the latter are the observations, that lead does not affect IL-I (27) nor TNF (manuscript in preparation) production by macrophages in vitro. Kupffer cells of rats show, after exposure to lead, ultrastructural changes, cells are swollen and cytoplasmatic vesicles increase significantly in numbers (25). Therefore it remains possible that lead directly reduces TNF production in vivo and further in vivo studies seem to be necessary.

TNF levels of mice exposed to lead were six and eight hours after stimulation higher than those of mice stimulated with endotoxin only. The prolonged exposure to TNF could be responsible for the enhanced sensitivity to endotoxin. These data suggests that lead interferes with clearance of TNF. The liver is an essential clearance organ and thus most likely also responsible for the clearance of TNF. The hepatotoxic agent lead might exert this effect by affecting liver function

The fact that the enhancement of levels of TNF in circulation only became significant six hours after stimulation suggests that lead exerts its maximal effects several hours after injection. This is in agreement with the observation of Hoffman, who reported morphological changes of the liver half an hour after administration of lead, but reported this change to be much stronger at six hours (25).

Finally we substantiated the importance of TNF in the mechanism of the enhanced sensitivity to endotoxin after exposure to lead. The administration of the anti-TNF monoclonal antibody TN3 significantly reduced lethality after combined exposure to lead and endotoxin. The observation that administration of antibodies directed against TNF was most effective in reducing lethal effects of combined lead-endotoxin exposure when administered seven hours before lead-endotoxin administration is analogous to data of others (15) using anti-TNF in preventing endotoxin induced septic death. 
Heavy metals are ubiquitous environmental agents. They are inhaled due to industrial emission and they are present as pollution in food. Extra exposure can be caused by work or by living in heavily polluted areas $(7,8)$. This emphasizes the importance of the studies concerning the enhanced susceptibility to endotoxin after exposure to heavy metals.

More insight in the phenomenon of the enhanced susceptibility to endotoxin after exposure to heavy metals will lead to more appropriate screening of putative agents enhancing susceptibility to endotoxin. It could also offer better future clinical treatment of patients exposed to heavy metals.

\section{FOOTNOTES}

1. Abbreviations $\mathrm{Pb}=$ lead, i.p. = intraperitoneally, $\mathrm{Mab}=$ monoclonal antibody, TN3 = hamster monoclonal anti murine TNF antibody, WB $=$ washing buffer

\section{REFERENCES}

1. Selye, H., Tuchweber, B. and Bertok, L., Effect of lead acetate on the susceptibility of rats to bacterial endotoxins, J. Bacteriol., 91:884, 1966.

2. Cook, J.A., Hoffmann, E.0. and Di Luzio, N.R., Influence of lead and cadmium on the susceptibility of rats to bacterial challenge, Proc. Soc. Exp. Biol. Med., 150:741, 1975.

3. Hemphill, F.E., Kaeberle, M.L. and Buck, W.B., Lead suppression of mouse resistance to Salmonella typhimurium, Science, 172:1031, 1971.

4. Cheadle, W.G,, Ausobsky, J.R., Trachtenberg, L.S., Lamont, P. and Polk, H.C., Effects of muramyl dipeptide and lead acetate on carbon clearance and endotoxin-induced mortality in mice. Am. Surg., $52: 613,1986$. 
5. Holper, K., Trejo, R.A., Brettschneider, L. and Di Luzio, N.R., Enhancement of endotoxin shock in the lead-sensitized subhuman primate, Surg., Gynecol. Obstet., 136:593, 1973.

6. Truscott, R.B., Endotoxin studies in chicks: effect of lead acetate. Can. J. Comp. Med., 34:134, 1970.

7. Kazantzis, G., Lead: sources exposure and possible carcinogenicity, IARC Sci. Publ., 71:103, 1986.

8. Goyer, R.A., in Cassarett and Doull's toxicology: the basis science of poison, edited by C.D. Klaassen, p.582, third edition, MacMillan, New York, 1986.

9. Cook, J.A., Di Luzio, N.R. and Hoffmann, E.O., Factors modifying susceptibility to bacterial endotoxin: the effect of lead and cadmium, CRC Crit. Rev. Toxicol, 4:201, 1975.

10. Dale, D.C. and Petersdorf, R.G., in Harrison's principles of internal medicine, edited by E., Braunwald et al., p. 474, eleventh edition, McGraw-Hill, New York, 1987.

11. Cybulski, M.I., Chan, M. K. and Movat, H.Z., Biology of disease: acute inflammation and microthrombosis induced by endotoxin, interleukin-1, and tumor necrosis factor and their implications in gram-negative infection, Lab. Invest., 4:365, 1988.

12. Borzotta, A.P. and Polk H.C., Multiple system organ failure. Surg. Clin. North Am.. 63:315, 1983.

13. Bauss, F., Droge, W. and Mannel, D.N., Tumor necrosis factor mediates endotoxic effects in mice, Infect. Immun., 55:1622, 1987.

14. Tracey, K.J., Beutler, B., Lowry, S.F., Merryweather J., Wolpe, S., Milsark, I.W., Hariri, R.J, Fahey III, T.J., Zentella, A., Albert, J. D., Shires, G.T. and Cerami, A., Shock and tissue injury induced by recombinant human cachectin, Science, 234:470, 1986.

15. Beutler, B, Milsark, I.W. and Cerami, A.C., Passive immunization against cachectin/tumor necrosis factor protects mice from lethal effect of endotoxin. Science, 229:869, 1985.

16. Old, L.J., Tumor necrosis factor, Science, 229:630, 1985.

17. Beutler, B. and Cerami A, Cachectin: more than a tumor necrosis factor, N. Engl. J. Med., 316:379, 1987. 
18. Beutler, B. and Cerami, A., Cachectin and tumour necrosis factor as two sides of the same biological coin, Nature, 320:584, 1986.

19. Beutler, B.A., Milsark, I.W. and Cerami, A., Cachectin/tumor necrosis factor: production distribution and metabolic fate in vivo, J. Immunol., 135: $3972,1985$.

20. Cook, J.A., Dougherty, W.J. and Holt, T.M., Enhanced sensitivity to endotoxin induced by the RES stimulant, glucan, Circ. Shock, 7:225. 1980.

21. Vogel, S.N., Moore, R.N., Sipe, J.D. and Rosenstreich, D.L., BCG induced enhancement of endotoxin sensitivity in $\mathrm{C} 3 \mathrm{H} / \mathrm{HeJ}$ mice. J. Immunol., 124:2004, 1980.

22. Seyberth, H.W., Schmidt-Gayk, H. and Hackenthal, E., Toxicity, clearance and distribution of endotoxin in mice as influenced by actinomycin $\mathrm{D}$, cycloheximide, $\alpha$-amanitin and lead acetate, Toxicon, $10: 491,1972$.

23. Cuturi, M.C., Murphy, M., Costa-Giomi, M.P., Weinmann, R., Perussia, B. and Trinchieri, G., Independent regulation of tumor necrosis factor and lymphotoxin production by human peripheral blood lymphocytes, J. Exp. Med., 165:1581, 1987.

24. Lehmann, V., Freudenberg, M.A. and Galanos, C., Lethal toxicity of lipopolysaccharide and tumor necrosis factor in normal and Dgalactosamine-treated mice. J. Exp. Med.. 165:657, 1987.

25. Hoffmann, E.O., Trejo, R.A., Di Luzio, N.R. and Lamberty, J., Ultrastructural alterations of liver and spleen following acute lead administration in rats, Exp. Mol. Pathol., 17:150, 1972.

26. Kiremidjian-Schumacher, L., Stotzky, G., Likhite, V., Schwartz, J. and Dickstein R.A., Influence of cadmium, lead, and zinc on the ability of sensitized guinea pig lymphocytes to interact with specific antigen and to produce lymphokine, Environ. Res, 24:96, 1981.

27. Kowolenko, M., Tracy, L., Mudzinski, S. and Lawrence, D.A., Effect of lead on macrophage function, J. Leukocyte Biol., 43:357, 1988.

The reference to the TN3 antibody is: Sheehan, K.C.F., Ruddle, N.H., Schrieber, R.D.: Generation and characterization of hamster monoclonal antibodies that neutralize murine tumor necrosis factor. $J$. Immunol. 142:3884, 1989. 
$-70-$ 


\section{Chapter 3}

Involvement of CD14 in Lipopolysaccharide-Induced Tumor Necrosis Factor- $a$, II-6 and II-8 Release by Human Monocytes and Alveolar Macrophages

Reprinted with permission 


\title{
Involvement of CD14 in Lipopolysaccharide-Induced Tumor Necrosis Factor- $\alpha$, IL-6 and IL-8 Release by Human Monocytes and Alveolar Macrophages ${ }^{1}$
}

\author{
Mieke A. Dentener, ${ }^{2 *+}$ Vladimír Bažil, ${ }^{\ddagger}$ Eckhardt J.U. Von Asmuth, ${ }^{*}$ Miroslav Ceska, ${ }^{\S}$ and \\ Wim A. Buurman* \\ "Department of Surgery, University of Limburg Mastricht, the Netherlands; 'Department of Pulmonary Diseases, \\ University Hospital Maastricht, the Netherlands; "Institute of Molecular Genetics, Czechoslovak Academy of Sciences, \\ Prague, Czechoslovakia; and 'Sandoz Forschungsinstitut, Vienna, Austria
}

Aвstract. CD14 has been reported to function as a receptor for bacterial LPS complexed with serum proteins, transducing an activation signal for TNF- $\alpha$ production. We found that the anti-CD14 mAb MEM-18 inhibited not only LPS-induced release of TNF- $\alpha$, but also LPS-induced, TNF- $\alpha$ independent release of IL- 6 and IL- 8 by human monocytes and alveolar macrophages. Inhibitory effect of MEM-18 was detected both in the presence of human or bovine calis serum and under serum-free conditions. In contrast, MEM-18 did not block release of these cytokines induced by IL-1 $\beta$, TNF- $\alpha$, PMA, and zymosan. We conclude that CD14 is involved in LPS-induced release of TNF- $\alpha$, IL-6, and IL-8 by monocytes and alveolar macrophages and that this receptor appears to be able to recognize LPS directly in the absence of serum. Journal of Immunology, 1993, 150: 2885.

$\mathrm{L}$ PS is a potent inducer of infiammatory response to Gram-negative bacterial infection. There are several lines of evidence indicating that CD14, a 53 kDa glycosyl-phosphatidylinositol anchored membrane protein strongly expressed on monocytes and macrophages (1) and weakly on polymorphonuclear leukocytes (2), is involved in LPS-induced cell activation. Anti-CD14 mAb were found to inhibit LPS-induced: 1) TNF- $\alpha$ release in whole blood or by isolated monocytes (3-5). 2) tyrosine phosphorylation of several proteins in monocytes (6), and 3) enhanced CDIlb/CDI 8 expression on $\operatorname{PMN}(2,7)$. In

Received for publication July 21, 1992. Accepted for publication December 31. 1992.

The costs of publication of this article were defrayed in part by the payment of page charges. This article must therefore be hereby marked advertisement in accordance with 18 U.S.C. Section 1734 solely to indicate this fact.

1 This work was supported by Grant 900-562-110 from NWO.

2 Address correspondence and reprint requests to Mieke $A$. Dentener, Department of Surgery. Unuversity of Limburg. P.O. Box 616, 6200 MD Maastricht. the Netherlands. addition, LPS has been shown to interact with CD14 in the presence of serum (8), purified serum LBP $(4,9,10)$, or "septin," a group of serum proteins with LPS opsonizing activity (11), demonstrating that CDI 14 functions as a receptor for LPS complexed with serum proteins.

Biologic effects induced by LPS are prevalently mediated by cytokines produced by mononuclear phagocytes. e.g., TNF- $\alpha$ and IL-6, known to be involved in septic shock $(12,13)$ and IL-8, a chemotactic and granulocyte-activating cytokine $(14,15)$. Regulation of the production of these cytokines, however, seems to be different for monocytes and tissue macrophages like $\mathrm{AM}^{3}(16,17)$. In this study we addressed the following questions 1) is surface CD14 on monocytes involved in a direct LPS-induced IL-6 and IL-8 production? 2) Do AM, mononuclear phagocytes that comprise only $50 \%$ of CD14-positive cells (18), produce cy-

\footnotetext{
Abbreviarions used in this paper: AM, atveolar macrophages; BCS, bontint calf serum; HUVEC, human umbilical vein endothelial calls; HS, human se. rum; LBP, LPS binding protein; M
} 
Table I

Effect of different anti-CDI 4 mAb on LPS-induced TNF- $\alpha$ release by monocytes"

\begin{tabular}{lc}
\hline \hline Anti-CD 14 mab & TNF- $\alpha$ (ng/mb) \\
\hline FMC17 & $4.8 \pm 0.4$ \\
UCHMI & $2.6 \pm 0.2$ \\
MEM-18 & $0.3 \pm 0.1$ \\
MEM-15 & $2.9 \pm 0.3$ \\
Cris6 & $0.1 \pm 0.1$ \\
Control & $4.1 \pm 0.2$ \\
None & $4.0 \pm 0.1$ \\
\hline
\end{tabular}

2 Monocytes were exposed to $1 \mathrm{ng} / \mathrm{ml}$ LPS in combination with the given anti-CD $14 \mathrm{mAb}(10 \mu \mathrm{g} / \mathrm{ml})$. The supernatant was collected after $20 \mathrm{~h}$ of incu. bation and release of TNF- $\alpha$ was determined with an ELISA. Data are expressed as mean $\pm \mathrm{SD}$ of four measurements.

t The nonspecific myeloma protein MOPC-21 ( $\left.\mathrm{IgG}_{1}\right)$ was used as control $\mathrm{mAb}$.

tokines in response to LPS via a CD14-mediated pathway? 3) Is CD14 able to transduce LPS-activating signal in the absence of serum?

\section{Materials and Methods}

Reagents and mAb

Human rTNF- $\alpha$ was kindly provided by BASF/Knoll (Ludwigshafen, FRG). Human $\mathrm{rL}-1 \beta$ and the dimeric human rTNFR-p80:Fc construct $(19,20)$ were a gift of Dr. S. Gillis (Immunex, Seattle, WA). LPS (from Escherichia coli, serotype 055:LB5), the phorbol ester PMA and BSA (low endotoxin $<0.1 \mathrm{ng} / \mathrm{ml}$ ), were purchased from Sigma (St. Louis, MO). M $\varphi$-SFM was obtained from GIBCO Europe (Paisley, Scotland). HS obtained from the local blood bank was sterilized by a $0.2-\mu \mathrm{m}$ filter, pooled, and stored at $4^{\circ} \mathrm{C}$. $\mathrm{BCS}$, purchased from HyClone (Logan, UT), was heated at $56^{\circ} \mathrm{C}$ for $30 \mathrm{~min}$ before storage at $4^{\circ} \mathrm{C}$. HS and BCS contained $<5 \mathrm{pg} / \mathrm{ml}$ endotoxin, as determined in the Limulusassay (Coatest, KabiVitrum, Stockholm, Sweden).

MEM-15 (IgGI) and MEM-18 (IgGI) specifically reacted with CD14 as described (21). The anti-CD14 mAb FMC17 (IgG2b) (22) was kindly provided by Dr. Zola (Bedford Park; SA), Cris6 (IgGl) (23) by Dr. Vilella (Barcelona, Spain), and UCHMI (IgG2a) (24) by Dr. Beverley (London, UK).

\section{Cell isolation and stimulation}

Monocytes, obtained from buffy coats of healthy volunteers, kindly provided by the local blood bank, were isolated as described (25). In short, mononuclear cell suspensions obtained after Lymphoprep (Nycomed, Oslo, Norway) centrifugation were allowed to clump by low speed centrifugation at $4^{\circ} \mathrm{C}$. Cell clumps, consisting for 80 to $95 \%$ of monocytes, were separated from the rest of the cells by sedimentation through ice-cold HS.

AM were recovered from the lung by bronchoalveolar lavage performed during routine fiberoptic bronchoscopy.

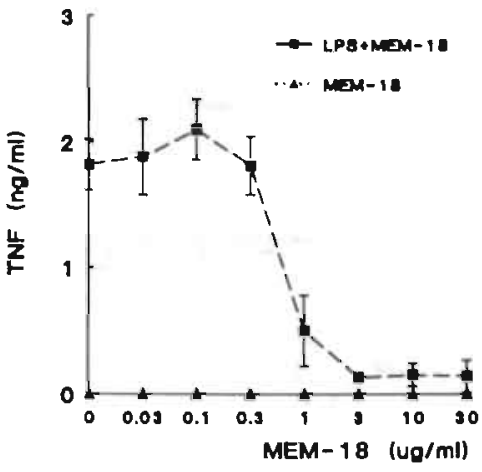

FIGURE 1. Effect of MEM-18 on LPS induced TNF- $\alpha$ release by monocytes. Monocytes were incubated in medium containing $10 \% \mathrm{HS}$, with various concentrations of MEM-18, in presence or absence of LPS $(1 \mathrm{ng} / \mathrm{ml})$. The supernatant was collected after $20 \mathrm{~h}$ incubation and TNF- $\alpha$ release was determined with an ELISA. Data are expressed as mean \pm SD of four measurements. SD bars are omitted if they fall within the symbol.

Bronchoalveolar lavage fluid was filtered through a nylon gauze and cells were washed three times. AM resuspended in medium consisting of RPMI 1640 (GIBCO) and $10 \%$ HS were purified by adherence to a plastic tissue culture flask (Costar, Cambridge, MA). After $2 \mathrm{~h}$, adherent cells were removed by gentle scraping with a nbber policeman.

Monocytes and AM were cultured in 96-well flat bottom tissue culture plates (Costar) in medium consisting of RPMI $1640,10 \% \mathrm{HS}$, and antibiotics. In serum-free conditions $10 \%$ HS was substituted by $0.1 \%$ BSA or M $\varphi-S F M$ was used. The cells were stimulated immediately after isolation for $20 \mathrm{~h}$. The supernatants were harvested and kept at $-20^{\circ} \mathrm{C}$ until use.

Isolation, culture, and stimulation of human umbilical vein endothelial cells (HUVEC) were performed as described (26). E-selectin expression was determined by ELISA, using the anti-E-Selectin mAb ENA 1 (IgGl) (26).

TNF- $\alpha$, IL- 6 , and IL- 8 ELISA

Cytokine concentrations in the culture supernatants were determined using sandwich-ELISA for TNF- $\alpha$ (27), IL-6, and IL-8 (28). In short. 96-well Immuno-Maxisorp plates (Nunc, Roskilde, Denmark) were coated overnight at $4^{\circ} \mathrm{C}$ with cytokine-specific monoclonal murine mAb; for IL. 6 a newly developed, inhibitory mAb, 5El (lgG1) was used. Human rTNF- $\alpha$, human rIL-6 (a kind gift from Prof. $W$. Sebald, Physiologisch-Chemisches Institut der Universität. Würburg. FRG), and human rlL-8 were used for standard titration curves. Test samples were added and incubated for 2 to $3 \mathrm{~h}$. Polyclonal rabbit anti-human TNF- $\alpha$ or polyclonal rabbit anti-human IL- 6 antiserum were followed by 

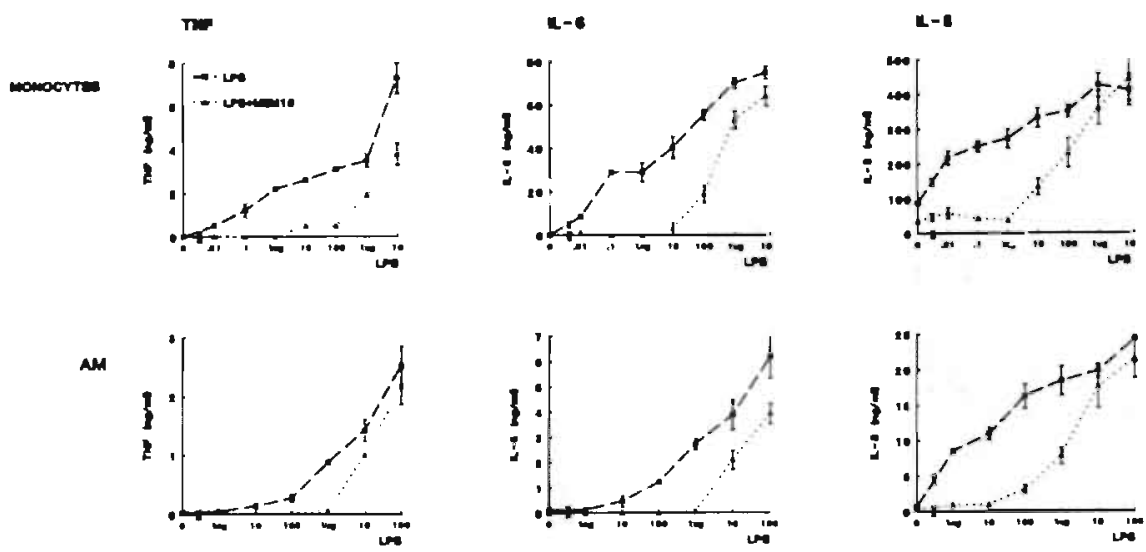

FIGURE 2. Effect of MEM-18 on cytokine release by monocytes and AM stimulated with LPS. Cells were incubated with different concentrations of LPS in the presence or absence of MEM-18 $(10 \mu \mathrm{g} / \mathrm{ml})$. After 20-h incubation, supernatant was collected and cytokine release was measured in cytokine-specific ELISA. Values are the mean \pm SD of four measurements. SD bars are omitted, if they fall within the symbol.

peroxidase-conjugated goat anti-rabbit $\mathrm{IgG}$ (Jackson ImmunoResearch, West Grove, PA). In the IL-8 ELISA goat anti-IL-8 phosphatase conjugate was used. $o$-Phenylenediamine (Sigma) was used as a substrate for peroxidase and p-nitrophenyl phosphate (Sigma) as the substrate for the phosphatase conjugate. Photospectrometry was performed at $492 \mathrm{~nm}$ (IL-6, TNF- $\alpha$ ) or $405 \mathrm{~nm}$ (IL-8). The lower detection level of ELISA was $20 \mathrm{pg} / \mathrm{ml}$ for TNF $-\alpha, 10 \mathrm{pg} / \mathrm{ml}$ for IL-6, and $100 \mathrm{pg} / \mathrm{ml}$ for IL-8.

\section{Results}

Effect of anti-CD1 4 mAb on LPS-induced TNF- $\alpha$, $\mathrm{IL}-6$, and IL- 8 release by monocytes and AM

Inhibiting capacity of five anti-CD 14 mAb on LPS-induced TNF- $\alpha$ release was tested (Table I). MAb MEM-18 and Cris 6 blocked TNF- $\alpha$ release for more than $90 \%$, whereas mAb UCHMI and MEM-15 inhibited TNF- $\alpha$ release to a lesser extent. FMC17 had no effect on TNF- $\alpha$ release. All the anti-CD $14 \mathrm{mAb}$ used were functional, as tested by flow cytometry. None of the anti-CD14 mAb induced TNF- $\alpha$ release by monocytes in absence of LPS (data not shown). MEM-18 that inhibited TNF- $\alpha$ release at concentrations higher than $0.3 \mu \mathrm{g} / \mathrm{ml}$, reaching a plateau at $3 \mu \mathrm{g} / \mathrm{ml}$ concentration (Fig. 1), was selected for further experiments.

In order to determine whether CDI 4 is involved in LPSinduced IL- 6 and IL- 8 release by monocytes, the effect of MEM- 18 on the release of these cytokines was tested. LPSinduced release of TNF- $\alpha, \mathrm{IL}-6$. and IL-8, respectively, in a concentration-dependent manner (Fig. 2). Release of TNF- $\alpha$ and IL- 6 was totally blocked by MEM- 18 when LPS concentration ranged from 0.01 to $1 \mathrm{ng} / \mathrm{ml}$. At higher LPS concentrations, the inhibition became incomplete, de- clining gradually with increasing LPS concentration. In contrast to TNF- $\alpha$ and IL- 6 , spontaneous IL- 8 release by monocytes was observed. Both the spontaneous and the LPS-induced IL- 8 release was inhibited by MEM-18. This inhibition also decreased, with increasing LPS concentrations.

LPS-induced cytokine release by AM was inhibited by MEM-18 in a similar manner as compared with monocytes (Fig. 2). A complete inhibition of TNF- $\alpha$ and IL-6 release was obtained at LPS concentrations ranging from $1 \mathrm{ng} / \mathrm{ml}$ to $1 \mu \mathrm{g} / \mathrm{ml}$. At higher concentrations of LPS, TNF- $\alpha$ and IL- 6 release were partially blocked by MEM-18. AM release of IL- 8 was abrogated by MEM- 18 and stayed at the spontaneous release level for LPS concentrations up to 10 $\mathrm{ng} / \mathrm{ml}$. At higher LPS concentrations, inhibition of $\mathrm{IL}-8$ release by MEM- 18 gradually declined.

To determine whether inhibition of TNF- $\alpha$ release by MEM- 18 was responsible for the reduced release of IL-6 and IL-8, the effect of a blocking anti-TNF- $\alpha$ reagent was tested. Dimeric human rTNFR-p80:Fc construct reduced LPS-induced IL- 6 and IL- 8 release partially, however, inhibition by MEM-18 was much stronger (Fig. $3 A$ ). Furthermore, it was shown that the dimeric TNFR-p80:Fc construct prevented TNF activity, as tested by E-Selectin expression and IL- 8 release by HUVEC, for more than $90 \%$ at the highest concentration used (Fig. $3 B$ ).

Effect of anti-CD14 mAb on cytokine release induced by IL-1 $\beta$, TNF- $\alpha$, PMA, and zymosan

In order to show that MEM-18 specifically inhibited LPS induced cytokine release, the effect of MEM-18 on IL-1 $\beta$. TNF- $\alpha$, PMA, and zymosan-induced cytokine release was 

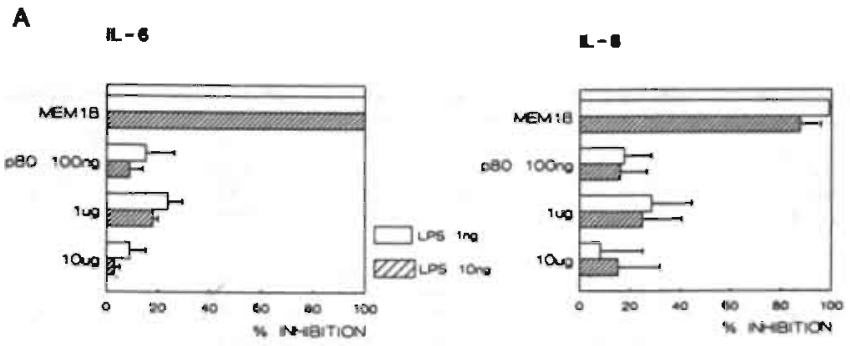

B
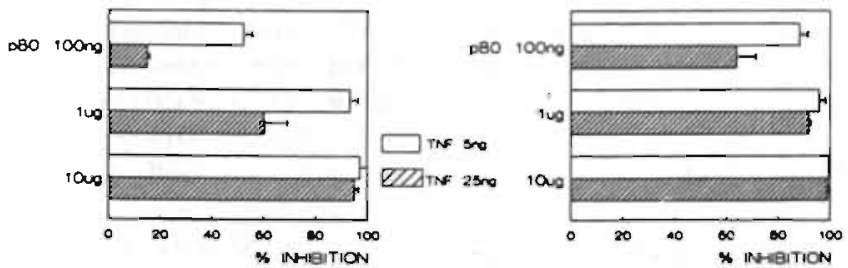

FIGURE 3. A, effect of MEM-18 and dimeric human rTNFR-p80:Fc construct on LPS-induced cytokine release by monocytes. Monocytes were stimulated with LPS in the absence or presence of either dimeric human rTNFR-pBO:Fc construct $\{1001$ ng'ml, $1 \mu \mathrm{g} / \mathrm{ml}$, or $10 \mu \mathrm{g} / \mathrm{ml})$ or MEM-18 $(10 \mu \mathrm{g} / \mathrm{ml})$. After 20 -h incubation, supernatant was collected and cytokine release was measured in cytokine-specific ELISA. The effect of MEM-18 and dimeric human rTNFR-p80:Fc construct are expressecl as percentage of inhibition of LPS-induced cytokine release. Data are expressecl as mean \pm SD of four experiments. SD bars are omitted if they fall within the symbol. $B$, effect of dimeric human rTNFR-p80:Fc construct on human rTNF- $\alpha$-induced HUVEC activation. HUVEC was stimulated with human rTNF- $\alpha$ in the absence or presence of dimeric human rTNFR-p80:Fc construct $(100 \mathrm{ng} / \mathrm{ml}, 1 \mu \mathrm{g} / \mathrm{ml}$, or $10 \mu \mathrm{g} / \mathrm{ml})$. After 6 -h incubation, supernatant was collected and HUVEC was fixed. IL-8 release and E-Selectin expression were measured in specific ELISA. The effect of dimeric human rTNFR-p80:Fc construct is expressed as percentage of inhibition of human rTNF- $\alpha$-induced HUVEC activation. Data are expressed as mean \pm SD of four experiments. SD bars are omitted if they fall within the symbol.
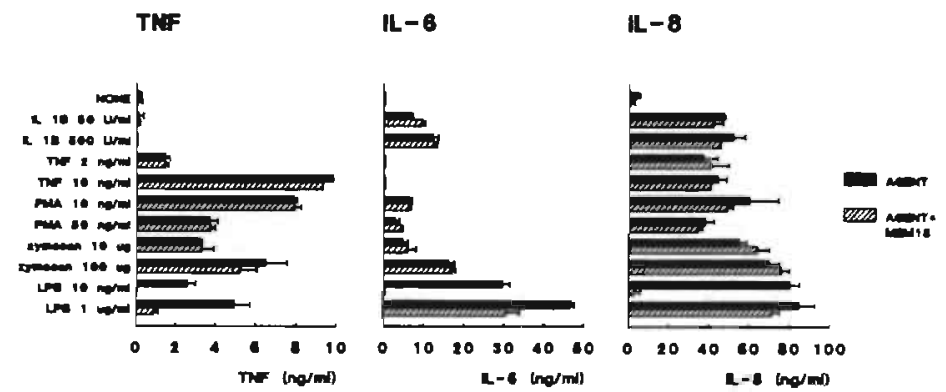

FIGURE 4. Effect of MEM-18 on cytokine release induced by different monocyte-stimulating agents. Monocytes were incubated with the listed agents in the presence or absence of MEM-18 (10 $\mu \mathrm{g} / \mathrm{ml})$. After $20-\mathrm{h}$ incubation, supernatant was collected and cytokine release was determined in cytokine-specific ELISA. Data are expressed as mean + SD of four measurements. SD bars are omitted if they fall within the symbol. 
Table II

Effect of serum on inhibition by anti-CDI4 mAb of LPS-induced cytokine production

\begin{tabular}{|c|c|c|c|c|c|c|}
\hline & \multicolumn{2}{|c|}{ TNF-a (ng/ml) } & \multicolumn{2}{|c|}{ IL-6 (ng/ml) } & \multicolumn{2}{|c|}{ (L-8 (ng/ml) } \\
\hline & without MEM-18 & with MEM-18 & without MEM-18 & with MEM-18 & without MEM-18 & with MEM-18 \\
\hline \multicolumn{7}{|l|}{ Monocytes } \\
\hline $10 \% \mathrm{HS}$ & $4.2 \pm 0.4$ & $0.4 \pm 0.1$ & $35.7 \pm 4.1$ & $3.4 \pm 1.7$ & $84 \pm 11$ & $66 \pm 21$ \\
\hline $10 \%$ BCS & $1.7 \pm 0.6$ & $0.1 \pm 0.1$ & $38.3 \div 3.7$ & $<0.01$ & $92 \pm 8$ & $15 \pm 3$ \\
\hline None & $0.3 \pm 0.1$ & $0.1=0.1$ & $2.2 \pm 0.5$ & $<0.01$ & $16 \pm 3$ & $7 \pm 1$ \\
\hline \multicolumn{7}{|l|}{$A M$} \\
\hline $10 \% \mathrm{HS}$ & $4.0=0.1$ & $1.5 \pm 0.2$ & $9.4 \pm 0.5$ & $3.5 \pm 0.7$ & $115 \geq 30$ & $70 \pm 15$ \\
\hline $10 \% \mathrm{BCS}$ & $3.0 \pm 0.3$ & $0.1 \pm 0.1$ & $12.9 \pm 0.5$ & $0.3 \pm 0.1$ & $100 \pm 33$ & $40 \pm 16$ \\
\hline None & $4.9 \pm 0.5$ & $0.3 \pm 0.1$ & $3.8 \pm 0.2$ & $0.1 \pm 0.1$ & $27 \pm 7$ & $14 \pm 3$ \\
\hline
\end{tabular}

- Cells were washed five times after isolation procedure and resuspended in medium containing indicated serum. After 20-h stimulation with LPS (monocytes $1 \mathrm{ng} / \mathrm{ml}$ LPS and AM $100 \mathrm{ng} / \mathrm{ml}$ LPS) in the absence or presence of MEM-18 $(10 \mu \mathrm{g} / \mathrm{ml})$. supernatant was harvested and cytokine release determined in cytokine-specific ELISA. Data are expressed as mean $\pm S D$ of four measurements.

studied. As shown in Figure 4, MEM-18 did not block cytokine release by monocytes induced by these agents. These data further show that anti-CD $14 \mathrm{mAb}$ did not interfere with the capacity of monocytes to be activated.

Effect of anti-CD14 mAb on LPS-induced cytokine release in the absence of serum

Stimulation of monocytes and AM with LPS under serumfree conditions (RPMI 1640 supplemented with $0.1 \%$ BSA or $\mathrm{M} \varphi-\mathrm{SFM}$ ), or with BCS used instead of HS, resulted in most experiments in a reduced release of TNF- $\alpha$, IL- 6 , and IL-8 (Table II). Nevertheless, MEM-18 was still able to inhibit the cytokine release under these conditions.

\section{Discussion}

Two out of the five anti-CDI4 mAb tested strongly inhibited LPS-induced TNF- $\alpha$ release. These two mAb (MEM-18 and Cris6) recognize a same CD14 epitope (29). MEM-18, MEM-15, and FMC17 mAb, interacting with different CD14 epitopes (29) varied as to their capacity to inhibit LPS-induced TNF- $\alpha$ release. These facts indicate that a specific CDI4 epitope is involved in CD14-LPS recognition.

MEM-18 that was able to block LPS-induced TNF- $\alpha$ release also inhibited IL- 6 and $\mathbb{L}-8$ release by human monocytes and AM. At low LPS concentrations, MEM-18 abrogated cytokine release, whereas at higher LPS concentrations inhibition was incomplete. There are two possible explanations for these observations: i) at high LPS concentrations, cytokines are either induced via both CD14-dependent and independent pathways, or ii) CD14 is not effectively blocked by MEM-18. Both mechanisms can also function simultaneously.

MEM-18 inhibited specifically LPS-induced cytokine release by monocytes because it did not interfere with the cytokine release induced by IL-1 $\beta$. TNF- $\alpha$, PMA, and zymosan. The data further show that also in differentiated mononuclear phagocytes, such as AM, CDI4 is involved in the LPS-induced cyrokine release. In case of AM only about $50 \%$ of the cells express CDI4 (18). At present it is not clear whether only these CD14-positive cells are responsible to LPS, or that the CD14-negative cell population consist of cells with a low, hardly detectable CD14 surface expression, which might be sufficient for LPS-induced activation.

Because TNF- $\alpha$ is known to induce other cytokines such as IL-6 (30) and IL-8 (31), we investigated whether inhibition by MEM- 18 of IL- 6 and IL- 8 release was caused by blocking TNF- $\alpha$ release. Dimeric human rTNFR-p80:Fc construct, effectively blocking TNF- $\alpha$ activity, added to cultures of monocytes stimulated with LPS, partially reduced both the IL- 6 and IL- 8 release. However, under these conditions MEM-18 caused a much stronger inhibition of IL- 6 and IL- 8 release. Thus inhibition of TNF- $\alpha$ by antiCD14 mAb accounts for only a small part of the reduced IL-6 and IL-8 release, indicating that CD14 is involved in a direct LPS-induced cytokine release that is TNF- $\alpha$ independent.

LPS-induced cytokine release differed in the systems using HS, BCS, or serum-free conditions. Because MEM- 18 inhibited cytokine release in all cases, LPS seems to be able to interact directly with CD14. This correlates with the data obtained by others, who reported that 1) LPS induced upregulation of $\mathrm{CD} 11 \mathrm{~b} / \mathrm{CD} 18$ expression on PMN can be inhibited by anti-CDI $4 \mathrm{mAb}$ both in the presence and absence of serum (7), 2) anti-CDI4 mAb MY-4 blocked LPSinduced TNF- $\alpha$ production under serum-free conditions ( 4 , 5), and 3) CD14-transfected $702 / 3$ cells show enhanced sensitivity to LPS under serum-free conditions (10). However, as the production of cytokines induced by LPS via $\mathrm{CD} 14$ is generally higher in the presence of serum, as compared with serum-free conditions, serum factors seem to enhance the affinity of LPS to membrane CD14. Some of these factors, e.g., LBP or "septin," that opsonize LPS in serum have been identified recently $(9,11)$.

In addition to CD14 several other LPS-binding receptors 
on the surface of monocytes have been described. For ex ample, a lectin-like monocyte membrane component has been found to interact with the polysaccharide part of LPS (32), known to stimulate monocytes to IL-I production (33). Another 80-kDa m.w. molecule expressed on human mononuclear phagocytes was reported to interact with the lipid A part of LPS (34). Antibodies recognizing this molecule induced, similar to L.PS, tumoricidal activity of macrophages (35), suggesting a functional role on these cells. The question of whether these structures are involved in LPS-mediated production of cytokines in concert with $\mathrm{CD} 14$, or these receptors mediate CDl4-independent cytokine production, remains to be answered. More insight in the pathways of LPS action will help to develop therapeutic strategies to intervene in LPS-mediated pathology.

\section{References}

1. Knapp, W. 1989. Myeloid section report. In Leucocyte Typing IV. W. Knapp. B. Dörken, W. R. Gilks. E. P. Rieber, R. E. Schmidt, H. Stein, and A. E. G. Kr. Von dem Borne, eds. Oxford University Press, Oxford, England, New York, and Tokyo, p. 747.

2. Wright, S. D., R. A. Ramos, A. Hermanowski-Vosatka, P. Rockwell, and P. A. Detmers. 1991. Activation of the adhesive capacity of CR3 on neutrophils by endotoxin: dependence on lipopolysaccharide binding protein and CD14. J. Exp. Med. 173:1281.

3. Wright, S. D., R. A. Ramos, P. S. Tobias, R. J. Ulevitch, and J. C. Mathison. 1990. CD14, a receptor for complexes of lipopolysaccharide (LPS) and LPS binding protein. Science 249:1431.

4. Heumann, D., P. Gallay, C. Barras, P. Zaech, R. J. Ulevitch, P. S. Tobias, M. Glauser, and J. D. Baumgarner. 1992. Control of lipopolysaccharide (LPS) binding and LPS-induced tumor necrosis factor secretion in human peripheral blood monocytes. j. Immunol. 148:3505.

5. Couturier, C., G. Jahns, M. D. Kazatchkine, and N. HaeffnerCavaillon. 1992. Membrane molecules which trigger the production of interleukin- 1 and tumor necrosis factor $-\alpha$ by lipopolysaccharide-stimulated human monocytes. Eur. J. Immunol. 22:1461.

6. Weinstein, S. W., C. H. June, and A. L. DeFranco. 1991. LPS stimulated protein tyrosine phosphorylation in human macrophages: involvement of CD14. J. Leucocyte Biol. (Suppl. 1):4I (Abstr).

7. Lynn, W. A., C. R. H. Raetz. N. Qureshi, and D. T. Golenbock. 1991. Lipopolysaccharide induced stimulation of CDIlb/ CD18 expression on neutrophils. J. Immunol. 147:3072.

8. Couturier, C. N. Haeffner-Cavaillon, M. Caroff, and M. D. Kazatchkine. 1991. Binding sites for endotoxin (lipopolysaccharides) on human monocytes. J. Immunol. 147:1899.

9. Schumann, R. R., S. R. Leong. G. W. Flaggs. P. W. Gray, S. D. Wright, J. C. Mathison, P. S. Tobias, and R. J. Ulevitch. 1990. Structure and function of lipopolysaccharide binding protein. Science 249:1429.

10. Lee, J. D., K. Kato, P. S. Tobias, T. N. Kirkland, and R. J. Ulevitch. 1992. Transfection of CD14 into $702 / 3$ cells dramatically enhances the sensitivity to complexes of lipopolysaccharide (LPS) and. LPS binding protein. J. Exp. Med. 175:1697.

11. Wright, S. D., R. A. Ramos, M. Patel, and D. S. Miller. 1992 Septin: a factor in plasma that opsonizes lipopolysaccharidehearing particles for recognition by $\mathrm{CD} 14$ on phagocyles. $I$. Exp. Med. 176:719.

12. Debets, J. M. H., R. Kamprneijer, M. P. M. H. Van der Linden, W. A. Buurman, and C. J. Van der Linden. 1989. Plasma tumor necrosis factor and mortality in critically ill septic patients. Crif. Care Med. 17:489.

13. Fletcher Stames, H., M. K. Pearce, A. Tewari, J. H. Yim, J. Zou, and J. S. Abrams. 1990. Anti-IL-6 monoclonal antibodies protect against lethal Escherichia coli infection and lethal tumor necrosis factor- $\alpha$ challenge in mice. J. Immunol. 145: 4185 .

14. Huber. A. R, S. L. Kunkel, R. F. Todd, and S. J. Weiss. 1991. Regulation of transendothelial neutrophil migration by endogenous interleukin-8. Science 254:99.

15. Nourshargh, S., J. A. Perkins, H. J. Showell, K. Matsushima, T. J. Williams, and P. D. Collins. 1992. A comparative study of the neutrophil stimulatory activity in vitro and proinflammatory properties in vivo of 72 amino acid and 77 amino acid IL-8. J. Immunol. 148:106.

16. Strieter, R. M., D. G. Remick, J. P. Lynch, M. Genord, C Raiford, R. Spengler, and S. L. Kunkel. 1989. Differential regulation of tumor necrosis factor-alpha in human alveolar macrophages and peripheral blood monocytes: a cellular and molecular analysis. Am. J. Respir. Cell. Mol. Biol. 1:57.

17. Standiford, T. J., S. L. Kunkel, M. W. Rolfe, H. L. Evanoff, R. M. Allen, and R. M. Strieter. 1992. Regulation of human alveolar macrophage- and blood monocyte-derived. interleukin- 8 by prostaglandin $\mathrm{E}_{2}$ and dexamethasone. $A m . J$. Respit Cell Mol. Biol. 6:75.

18. Hoogsteden, H. C. J. J. M. Van Dongen, P. T. W. Van Hal. M. Delahaye, W. Hop, and C. Hilvering. 1989. Phenotype of blood monocytes and alveolar macrophages in interstitial lung disease. Chest 95:574.

19. Smith, C. A., L. Lauffer, T. Davis, M. Widmer, S. Dower, C. Jacobs, K. Mohler, and R. G. Goodwin. 1991. Chimeric TNF receptors, of viral and cellular origin. Cytokines. 3:478 ( $\mathrm{Ab}$ str.

20. Hwu, P. S. Schwarz, M. Custer, C. A. Sinith, J. J. Mule, and S. A. Roserberg. 1902. Use of soluble reconnbinant TNF receptor to improve detection of TNF secretion in culures of tumor infiltrating lymphocytes. J. Imminol. Methods 15I: 139.

21. Bažil, V., V. Hợejši, M. Baudys, H. Krištofová, J. L. Strominger, W. Kostka, and I. Hilgert. 1986. Biochemical characterization of a soluble form of the 53-kDa monocyte. surface antigen. Eur. J. Immunol. 16:1583.

22. Hancock, W. W. H. Zola, and R. C. Atkins. 1983. Antigenic heterogeneity of human mononuclear phagocytes: immunohistologic anafysis using monoclonal antibodies. Blood 62 . 1271 .

23. Hogg, N., and M. A. Horton. 1987. Myeloid antigens: new and previously defined clusters. In Leucocyte Typing III McMichael, A. J. P. C. L. Beverly, S. Cobbold, M. J. Crumpton, W. Gilks. F. M. Gotch, N. Hegg, M. Horton, N. Ling, I C. M. MacLennan, D. Y. Masors, C. Milstein, D. Spiegelhalter, and H. Waldmann, eds. Oxford University Press, Oxford, New York and Tokyo, p. 576. 
24. Hogg. N., S. Macdonald. M. Slusarenko, and P. C. L. Beverley. 1984. Monoclonal antibodies, specific for human monocytes, granulocytes and endothelium. Immunology 53:753.

25. Graziano, R. F. and M. W. Fanger. 1987. FcyRI and FcyRII on monocytes and 1991 granulocytes are cytotoxic trigger molecules for tumor cells. J. Immunol. 139:3536.

26. Von Asmuth, E. J. U., J. F. M. Leeuwenberg. M. Ceska, and W. A. Buurman. 1991. LPS and cytokine induced endothelial cell IL- 6 release and ELAM- 1 expression; involvement of serum. Eur. Cyrokine Net. 2:291.

27. Engelberts, I., A. Möller, G. J. M. Schoen. C. J. Van der Linden, and W. A. Buurman. 1991. Evaluation of measurement of human TNF in plasma by ELISA. Lymfokine $C y-$ tokine Res. 10:69.

28. Ceska, M., F. Effenberger. P. Peichi, and E. Pursch. 1989. Purification and characterization of monoclonal and polyclonal antibodies to neutrophil activating peptide (NAP-1): the development of a sensitive ELISA for the determination of NAP- 1 and anti-NAP-1 antibodies. Cylokine 1:136 (Abstr).

29. Bażil, V., and V. Hotejłí. 1989. Epitopes of the CD14 antigen recognized by some of the $\mathrm{CD} 14$ panel antibodies. Tissue Antigens 33:194.
30. Shalaby, M. R. A. Waage. L. Aarden, and T. Espevik. 1989. Endotoxin, tumor necrosis factor- $\alpha$ and interleukin 1 induce interleukin 6 production in vivo. Clin. Immunol. Immunopathol. 53:488.

31. Baggiolini, M., A. Walz and S. Kunkel. 1989. Neutrophilactivating peptide-1/interleukin 8 , a new cytokine that activates neutrophils. J. Clin. Invest. 84:1045.

32. Haeffner-Cavailton, N., J. Cavaillon. M. Etievant, S. Lebbar, and L. Szabo. 1985. Specific binding of endotoxin to human monocytes and mouse macrophages: serum requirement. Cell Immunol 91:119.

33. Haeffner-Cavaillon, N., J. Cavaillon, M. Moreau, and L. Szabo. 1984. Interleukin I secretion by human monocytes sumulated by the isolated polysaccharide region of the Bordetella perfussis endotoxin. Mol. Immunel. 21:389.

34. Lei, M., and D. C. Morrison. 1988. Specific endotoxic lipopolysaccharide-binding proteins on murine spenocytes. $J$. Immunol. 141:996.

35. Chen, T.. S. W. Bright, J. L. Pace, S. W. Russell, and D. C. Morrison. 1990. Induction of macrophage-mediated tumor cytotoxicity by a hamster monoclonal antibody with specificity for lipopolysaccharide receptor. J. Immunol. I45:8. 


\section{Chapter 4}

Anti-CD14 Antibodies Reduce Responses of Cultured Human Endothelial Cells to Endotoxin

Reprinted with permission 


\title{
Anti-CD14 antibodies reduce responses of cultured human endothelial cells to endotoxin
}

\author{
E. J. U. VON ASMUTH, M. A. DENTENER, V. BAŻIL, * M. G. BOUMA, J. F. M. LEEUWENBERG \& \\ W. A. BUURMAN Depariment of Surgery, Biomedical Center, University of Limburg, Maastricht, The Netherlands and \\ *Harvard University. Depariment of Biochemistry and Molecular Biology. Cambridge, Mossachusents. U.S.A.
}

Accepted for publication 5 March 1993

\begin{abstract}
SUMMARY
l.tpopolysuccharide (LPS) activates both myeloid and endothelial cells. Whereas CDIt has been shown to be involved in I.PS recognition by myeloid cells, the mechanism responsible for the strong response of endothelial cells to LPS remains to be elucidated. The role of CDI 4 in this process was studied using CDI4-specific antibodies (Ab). Anti-CD14 Ab inhibited LPS-induced interleukin-6 (II.-6) release and E-selectin expression by cultured human umbilical vein endothelial cells (HIJVEC). Messenger RNA encoding IL-6 and E-selectin was reduced in parallel. The inhibitory effect of anti-CDI4 Ab was epitope dependent, maximal at low LPS concentrations and dropping with increasing LPS dosex. Anti-CID/4 Ab did not affect endothelial cell activation induced by IL-1 $\beta$, tumour necrosis factor- $\alpha$ (TNF- $\alpha$ ) and phorbol 12-myristate 13-acelate (PMA). IL-6 release and E-selectin expression of HUVEC were strongly reduced when LPS activation was performed in the absence of serum, indicating involvement of serum components in LPS activation of HUVEC. Nevertheless, anti-CD14 Ab also blocked LPS-induced HUVEC activation in the absence of serum. Although the role of serum components in LPS activation remains to be elucidated. CD 14 seems to be a key mediator in LPS-induced activation of endothelial cells.
\end{abstract}

\section{INTRODUCTION}

Endothelial cells are immunologically active cells and respond strongly to lipopolysaccharide (LPS) presence. De novo expression of the leucocyle adhesion molecule E-selectin, ${ }^{1.2}$ and the relcase of interleukin-6 (IL-6), ${ }^{3,4}$ a cytokine that is involved in inflammatory reaction, are part of this response. The mechanism of LPS-induced activation of endothelial cells, howevet, has not been clarified.

C.DI4 has been shown to be involved in L.PS activation of monocytes, ${ }^{5-7}$ alveolar macrophages ${ }^{7}$ and neutrophils. ${ }^{.9}$ CD 14 binds L.PS complexed with an acute phase protein, designated LPS binding protein (LBP), ".t or with 'septin', "a group of serum proteins that, in co-operation, facilitatc LPS interaction with this receptor ${ }^{10}$ It seems that CDI4 is also able to recognize LPS directly in the absence of serum. ${ }^{2,8.11 .12}$ It is generally accepted that LBP and 'septin' opsonize L.PS, cnhancing its affinity 10 CDI4. CDI4 is a glycosylphosphatidylinositol-anchored protein $^{13.14}$ that has originally been considered as a monocyte/

Abbreviations; BCS, bovine calf serum: HS, human serum; HUVEC, human umbilical vein endothelial cells; LBP, LPS binding protein: LPS. lipopolysaccharide.

Correspondence: Dr W. A. Buurman. Dept. of Surgery. Biomedical Center, University of Limburg. PO Box 616, 6200 MD Maastricht. The Netherlands. macrophage-specific surface marker. ${ }^{13}$ CDI4 has also been reported to be expressed on neutrophils ${ }^{9.16}$ and B cells, ${ }^{17.1}$ although to a lesser extent compared to monocytes. Weak interaction of anti-CD14 monoclonal antibodies ( $\mathrm{mAb}$ ) with endothelial cells has been described previously. ${ }^{10-21}$ suggesting that small amounts of CD14 are also present on endothelia cells. These data prompted us to study the role of CD 14 in LPSinduced activation of endothelial cells.

\section{MATERIALS AND METHODS}

Reugens und mab

Recombinant human (rh) tumout necrosis factor- $\alpha$ (TNF- $\alpha$ ) was kindly provided by BASF/Knoll AG (Ludwigshafen Germany); rhIL-1 $\beta$ was a kind gift of Dr Gillis (Immunex Seattle, WA): LPS (phenol extracl, chromatographically purified from Escherichia coli, serotype 055: LB5) and phorbol 12 myristate 13-acetatc (PMA) were purchased from Sigma (SI Louis, MO). Preparations of TNF, IL- $1 \beta$ and PMA were tested for endotoxin contamination by the chromogenic limulus amoebocyte lysate assay (Coatest, Kabi Diagnostica, Nyköping. Sweden), and were found to contain less than $5 \mathrm{pg} / \mathrm{ml} \mathrm{LPS}$ in final solutions. The following $C D 14$ reactive $A b$ were used MEM-15 and MEM-18,27 both IgG1; Cris6, ${ }^{16}$ IgGl, kindly provided by Dr Vileila (Servei d'Immunologia, Hospital Clinic Villarroel, Barcelona, Spain); UCHM $1,{ }^{19}$ IgG2a, kindly pro- 


\section{Anti-CDIA Ab reduce responses of human endothelial cells to endotoxin}

vided by Dr Beverly (ICRF Human Tumor Immunology Group, University College Hospital, London, U.K.); BL-467, ${ }^{23}$ IgGI kindly provided by Dr Fiebig (Section of Biosciences, University of Leipzig, Leipzig، Germany). Rabbit anti-CDI4 $A b$ were isolated from serum derived from CD14-immunized rabbits. Monoclonal antibody MOPC21, IgG1, a non-specific control mAb, was kindly provided by Celltech (Slough, U.K.).

\section{Cells}

Human umbilical vein endothelial cells (HUVEC) were obtained by collagenase treatment of the human umbilical vein. The cells were cultured in fibronectin-coated (fibronectin kindly provided by Dr van Mourik, CLB, Amsterdam, The Netherlands) tissuc culture flasks (Costar, Cambridge, MA) in RPMI1640 (Gibco, Paisley, U.K.), supplemented with $10 \%$ pooled $0.2 \mu \mathrm{m}$ filtered heat-inactivated human serum (HS) derived from the local blood bank, $10 \%$ heat-inactivated bovine calf serum (BCS) (Hyclone, Logan, UT), $50 \mu \mathrm{g} / \mathrm{ml}$ heparin (Sigma), $30 \mu \mathrm{g} / \mathrm{ml}$ endothelial growth supplement (Collaborative Research Incorporated, Bedford, MA) and antibiotics. Endothelial cells were characterized by their pavement-like monolayer morphology. by positive staining with $\mathrm{mAb}$ hec7 directed against PECAM-1, ${ }^{24}$ generousiy provided by Dr Muller (Rockefeller University, NY), and by positive staining with the anti-Eselectin $\mathrm{mAb}$ ENAl ${ }^{25}$ after $4 \mathrm{hr}$ of incubation with TNF- $\alpha$.

\section{Induction of cyrokine release}

HUVEC of passage 3 were seeded at $10^{4}$ cells; well in fibroncctincoated 96-well flat-bottom tissue culture plates (Costar) in culture medium. I day prior to stimulation. HUVEC were rinsed twice with RPMI-1640 and the medium was replaced by the appropriate agents in $200 \mu \mathrm{l} /$ wcll RPMI- 1640 supplemented with antibiotics. without growth factor, and with $10 \%$ HS (not heat-inactivated), or $0.1 \%$ BSA (endotoxin contamination $<0.1 \mathrm{ng} / \mathrm{g}$ : Sigma) in experiments in which serum-free medium was employed. Media were tested for endotoxin contamination in the chromogenic limulus amoebocyte lysate assay, and were found to contain less than $5 \mathrm{pg} / \mathrm{ml}$ LPS. Supernatants were harvested and kept at $-20^{\circ}$ until use in the IL-6 ELISA Endothelial cell monolayers were washed, fixed with $0.05 \%$ glutaraldehyde for $10 \mathrm{~min}$ at room temperature, and kept at $4^{\circ}$ until use in the E-selectin ELISA. Human monocytes were isolated as described previously? ${ }^{7}$ and incubated with the indicated reagents at $10^{4} \mathrm{cells} / \mathrm{well}$ in flat-bottom tissue culture plates in $200 \mu \mathrm{l} /$ well RPMI-1640 supplemented with $10 \%$ HS and antibiotics

\section{IL-6 ELISA}

The IL- 6 concentration in the culture supernatant was determined using a previously described sand wich ELISA for $1 \mathrm{~L}-6^{\text {.h }}$ In short. 96-well immuno maxisorp plates (Nunc. Roskilde, Denmark) were coated with a newly developed murine mAb SEI, specific for human IL-6. Recombinant human IL-6 (a generous gift from Professor Sebald, Physiologisch-Chemisches Institut der Universitāt, Würzburg, Germany) was used for standard titration curves. Test samples were added. Plates were incubated with polyclonal rabbit anti-human IL-6 Ab. followed by peroxidase-conjugated goat anti-rabbit IgG (Jackson, Westgrove, PA). $O$-phenylene-diamine (Sigma) was added as a substrate and photospectometry was performed at $492 \mathrm{~nm}$. Standard titration curves were not influenced by the presence of serum in the sample buffer. The IL 6 ELISA had a lower detection limit of $10 \mathrm{pg} / \mathrm{ml}$ IL-6.

\section{Detection of E-selectin expression}

E-selectin expression was determined by ELISA using the Eselectin specific mAb ENAI, ${ }^{25}$ followed by peroxidase-conjugated goat anti-mouse IgG. O.phenylene-diamine (Sigma) was added as a substrate and photospectometry was performed at $492 \mathrm{~nm}$.

\section{Preparation and analysis of RNA}

HUVEC was grown and stimulated, as aiready described, in $150 \mathrm{~cm}^{2}$ tissue culture flasks (Costar). Total cellular RNA was isolated as described previously. ${ }^{27}$ RNA samples were treated as recommended by Amersham and applied onto a $N$ * Membrane (Amersham International, Amersham, U.K.), using a Biodot apparatus (BioRad, Richmond, CA). cDNA probes were labelled with $\left[{ }^{2} \mathrm{P}\right] \mathrm{dCTP}$ using the random primer labelling kit of Boehringer Mannheim (Mannheim, Germany) and hybridized to the blot $\left(10^{6}\right.$ c.p.m. $\left./ \mathrm{ml}\right)$ as described previously. ${ }^{25}$ The $1 \mathrm{~L}-6$ probe [1.3 kilobase (kb) HIIl-EcoRI fragment] was kindly provided by Dr Aarden (CLB. Amsterdam, The Netherlands), the E-selectin probe (1.0 kb EcoRI-BglII fragment) was kindly provided by Celltech and the actin probe (1.3Pst fragment) was kindly provided by Dr Berkvens (University of Leiden, Leiden, The Netherlands). Labelled bands were visualized by autoradiography.

\section{RESULTS}

\section{Anti-CD14 Ab inhibit LPS-induced HUVE.C responses}

HUVEC monolayers were incubated with $1 \mu \mathrm{g} / \mathrm{ml}$ LPS in RPMI-1640 enriched with $10 \%$ HS and antibiotics. The influence of co-incubation with five murine anti-CD $14 \mathrm{mAb}$. MEM-18, Cris6, UCHM1, MEM-15 and BL-467, and of serum of CD/4-immunized rabbits ( $\mathrm{gG}$ concentration $10 \mu \mathrm{g} / \mathrm{ml}$ ), on 1L-6 release and on E-selectin expression by HUVEC was investigated. MEM-18, Cris6, MEM-15 and rabbit polyclonal anti-CDI4 antibodies prevented LPS-induced IL- 6 release and E-selectin expression by $80 \%$ or more. UCHMI inhibited HUVEC responses less effectively, while BL-467 as well as a non-reactive control $\mathrm{MAb}$ did not influence HUVEC responses (Table 1). As a control, the same panel of $\mathrm{Ab}$ was tested for their influence on $100 \mathrm{pg} / \mathrm{ml}$ LPS-induced TNF and IL. -6 release by human monocytes. The LPS-induced release of both cytokines was completely prevented by co-incubation with MEM- 18 and Cris6, while MEM-15 and rabbit anti-CD14 Ab reduced both TNF and IL-6 release by more than $60 \%$ (Table 1). In parallel to the effect on LPS-induced HUVEC activation, $\mathrm{AAb}$ BL-467 hardly influenced LPS-induced monocyle TNF and $I L-6$ release (Table 1). None of the anti-CDI4 antihodies induced HUVEC IL-6 release, HUVEC E-selectin expression or monocyte cytokine release in the absence of LPS (data not shown). MEM-18, which inhibited HUVEC 11 .-6 release and E-sclectin expression at $0.2 \mu \mathrm{g} / \mathrm{ml}$, with a maximal inhibition at $2 \mu \mathrm{g} / \mathrm{ml}$ (data not shown), was selected for further experiments.

Next, the influence of MEM-18 on HUVEC IL-6 and Eselectin mRNA expression induced by incubation with $1 \mu \mathrm{g} / \mathrm{ml}$ LPS for $2 \mathrm{hr}$, was determined. In the presence of MEM-18, substantially reduced amounts of mRNA encoding IL-6 and E- 


\section{E. J. U. von Asmuth et al.}

Table 1. Anti-CD14 antibodies can inhibit LPS-induced responses of both HUVEC and buman monocytes

\begin{tabular}{|c|c|c|c|c|}
\hline & \multicolumn{2}{|c|}{ HUVEC } & \multicolumn{2}{|c|}{ Human monocytes } \\
\hline & $\begin{array}{c}\mathrm{IL}-6 \\
\text { (ng/mi) }\end{array}$ & $\begin{array}{l}\text { E-selectin } \\
\text { (A } 492 \mathrm{~nm} \text { ) }\end{array}$ & $\begin{array}{c}\text { TNF } \\
(\mathrm{ng} / \mathrm{ml})\end{array}$ & $\begin{array}{c}\text { IL-6 } \\
\text { (ng/ml) }\end{array}$ \\
\hline Unstimulated & $0-1 \pm 0-1$ & $0.02 \pm 0.02$ & $0.02 \pm 0.02$ & $0.3 \pm 0.1$ \\
\hline LPS & {$[1 \cdot 2 \pm 0.7$} & $1.6 \pm 0.08$ & $1.4 \pm 0.2$ & $8.4 \pm 0.5$ \\
\hline LPS + MEM-18 & $0.9 \pm 0.2$ & $0.12 \pm 0.04$ & $0.1 \pm 0.1$ & $0.04 \pm 0.01$ \\
\hline LPS + Cris6 & $0.5 \pm 0.2$ & $0.09 \pm 0.04$ & $0.1 \pm 0.1$ & $0.02 \pm 0.01$ \\
\hline LPS + UCHMI & $2.7 \pm 0.7$ & $0.28 \pm 0.05$ & $0.87 \pm 0.08$ & $5 \cdot 0 \pm 0.4$ \\
\hline LPS + MEM-I5 & $1 \cdot 2 \pm 0 \cdot 2$ & $0.22 \pm 0.04$ & $0.50 \pm 0.04$ & $3 \cdot 2 \pm 0 \cdot 4$ \\
\hline LPS + BL- 467 & $12 \cdot 4 \pm 1.5$ & $1.6 \pm 0.1$ & $0.97 \pm 0.05$ & $7.2 \pm 0.6$ \\
\hline LPS + rabbit anti-CDI4 & $1.4 \pm 0.3$ & $0.19 \pm 0.05$ & $0.12 \pm 0.07$ & $1.5 \pm 0.1$ \\
\hline $\mathrm{LPS}+\mathrm{MOPC} 21$ & $108 \pm 1.0$ & $1.5 \pm 0.1$ & $1 \cdot 2 \pm 0.2$ & $8 \cdot 3 \pm 0.4$ \\
\hline
\end{tabular}

Influence of $10 \mu \mathrm{g} / \mathrm{ml} \mathrm{mAb}$ and rabbit polyclonal Ab reactive with CD/4 on HUVEC IL-6 release and E-selectin expression and monocyte TNF and IL-6 release induced by LPS. MOPC21, a non-reactive MAb of the IgGI subclass, was used as a control. Cells were incubated in presence of LPS (monocytes with $100 \mathrm{pg} / \mathrm{ml}$ and HUVEC with $1 \mu \mathrm{g} / \mathrm{ml}$ LPS) and antibodies for $5 \mathrm{hr}$ (10 determine maximal E-selectin expression) and $18 \mathrm{hr}$ (to determine cytokine release). Data are expressed as mean \pm SD of four measurements.

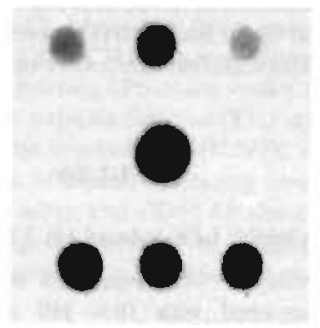

Figure 1. MEM-18 inhibits LPS-induced IL-6 and E-selectin mRNA expression in HUVEC. Messenger RNA was isolated from untreated HUVEC (A) and HUVEC stimulated for $2 \mathrm{hr}$ with $\mathrm{t} \mu \mathrm{g} / \mathrm{ml}$ LPS in the absence (B) or presence (C) of $5 \mu \mathrm{g} / \mathrm{ml}$ MEM-18, in medium containing $10 \%$ HS. Parallel blots were run and hybridized with actin probe to compare the amount of RNA in different samples.

setectin were detected (Fig. 1). indicating interference of MEMIs with LLPS-induced IL-6 release and E-selectin expression on a pre-transcriptional level.

To investigate whether anti-CD 4 Ab specifically inhibited HUVEC responses to LPS, we compared HUVEC responses to LPS, IL-1 $\beta$, TNF- $x$ and PMA in the presence and absence of MEM-18. Whereas MEM-18 induced a major reduction in Eselectin expression and $\mathrm{IL}-6$ release in response to $5 \mathrm{ng} / \mathrm{ml}$ LPS and $5 \mu \mathrm{g} / \mathrm{m} ! \mathrm{L} . \mathrm{PS}$, no clear influence was found in the responses of HUVEC monolayers stimulated with IL-1 $\beta$. TNF- $\alpha$ and PMA (Fig. 2).

Inhibition of LPS-induced HUVEC IL-6 release and E-selectin expression is not abrogated in the absence of serum

To investigate whether serum presence is a prerequisite for CDI4-mediated LPS activation of HUVEC. HUVEC monolayers were rinsed intensively with serum-free medium before the addition of LPS, to ensure maximal removal of soluble serum components. Monolayers were subsequently incubated in the presence or absence of $10 \%$ HS with LPS concentrations ranging from I $\mathrm{ng} / \mathrm{ml}$ to $100 \mu \mathrm{g} / \mathrm{ml}$ in RPMI- 1640 supplemented with $0.1 \%$ BSA. In the presence of serum, MEM- 18 reduced IL6 release and E-selectin expression in response to $1-100 \mathrm{ng} / \mathrm{m}$ ! LPS for $90 \%$ or more. This reduction was partly overcome by stimulation with higher concentrations of LPS (Fig. 3). As reported previously ${ }^{29}$ HUVEC showed diminished responses to LPS in the absence of serum (Fig. 3). MEM-18, however, still effectively reduced both LPS-induced IL- 6 release and Eselectin expression in the absence of serum in the incubation medium (Fig. 3). The use of special serum-free endothelial cell culture medium (Endothelial-SFM, Gibco) instead of RPMI supplemented with bovine serum albumin (BSA), and additional attempts to remove serum proteins, either by repeating the wash procedure or by $24-\mathrm{hr}$ culture in serum-free medium before washing and activation in new serum-free medium, did not prevent the inhibitory effects of MEM-18 co-incubation in the above-described experiment (data not shown).

\section{DISCUSSION}

We demonstrated that certain anti-CD 14 Ab inhibited LPSinduced activation of cultured HUVEC, measured by induction of: (1) IL-6 release; (2) E-selectin surface expression, and (3) IL-6 and E-selectin mRNA expression. We also found that antiCDI4 mAb reduced LPS-induced IL-8 release, and surface expression of ICAM-1 and VCAM-1 (data not shown). On the basis of these results, we conclude that CD14 participates in the response of endothelial cells to LPS. A recent study of Frey et al., ${ }^{30}$ also demonstrates CD14 involvement in endothelial cell activation by LPS. This finding extends the immunological importance of CDI4 in terms of its role in LPS-induced activation of not only haemopoietic, but also non-hemopoietic cells. Like others, we have found clear differences in the capacities of anti-CDI4 Ab to block LPS-induced cellular activation. ${ }^{530}$ Differences in both epitope specificity and affinity 

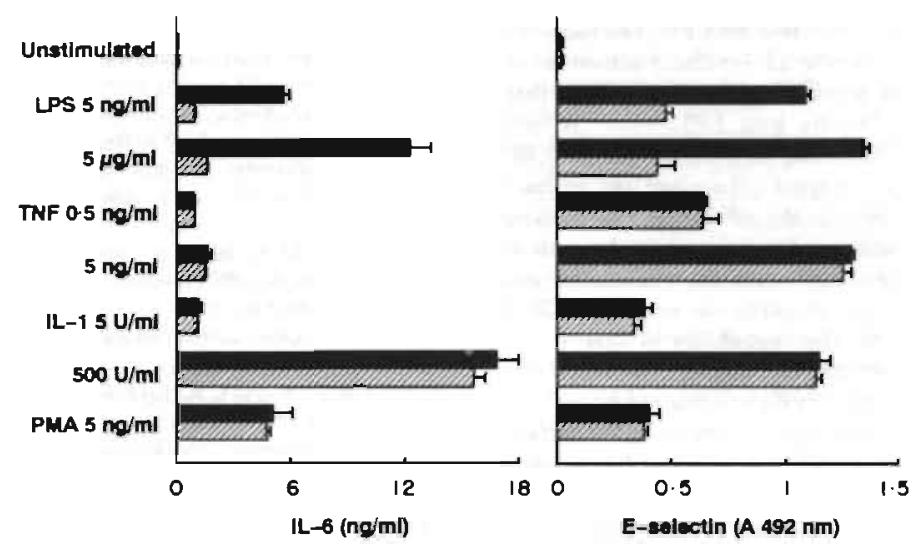

Figure 2. MEM-18 inhibits LPS-induced, but not TNF-, 1L-1 $\beta$ - or PMA-induced IL-6 release and E-selectin expression. HUVEC were incubated with the indicated reagents in the absence (D) and presence (E) of $5 \mu \mathrm{g} / \mathrm{ml} \mathrm{MEM}-18$. E-selectin expression and IL-6 release were measured after 5 and $18 \mathrm{hr}$ respectively as indicated in Materials and Methods. Data are expressed as means \pm SD of four measurements.
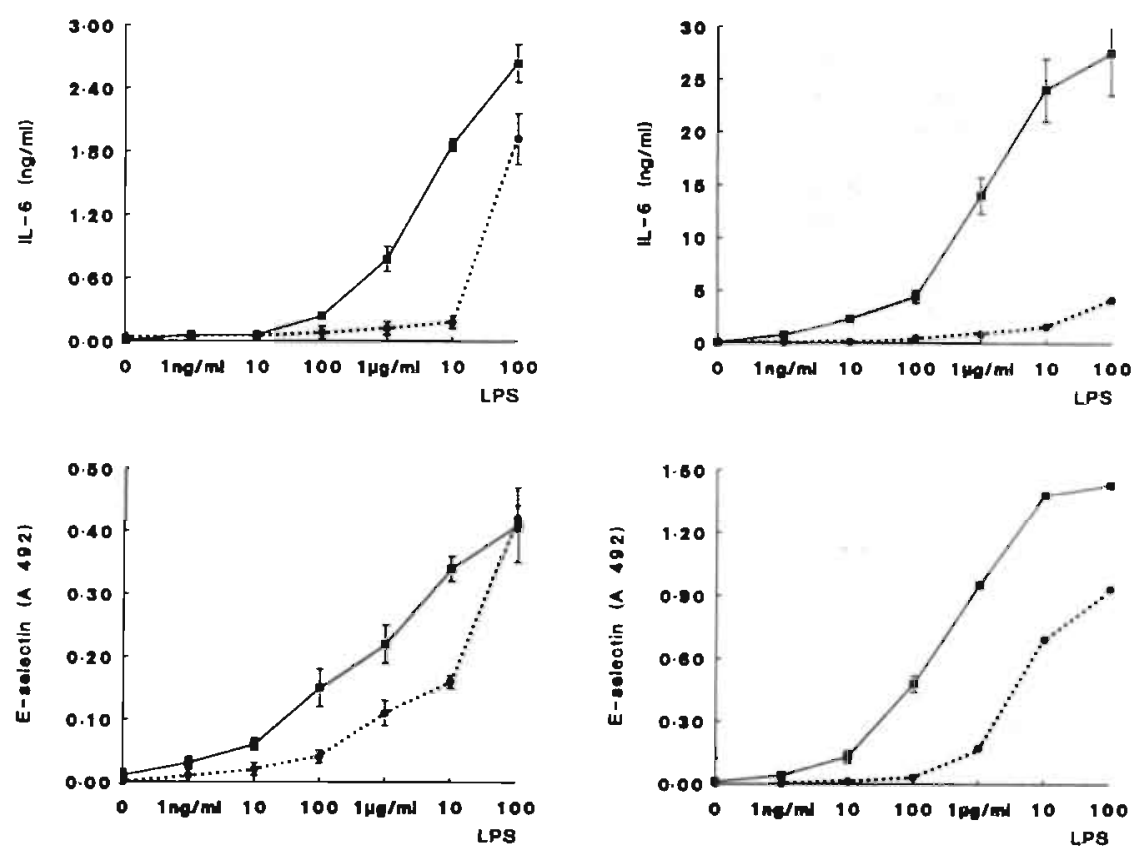

Figure 3. MEM-18 inhibits LPS-induced IL-6 release and E-selectin expression both in the absence (left graphs) and presence (right graphs) of $10 \%$ HS. HUVEC were incubated with different concentrations of LPS in the absence ( $)$ or presence of ( ) $5 \mu \mathrm{g} / \mathrm{ml}$ MEM- 18 for $5 \mathrm{hr}$ (to determine maximal E-selectin expression) and $18 \mathrm{hr}$ (to determine IL-6 release) in the presence or absence of serum.

Data are expressed as means \pm SD of four measurements (where SD bars are not shown, they fall within the symbol).

of the individual anti-CD14 $\mathrm{Ab}$ may have contributed to this variation. Capacities of anti-CDI4 Ab to block LPS-induced HUVEC activation were, however, similar to the capacities of these $\mathrm{Ab}$ to block LPS-induced activation of monocytes, indicating that the same CDI4 epitope is involved in the activation process. The firding that anti-CD14 $\mathrm{mAb}$ do not inhibit endothelial cell responses to cytokines and PMA demonstrates that CDI4 is specifically involved in the L.PS-induced activation.

There are still several questions to be answered. First, what is 


\section{E. J. U. von Asmuth et al.}

the role of CDI4 in cellular activation by LPS? The fact that anti-CDi4 $\mathrm{mAb}$ are able to inhibit LPS-induced activation of HUVEC in the absence of serum supports the concept that $\mathrm{CD} / 4$ is able to inieract directly with LPS $^{7.11 .12 .30}$ It can. however, not be excluded that some serum proteins like LBP may remain bound to the endothelial cell surface and mediate LPS-CDI4 interactions, despite the efforts to wash these proteins away. Another conclusion drawn from this observation is that CD14 must be associated with the endothelial cell membrane. The next question concerns the origin of CDI4 present on endothelial cells. One possibility is that CDI4 represents an endogenous membrane molecule. Since soluble $\mathrm{CDI} 4$ is found in large amounts in normal plasma, ${ }^{22.31}$ association of exogenous CD/4 with a counter receptor on the surface of endothelial cells would be another option, which has recently been claimed. Attempts to prevent association of exogenous CDI4 with the endothelial cell surface by culturing HUVEC monolayers under serum-free conditions before LPS activation did not, however, prevent the inhibitory effect of anti-CD14 $\mathrm{mAb}$. Whatever the answer, the quantity of cell surfaceassociated CDI4 on HUVEC seems to be fairly low, as we were not able to detect surface CDI4 using either flow cytometry analysis or precipitation from detergent lysate of surface iodlinated HUVEC (data not shown). In contrast, we obtained positive results using both these methods for detection of surface CD14 on monocytes (data not shown). However, in addition to the functional evidence for the presence of CD14 on endothelial cells, weak staining of endothelial cells by anti$\mathrm{CD} ! 4 \mathrm{mAb}$ has been reported. ${ }^{19-2}$ Finally, it is not clear which serum proteins are involved in CDI4-dependent activation of endothelial cells in the presence of serum. For monocytes. LBP and 'septin' have been identified as serum components which enhance CDI4-mediated LPS activation. ${ }^{16.10}$ The fact that the LPS-induced response of endothelial cells in the presence of serum is much stronger compared to serum-free conditions. clearly indicates that serum factors such as LBP participate in this process. The experiments addressing the questions mentioned above are currently being addressed in our laboratory.

\section{ACKNOWLEDGMENTS}

This work was supported by the Dutch Kidney Foundation (Nederlandse Nier Stichting. grant no. C88.739).

\section{REFERENCES}

1. Sombentre R.P. \& RUtLenot B.K. (1986) Cultured human vascular endothelial cells acquire adhesiveness for neutrophils after stimulation with interleukin I, endotoxin, and tumor-producing phorbol diesters. J. Immunol. 136, 649

2. Bemlacoua M.P. Porfi J.S. Mendrick D.L., Cotran R.S. \& Gimbrone M. A. (1987) Identification of an inducible endotheliallcukocyte adhesion molecule. Proc. nati. Acad. Sci. U.S.A. 84, 9238

3. May L.T. Torcia Gi. Cozzolino F., Ray A.. Thtier S.B. Santhanam U., Sëhgal P. B. \& Stern D. (1989) Interleukin-6 gene expression in human entothelial cells; RNA start sites. multiple IL-toprotcins and inhibition of proliferation. Biochem. hiophys. Res. Comm. 159.991

4. LoPPNOW H. L Li88y P. (1989) Human endothelial cells express the IL-6 gene in response io interleukin I and bacterial LPS. Cell. Iommunal. 122, 493
5. WRIGHT S.D. R/MOS: R.A., TOBIAS P.S, ULFWITCH R.J. \& Mathlson J.C. (1990) CD14, a receptor for complexes of lipopolysaccharide (LPS) and LPS binding protein. Science, 249, 1431.

6. Heumann D. Gallay P., Barras C, Zafch P., Ulevitch R.J., Toblas P.S., Glauser M-P. \& Bacmeartnek J.D. (1991) Conirol of lipopolysaccharide (LPS) binding and LPS-induced tumor necrosis factor secretion in human peripheral blood monocytes. J. Imminol. 148, 3505 .

7. Dextener M.A, Bazkil V. von Asmuth E.J.U., Ceska M. \& BUURmax W.A. (1993) Involvement of CD14 in lipopolysaccharide induced tumor necrosis factor- $x$, interleukin-6 and interleukin-8 release by buman monocytes and ulveolar macrophages. J. I mmmnot. 150, 2885.

8. LYNN W.A. RAETZ C.R.H. QURESH N. \& GOLENEOCK D.T. (1991) Lipopolysaccharide-induced stimulation of CDIJb/CDI8 expression on neutrophils. Evidence of specific receptor-based response and inhibition by lipid A-based antagonists. J. Immunol. 147, 3072 .

9. Wright S.D. Ramos R.A., Hermanowski-Vosatka A., RockWIL P. \& Detmers P.A. (1991) Activation of the adhesive capacity of CR3 on neutrophils by endotoxin: dependence on lipopolysaccharide binding protein and CD14. J. exp. Med. 173, 1281

10. WRIGHT S.D., Ramos R.A., PATE.L M. \& MILLER D.S. (1992) Septin: a factor in plasma that opsonizes lipopolysaccharide-bearing particles for recognition by $\mathrm{CD} / 4$ on phagocytes. I. exp. Med. 176. 719

11. LEE.J.-D., KATO K. TOHIAS P.S, KIRKLAND T.N. \& ULFVITCH R.J. (1992) Transfection of CDI4 into 70Z/3 cells dramatically enhances the sensitivity to complexes of lipopolysaccharide (LPS) and LPS binding protein. J. exp. Med. 175, 1697.

12. KITCHENS ER.L., ULFUitCH R.J. \& MUNFone R.S. (1992) Lipopoly. saccharide (LPS) partial structures inhibit responses to L.PS in a human macrophage: cell line without inhibiting LPS uptake by a CDI4-mediated pathway. J. exp. Med. 176, 485.

13. Haziot A. Chan S. Ferremo E., Low M.G. Silben R. \& Goyemi S.M. (1988) The monocyle differentiation antigen. CD14, is: anehored to the cell mernbrane by a phospliatidyl-inositol linkage. J. Immunol, 141, 547 .

14. Simmons D.L., Tan S., Texfex D.G., Nichol Son-Weller A. \& SEFD B. (1989) Monocyte antigen CDI4 is a phospholipid anchored membrane protein. Blooa', 73, 284.

15. Van Voorhis W. C., Steinman R M., Hair L.S., Luhan J., Wither M.D. Kond S. \& COHN Z.A. (1983) Specific antimononuclear phagecyte monoclonal antibodies. Application to the purification of dendritic cells and the tissue focalization of macrophages. . . exp. Med. 158, 126.

16. Hoci N. \& Horrox M.A. (1987) Myeloid antigens: new and previously defined clusters. In: Lewtocyte Typing III. (ed. A. J. McMichaell, p. 576. Oxford University Press, Oxford

17. Ziegler-heitbrock W. Passluck B. \& Flieger D. (1988) The monaclonal antibody. $M Y 4$ stains $B$ lymphocytes, and two distinct monocyte subsets in humun peripheral blood. Mybriatoma: 7, 521

18. Labita M.O. LanomakN R., OBReCht J.P. \& ORRISt R. (1901) Human B-cells express membrane-bound and soluble forms of CDI4 myeloid antigen. Molec. Immunol. 289, 115.

19. Hogr N. MacDonald S., Slusakexko M. \& Beverly P.C.L. (1984) Monoclomal antibodies specific for human monocytes. gra nulocyles and endothelium. Immumology, 53, 753.

20. Medeiros L J. Mfrring ton R.D., Gonzales C.L. Jaffe E.S. \& Cossmas I. (1901) $\mathrm{M} y 4$ antibody staining of non-Hodgkin lymphomas. Am. J. clin. Pathol. 95, 363.

21. BogmaN M J.T. DoOper IM.M. VAN de WINKEL J.G.J.. TAX W.J.M. HOISSAa A.J. AssManN K.J.M. RUITER D.J. \& KOFNE R.A.P. \{1989\} Diagnosis of renal allograft rejection by macrophage. immunostairing with a CD/4 monoclonal antibody. WT14. Luncer. 2,235.

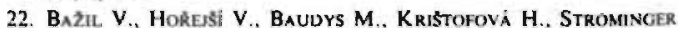




\section{Anti-CDI4 Ab reduce responses of human endothelial cells to endotoxin}

J.L. KOSTKA W. \& HILGERT I. (1986) Biochemical characterization of a soluble form of the $53-\mathrm{kDa}$ monocyle surface antigen. Eur. $J$. Immunol. 16, 1583.

23. Govert S.M., Tesio L., Ashman L.K., BälïE., Bazil V., Garrido F. el al. (1989) Report on the CDI4 cluster Workshop. In: Lukncile Typing $I V$ (ed. W. Knapp), p. 789. Oxford University Press, Oxford.

24. MUller W.A., RATti C.M., MCDONNELL. S.L. \& COHN Z.A. (1989) A human endothelial cell-restricted, externally disposed plasmalemmal protein enriched in intercellular junctions. J. exp. Mcd. 170, 399.

25. LeeuWEnberg J.F.M. Jeunhomme G.M.A.A. \& BuUrman W.A (1990) Characterization of two monoclonal antibodies directed against an adhesion molecule on endothelial cells. Transplant. Proc. 22. 1991.

26. LeEUWENBerg J.F.M, voN ASMUth E.J.U, JeUnhome T.M.A.A \& BUURMAN W.A. (1990) IFN-y regulates the expression of the adhesion molecule ELAM-1 and IL-6 production by human endothelial cells in virro. J. Immunol. 145, 2110

27. SAmbróok J., Fritsch E.F. \& Maniatis T. (1989) Exiraction, purification, and analysis of messenger RNA from eukaryotic cells. In: Molecular Claning. Vol. 1, edn 2, p. 7.10. Cold Spring Harbor Laboratory Press, New York.

28. SAmbrook J., Fritsch E.F. \& Maniatis T. (1989) Extraction, purification, and analysis of messenger RNA from eukaryotic cells. In: Molecular Cloning. Vol. I, edn 2, p. 7.52. Cold Spring Harbor Laboratory Press. New York.

29. von Asmuth E.J.U., LeEuWenberg J.F.M., Ceska M. \& BuUrman W.A. (1991) LPS and cytokine-induced endothelial cell IL-6 release and ELAM-1 expression; involvement of serum. Eur. Cywkine Net. 2.291.

30. Frey E.A., Miller D.S., Gulistein Jahr T., Sundan A., Bazil. V., EspeyiK T., Finlay B.B. \& Whight S.D. (1992) Soluble CDI4 participates in the response of cells to lipopolysaccharide. $J$. exp. Med. 176, 1665 .

31. Krúger C., Schütt C., Obertacke U., Joka T., Mũller F.e., KNÖLLER J., KÖLLER M., KÖNIC W. \& SCHÖNFELD W. (1991) Serum CD 14 levels in polytraumalized and severely bumed patients. Clin. exp. Immunol. 85, 297. 
$-86-$ 
Chapter 5

Lipopolysaccharide LPS-Mediated Soluble TNF Receptor Release and TNF Receptor expression by Monocytes

Reprinted with permission 


\title{
Lipopolysaccharide LPS-Mediated Soluble TNF Receptor Release and TNF Receptor Expression by Monocytes
}

\section{Role of CD14, LPS Binding Protein, and Bactericidal/Permeability-Increasing Protein ${ }^{1}$}

\author{
Jet F. M. Leeuwenberg, ${ }^{2 *}$ Mieke A. Dentener, ${ }^{\star}$ and Wim A. Buurman ${ }^{*}$ \\ "Department of Surgery, University of Limburg, Maastricht, The Netherlands; and 'Department of Pulmonary Diseases, \\ University Hospital Maastricht, The Netherlands
}

Previously we demonstrated that two soluble (s) tumor necrosis factor receptors, TNF-R55 as well as sTNF-R75, are constitutively released in vitro by monocytes, and that this release was markedly enhanced after activation. Because LPS is an important activator of monocytes, we investigated the effect of LPS on sTNF-R release by monocytes. It was found that release of sTNF-R75, but not (or minimally) release of sTNF-R55, was enhanced after activation with LPS, reaching plateau levels after approximately 2 days. CD14, one of the membrane receptors for LPS, is an intermediate in this process, as shown in experiments using mAb directed against CD14. Under serumfree conditions, LPS-induced STNF-R75 release was less as compared with release in the presence of serum, suggesting involvement of serum proteins. Addition of LPS binding protein (LBP) enhanced the LPS-induced STNF-R75 release under serum-free conditions, but had no effect in the presence of serum. On the other hand, bactericidal/permeability-increasing protein (BPI), known to possess LPS neutralizing activity, inhibited LPS-induced STNF-R75 release. Furthermore, cell surface expression of both types of TNF-R was shown to be controlled by LPS, I.BP, and BPI. LPS caused, within $1 \mathrm{~h}$, a complete reduction of TNF-R55 as well as TNF-R75 expression, followed by enhanced re-expression of both receptors after $24 \mathrm{~h}$. The down-modulation of expression was increased by LBP, whereas BPI counteracted the LPS-induced down-regulation. The LPS-enhanced release of sTNFR75, capable of inactivation of TNF, as well as LPS-induced initial down-modulation of TNF-R expression leading to postulated temporary unresponsiveness to TNF may share in a physiological mechanism to carefully control the effects of TNF. Journal of Immunology, 1994, 152: 5070.

$\mathrm{T}$ NF receptors (TNF-R) ${ }^{3}$ are expressed on a number of cell types $(1,2)$ and are believed to mediate the effects of TNF. Two different types of TNF-R have been characterized with molecular masses of $55 \mathrm{kDa}$ (TNF-R55) and of $75 \mathrm{kDa}$ (TNF-R75) (3). Appropriate activation of polymorphonuclear cells (PMNs) and acti-

Received for publication December 28, 1993. Accepted for publication March 7, 1994.

The costs of puthlication of this article were defrayed in part by the payment of page charges. This article must therefore be hereby marked advertisement in accordance with 18 U.S.C. Section 1734 solely to indicate this fact.

1 This work was supported by the Dutch Kidney Foundation (Nederlandse Nierstichting, Grant No. C91.10901.

${ }^{2}$ Address correspondence and reprint requests to Dr. I. Leeuwenberg, Department of Surgery, P.O. Box 616,6200 MD Maastricht. The Netherlands.

'Abbreviations used in this paper: TNF.R. TNF receptor; BPI, bactericidal permeability-increasing protein; If, immunolluorescence; HS, human serum; LBP, L.PS binding protein; M\$SFM, macrophage serum-free medium; s, soluble: PMN, polymorphonuclear cell. vated $T$ cells induces rapid shedding of membrane-bound TNF-R in vitro, leading to soluble (s) forms of TNF-R55 and TNF-R75 of $30 \mathrm{kDa}$ and $40 \mathrm{kDa}$, respectively (4). Recently, we described the release of both STNF-R55 and STNF-R75 by monocytes upon activation by $\mathrm{IL}-10$ and phorbol esters in vitro (5). In vivo, sTNF-R are present in the blood of normal healthy individuals at low levels (6), whereas elevated plasma sTNF-R are found in pathological situations, such as rheumatoid arthritis $(7,8)$, sepsis $(9,10,11)$, and experimental inflammation during which bealthy volunteers received LPS (12, 13). Furthermore, in experimental models it was found that LPS infusion induced enhancement of STNF-R in mice (14). In this study (14), no evidence was found for intermediates such as TNF, suggesting that LPS is directly involved in the enhancement of sTNF- $R$ in plasma. STNF-R probably play a role in inactivation of circulating TNF, resulting in a decrease of systemic effects of TNF. 
The major targets for L.PS are mononuclear phagocytes. An increasing number of LPS-induced activities are shown to be mediated via the LPS receptor CD14 (15), among which is TNF release $(16,17)$. The interaction of LPS with CD14 is facilitated by serum proteins, such as the acute phase reactant LPS binding protein (LBP) (reviewed in Refs. 18 and 19) and septin (20), resulting in an enhancement of LPS-induced activation. On the other hand, LPS effects are inhibited by a PMN-derived product, bactericidal/permeability-increasing protein (BPI) (21), which is strongly homologous to LBP (18). BPI was recently shown to antagonize LBP effects by competing for binding to LPS $(22,23)$.

Here, we studied the effect of L.PS on STNF-R release and on TNF-R expression by monocytes. In addition, we investigated whether the mechanism via which LPS affects sTNF-R release and TNF-R expression was mediated via the same pathway as LPS-induced cytokine release, i.e., via CD14. The involvement of LBP and BPI in LPS-induced sTNF-R release and in the regulation of TNF-R expression was studied.

\section{Materials and Methods \\ Antibodies and reagents}

mAlss specifically directed againse TNF-RS5 and specifically directed against TNF-R75 were obtained by immunizing BALB/c mice with sTNFR55 or STNF-R75. To this end, STNF-R55 and STNF-R75 were purified from the culture supernatant of NSO cells (transfected with the extracellular part of either TNF-R55 or TNF-R75; kindly provided by Celltech, Slough, UK) by affiniry chromatography on a TNF-coupled agarose column (Amino Link column, Pierce, Rockford, IL). Spleen cells of immunized mice were fused with Sp20 mouse myeloma cells, and growing hybridomas were cested for production of mAb specifically reactive with sTNF-R55 or STNFR75. mAb MR1-1 (IgGI) and mAb MRI-2 (ggGl) were specifically directed against TNF-R55. mAb MR2-1 (IgG1) and mAb MR2-2 (IgG1) were specifically directed against TNF-R75. MR1-1 and MR2-2 were selected for their capacity to bind soluble forms of TNF-R55 and TNF-R75, respectively, without being inhibited by TNF (5), whereas MR1-2 and MR2-1 were selected for capacity to bind membrane-bound TNF-RS5 and TNF-R75, respectively, without being inhibited by TNF. Polyclonal rabbit antisera anti-TNF-R55 and anti-TNF-R75 were obtained by immunizing rabbits with sTNF-RS5 and sTNF-R75, respectively. mAb MOPC-21 (IgG1, kindly provided by Cellech) was used as a negative control. mAb MEM-18 (IgG1) directed against human CD14 was kindly provided by Dr. Horejsi (Inst. of Molecular Genetics, Prague, Czech Republic). LPS Escherichio coli (wild type, serotype 055:B5, CaL no L-2880) and PMA were purchased from Sigma (St. Louis, MO). LPS derived from Salmonella minnesota (Re mutant R595, rough, cal. no 24-08-43) was obtained from SEBAK Biologisches Forschungs GmbH (Aidenbach, Germany). Human rBPI and rLBP were kindly provided by Dr. Marra (Incyte Pharmaceuticals Inc., Palo Alto, CA). Macrophage serum-free medium (M $\phi-S F M)$ and RPMI 1640 were obtained from GIBCO Europe (Paisley, UK). Human serum (HS) was obtained from the local blood bank

\section{Cell isolation and activation}

PBMCs of normal healthy donors were isolated by buoyant density centrifugation of buffy coat cells on Lymphoprep (Nycomed, Oslo, Norway) The cells were kindly provided by the Red Cross Blood Bank ZuidLimburg (Maastrichi, The Netheriands). Blood was donated by human volunteers, after informed consent for research was obtained. Monocytes were isolated according to Graziano and Fanger (24). In short, PBMCs were allowed to clump by low-speed centrifugation at $4^{\circ} \mathrm{C}$. Cell clumps, consisting of more than $80 \%$ monocytes as evidenced by esterase staining. were separated from the rest of the cells by sedimentation through ice-cold bovine calf serum (HyClone, Logan. UT). After five washings in HBSS to remove all serum components, cells were cultured either in
RPM1 1640 supplemented with 10\% HS, or in M\$-SFM (serum-free condition) or in M $\phi$-SFM supplemented with $10 \%$ HS. For measurement of sTNF-R release, cells (final volume $200 \mu /$ per well, $1.5 \times 10^{6}$ cells' $\mathrm{ml}$ ) were cultured in 96-well flat bottom tissue culture plates (Costar, Cambridge, MA) in triplicate, suppletnented with reagents. After ind;cated time periods the plates were centrifuged and supernatants were harvested and frozen at $-20^{\circ} \mathrm{C}$. For immunofluorescence (IF), cells were cultured in polypropylene tubes (Greiner, GmbH, Solingen, Germany). supplemented with reagents.

\section{ELISA}

For detection of STNF-R55 and STNF-R75 in ELISA, immunoassay plates (Nunc-Immuno Plate Maxisorp, Roskilde, Denmark) were coated with mAb MR1-1 (5 $\mu \mathrm{g} / \mathrm{ml})$ or with mAb MR2-2 (5 $\mu \mathrm{g} / \mathrm{ml})$, respectively, overnight at $4^{\circ} \mathrm{C}$, followed by saturation with i\% BSA. Samples of culture supematant ( $1 / 2$ dilution) were added, and after $2 \mathrm{~h}$ at roorn temperature, the plates were washed with PBS- $-0.1 \%$ BSA and incubated for $1 \mathrm{~h}$ at room temperature with specific biotin-labeled rabbit antisTNF-R Ig. After washing, peroxidase-labeled streptavidin (Dako, Glostrup, Denmark) was added. Peroxidase activity was determined by addition of TMB (3, 3', 5, 5'-tetramethylbenzidine) substrate (Kirkegaard \& Perry Lab., Gaithersburg, MD) and photospectrometry (450 nm) was performed using a micro ELISA autoreader. The ELISA had a lower detection limit of approximately $100 \mathrm{pg} / \mathrm{ml}$. Measurements of sTNF-R were not affected by the addition of TNF (5), indicating that TNF produced by monocytes during the activation period did not mask sTNF-R release. The intra-assay variation was tess than $10 \%$.

\section{Indirect IF and FACS analysis}

Cells of the monocytic fraction $\left(2 \times 10^{6}\right)$ were cultured in polypropylene tubes in the absence or presence of I.PS, or L.BP BPI Bs indicated. After different periods of time, cells were washed with ice-cold PBS $(0.1 \%$ BSA, $0.1 \% \mathrm{NaN}_{3}$ ) and resuspended. Aliquots of cells were incubated with mAb MOPC-21 (background control), WT32 (mAb anti-CD3), MR1-2, or MR2-1 (final concentration $10 \mathrm{\mu g} / \mathrm{ml}$ ) for $30 \mathrm{~min}$ at $4^{\circ} \mathrm{C}$. After two washes, cells were stained with FTrC-labeled $F\left(a b{ }^{2}\right)$ frugments of goat unti-mouse IgG (Jackson, ImmunoResearch, Westgrove, $\mathrm{PA}$ ) on ice for $30 \mathrm{~min}$. The cells were analyzed by FACSorter (Becton Dickinson \& $\mathrm{Co}$, Mountain View, CA). Cells were gated using forward vs side scatter to select for receptor expression on monocytes, excluding dead cells and debris. The selected cells were CD3 negative (data not shown). Net median fluorescence intensity was expressed as channel number of TNF-R expression after subiraction of the background fluoresoence.

\section{Statistical analysis}

Statistical evaluations were performed with the Wileoxon matehed-pairs signed-ranks test.

\section{Results}

\section{LPS-induced release of STNF-R by monocytes}

sTNF-R55 and sTNF-R75 were measured in supernatant derived from monocytes cultured in the absence or presence of different concentrations of LPS ( $t$. coli derived) or with PMA. As shown in Figure 1, release of both sTNFR55 and sTNF-R75 was enhanced upon activation with LPS as well as with PMA. However, LPS-induced sTNFR55 release was only minimally increased as compared with the release of sTNF-R55 induced by PMA. During the culture period, the concentration of sTNF-R in supernatant gradually increased spontaneously as well as upon activation with LPS and PMA. reaching plateau values after approximately $48 \mathrm{~h}$.

A dose-response curve of L.PS from $E$. coli (smooth LPS) and from $S$. minnesota (rough) is shown in Figure 2. 

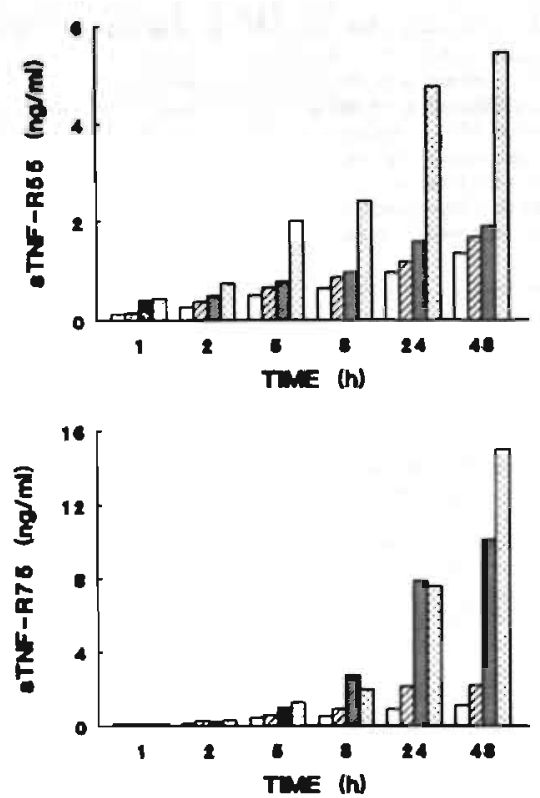

FIGURE 1. Enhanced release of STNF-R by monocytes after stimulation with LPS. Cells were cultured in RPMI 1640 supplemented with 10\% HS in the absence (open bars) or presence of LPS $(1 \mathrm{ng} / \mathrm{ml}$, hatched bars; $100 \mathrm{ng} / \mathrm{ml}$, double hatched bars), or with PMA (50 ng/ml, dotted bars). After the indicated periods of time, culture supernatant was taken in which STNF-R were determined by ELISA. One representative experiment from a series of four independent experiments is shown. Data are given as the mean of triplicate samples. SD was less than 10\% (not shown).

STNF-R75 release reached plateau values at a concentration of approximately 100 to $1000 \mathrm{ng} / \mathrm{ml}$ LPS from $E$. coli. Even at high concentrations of LPS, no enhanced release of sTNF-R55 was observed. Similarly, LPS from $S$. minnesota enhanced the release of STNF-R75, but not of STNF-R55, although higher concentrations of LPS from $S$. minnesota are required than from $E$. coli to enhance release. LPS derived from $E$. coli is used in all of the following experiments. Because sTNF-R55 release was minimally or not at all affected by LPS, only data of sTNF$\mathrm{R} 75$ release are shown.

\section{Involvement of CD14 in LPS-induced STNF- $R 75$ release}

To study the role of CD14 in the LPS-induced STNF-R75 release, monocytes were stimulated for $48 \mathrm{~h}$ with LPS alone or in combination with anti-CD14 mAb. Figure 3 shows that the LPS-induced sTNF-R75 release was abrogated by anti-CD14 mAb MEM-18 at LPS concentrations ranging from $1 \mathrm{ng} / \mathrm{ml}$ to $10 \mathrm{ng} / \mathrm{ml}$. At higher LPS concentrations, the inhibitory effect gradually declined and was
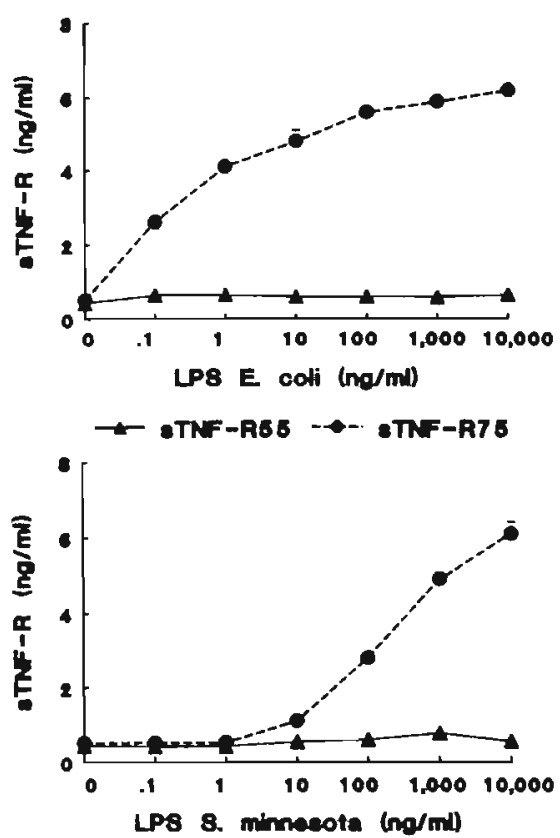

FIGURE 2. Effect of LPS concentration on release of STNF-R by monocytes. After a 48 -h culture period of monocytes in RPMI 1640-10\% HS with different concentrations of L.PS from E. coli (upper graph) and LPS from S. minnesola (lower graph), sTNF-R55 (solid line, $\mathbf{\Delta}$ ) and sTNF-R75 (dashed line, ) were determined by ELISA. One representative experiment form a series of four independent experiments is shown. The data represent the mean \pm SD of triplicate samples. SD bars are omitted if they fall within the symbol.

not detectable at a concentration of $10 \mu \mathrm{g} / \mathrm{ml}$ LPS. The inhibitory effect of MEM-18 was specifically directed against activation by LPS, because PMA-induced STNFR55 and STNF-R75 release was not affected by MEM-18 (data not shown).

\section{Effects of $\angle B P$ and BPI on LPS-induced sTNF- $R$ release}

First, it was investigated whether serum affected LPS-induced sTNF-R75 release. Figure 4 shows that in the absence of serum the release of sTNF-R75 during a 48-h culture period was strongly diminished as compared with the release in the presence of $10 \%$ HS. Addition of LBP under serum-free conditions enhanced the release of STNF-R75 using suboptimal concentrations of LPS (Fig. SA). However, enhancement by LBP was not observed in the presence of serum (data not shown). Furthermore, the levels of sTNF-R75 release were always lower under serum-free conditions, even when LBP was added, than in the presence of $10 \%$ HS. 


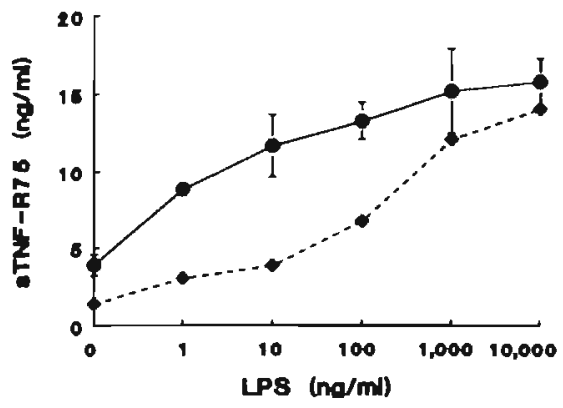

FIGURE 3. Inhibition by anti-CD14 mAb MEM-18 of LPSinduced STNF-R75 release by monocytes. Cells were cultured in RPMI 1640 - 10\% HS with different concentrations of IPS (E. Coh) in the absence (solid line) or presence (dashed line) of MEM-18 $(10 \mu \mathrm{g} / \mathrm{ml})$. After a $48-\mathrm{h}$ culture period, supernatant was collected and STNF-R7 5 release was measured by ELISA. One representative experiment from a series of eleven independent experiments is shown. The data represent the mean $\div$ SD of triplicate samples. SD bars are omitted if they fall within the symbol. Statistical analy'sis of 11 experiments showed that the mean \pm SEM inhibition by MEM-18 was $54 \% \pm 6 \%(p<0.004)$ at an LPS concentration of $10 \mathrm{ng} / \mathrm{ml}$.

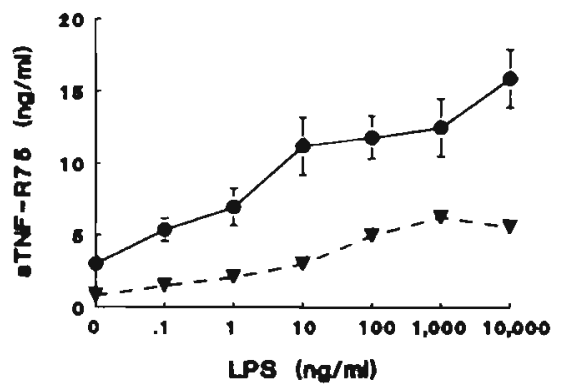

FIGURE 4. Enhancement of LPS-induced STNF-R75 release by serum. Monocytes were cultured in M $\phi$-SFM with different concentrations of LPS (E. coli) in the absence (dashed line) or presence (solid line) of $10 \%$ HS. After a $48-\mathrm{h}$ culture period, culture supernatant was collected and sTNFR7 5 release was measured by ELISA. One representative experiment from a series of ten independent experiments is shown. The data represent the mean \pm SD of triplicate samples. SD bars are omitted if they fall within the symbol. Statistical analysis of 10 experiments showed that the enhancement by HS (mean \pm SEM) was $222 \% \pm 32 \%(\rho<0.008)$ at an L.PS concentration of $10 \mathrm{ng} / \mathrm{ml}$.

To investigate the effect of BPI, experiments were performed in which LPS was preincubated with BPI for at least $30 \mathrm{~min}$, followed by addition of HS and monocytes. STNF- $R$ release was measured after a culture period of $48 \mathrm{~h}$. It was found that BPI inhibited the LPS-induced sTNF-R75 release (Fig. 5B). This inhibitory effect was
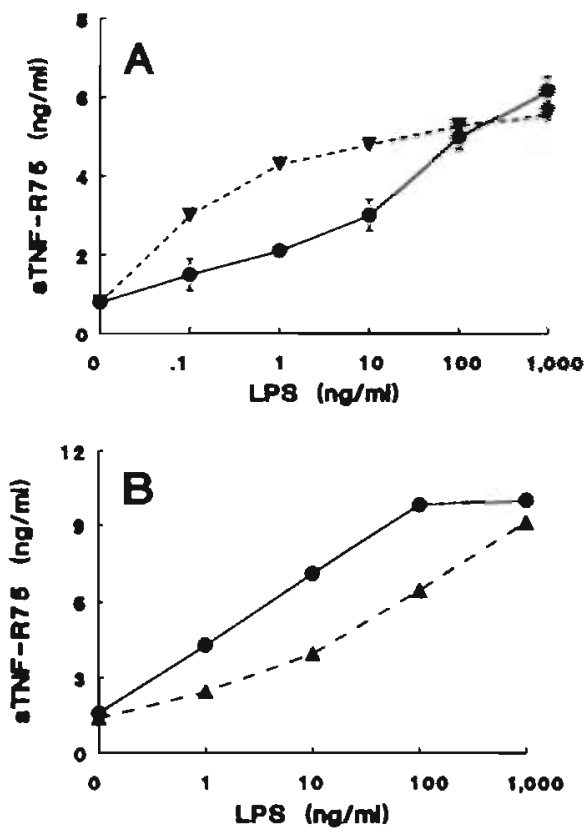

FIGURE 5. Effect of LBP and BPI on LPS induced $\$ T N F \cdot R$ release. (A) L.BP enhanced the LPS-induced STNF-R75 release. Cells were cultured in $M \phi-S F M$ with different concentrations of LPS ( $E$. coli) in the absence isolid line) or presence of $500 \mathrm{ng} / \mathrm{ml}$ LBP (dashed line) under serum-free conditions. Enhancement by LBP (mean \pm SEM) of 10 experiments was $182 \% \pm 17 \%$ at an LPS concentration of $10 \mathrm{ng} / \mathrm{ml}$ ( $p<$ 0.008). (B) BPI inhibited the LPS-induced STNF-R75 release. Cells were incubated with different concentrations of LPS (E. colh) in the absence (solid line) or in the presence of 500 $\mathrm{ng} / \mathrm{ml}$ BPI (dashed line) in M $\phi$-SFM supplemented with $10 \%$ HS. After a 48-h culture period, supernatant was collected and 5 TNF-R75 release was measured by EL.ISA. Inhibition by $\mathrm{BPI}$ (mean \pm SEM) of 10 experiments was $37 \% \pm 5 \%$ at an LPS concentration of $10 \mathrm{ng} / \mathrm{ml}(\rho<0.004)$. One representative experiment from a series of ten independent experiments is shown. The data represent the mean $\pm S D$ (omitted if they fall in symbol) of triplicate samples.

not observed at a high concentration of LPS (1000 ng $\mathrm{ml}$ ) and was less pronounced in the absence of HS (data not shown).

\section{Effect of LPS on kinetics of TNF-R expression by monocytes}

To investigate the effect of LPS on membrane TNF-R expression, we studied the expression on monocytes. Cells were analyzed either freshly isolated, or cultured $30 \mathrm{~min}$, $1 \mathrm{~h}, 2 \mathrm{~h}$, and $24 \mathrm{~h}$ in the absence or presence of 1 or 1000 $\mathrm{ng} / \mathrm{ml}$ LPS (Fig. 6). On freshly isolated monocytes, TNFR55 and TNF-R75 were equally expressed (net median 

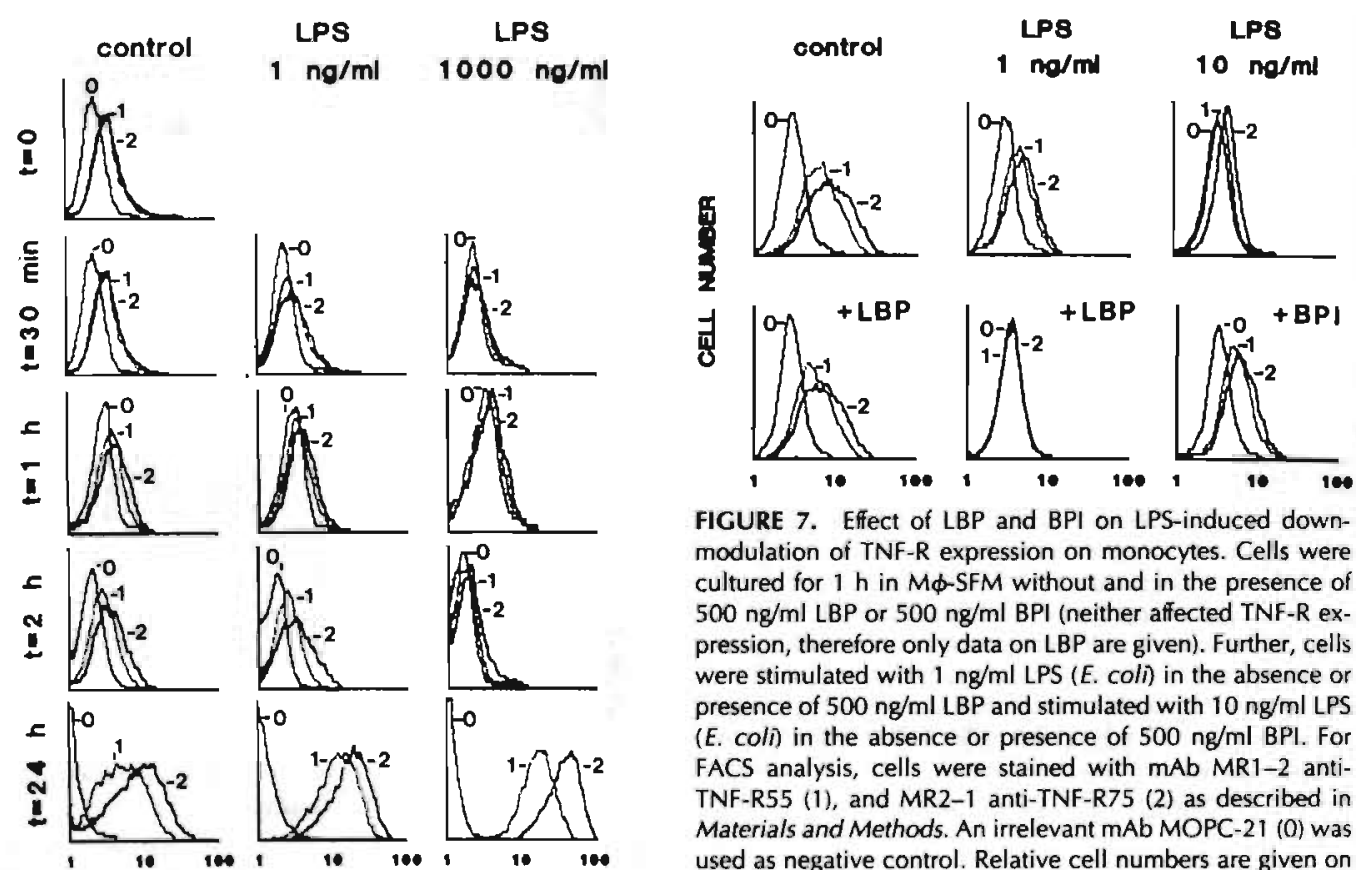

FIGURE 7. Effect of LBP and BPI on LPS-induced downmodulation of TNF-R expression on monocytes. Cells were cultured for $1 \mathrm{~h}$ in $M \phi$-SFM without and in the presence of $500 \mathrm{ng} / \mathrm{ml}$ LBP or $500 \mathrm{ng} / \mathrm{ml} \mathrm{BPI} \mathrm{(neither} \mathrm{affected} \mathrm{TNF-R} \mathrm{ex-}$ pression, therefore only data on LBP are given). Further, cells were stimulated with $1 \mathrm{ng} / \mathrm{ml}$ LPS ( $E$. coli) in the absence or presence of $500 \mathrm{ng} / \mathrm{ml} \mathrm{LBP}$ and stimulated with $10 \mathrm{ng} / \mathrm{ml} \mathrm{LPS}$ ( $E$. coli) in the absence or presence of $500 \mathrm{ng} / \mathrm{ml} \mathrm{BPI}$. For FACS analysis, cells were stained with MAb MR1-2 antiTNF-R55 (1), and MR2-1 anti-TNF-R75 (2) as described in Materials and Methods. An irrelevant mAb MOPC-21 (0) was used as negative control. Relative cell numbers are given on the ordinates and fluorescence intensity on a logarithmic scale on the $x$-axis. One of four independent experiments with similar results is shown. lated cells $(t=0)$ and on cells cultured in RPMI 1640-10\% HS during $30 \mathrm{~min}, 1 \mathrm{~h}, 2 \mathrm{~h}$, and $24 \mathrm{~h}$ in the absence or presence of 1 or $1000 \mathrm{ng} / \mathrm{ml}$ L.PS (E. colh). Cells were stained with mAb MR1-2 anti-TNF-R55 (1), and MR2-1 anti-TNFR75 (2) as described in Materials and Methods. An irrelevant mAb MOPC-21 (0) was used as the negative control. Relative cell numbers are given on the ordinates and fluorescence intensity on a logarithmic scale on the $x$-axis. One of four independent experiments with similar results is shown.

channel number 1.2). During the culture period without LPS treatment, expression of TNF-R55 and TNF-R75 gradually increased starting approximately after $1 \mathrm{~h}$ being approximately three- and sixfold enhanced, respectively. after $24 \mathrm{~h}$ as compared with expression on freshly isolated cells. A different pattern was observed when cells were treated with LPS. At a concentration of $1 \mathrm{ng} / \mathrm{ml}$ LPS, expression of both TNF-R was reduced after a culture period of $30 \mathrm{~min}$ and of $1 \mathrm{~h}$. Complete down-modulation of INF-R expression was observed at a concentration of $1000 \mathrm{ng} / \mathrm{ml}$ within $30 \mathrm{~min}$, and this down-modulation was sustained for at least $1 \mathrm{~h}$. After $2 \mathrm{~b}$, TNF-R expression slightly recovered and was even more enhanced after $24 \mathrm{~h}$ than on unactivated cells (Fig. 6). The expression of TNFR75 showed a stronger increase than that of TNF-R55 after $24 \mathrm{~h}$ both on unactivated cells (net median channel numbers 7 and 3.5 , respectively) and on LPS-treated cells (net median channel numbers 11.5 and 7 , respectively, at a concentration of $1 \mathrm{ng} / \mathrm{ml}$ LPS; net median channel numbers 31 and 14, respectively, using $1000 \mathrm{ng} / \mathrm{ml} \mathrm{LPS}$ ).

\section{Effect of $L B P$ and BPI on LPS-modulated TNF-R expression}

To examine whether LBP and BPI affects LPS-induced down-modulation of TNF-R, monocytes were cultured for $1 \mathrm{~h}$ with different concentrations of LPS in the absence or presence of LBP or BPI under serum-free conditions (Fig. 7). Incubation of cells with LBP or BPI in the absence of LPS did not affect TNF-R expression. A concentration of $1 \mathrm{ng} / \mathrm{ml}$ LPS caused a clear decrease of TNF-R expression. Addition of LBP to this suboptimal concentration of LPS led to a complete down-modulation of expression of both TNF-R. On the other hand, BPI could largely prevent the decrease of TNF-R expression induced by $10 \mathrm{ng} / \mathrm{ml} \mathrm{LPS}$. Thus, as in the case of STNR-R release, the effect of LPS on TNF-R expression was augmented by LBP and abrogated by $\mathrm{BPI}$.

\section{Discussion}

In this study we investigated the effect of LPS on release and expression of TNF-R55 and TNF-R75 by monocytes. It was found that LPS enhanced the release of STNF-R75 
and, to a slight degree, the release of STNF-R55. Similar to the enhancement induced by IL-10 and phorbol esters (5), LPS-induced release was a relatively slow and ongoing process. Although LPS predominantly induced an enhanced release of sTNF-R75, the membrane expression of both types of TNF-R was rapidly down-modulated in response to LPS. Our data are supported by Ding et al. (25), who described rapid internalization of TNF-R expressed on macrophages in response to LPS, leading to loss of membrane-bound TNF-R and to a TNF refractory state (26). The internalization of TNF-R was followed by de novo synthesis of TNF-R, and within $18 \mathrm{~h}$ TNF-R expression was restored as measured in binding experiments using ${ }^{125}$ I-labeled TNF (25). Our studies show that after $24 \mathrm{~h}$ there is enhanced expression of both TNF-R55 and TNFR75 on unactivated cells. On LPS-activated cells, both receptors reappeared strongly enhanced on the membrane after $24 \mathrm{~h}$. The synthesis of membrane-bound TNF-R seemed to be accompanied by release of sTNF-R75, but not of STNF-R55. In a previous study, we described enhanced reexpression of both TNF- $R$ and enhanced release of both sTNF-R upon activation with IL-10 or with phorbol esters (5), suggesting a different activation mechanism as compared with activation with LPS.

Furthermore, using specific mAbs for detection of individual TNF-R expression, it is shown that TNF-R75 expression is more strongly enhanced than TNF-R55 after $24 \mathrm{~h}$. The physiological meaning of this difference in expression pattern of TNF-R55 and TNF-R75 is as yet not clear. Literature dealing with the function of TNF-R55 and TNF-R75 contains conflicting theories, and an illustrative example of this is the discussion about whether TNF-induced cytoxicity $(27,28)$ and proliferation $(29,30)$ are mediated via TNF-R55 or via TNF-R75. The concept proposed by Tartaglia and Goeddel (3) that both receptors signal distinct TNF activities, and that TNF-R75 in addition serves as a catcher of TNF and delivers it somehow to TNF-R55, may largely reconcile the controversies. In addition, it is conceivable that, depending on the cell type, the two TNF-R mediate different biological effects.

A number of LPS-induced activities, such as cytokine release by monocytes $(16,17,23)$, enhanced CD11b/CD18 expression on PMNs (31), and IgM expression by a CD14transfected pre-B cell line (32) are mediated via CD14, a receptor for LPS, and the serum protein LBP, known to enhance the binding of LPS to CD14 (reviewed in Refs. 18 and 19). In this study, we show that CD14 and LBP are also involved in the enhanced release of sTNF-R75 and the modulation of TNF-R expression by monocytes in response to LPS. We previously described that LBP and the neutrophil product BPI, known to block several LPS effects in vitro, e.g., cytokine release by monocytes $(22,23)$, have counteractive effects upon LPS-induced cell activation by competing for binding to LPS (23). Here, we showed that BPI also inhibited LPS-induced STNF-R75 release and down-modulation of TNF-R expression. The inhibitory effect of BPI was most pronounced in the presence of serum. This results from the antagonistic effect of BPI on LBP, which is normally present in serum (19).

In vivo, enhanced plasma levels of sTNF-R have been found in clinical situations in which endotoxin is involved, such as sepsis (endotoxemia, meningococcaemia) (9-12). Furthermore, in human $(12,13)$ as well as in animal experimental models, LPS administration led to enhanced sTNF-R levels in plasma $(11,14)$. In the mouse model (14), it was found that injection of endotoxin resulted in an increase of both STNF-R55 and sTNF-R75 levels within $30 \mathrm{~min}$. Inhibitors of the most likely intermediates, such as TNF, leukemia inhibitory factor, IL-1, and IFN- $\gamma$, did not inhibit the LPS-induced enhancement, suggesting that LPS is directly involved in this process (14). The kinetics suggest that these STNF-R are derived from activated neutrophils, because shedding of TNF-R by neutrophils upon appropriate activation is a rapidly occurring event (4). However, sTNF-R75 levels in plasma increased during $8 \mathrm{~h}$ after LPS administration in the mouse model and were significantly enhanced at least during the following $16 \mathrm{~h}$. STNF-R are rapidly cleared by the kidney (33), which may account for the rapid decrease observed for sTNF-R55. Assuming a similar mechanism in mice and men, it is conccivable that the prolonged presence of sTNF-R75 is caused by the slow and ongoing release of STNF-R75 by monocytes, as we found in our study an enhanced release of sTNF-R75, but little or no release of sTNF-R55 by monocytes upon activation with LPS.

TNF has been shown to play a role in the physiological protection against microorganisms such as Listeria (34). However, TNF is also thought to play an important role in the pathophysiology during endotoxemia and sepsis (35). In the context of a tight regulation of TNF release and responsiveness, a transient TNF refractory state could be of importance, mediated either via intemalization of TNF-R by monocytes or via shedding of TNF-R by neutrophils upon appropriate activation. Thus, in vivo at the site of inflammation, cells may be temporarily desensitized for locally produced TNF by rapid loss of TNF-R. The biological function in vivo of this temporary unresponsiveness to TNF of monocytes as well as neutrophils has still to be proven. The subsequent enhanced levels of STNF-R derived from activated ncutrophils and monocytes in the circulation will provide a mechanism for systemic inactivation of TNF by formation of TNF $-S T N F-R$ complexes followed by enhanced clearance (33). The desensitization for TNF as well as the release of STNF-R induced by LPS is shown in this study to be accelerated by LBP, but inhibited by BPI. Thus, the balance between I.PS-potentiating proteins and LPS inhibitory proteins will be an important factor in the outcome of host defense against a microbial infection.

In summary, we demonstrated that LPS affected TNF-R in at least two ways. It was found that LPS induced a slow release of STNF-R75 by monocytes, and CD14 was shown to play a major role in this process. Furtbermore, LPS 
caused a rapid down-modulation of both TNF-R expressed by monocytes, followed by enhanced re-expression of both TNF-R within $24 \mathrm{~h}$. The acute phase protein LBP was found to enhance both LPS effects, whereas BPI was inhibitory. Thus, sTNF-R release as well as modulation of TNF-R expression induced by LPS are mediated by $\mathrm{CD} 14$ and LBP.

\section{References}

1. Ryffel, B., M. Brockhaus, B. Greiner, M. J. Mihatsch, and F. Gudat. 1991. Tumor necrosis factor receptor distribution in human lymphoid tissue. Immunology 76:446.

2. Brockhaus, M., H. J. Schoenfeld, E. J. Schlaeger, W. Hunziker, W. Lesslaver, and H. Loetscher. 1990. Identification of two types of tumor necrosis factor receptors on human cell lines by monoclonal antibodies. Proc. Nall Acad Sci. USA 87:31271.

3. Tartaglia, L., and D. Goeddel. 1992. Two TNF receptors. Immunol. Today 13:151.

4. Ding. A., and F. Porteu. 1992. Regulation of tumor necrosis factor receptars on phagocytes. Pros. Soc. Exp. Biol. Med. 200:458.

5. Leeuwenberg, J. F. M., T. M. A. A. Jeunhomme, and W. A. Buurman. 1994. Slow release of soluble TNF receplors by monocytes in vitro. J. Immunol. In press.

6. Aderka, D., H. Engelmann, Y. Shemer-Avai, V. Hornik, A. Galil, B. Sarov, and D. Wallach. 1992. Variation in serum levels of the soluble TNF receptors among healthy individuals. Lymphokine $\mathrm{Cy}$ rokine Res. 11:157.

7. Heilig, B., M. Wermann, H. Gallati, M. Brockhaus, B. Berke, O. Egen, A. Pezrutto, and W. Hunstein. 1992. Elevated TNF receptor plasma concentrations in patients with theumatoid arthritis. Clin. Invest. 70:22.

8. Cope, A. P., D. Aderka, M. Doherty, H. Engelmann, D. A. C. Jones, F. M. Brennan, R. N. Maini, D. Wallach, and M. Feldmann. 1992. Increased levels of soluble tumor necrosis factor receptors in the sera and synovial fluid of patients with rheumatic diseases. Arthritis Rheum. 35:1160

9. Froon, A. H. M., M. H. A. Bemelmans, J. W. Greve, C. J. van der Linden, and W. A. Buurman. 1994. Increased plasma levels of soluble tumor necrosis factoir receptors in sepsis syndrome: correlation with plasma creatinine. Cric. Care Med. In press.

10. Girardin, E., P. Roux-Lombard, G. E. Grau, P. Suter, H. Gallati, The J5 Study Group, and J. Dayer. 1992. Imbalance between tumour necrosis factor- $\alpha$ soluble TNF receptor concentrations in severe meningococcaemia. Immunology 76:20.

11. van der Poll, J. Jansen, D. van Leenen, M. von der Möhlen, M. Levi, H. ten Cate, H. Gallati, J. W. ten Cate, and S. J. H. van Deventer. 1993. Release of soluble receptors for tumor necrosis factor in clinical sepsis and experimental endotoxemia. J. Infect. Dis. 168:95.5.

12. Van Zee, K., T. Kohno, E. Fischer, C. S. Rock, L. L Moldawer, and S. F. Lowry. 1992. Tumor necresis factor soluble receptors circulate during experimental and clinical inflammation and can protect against excessive tumor necrosis factor $\alpha$ in vitro and in vivo. Proc. Narl Acad Sci. USA 89:4845.

13. Spinas, G., U. Keller, and M. Brockhaus. 1992. Release of soluble receptors for tumor necrosis factor (TNF) in relation to circulating TNF during experimental endotoxemia. J. Clin. Invest. 90:533.

14. Bemelmans, M. H. A., D. J. Gouma, and W. A. Buurman. 1993. LPS-induced STNF-Receptor release in vivo in a murine model: investigation of the role of TNF, IL-1 and IFN- $\gamma . J$. Immunol 15I: 5554 .

15. Wright, S. D., R. A. Ramos, P. S. Tobias, R. J. Ulevitch, and J. C. Mathison. 1990. CD 14, a receptor for complexes of lipopolysaccharide (LPS) and LPS binding protein. Science 249:1431.

16. Heumann, D., P. Gallay, C. Barras, P. Zaech, R. J. Ulevitch, P. S. Tobias, M. Glauser, and I. D. Baumgartner. 1992. Control of lipo- polysaccharide (LPS) binding, and LPS-induced tumor necrosis factor secretion in human peripheral blood monocytes. I. Immunot. 148 . 3505 .

17. Dentener, M. A., V. Bazil, E. J. U. von Asmuth, M. Ceska, and W. A. Buurman. 1993. Involvement of CD14 in lipopolysaccharide-induced tumor necrosis factor-a, IL- 6 , and IL- 8 release by human monocytes and alveolar mucrophages. J. Immunol 150:2885.

18. Ulevitch, R. J., J. C. Mathison, R. R. Schumann, and P. S. Tobias, 1990. A new model of macrophage stimulation by bacterial lipopolysaccharide. I. Trauma (Suppl) 310:189.

19. Schumann, R. R., S. R. Leong, G. W. Flaggs, P. W. Gray, S D. Wright, J. C. Mathison, P. S. Tobias, and R. J. Ulevitch. 1990. Structure and function of lipopolysaccharide binding protein. Science 2,49: 1429.

20. Wright, S. D., R. A. Ramos, M. Patel, and D. S. Miller. 1992. Septir: a factor in plasma that opsonizes lipopolysaccharide-bearing particles for recognition by CD14 on phagocyles. I. Exp. Med. 176:719.

21. Weiss, J, P. Elsbach, I. Olsson, and H. Odeberg. 1978. Purification and characterization of a potent bactericidal and membrane active protein from the granules of human polymorphonuclear leucocytes. J. Biol. Chem. 253:2064.

22. Heumann, D., P. Gallay, S. Betz-Comadin, C. Barras, J.-D. Baumgartnet, and M. P. Glauser. 1993. Competition between bactericidal permeability-increasing protein and lipopolysaccharide binding to monocytes. J. Infect. Dis. 167:1351.

23. Dentener, M. A., E. J. U. von Asmuth, G. J. M. Francot, M. N. Marra, and W. A. Buurman. 1993. Antagonistic effects of lipopolysaceharide binding protein and bactericidalpermeability-increasing protein on lipopolysaccharide-induced cytokine release by mononuclear phagocytes. J. Immunol. 151:4258

24. Graziano, R. F., and M. W. Fanger. 1987. Human monecyte-mediated cytotoxicity: antibndy to the high affinity Fe receptor for $\lg 6$ mediated cytotoxicity by human monocyces that is enhanced by inIerferon- $y$ and is not blocked by human IgG. J. Immunol. 138:945.

25. Ding, A. H., E. Sanchez, S. Srimal, and C. F. Nathan. 1989. Macrophages rapidly internalize their tumor necrosis factor receptors in response to bacierial lipopolysaceharide. J. Immunol. 264:3924.

26. Ding. A. H., and C. F. Nathan. 1987. Trace levels of bacterial lipopolysaceharide prevent interferon- $\gamma$ or tumor necrosis: factor- $\alpha$ frorn enhaneing mouse peritoneal macrophage respiratory burst capacity. I. Immunol. 139:1971.

27. Tartiglia, T. A., M. Rothe, Y.-F. Hu, and D. V. Goeddel. 1993. Tumor necrosis factor's cytotoxic activity is signaled by the p55 TNF receplor. Cell 73:213.

28. Heller, R. A., K. Song, and N. Fan. 1993. Cytoxicity by mor necrosis factor is mediated by boih $\mathrm{p} 55$ and $\mathrm{p} 70$ receptors. Cell $73: 216$.

29. Gehr, G., R. Gentz, M. Brockhaus, H. Loetscher, and W. Lesslauer. 1992. Both tumor necrosis facor receptor types mediate proliferative signals in human mononuclear cell activation. J. Immunol. 149:911.

30. Tartaglia, I. A. G. V. Goeddel, C. Reynolds, I. S. Figari, R. F. Weber, B. M. Fendly, and M. A. Palladino, 1993. Stimulation of human $\mathrm{T}$-cell proliferation by specific activation of the $75 \cdot \mathrm{kDa}$ lumor necrosis factor receptor. J. Immunol. 151:4637.

31. Wright, S. D., R. A. Ramos, A. Hermanowski-Vosatka, P. Rockwell, and P. A Detmers. 1991. Activation of the adhesive capacity of CR3 on neutrophils by endotoxin: dependence on lipopolysaccharide binding protein and CD14. J. Exp. Med. 173:1281.

32. Lee, J.-D., K. Kato, P. S. Tobias, T. N. Kirkland, and R. J. Ulevitch. 1992. Transfection of CD14 into $70 Z / 3$ cells dramatically enhances the sensitivity to complexes of lipopolysaccharide (LPS) and L.PS binding protein. J. Exp. Med 175:1697.

33. Bemelmans, M. H. A., D. J. Gouma, and W. A. Buurman. 1993. Influence of nephrectomy on tumor necrosis factor clearance in a murine model. J. Immunol. 150:2007.

34. Havell, E. 1989. Evidence that tumor necrosis factor has an important role in antibacterial resistance. $J$. Immund. 143:2894.

35. Beutler, B., and A. Cerami. 1987. The endogenous mediator of endotoxie shock. Clin. Res. 35:192. 


\section{Chapter 6}

Antagonistic Effects of Lipopolysaccharide Binding Protein and Bactericidal/Permeability-Increasing Protein on Lipopolysaccharide-Induced Cytokine Release by Mononuclear Phagocytes 


\title{
Antagonistic Effects of Lipopolysaccharide Binding Protein and Bactericidal/Permeability-Increasing Protein on Lipopolysaccharide-Induced Cytokine Release by Mononuclear Phagocytes
}

\author{
Competition for Binding to Lipopolysaccharide'
}

\author{
Mieke A. Dentener, ${ }^{2{ }^{+}}$Eckhardt J. U. Von Asmuth, ${ }^{*}$ Gaby J. M. Francot,* \\ Marian N. Marra, ${ }^{\neq}$and Wim A. Buurman* \\ "Department of Surgery, University of Limburg, Maastricht, The Netherlands; 'Department of Pulmonary Diseases, \\ University Hospital Maastricht, The Netherlands; and "Incyte Pharmaceuticals Inc., Palo Alto, CA
}

\begin{abstract}
Serum proteins play an important role in LPS-induced cell activation. The LPS binding protein (LBP) enhances cellular responses to LPS, whereas the polymorphonuclear leukocyte product bactericidal/permeabilityincreasing protein $(\mathrm{BPI})$ inhibits LPS-induced cell activation. In this study the influences of LBP and BPI, two proteins with opposite effects, but with considerable sequence homology, on LPS-induced mononuclear phagocytic cell cytokine release was studied. LBP was shown to enhance LPS-induced TNF- $\alpha$, IL- 6 , and IL- 8 release by mononuclear phagocytic cells, whereas BPI inhibited the release of these cytokines. Furthermore, the effects of LBP and BPI on LPS-induced cytokine release by mononuclear phagocytic cells were shown to be counteractive. BPI interfered with the enhancing effect of LBP on the LPS-induced cytokine release. At high LBP to BPI ratios, BPI could no longer inhibit LBP-induced enhancement. In accordance, increasing concentrations of BPI abrogated the LBP effect. Next, it was shown that LBP and BPI compete for binding to LPS by using an assay system that detects binding of free BPI to an anti-BPI mAb. LPS prevented binding of BPI to anti-BPI mAb, whereas preincubation of LPS with LBP prevented the L.PS-induced inhibition. Also, it was observed that both BPI and LBP inhibited LPS activity in the chromogenic. LAL assay. We conclude from this study that LBP and BPI have counteractive effects on LPS-induced mononuclear phagocytic cell cytokine release by competing for binding to LPS. Journal of Immunology, 1993, 151: 4258.
\end{abstract}

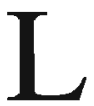

PS is known to activate a number of cell types such as $\mathrm{PMN}^{3}$ mononuclear phagocytes, and endothelisl cells. Serum proteins have been found to play an important role in LPS-mediated cell activation. Among

Received for publication May 13, 1993. Accepted for publication June 30 , 1993.

The costs of publication of this article were defrayed in part by the payment of page charges. This anticle must therefore be hereby marked advertisement in accordance with 18 U.S.C. Section 1734 solely to indicate this fact.

' This study was supported by Grant 900-562-110 fronn NWO.

${ }^{2}$ Address correspondence and reprint requests to $\mathrm{Dr}$. Mieke A Dentener, Department of Surgery, University of timbarg, P.O. Box 616,6200 MD, Mass. tricht, The Netherlands.

Abbreviations used in this paper: PNA, polymorphonuclear leukocytes; BPI, bactericidalpermeability-increasing protein; HS, human serum; LBP, LPS binding protein; MO-SFM, macrophage serurn-free medium. these proteins is LBP, a $60-\mathrm{kDa}$ acute phase reactant, which is also present in normal plasma $(1,2)$. This glycoprotein facilitates binding of LPS to CD14, a newly described receptor for LPS (3). The presence of LBP increases the capacity of LPS 1) to prime PMN (4-6), 2) to induce cytokine release by mononuclear phagocytes $(3,7-9)$, and 3 ) to induce IgM expression by a CD14 transfected pre-B cell line $70 Z / 3$ (10). In addition to LBP, a new group of serum proteins with LPS opsonizing activity for binding to CD14, called 'septin', has been described (11).

Also, LPS-inhibiting proteins have been reported. PMN produce the very potent BPI, which is stored in the azurophilic granule (12), but is also expressed on the cell surface $(13,14)$. This protein was shown to bind to LPS with high affinity $(15-17)$, to induce bacterial killing $(18,19)$, and to 
inhibit effects of LPS in several in vitro settings. BPI inhibits LPS-induced PMN priming, TNF- $\alpha$ production in whole blood, and activation of procoagulant proteases in Limulus amoebocyte lysates $(13,20-22)$. BPI and LBP, two proteins with opposite effects on LPS activation, have considerable sequence homology $(1,2,23-25)$. Furthermore, both bind to the lipid A part of LPS (7, 13, 20, 26, 27).

In this study, we investigated whether LBP and BPI affect, besides the LPS-induced TNF- $\alpha$ release, the LPSinduced IL- 6 and IL-8 release by mononuclear phagocytes. Furthermore, we investigated the functional relationship between LBP and BPI on L.PS-induced cytokine release. Our data indicate that the properties of LBP and BPI are counteractive. These data prompted us to investigate whether these counteractive effects could be explained by competition for binding to LPS.

\section{Materials and Methods}

Reagents

Human rTNF- $\alpha$ was kindly provided by BASF/Knoll Ag (Ludwigshafen, Germany); human rIL-6 by Prof. W. Sebald (Physiologisch-Chemisches Institut der Universität, Würzburg, Germany); human rlL-8 by Dr. I. Lindley (Sandoz Forschungsinstitut, Vienna); and human rlL-1 $\beta$ by Dr. S. Gillis (Immunex, Seattle, WA). LPS (from Escherichia coli, serotype 055:B5), the phorbol ester PMA, and polymyxin B sulfate were purchased from Sigma (St. Louis, MO). M $\varnothing-S F M$ was obtained from GIBCO Europe (Paisley, Scotland). HS, which was obtained from the local blood bank, was pooled, sterilized by a $0.2 \mu \mathrm{m}$ filter, heated to $56^{\circ} \mathrm{C}$ for $30 \mathrm{~min}$, and stored at $4^{\circ} \mathrm{C}$. HS contained $<5 \mathrm{pg} / \mathrm{ml}$ endotoxin, as determined in the chromogenic LAL assay (Kabi Pharmacia, Mölndal, Sweden). Human rBPI was produced by transfected Chinese hamster ovary cells and was purified sequentially by ion exchange column and by size exclusion column. Human rLBP was produced by the transfected human embryonic kidney cell line 293 EBNA provided by Jnvitrogen (San Diego, CA). The conditioned medium contained $\pm 2.5 \mu \mathrm{g} / \mathrm{ml}$ human rLBP. A BPI neutralizing mAb 4E3 was obtained by injecting mice with human rBPI followed by classical procedures. The selection and properties of the mAb will be discussed in detail elsewhere. In short, the antibody was selected on basis of the following properties 1) reactivity with human rBPI, 2) inhibition of the biologic property of. BPI to reduce the LPS-induced cell activation, as measured by mononuclear phagocytic cell TNF- $\alpha$ release, and 3 ) inhibition by LPS of $\mathrm{mAb}$ reactivity to BPI. An antiserum to BPI was obtained by immunizing rabbits with human rBPI. This anti-BPI antiserum did not cross-react with human rLBP as tested in ELISA assay.

\section{Endotoxin determination}

Endotoxin was measured using Chromogenic Limulus Amoebocyte Lysate assay, performing the assay as described by the manufacturer (Kabi Pharmacia). For measurement of endotoxin content in serum, the serum was heated to $75^{\circ} \mathrm{C}$ for $5 \mathrm{~min}$ to inactivate all serum proteins.

\section{Cells}

The monocytic cell line Mono Mac 6 was obtained from DSM (Braunschweig, Germany) (28). Human peripheral blood mononuclear phagocytes, obtained from buffy coats of healthy volunteers, kindly provided by the local blood bank, were isolated as described (29). In short, mononuclear cell suspensions obtained after Lymphoprep (Nycomed, Oslo, Norway) centrifugation were allowed to clump by low speed centrifugation at $4^{\circ} \mathrm{C}$. Cell clumps, consisting of 80 to $95 \%$ of mononuclear phagocytes, were separated from the rest of the cells by sedimentation through ice-cold HS. PMN contamination of the cell suspension was less than $5 \%$.

\section{Induction of cytokine release}

LPS, LBP, and BPI were resuspended in MØ-SFM or in medium consisting of RPMI 1640 (GIBCO) and $10 \% \mathrm{HS}$. These reagents, alone or in combination, were added in 96-well flat bottom tissue culture plates (Costar, Cambridge, MA) reaching an end volume of $150 \mu \mathrm{l} / \mathrm{well}$, and incubated for $30 \mathrm{~min}$ at $37^{\circ} \mathrm{C}$. Mononuclear phagocytic cells or Mono Mac 6 cells were washed five times to remove all serum components, resuspended in the required medium, and subsequently added to the plates $\left(10^{6} \mathrm{cells} / \mathrm{ml}\right.$ mononuclear phagocytes or $4 \times 10^{6}$ cells/ml Mono Mac 6 , $50 \mu \mathrm{l} /$ well). Indicated concentrations of the reagents in the experiments refer to the concentrations at the beginning of the cell incubation, which were $75 \%$ of the preincubation concentrations. After $18 \mathrm{~h}$ incubation at $37^{\circ} \mathrm{C}$, supernatants were barvested and kept at $-20^{\circ} \mathrm{C}$ until use in the cytokincspecific ELISA.

\section{Competitive assay for LPS binding of LBP and BPI}

Competition of LBP and BPI for binding to LPS was assayed with $B P I-s p e c i f i c$ mAb $4 E 3$. This mAb recognizes only free BP] and does not interact with BPI that has formed a complex with LPS. The assay measures the influence of LBP on LPS-induced inhibition of binding of BPI to antiBPI mAb 4E3. The 96-well immunomaxisorp plates (Nunc, Roskilde, Denmark) were coated ovemight at $4^{\circ} \mathrm{C}$. with 4E3. A concentration range of LPS was preincubated 30 min at $37^{\circ} \mathrm{C}$ with different concentrations of LBP. Next, human rBPI $(40 \mathrm{pg} / \mathrm{ml})$ was added and the mixture was further incubated $30 \mathrm{~min}$ at $37^{\circ} \mathrm{C}$. Subsequently, the mixture of reagents was added to the plates and incubated $1 \mathrm{~h}$ 
A

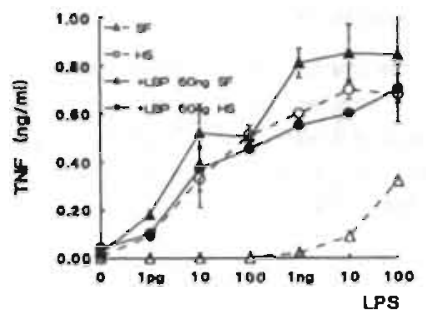

B

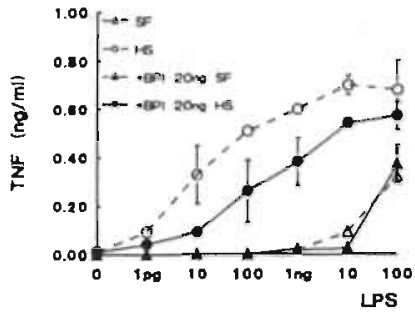

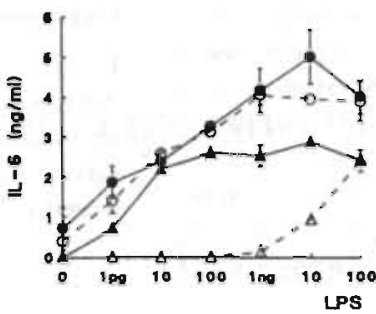

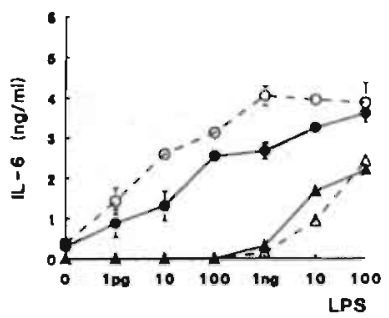

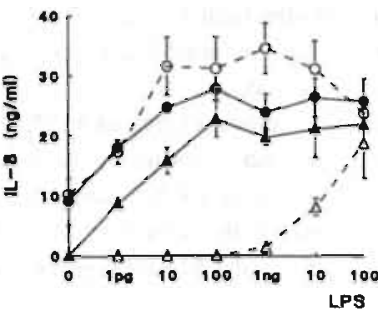

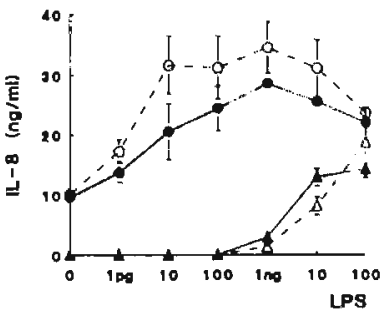

FIGURE 1. Influences of $L B P(A)$ and $B P I(B)$ on $L P S$-induced mononuclear phagocytic cell cytokine release. $A$ concentration range of L.PS was preincubated $30 \mathrm{~min}$ at $37^{\circ} \mathrm{C}$ with no other reagent with $60 \mathrm{ng} / \mathrm{ml} \mathrm{LBP}$ or $20 \mathrm{ng} / \mathrm{ml} \mathrm{BPI}$ under serum-free (SF) conditions or in the presence of $10 \% \mathrm{HS}$. Mononuclear phagocytes were stimulated for $18 \mathrm{~h}$, and TNF- $\alpha$, IL- -6 , and IL- 8 release were determined in specific ELISA. Data are expressed as mean and SD of four measurements. SD bars are omitted if they fall within the symbol.

at room temperature. Washing and dilution of reagents were performed in assay buffer, consisting of $50 \mathrm{mM}$ Tris, $\mathrm{pH}$ $7.4,150 \mathrm{mM} \mathrm{NaCl}, 0.05 \%$ Tween 20 , and $1 \mu \mathrm{g} / \mathrm{ml}$ polymyxin B sulfate. Assay buffer contained $\pm 10 \mathrm{ng} / \mathrm{ml}$ endotoxin. Plates were developed with polyclonal anti-BPI antiserum and peroxidase-conjugated goat anti-rabbit IgG (Jackson ImmunoResearch, Westgrove, PA). TMB (KPL, Gaithersburg, MD) was used as a substrate for peroxidase. Photospectrometry was performed at $450 \mathrm{~nm}$.

TNF- $\alpha$, IL-6, and IL-8 ELISA

Cytokine concentrations in the culture supernatants were determined using sandwich ELISA for TNF- $\alpha$ (30). IL- 6 (31), and IL-8 (32). In short, 96-well immunomaxisorp plates (Nunc) were coated overnight at $4^{\circ} \mathrm{C}$ with cytokinespecific murine mAb. Human ITNF- $\alpha$, human rIL- 6 , and human rIL-8 were used for standard titration curves. Test samples were added and incubated for 2 to $3 \mathrm{~h}$ at room temperature. Polyclonal rabbit anti-human TNF- $\alpha$, antihuman IL- 6 , and anti-human IL- 8 antiserum were followed by peroxidase-conjugated goat anti-rabbit IgG (Jackson ImmunoResearch). TMB (KPL) was used as a substrate for peroxidase. Photospectrometry was performed at $450 \mathrm{~nm}$. The lower detection level of ELISA was $20 \mathrm{pg} / \mathrm{ml}$ for TNF- $\alpha, 10 \mathrm{pg} / \mathrm{ml}$ for IL- 6 , and $10 \mathrm{pg} / \mathrm{ml}$ for IL-8.

\section{Results}

Influences of LBP and BPI on LPS-induced mononuclear phagocytic cell cytokine release

The influences of LBP and BPI on LPS-induced TNF- $\alpha$, IL-6, and IL- 8 release by mononuclear phagocytes were studied. To this end a concentration range of LPS was preincubated for $30 \mathrm{~min}$ at $37^{\circ} \mathrm{C}$ with $60 \mathrm{ng} / \mathrm{ml} \mathrm{LBP}$ or 20 $\mathrm{ng} / \mathrm{ml} \mathrm{BPI}$ and added to mononuclear phagocytic cells either under serum-free conditions or in the presence of $10 \%$ HS. Cytokine release by mononuclear phagocytic cells was shown to be strongly dependent on presence of serum (Fig. 1). The enhancing effect of serum was less pronounced at higher LPS concentrations $(10-100 \mathrm{ng} / \mathrm{ml})$. Addition of LBP to different concentrations of LPS, in the absence of serum, strongly enhanced mononuclear phagocytic cell TNF- $\alpha, I L-6$, and IL- 8 release, resulting in cytokine release comparable with that observed in the presence of $10 \% \mathrm{HS}$ (Fig. 1A). In the presence of serum, LBP did not influence LPS-induced cytokine release.

BPI inhibited mononuclear phagocytic cell TNF- $\alpha$, IL-6, and IL- 8 release partially in the L.PS range from $1 \mathrm{pg}$ to $10-100 \mathrm{ng} / \mathrm{ml}$, depending on the cytokine studied, in the presence of $10 \%$ HS (Fig. 1B). Using higher BPI concentrations, up to $3 \mu \mathrm{g} / \mathrm{ml}$, the inhibitory effect of BPI was enhanced, although a complete inhibition was never observed (data not shown). Under serum-free conditions no 


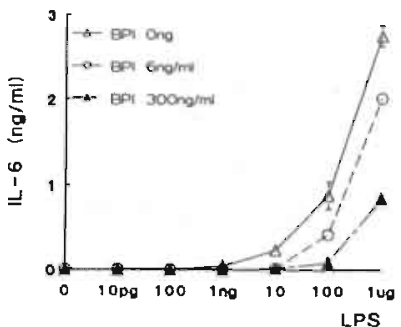

FIGURE 2. Influence of BPI on LPS-induced IL-6 release by Mono Mac 6 . A concentration range of LPS was preincubated $30 \mathrm{~min}$ at $37^{\circ} \mathrm{C}$ with different concentrations of $\mathrm{BPI}$ under serum-free conditions. Cells were stimulated for $18 \mathrm{~h}$ and IL-6 release was determined in an ELISA. Data are expressed as mean and SD of four measurements. SD bars are omitted if they fall within the symbol.

inhibitory effect of BPl was observed. BPI did not reduce mononuclear phagocytic cell TNF- $\alpha$-release in response to IL-1 $\beta$ and PMA in the presence of serum (data not shown), indicating that BPI selectively reduced LPS-induced mononuclear phagocytic cell responses. Neither LBP nor BPI induced detectable amounts of mononuclear phagocytes cytokine release in the absence of LPS (Fig. 1).

A minor contamination of mononuclear phagocytic cell preparation with PMN could lead to PMN-produced BPI, which may obscure the effect of exogenous BPI in the described serum-free experiments. Therefore, the effect of BPI under serum-free conditions on the LPS-induced cytokine release by the monocytic cell line Mono Mac 6 was investigated. This cell line responds to relative high LPS concentrations by relcasing cytokines (33). In these experiments, BPI substantially reduced LPS-induced IL -6 relcase (Fig. 2). These data showed that BPI can, also in the absence of serum, inhibit LPS-mediated cell activation.

\section{Counteractive effects of $L B P$ and BPI on LPS activity}

The observation that BPI and LBP have opposite effects on LPS-induced cytokine release by mononuclear phagocytic cells and the reports that LBP and BPI, proteins with considerable sequence homology (25), both bind to the lipid $A$ part of LPS $(26,27)$ prompted us to investigate whether the effects of BPI and LBP are counteractive. The influence of BPI on LBP-enhanced mononuclear phagocytic cell cytokine release by LPS was studied by preincubation $(30 \mathrm{~min}$ at $\left.37^{\circ} \mathrm{C}\right)$ a concentration range of LBP and LPS $(1 \mathrm{ng} / \mathrm{ml})$ in the presence or absence of BPI $(3 \mathrm{ng} / \mathrm{ml})$. Figure $3 A$ shows that LBP, in a concentration-dependent manner, enhanced LPS-induced TNF- $\alpha$, IL-6, and IL- 8 release. The presence of BPI reduced the enhancement of the response induced by LBP. BPI could no longer reduced LBP-induced enhancement at a LBP concentration of $600 \mathrm{ng} / \mathrm{ml}$.

$\mathrm{Next}$, the influence of increasing concentrations of BPI on the enhancement by LBP $(60 \mathrm{ng} / \mathrm{ml})$ of the cellular re- sponses to LPS $(5 \mathrm{ng} / \mathrm{ml})$ was studied. In accordance with the above mentioned data, BPI, even at higher concentrations, did not inhibit L.PS-induced cytokine release by mononuclear phagocytic cells (Fig. 3B). However, BPI reduced the LBP-enhanced cytokine release in a concentration-dependent manner. At a BPI concentration of $3 \mu \mathrm{g} / \mathrm{ml}$, there was no difference between L.PSinduced cytokine release in the absence or presence of L.BP. These results show that LBP and BPI have counteractive properties on LPS-induced cell activation.

\section{LBP and BPI complete for binding to LPS}

Next, it was investigated whether the described counteractive effects of LBP and BPI on LPS-induced cell activation were caused by competition for binding to LPS. To this end an assay was developed; competition of LBP and BPI for LPS binding was assayed by means of BPI-specific $\mathrm{mAb} 4 \mathrm{E} 3$. This mAb, coated on the bottom of a 96-well plate, can only recognize free BPI and does not interact with BPI that has formed a complex with LPS. Binding of BPI to $4 \mathrm{E} 3$ was detected with polyclonal anti-BPI antiserum and peroxidase-conjugated goat anti-rabbit IgG. The influence of LPS on BPI binding to the anti-BPI mAb $4 E 3$ was measured in the presence $c r$ absence of LBP. The data showed that LPS prevented binding of BPI to $4 \mathrm{E} 3$ (Fig. 4). Addition of LBP abrogated the LPS-mediated inhibition of BPI binding. This effect appeared to be both LPS and LBP concentration dependent. Even at LPS concentrations as low as $10 \mathrm{ng} / \mathrm{ml}$, the LPS content of the assay buffer, addition of LBP induced a substantial enhancement of BPI binding to anti-BPI $m A b$. These data indicate that L.BP and BPI compete for binding to LPS, probably by binding to or nearby the same epitope.

Influences of BPI and LBP on LPS activity in the chromogenic LAL assay

Because LBP and BPI appeared to react with related or identical epitopes on L.PS, it was of interest to determine whether LBP like BPI $(20,21)$ interfered with the activity of LPS in the LAL assay. Therefore, LPS $(100 \mathrm{pg} / \mathrm{ml})$ was incubated for $30 \mathrm{~min}$ at $37^{\circ} \mathrm{C}$ with different concentrations of LBP or BPI. Both proteins, LBP at $1.5 \mu \mathrm{g} / \mathrm{ml}$ and BPI at $3 \mathrm{ng} / \mathrm{ml}$, completely prevented the activation of procoagulant proteases in the Limulus-amoebocyte lysates by LPS (Fig. 5).

\section{Discussion}

In this study we showed that LBP functions as a general enhancer of LPS-induced cell activation. Besides LPSinduced release of TNF- $\alpha$ by mononuclear phagocytes (3, 7-9), release of IL-6 and IL-8 was enhanced. These data are 
A

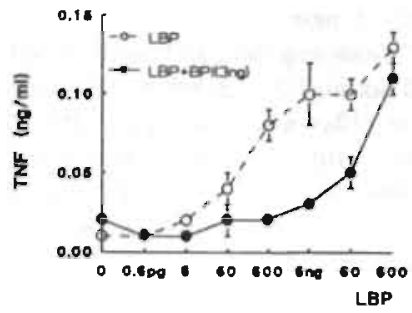

B

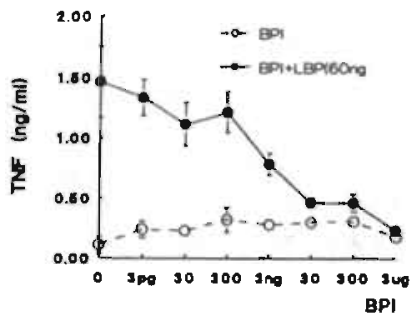

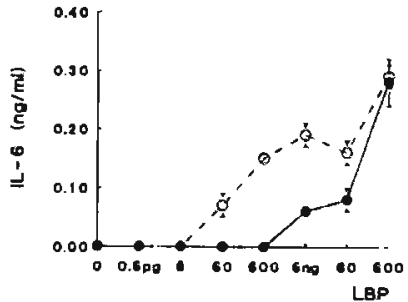

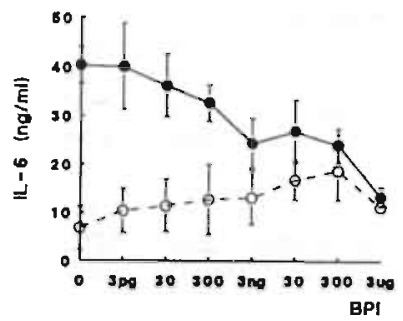

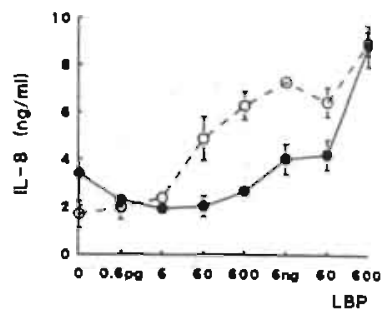

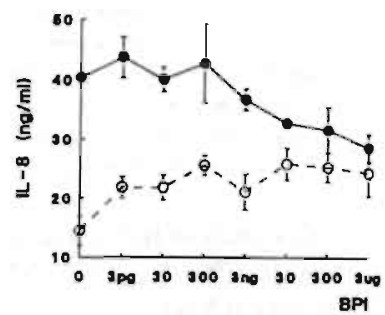

FIGURE 3. Antagonistic effects of LBP and BPI on LPS-induced mononuclear phagocytic cell cytokine release. Different concentrations of LBP were preincubated $30 \mathrm{~min}$ at $37^{\circ} \mathrm{C}$ with $1 \mathrm{ng} / \mathrm{ml}$ LPS in the presence or absence of $3 \mathrm{ng} / \mathrm{ml} \mathrm{BP!}(A)$ or different concentrations of BPI were preincubated $30 \mathrm{~min}$ at $37^{\circ} \mathrm{C}$ with $5 \mathrm{ng} / \mathrm{ml} \mathrm{LPS}$ in the presence or absence of $60 \mathrm{ng} / \mathrm{ml} \mathrm{LBP}$ (B) under serum-free conditions. Cells were stimulated for $18 \mathrm{~h}$ and TNF- $\alpha, \mathrm{IL}-6$, and IL-8 release were determined in specific ELISA. Data are expressed as mean and SD of four measurements. SD bars are not shown if they fall within the symbol.

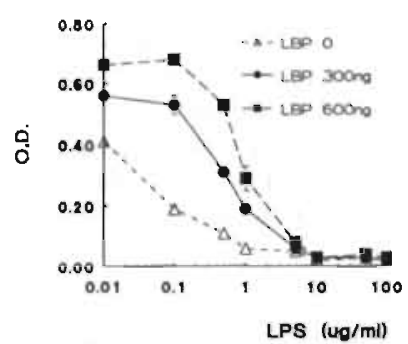

FIGURE 4. Effects of LPS and LBP on binding of BPI to anti-BPI mAb 4E3. A concentration range of LPS was incubated $30 \mathrm{~min}$ at $37^{\circ} \mathrm{C}$ with LBP (300 or $\left.600 \mathrm{ng} / \mathrm{ml}\right)$. After adding $\mathrm{BPI}(40 \mathrm{pg} / \mathrm{ml})$ the mixture was further incubated 30 min at $37^{\circ} \mathrm{C}$ and subsequently added to plates coated with anti-BPI mAb 4E3. Plates were developed with polyclonal anti-BPI antiserum and peroxidase-conjugated goat anti-rabbit $\lg C$. Data are expressed as OD and are mean and SD of three values. SD bars are not shown if they fall within the symbol.

further supported by data of others showing that LBP enhances LPS-induced priming of PMN (4-6) and IgM expression by CD14-transfected $702 / 3$ cells (10). The presence of HS also enhanced LPS-induced cytokine release strongly and addition of L.BP under these conditions did not further enhance L.PS-induced cytokine release. These data suggest that in HS, LBP and septin (11), which both opsonize LPS for binding to CD14, are available in adequate amounts to opsonize all exogenous LPS. In serum a balance will exist between several LPS activity regulating proteins, among which soluble CD14 described to inhibit LPS activation $(34,35)$. The presence of these proteins could be the explanation for the observation that cytokine release in the presence of serum-free medium supplemented with LBP is not exactly equal to cytokine release in the presence of $10 \%$ HS.

BPI was shown to partially block, not only the LPSinduced release of TNF- $\alpha(13,21,22)$, but also the release of IL- 6 and IL- 8 by mononuclear phagocytic cells in the presence of serum. In contrast, under serum-free conditions no effect of BPI was detected. The relatively high concentrations of LPS that are required to induce cytokine release under serum-free conditions might trigger a mechanism of LPS-induced activation of mononuclear phagocytes that is independent of CD14, LBP, and BPI (31). Another explanation for the lack of effect of BPI under serum-free conditions could be that a minor contamination with PMN of the mononuclear phagocytic cell suspension might be responsible for endogenously produced BPI, which could obscure the effect of exogenous BPI. This last hypothesis was confirmed by the observation that the LPS-induced IL-6 release, under serum-free conditions, of the monocytic cell line Mono Mac 6 was significantly inhibited by BPI. It is therefore concluded that BPI can inhibit the LPS-induced cytokine release by mononuclear phagocytes in the presence and absence of serum. 
FIGURE 5. Influences of LBP and BPI on the activity of L.PS in the chromogenic LAL assay. LPS $(100 \mathrm{pg} / \mathrm{ml})$ was preincubated for $30 \mathrm{~min}$ at $37^{\circ} \mathrm{C}$ with different concentrations of LBP (A) or BPI (B). LPS activity was then determined in the LAL assay. The effects of LBP and BPI are expressed as percentage of recovery of LPS activity in the LAL assay. One representative experiment out of a series of three is shown.
A

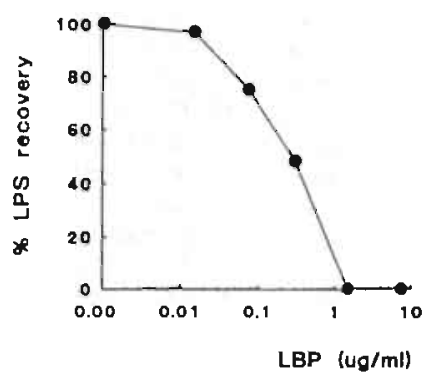

B

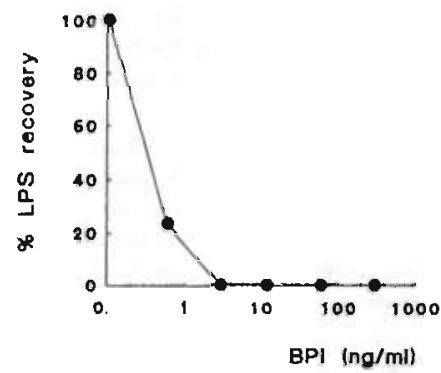

Furthermore, we showed that the effects of LBP and BPI on LPS-induced cytokine release by mononuclear phagocytic cells are counteractive. BPI, concentration dependent, interfered with the enhancing effect of LBP on the LPSinduced cytokine release. At high LBP to BPI ratios, BPI could no longer block the LBP-induced enhancement. In accordance, it was shown that increasing concentrations of BPI abrogated the LBP effect.

The antagonistic effects of LBP and BPI can explain the above discussed observation that BPI, in presence of serum, only partially inhibited the LPS-induced cytokine release. The LBP present in serum has an antagonistic influence on the exogenously added BPI. Furthermore, this phenomenon could explain the observations of Aida et al. (36) that PMN are not able to inactivate LPS in the presence of plasma. In line with the suggestion of the authors, we hypothesize that LBP protects LPS against inactivation by BPI, produced by activated $P M N$.

Becausc both LBP and BPI are known to bind to the lipid A part of LPS $(7,13,20,26,27)$, we investigated whether the antagonistic effect was based on a competitive binding of LBP and BPI to LPS. Using an assay system that consisted of a detection system for free BPI, we are the first to show that BPI and LBP compete for binding to LPS. Moreover, the fact that both BPI $(20,21)$ and LBP inhibit LPS activity in the LAL assay provide further evidence for the theory that these two proteins bind to the same or near the same region on the LPS molecule. We therefore conclude that the observed antagonistic effects of LBP and BPI on LPS-induced cytokine release by mononuclear phagocytic cells can be explained by competition of LBP and BPI for binding to LPS.

Responses of cells to relatively low concentrations of LPS is mediated via the glycosyl-phosphatidylinositolanchored membrane protein CD14, which is strongly expressed on mononuclear phagocytes (37) and weakly on PMN (4). Interaction of LPS with CD14 is facilitated by LBP and septin. Here we showed that BPI may interfere in this signal transduction pathway by competing with LBP for binding to LPS and thus interfering with the LPS-LBP complex interaction with CD14. Both LBP and BPI were shown to be involved not only in LPS-induced TNF- $\alpha$ release $(3,7-9,13,21,22)$, but also in LPS-induced IL-6 and IL-8 release, as was also recently described for CD14 (31). The fact that CD14 mediates LPS effects primarily at low LPS concentrations explains the observation that the effects of LBP and BPI on LPS-induced cytokine release were absent at high LPS concentrations.

Because of the observation that LBP and BPI have antagonistic effects on L.PS-induced cell activation, we expect that the balance between these two proteins determines L.PS activity under physiologic conditions. The role of septin in this process needs to be elucidated. The nature of these proteins influencing LPS activity is quite different. BPI is rapidly produced by $\mathrm{PMN}$ in response to LPS and other stimuli, although only a small part is reported to be released $(12,13)$. LBP on the other hand is an acute phase reactant, which is continuously present in plasma, that increases with slower kinetics (2). Septin is alsi reported to be constitutively present in plasma (11).

Summarizing, in this study we investigated the functional relationship between $L B P$ and BPI, two proteins involved in the response to gram-negative bacteria with considerable sequence homology but with opposite effects. LBP and BPI were shown to have antagonistic effects on the LPS-induced TNF- $\alpha$, IL- 6 , and IL- 8 release by mononuclear phagocytic cells by competition for binding to L.PS.

\section{References}

1. Tobias, P. S., K. Soldau, and R. I. Vlevirch. 1986. Isolation of a lipopolysaccharide-tinding acute phase reactant from rabbil serum. J. Exp. Med. 164:777.

2. Schumann, R. R., S. R. Leong, G. W. Flaggs, P. W. Gray, S. D. Wright, J. C. Mathison, P. S. Tobias, and R. J. Ulevitch. 1990. Structure and function of lipopolysaccharide binding protein. Science 249:1429.

3. Wright, S. D., R. A. Ramos, P. S. Tobias, R. J. Ulevitch, and J. C. Mathison. 1990. CD14, a receptor for complexes of 
lipopolysaccharide (LPS) and L.PS binding protein. Science 2\$9:1431.

4. Wright, S. D., R. A. Ramos, A. Hermanowski-Vosatka, P. Rockwell, and P. A. Detmers. 1991. Activation of the adhesive capacity of CR3 on neutrophils by endotoxin: dependence on lipopolysaccharide binding protein and CD14. J. Exp. Med. 173:1281.

5. Vosbeck, K., P. Tohias, H. Mueller, R. A. Allen, K.-E. Arfors, R. J. Ulevitch, and L. A. Skiar. 1990. Priming of polymorphonuclear granulocytes by lipopolysaccharide and its complexes with lipopolysaccharide binding protein and high density lipoprotein. J. Leukocyre Biol. 47:97.

6. Worthen, G. S., N. Avdi, S. Vukajlovich, and P. S. Tobias. 1992. Neutrophil adherence induced by lipopolysaccharide in vitro; role of plasrna component interaction with lipopolysaccharide. J. Clin. Invest. 90:2526.

7. Mathison, J. C., P. S. Tobias, E. Wolfson, and R. J. Ulevitch. 1992. Plasma lipopolysaccharide (LPS)-binding protein, a key component in macrophage recognition of gram-negative LPS. J. Immunol. 149:200.

8. Heumann, D., P. Gallay, C. Barras, P. Zaech, R. J. Ulevitch, P. S. Tobias, M. Glauser, and J. D. Baumgartner. 1992. Control of lipopolysaccharide (LPS) binding and LPS-induced tumor necrosis factor secretion in human peripheral blood monocytes. J. Immunol. 148:3505.

9. Martin, T. R., J. C. Mathison, P. S. Tobias, D. J. Leturcq, A. M. Moriarty, R. J. Maunder, and R. J. Ulevitch. 1992. Lipopolysaccharide binding protein enhances the responsiveness of alveolar macrophages to bacterial lipopolysaccharide. $J$. Clin. Invest. 90:2209.

10. Lee, J.-D., K. Kato, P. S. Tobias, T. N. Kirkland, and R. J. Ulevitch. 1992. Transfection of CD14 into $70 Z / 3$ cells dramatically enhances the sensitivity to complexes of lipopolysaccharide (LPS) and L.PS binding protein. J. Exp. Med. 175:1697.

11. Wright, S. D., R. A. Ramos, M. Patel, and D. S. Miller. 1992. Septin: a factor in plasma that opsonizes lipopolysaccharidebearing particles for recognition by CD14 on phagocytes. J. Exp. Med. 176,719 .

12. Weiss, J., and 1. Olsson. 1987. Cellular and subcellular localization of the bactericidal/permeability-incressing protein of neutrophils. Blood 69:652.

13. Marra, M. N., C. G. Wilde, M. S. Collins, J. L. Snable, M. B. Thomton, and R. W. Scott. 1992. The role of bactericidal/ permeability-increasing protein as a natural inhibitor of bacterial endotoxin. J. Immunol. 148:532.

14. Weersink, A. J. L., K. P. M. van Kessel, M. E. van den Tol, J. A. G. van Strijp, R. Torensma, J. Verhoef, P. Elsbach, and J. Weiss. 1993. Human granulocytes express a $55-\mathrm{kD}$ a lipopolysaccharide-binding protein on the cell surface that is identical to the bactericidal/permeability-increasing protein. J. Immunot. 150:253.

15. Weiss, J., S. Beckerdite-Quagliata, and P. Eisbach. 1980. Resistance of gram-negative bacteria to purified bactericidal leucocyle proteins. J. Clin. Invesi. 65:619.

16. Weiss, J., K. Muello, M. Victor, and P. Elsbach. 1984. The role of lipopolysaccharides in the action of the bactericidal/ permeability-increasing neutrophil protein on the bacterial envelope. J. Immund. 132:3109.

17. Mannion, B. A., E. S. Kalatzis, J. Weiss, and P. Elsbach, 1989 Preferential binding of the neutrophil cytoplasmic granule- derived bactericidal/permeability increasing protein to target bacteria. J. Immunol. 142:2807.

18. Weiss, J., P. Elsbach, I. Olsson, and H. Odeberg. 1978. Purification and characterization of a potent bactericidal and membrane active protein from the granules of human polymorphonuclear leucocytes. J. Biol Chem. 253:2664.

19. Elsbach, P., J. Weiss, R. C. Franson, S. Beckerdite-Quagliata, A. Schneider, and L. Harris. 1979. Separation and purification of a potent bactericidal/permeability-increasing protein and a closely associated phospholipase $\mathrm{A}_{2}$ from rabbit polymorphonuclear leucocytes; observations on their relationship. J. Biol. Chem. 254:11000.

20. Marra, M. N., C. G. Wilde, J. E. Griffith, J. L. Snable, and R. W. Scott. 1990. Bactericidal/permeability-increasing protein has endotoxin-neutralizing activity. J. Immunol. 144:662.

21. Ooi, C. E., J. Weiss, M. E. Doerfler, and P. Elsbach. 1991. Endotoxin-neutralizing properties of the $25 \mathrm{kD} \mathrm{N}$-terminal fragment and a newly isolated $30 \mathrm{kD}$ C-terminal fragment of the $55-60 \mathrm{kD}$ bactericidal/permeability-increasing protein of human neutrophils. J. Exp. Med. 174:649.

22. Weiss, J., P. Elsbach, C. Shu, J. Castillo, L. Grinna, A Horwitz, and G. Theofan. 1992. Human bactericidal permeability-increasing protein and a recombinant $\mathrm{NH}_{2}-$ terminal fragment cause killing of serum-resistant gramnegative bacteria in whole blood and inhibit tumor necrosis factor release induced by the bacteria.J. Clin. Invest. 90:1122.

23. Ooi, C. E., J. Weiss, P. Eisbach, B. Frangione, and B. Mannion. 1987. A 25-kDa NH 2 terminal fragment carries all the antibacterial activities of the human neutrophil 60-kDa bactericidal/permeability-increasing protein. J. Biol. Chem. 262:14891.

24. Gray, P. W., G. Flaggs, S. R. Leong, R. J. Gumina, J. Weiss, C. E. Ooi, and P. Elsbach. 1989. Cloning of the cDNA of a human neutrophil bactericidal protein, structural and functional correlations. J. Biol. Chem. 264:9505.

25. Tobias, P. S., J. C. Mathison, and R. J. Ulevitch. 1988. A family of lipopolysaccharide binding proteins involved in responses to gram-negative sepsis. J. Biol. Chem. 263:13479.

26. Tobias, P. S., K. Soldau, and R. J. Ulevitch. 1989. Identification of a lipid A binding site in the acute phase reactant lipopolysaccharide binding protein. J. Biol. Chem. 264:10867.

27. Gazzano-Santoro, H., J. B. Parent, L. Grinna, A. Horwitz, T. Parsons, G. Theofan, P. Elsbach, J. Weiss, and P. J. Conlon. 1992. High-affinity binding of the bactericidal/permeabilityincreasing protein and a recombinant amino-terminal fragment to the lipid A region of lipopolysaccharide. Infect. Immun. 60:4754.

28. Ziegler-Heitbrock, H. W. L., E. Thiel, A. Fütterer, V. Herzog, A. Wirtz, and G. Riethmüller. 1988. Establishment of a human cell line (Mono Mac 6) with characteristics of mature monocytes. Int. J. Cancer 41:456.

29. Graziano, R. F, and M. W. Fanger. 1987. FcyRI and FcyRII on monocytes and granulocytes are cytotoxic trigger molecules for tumor cells. J. Immunol. 139:3536.

30. Engelberts, I., A. Möller, G. J. M. Schoen, C. J. Van der Linden, and W. A. Buurman. 1991. Evaluation of measurement of human TNF in plasma by ELISA. Lymphokine Cyrokine Res. 10:69.

31. Dentener, M. A., V. Bažil, E. J. U. von Asmuth, M. Ceska, and W. A. Buurman. 1993. Involvement of CD14 in lipopolysaccharide-induced tumor necrosis factor- $\alpha$, IL-6 
and IL-8 release by human monocytes and alveolar macrophages. I. Immunol. 150:2885.

32. Ceska. M.. F. Effenberger, P. Peichi, and E. Pursch. 1989. Purification and characterization of monoclonal and polyclonal antibodies to neutrophil activating peptide (NAP-1): the development of a sensitive ELISA for the delermination of NAP-1 and anti-NAP-1 antibodies. Cyrokine 1:130 (Abstr).

33. Rafferty, B., J. A. Mower, Y. S. Taktak, and S. Poole. 1991. Measurement of cytokine production by the monocytic cell line Mono Mac 6 using novel immunoradiometric assays for interleukin-1B and interleukin-6. J. Immunol. Methods 144:69.

34. Bažil, V., V. Hořejší, M. Baudyš, H. Krištofová, J. L.
Strominger, W. Kostka, and I. Hilgert. 1986. Biochemical characterization of a soluble form of the $53-\mathrm{kDa}$ monocyte surface antigen. Eur. J. Immunol. 16:1583.

35. Schüt, C., T. Schilling, U. Grunwald, W. Schönfeld, and C. Krüger. 1992. Endotoxin-neutralizing capacity of soluble CD14. Res. Immunol. 143:71.

36. Aida, Y, and M. J. Pabst. 1990. Priming of neutrophils by lipopolysaccharide for enhanced release of superoxide, requirement for plasma but not for tumor necrosis factor- $\alpha$. J. Immunol 145:3017.

37. Knapp, W. 1989. Myeloid section report. In Leucocyte Typing V. W. Knapp, B. Dörken, W. R. Gilks, E. P. Rieber, R. E. Schmidt, H. Stein, and A. E. G. Kr. Von dem Borne, eds. Oxford University Press, Oxford, UK, p. 747. 
$-104-$ 


\section{Chapter 7}

Characterization of Two Monoclonal Antibodies Directed against Bactericidal/Permeability-Increasing Protein

Reprinted with permission 


\title{
Characterization of Two Monoclonal Antibodies Directed against Bactericidal/ Permeability-Increasing Protein
}

\author{
Mieke A. Dentener, Frederieke T. Smit, \\ Gaby J. M. Francot, and Wim A. Buurman
}

Department of Sargery. University of Limburg. Maastrichi, and Depariment of Pulmonology. University Hospital Moastrich. Netherlands

\begin{abstract}
In this study the production and characterization of two monoclonal antibodies (MAbs), 4E3 and SD7, against the bactericidal/permeability-increasing protein (BPI) were described. Using ELISAs, both 4E3 and 5D7 were shown to detect recombinant (r) BPI. Furthermore, natural BPI present in polymorphonuclear leukocytes (PMNL) was detected by both $4 E 3$ and 5D7. The use of both MAbs in flow cytometry revealed that PMNL expressed low levels of cell-surface BPI. Lipopolysaccharide (LPS) was shown to block the interaction between anti-BPI MAb and rBPI. In addition, the MAbs blocked biologic activity of rBPI. The inhibition by BPI of LPS activation of the limulus amebocyte lysate assay and of LPS-induced tumor necrosis factor- $\alpha$ release by monocytes was prevented by $4 \mathrm{E} 3$ and $5 \mathrm{D} 7$. Both MAbs are specifically directed against $\mathrm{BPI}$ and can inhibit BPI bioactivity.
\end{abstract}

Infection with gram-negative bacteria elicits a variety of pathophysiologic effects. Lipopolysaccharide (LPS), a component in the wall of gram-negative bacteria. is responsible for most of these effects. LPS can induce broad reactions like activation of blood coagulation and of complement. Furthermore. L.PS activates cells (e.g. monocytes) to release inflammatory mediators [1].

Polymorphonuclear leukocytes (PMNL) are part of the first line of defense against invading microorganisms [2]. Among the many cytotoxic proteins present in the granules is the bactericidal/permeability-increasing protein (BPI), a potent bactericidal protein of 55-60 kDa [3. 4]. This protein is found in the azurophilic granules $[5,6]$ but has also been found on the cell membrane of PMNL $[7,8]$. Because of high affinity for LPS, BPI binds specifically to gram-negative bacteria [9-11]. causing growth arrest and increased permeability of the bacterial cell wall and then bacterial death [12].

BPI also blocks LPS activity. such as the induction of cytokine and nitric oxide release by monocytes and priming of PMNL [7, 13-18]. In addition. BPI has been shown to be protective against experimental endotoxemia [18-22]. We have recently shown that BPI antagonizes LPS binding protein (LBP) effects during LPS-induced monocyte cytokine release, which is caused by competition of these proteins for binding to LPS [15.23]. We report the production and char-

Received II March 1994: revised 7 July 1994.

The first 2 authors contributed equally to this work

Volunteer blood donors gave informed consent

Grant support: Netherlands Organization for Seientific Research $(900$ $562-110)$.

Reprints or correspondence: Dr. Mieke A. Dentener, Dept. of Surgery. University of Limburg. P.O. Box 616.6200 MD Maastricht, Netheriands.

The Journal of Infectious Dismases 1994;170:1483-9

- 1994 by The University of Chicago. All nights reserved.

$0022-1899 / 94 / 7006-001750100$ acterization of two monoclonal antibodies (MAbs) directed against $\mathrm{BPI}$.

\section{Material and Methods}

Reagents. LPS (from Escherichia coli serotype O55:B5) and bovine serum albumin (BSA) were purchased from Sigma (St. Louis). Bovine calf serum (BCS: HyClone, Logan, UT) was heated at $56^{\circ} \mathrm{C}$ for $30 \mathrm{~min}$ before storage at $4^{\circ} \mathrm{C}$. BCS contained $<5 \mathrm{pg} / \mathrm{mL}$. endotoxin. Human full-length recombinant (r) BPI. provided by M. Marra (Incyte Pharmaceuticals, Palo Alto. CA). was produced by transfected Chinese hamster ovary cells. Purification occurred sequentially by ion-exchange and size-exclusion chromatography. BPI was biotinylated as described [24], using biotin-X-NHS (Calbiochem. La Jolla. CA). Human rLBP. produced by transfected human embryonic kidney cells. was prom vided by $M$. Marra.

Production and selection of MAbs. BALB/c mice (from the central animal facilities of the University of Limburg) were immunized using standard procedures. In short, mice received sequentially intraperitoneal injections of $5 \mu \mathrm{g}$ of human $\mathrm{rBPI}$ in Freund's complete adjuvant (Difco. Detroit), in incomplete adjuvant (Difco), and in PBS. At 30 days later, mice received a booster injection ( $5 \mu \mathrm{g}$ of rBPI in PBS) in the spleen. Spleen cells were fused with SP2/0 mouse myeloma cells in a $1: 8$ ratio. Supernatants of wells containing proliferating cells were screened for the presence of anti-BPI antibody using an ELISA. For this purpose. 96-well immunomaxisorp plates (Nunc. Roskilde. Denmark) were coated overnight with goat anti-mouse IgG-Fc (Nordic. Tilburg. Netherlands). Incubation of supernatant was followed by addition of biotinylated rBPI and peroxidase-conjugated streptavidin (Dakopatts. Glostrup. Denmark). TMB (3,3',5.5'-tetramethylbenzidine: Kirkegaard \& Perry Laboratories. Gaithersburg. MD) was used as a substrate for peroxidase. Photospectrometry was done at $450 \mathrm{~nm}$ using a micro-ELISA autoreader.

Hybridomas producing anti-BPI antibody were cloned twice 
by sequential limiting dilution. MAb isotype was determined by ELISA, using rabbit anti-mouse IgG subclass antibodies (BioRad Laboratories. Hercules, CA). Anti-BPI MAbs were purified from culture supernatant by affinity chromatography on a Protein $G$ Sepharose 4 Fast Flow gel (Pharmacia Biotechnology. Uppsala. Sweden) and subsequently biotinylated. Polyclonal antiserum to BPI and to LBP was obtained by immunizing rabbits with rBPI or rLBP. respectively. using standard procedures.

Interaction of ani-BPI MAbs with $r B P I$ and influence of LPS. Two ELISA systems were used to investigate anti-BPI $\mathrm{MAb}$-BPI interaction. In the first, wells of 96-well immunomaxisorp plates were coated overnight at $4^{\circ} \mathrm{C}$ with a range of concentrations of $\mathrm{rBPI}$. Free sites were blocked by a $1-\mathrm{h}$ incubation with PBS plus 1\% BSA at room temperature. The wash and dilution buffer used was PBS plus $0.1 \%$ BSA. Sequentially biotinylated anti-BPI MAb and peroxidase-conjugated streptavidin were added and incubated for $1 \mathrm{~h}$ at room temperature. TMB was used as the substrate, and absorbance was read at $450 \mathrm{~nm}$. In the second ELISA, anti-BPI MAbs were coated. A dilution curve (different concentrations) of biotinylated rBPl was added. followed by peroxidase-conjugated streptavidin.

To test the influence of L.PS on the anti-BPI MAb-BPI interaction. the second ELISA was used. rBPI was preincubated for $30 \mathrm{~min}$ at $37^{\circ} \mathrm{C}$ with different concentrations of LPS and added to the wells coated with anti-BPI MAb. BPI was detected by sequential addition of rabbit anti-BPI antiserum and peroxidaseconjugated goat anti-rabbit IgG (Jackson ImmunoResearch Laboratories. West Grove. PA).

LPS determination. LPS was measured using a chromogenic limulus amebocyte lysate (LAL) assay as described by the manufacturer (Kabi Pharmacia. Mölndal. Sweden). To test the influence of rBPI and anti-BPI MAb on LPS activity, rBPI was incubated with anti-BPI MAb for $30 \mathrm{~min}$ at $37^{\circ} \mathrm{C}$ : LPS ( $E$. coli O55:B5) was then added. After another 30-min incubation. LPS activity was measured.

Production of $F\left(a b^{\prime}\right)_{2}$-fragment of MAb. The MAb with Fc portions highly reactive with protein $\mathrm{A}$ were isolated by protein A (Pharmacia Biotechnology) affinity purification. Immobilized pepsin (Pierce, Rockford. IL) was added to purified $\operatorname{lgG}$ and digested as described by the manufacturer. After $6 \mathrm{~h}$ at $37^{\circ} \mathrm{C}$. optimal digestion was obtained. The digested MAb was run again on a protein A column to remove the Fc parts. Purity of the $F\left(a b^{\prime}\right)_{2}$ fragments was ascertained by SDS-PAGE on a Fast system (Pharmacia Biotechnology).

Flow cylometry. For intracellular fluorescence. PMNL were permeabilized. After a 10-min incubation at room temperature with $2 \%$ paraformaldehyde (Merck. Darmstadt, Germany). cells were incubated in $70 \%$ methanol (Merck) for $30 \mathrm{~min}$ on ice. Aspecific binding 10 cells was blocked by incubation for $30 \mathrm{~min}$ with $1 \%$ glycine (Merck) in PBS at room temperature.

Both membrane (unpermeabilized PMNL) and intracellular (permeabilized PMNL) fluorescence was measured. PMNL $\left(10^{7}\right.$ cells $/ \mathrm{mL}$ ) were incubated with $50 \mu \mathrm{L}$ of the first antibody ( 50 $\mu \mathrm{g} / \mathrm{mL} 4 \mathrm{E} 3,30 \mu \mathrm{g} / \mathrm{mL}$ F $\left[\mathrm{ab}^{\prime}\right]_{2}$ fragment of 5D7) for $1 \mathrm{~h}$ on ice. Anti-MHC-I MAb W6/32 (IgG2a: $5 \mu \mathrm{g} / \mathrm{mL}$ ) was the positive control; the nonspecific myeloma protein MOPC-21 (lgGI, 50 $\mu \mathrm{g} / \mathrm{mL}$ : Celltech. Slough. UK) was the negative control. Next, cells were incubated with fluorescein isothiocyanate (FITC)- conjugated goat anti-mouse IgG/IgM (Jackson ImmunoResearch) for I h on ice and subsequently analyzed with a FAC. Sort (Becton Dickinson, Mountain View, CA). PMNL were gated using forward versus side scatter to exclude aggregates, dead cells, and debris. Fluorescence intensity was expressed as mean channel number.

Fluorescence microscopy. PMNL centrifuged on a slide were fixed and permeabilized with $96 \%$ ethanol for 15 min on ice. Cells were washed with PBS and incubated for $1 \mathrm{~h}$ with $100 \mu \mathrm{L}$ of $50 \mu \mathrm{g} / \mathrm{mL}$. $4 \mathrm{E} 3$ in a wet chamber, followed by FITC-conjugated goat anti-mouse IgG/IgM incubation for I h. After the slides were washed with PBS, cells were evaluated by fluorescence microscopy.

Isolation of human PMNL and monocytes. PMNL and monocytes were obtained from blood provided by the Red Cross Blood Bank Zuid Limburg (Maastricht). Blood was donated by volunteers. Monocytes were isolated as described [25]. Briefly. mononuclear cells were obtained after centrifugation (Lymphoprep: Nycomed, Oslo). These cells were allowed to clump by low-speed centrifugation at $4^{\circ} \mathrm{C}$. Cell clumps were separated by sedimentation through ice-cold BCS. The cell suspensions consisted of $80 \%-95 \%$ monocytes.

The mixture of PMNL and red blood cells collected after centrifugation was dissolved in Plasmasteril (Fresenius. Bad Homburg. Germany) and left for $30 \mathrm{~min}$ at $37^{\circ} \mathrm{C}$. The leukocyte-rich supernatant was collected and centrifuged. PMNL were collected from the interphase after the pellet was separated on a discontinuous $75 \%$ Percoll (Pharmacia Biotechnology) gradient.

Stimulation of human monocytes. Monocytes were cultured in 96-well flat-bottom tissue culture plates (Costar. Cambridge, MA) in medium consisting of RPMI 1640 (Life Technologies GIBCO BRL. Paisley, UK), $10 \%$ BCS, and antibiotics. To test the influence of $\mathrm{rBPI}$ in combination with anti-BPI MAb on LPS-induced monocyte activation. rBPI was incubated with anti-BPI MAb for $30 \mathrm{~min}$ at $37^{\circ} \mathrm{C}$. L.PS was then added, and the mixture was incubated for another $30 \mathrm{~min}$ at $37^{\circ} \mathrm{C}$. Monocytes were stimulated with these reagents immediately after isolation. After an 18-h incubation, the supernatants were harvested and kept at $-20^{\circ} \mathrm{C}$ until determination of tumor necrosis factor- $\alpha$ (TNF $\alpha$ ) concentration by ELISA.

TNFa sandwich ELISA. TNF a concentrations in culture supernatants were determined using sandwich ELISA. as described previously [26]. In shor, 96-well immunomaxisorp plates were coated overnight at $4^{\circ} \mathrm{C}$ with murine anti-human TNF $\alpha$ MAb 6IE71. Human rTNF $\alpha$ (BASF/Knoll: Ludwigshafen, Germany) was used for standard titration curves. Test samples were added and incubated for $3 \mathrm{~h}$. Polyclonal rabbit anti-human TNF $\alpha$ antiserum was followed by peroxidase-conjugated goat anti-rabbit IgG. TMB was used as substrate and absorbance was read at $450 \mathrm{~nm}$. The lower detection level of ELISA was $10 \mathrm{pg} / \mathrm{mL}$

\section{Results}

Production and selccion of MAb. Five fusions resulted in 991 proliferating hybridomas. The selection method used for recognition of anti-BPI MAb-producing hybridomas was based on the ability of MAbs to capture biotinylated BPI. 

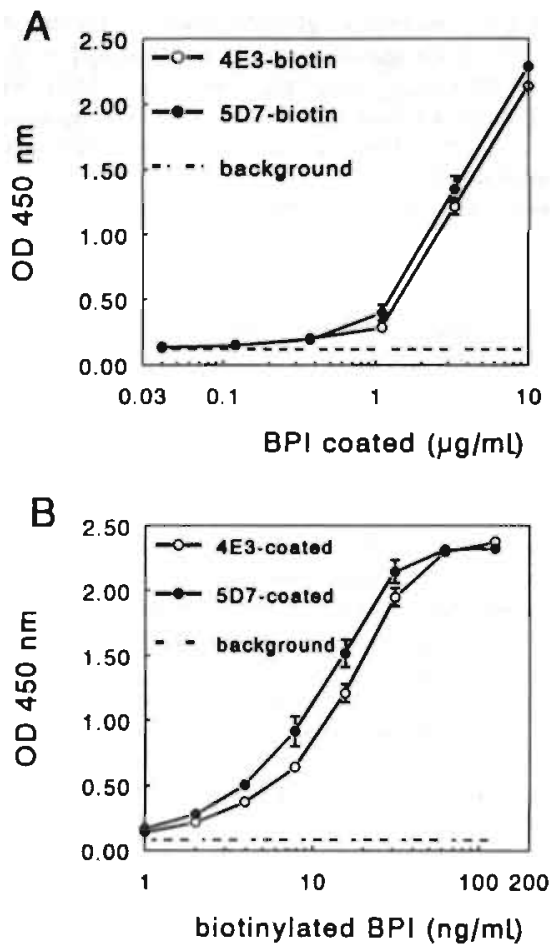

Figure 1. Interaction of anti-bactericidal/permeability-increasing protein (BPI) monoclonal antibody with BPI. A. Biotinylated $4 \mathrm{E} 3(0.5 \mu \mathrm{g} / \mathrm{mL})$ and $5 \mathrm{D} 7(1 \mu \mathrm{g} / \mathrm{mL})$ were added to $96-$ well immunomaxisorp plates coated with different concentrations of BPI. B. Concentration range of biotinylated BPI was added to plates coated with $2.5 \mu \mathrm{g} / \mathrm{mL}$ of $4 \mathrm{E} 3$ and $5 \mathrm{D} 7$. Plates were developed with peroxidase-labeled streptavidin. Data are expressed in mean \pm SD of 2 values. SD bars are omitted if they fall within the symbol. Background optical density (OD) is indicated. One experiment from a series of 3 is shown.

Two positive, anti-BPI MAb-secreting hybridomas were found and designated 4E3 $(\operatorname{lgG} 1)$ and SD7 ( $\lg G 2 a)$.

Specificity of MAbs. The specificity of the MAbs for BPI was further analyzed: we tested whether they immunodetected BPI separated by SDS-PAGE and blotted to a polyvinylidene difluoride (PVDF) membrane. Neither MAb could detect the blotted BPI. although a polyclonal rabbit anti-BPI antiserum interacted with blotted BPI (data not shown). When BPI $(2 \mu \mathrm{g} / \mathrm{mL})$ was spotted directly onto a PVDF membrane, the MAb reacted with BPI dissolved in PBS but not with BPI dissolved in SDS (2.5\%) buffer (data not shown). indicating that neither MAb recognized denatured BPI.

Furthermore. the interaction of anti-BPJ MAb with BPI was analyzed using two different ELISAs. Figure IA shows that BPI coated on wells of a 96 -well immunomaxisorp plate interacted, in a BPI concentration-dependent manner, with both biotinylated $4 \mathrm{E} 3$ and biotinylated 5D7. In addition, the anti-BPI MAbs coated in wells caught biotinylated BPI (figure IB). A concentration-dependent signal was seen, which reached a plateau at $\sim 125 \mathrm{ng} / \mathrm{mL}$. biotinylated $\mathrm{BPI}$.

Next, we tested whether both MAbs interacted with LBP. a protein with considerable sequence homology with BPI [27]. LBP $(2.5 \mu \mathrm{g} / \mathrm{mL})$ spotted directly on a PVDF membrane was not detected by either $4 E 3$ or $5 \mathrm{D} 7$ (data not shown). Moreover, addition of LBP $(100 \mathrm{ng} / \mathrm{mL})$ to 96 -well immunomaxisorp plates coated with anti-BPI MAb $(2.5 \mu \mathrm{g} /$ $\mathrm{mL}$ ) and development of the plates with polyclonal rabbit anti-LBP antiserum and peroxidase-labeled goat anti-rabbit IgG did not yield any signal (data not shown). These data indicate that neither anti-BPI MAb 4E3 nor 5D7 crossreacted with LBP.

Detection of natural BPI by MAbs using fow cytometry and immunofuorescence micrascopy. To investigate whether the MAbs could also detect natural BPI in and on PMNL. these cells were examined by flow cytometry and immunofluorescence microscopy. PMNL were either untreated, to study membrane expression. or permeabilized, to study intracellular expression of BPI. Studies were done with whole $4 E 3 \mathrm{MAb}$ or with $\mathrm{F}\left(\mathrm{ab}^{\prime}\right)_{2}$ fragments of $5 \mathrm{D} 7$, to prevent $\mathrm{Fc}$ receptor interaction. Flow cytometric studies showed that in permeabilized PMNL. BPI was detected by both MAbs (figure $2 \mathrm{~A}$ ). The mean channel number of fluorescence increased from 5 (MOPC21) to 120 (4E3) or 24 ( $F\left[\mathrm{ab}^{\prime}\right]_{2}-5 \mathrm{D} 7$ ). Furthermore, both MAbs detected BPI surface expression on PMNL at low levels (mean channel number of fluorescence of 13 (4E3) or $\left.10\left(\mathrm{Fab}^{\prime}\right]_{2}-5 \mathrm{D} 7\right)$ versus 6 (MOPC 21 ): figure $2 \mathrm{~B}$. Immunofluorescence revealed the intracellular presence of BPI in abundant small cytoplasmic vesicles (figure 3 ).

Effecl of LPS on inleraction of anti-BPI MAbs with $\overline{B P}$. Since BPI binds specifically to LPS [9-11], we tested whether LPS interfered with the recognition of BPI by the MAbs in an ELISA system. Plates were coated with $4 \mathrm{E} 3$ or SD7: BPI. preincubated with different concentrations of L.PS, was added. BPI was detected by sequential addition of rabbit anti-BPI antiserum and peroxidase-conjugated goat anti-rabbit lgG. In this assay. BPI levels of $0.1-50 \mathrm{ng} / \mathrm{mL}$ could be detected. As shown in table 1. LPS. in a concentration-dependent manner, prevented the interaction of both anti-BPI MAbs with BPI $(2 \mathrm{ng} / \mathrm{mL}$ ). Almost complete inhibition of anti-BPI MAb-BPI interaction by LPS $(1-10 \mu \mathrm{g} / \mathrm{mL})$ was seen at BPI levels up to $5 \mathrm{ng} / \mathrm{mL}$, whereas at higher BPI concentrations only a partial disturbance was observed (data not shown). At BPI concentrations of $\geqslant 50 \mathrm{ng} / \mathrm{mL}$. LPS ( 1 $10 \mu \mathrm{g} / \mathrm{mL}$ ) did not affect BPI anti-BPI MAb interaction (data not shown).

Effeci of ani-BPI MAbs an biologic activity of BPI. Since data suggested that both MAbs recognized the epitope on 


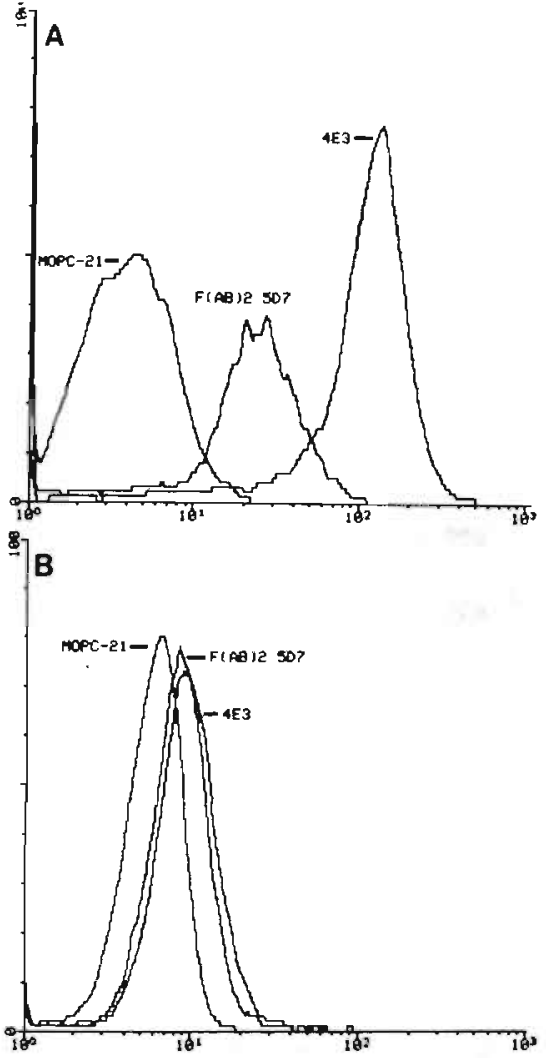

Figure 2. Flow cytometric analysis of intracellular (A) and membrane (B) expression of BPI. Polymorphonuclear leukocytes were incubated with $4 \mathrm{E} 3(50 \mu \mathrm{g} / \mathrm{mL})$. F $\left(\mathrm{ab}^{\circ}\right)_{2}$ fragment of $5 \mathrm{D} 7(30$ $\mu \mathrm{g} / \mathrm{mL}$ ), or MOPC -21 ( $50 \mu \mathrm{g} / \mathrm{mL}$; negative control). followed by fluorescein isothiocyanate-conjugated goat anti-mouse $\mathrm{IgG} / \mathrm{lgM}$. Representative experiment from series of 5 is shown.

BPI involved in interaction with LPS. the influence of the MAbs on the biologic effects of BPI, as measured by inhibition of LPS activity. was investigated.

LPS activity in the LAL assay was studied. LPS activated proenzyme in the LAL assay in a concentration-dependent manner (data not shown). Adding BPI at $30 \mathrm{ng} / \mathrm{mL}$ almost completely inhibited LPS activity (figure 4); this inhibition was partly prevented by $4 \mathrm{E} 3(12.5 \mu \mathrm{g} / \mathrm{mL}$; figure 4$)$ and $5 \mathrm{D} 7$ (data not shown). Anti-BPI MAb alone did not affect proenzyme activation.

Next, we studied LPS ( $1 \mathrm{ng} / \mathrm{mL}$ )-induced TNF $\alpha$ release by monocytes in the presence of serum. BPI blocked this release in a concentration-dependent manner (figure 5A). At a BPI concentration of $3 \mu \mathrm{g} / \mathrm{mL}$. $80 \%$ inhibition was observed: anti-BPI MAb 4E3 (figure 5B) and 5D7 (data not

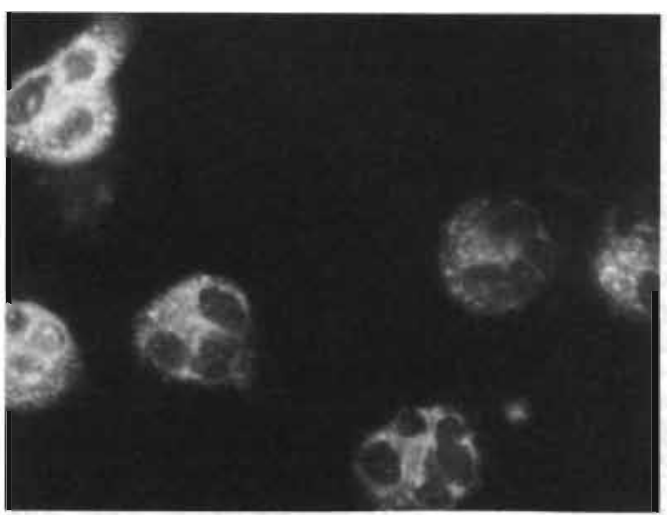

Figure 3. Immunodetection of BPI in permeabilized polymorphonuclear leukocytes (PMNL) by fluorescence microscopy. Permeabilized PMNL were incubated with $4 \mathrm{E} 3(50 \mu \mathrm{g} / \mathrm{mL})$, followed by fluorescein isothiocyanate-conjugated goat anti-mouse IgG/ $\mathrm{IgM}$. Representative experiment from series of 3 is shown.

shown) abrogated this inhibition. $\mathrm{g}($; at $2.5 \mu \mathrm{g} / \mathrm{mL} \mathrm{com}-$ pletely abolished the BPI effect.

\section{Discussion}

In this report the development and characterization of two BPI-specific MAbs, $4 \mathrm{E} 3$ and $5 \mathrm{D} 7$, are described. The specificity of these MAbs was shown in several ways. Both reacted with BPI coated on 96-well immunomaxisorp plates and captured biotinylated BPI. The MAbs apparently recognized native BPI but not BPI denatured by SDS. Furthermore. both $4 E 3$ and SD7 lacked affinity for L.BP, a protein with sequence homology very similar to that of $\mathrm{BPI}$ [27].

The MAbs that were made using rBPI as antigen were shown to be reactive with natural BPI. Fiow cytometric analysis revealed that PMNL contained intracellular BPI, which

Table 1. Inhibition by lipopolysaccharide (LFS) of anti-bactericidal/permeability-increasing protein (BPI) monoclonal antibody (MAb)-BPI interaction in ELISA.

\begin{tabular}{lcc}
\hline & \multicolumn{2}{c}{ \% bound BPI } \\
\cline { 2 - 3 } L.PS $(\mu \mathrm{g} / \mathrm{mL})$ & Coated 4E3 & Coated SD7 \\
\hline 0 & 100 & 100 \\
0.1 & 22 & 24 \\
1.0 & 0 & 12 \\
10.0 & 0 & 11 \\
\hline
\end{tabular}

NOTEE. $2 \mathrm{ng} / \mathrm{mL}$. BPI was preincubated $30 \mathrm{~min}$ at $37^{\circ} \mathrm{C}$ with a range of concentrations of LPS and added to wells coated with $2.5 \mu \mathrm{g} / \mathrm{mL} .4 \mathrm{E} 3$ or SD7. Data are mean of 2 values and are expressed as $\%$ BPi that interacted with anti-BPI MAb, I representative experiment from series of 4 is shown. 

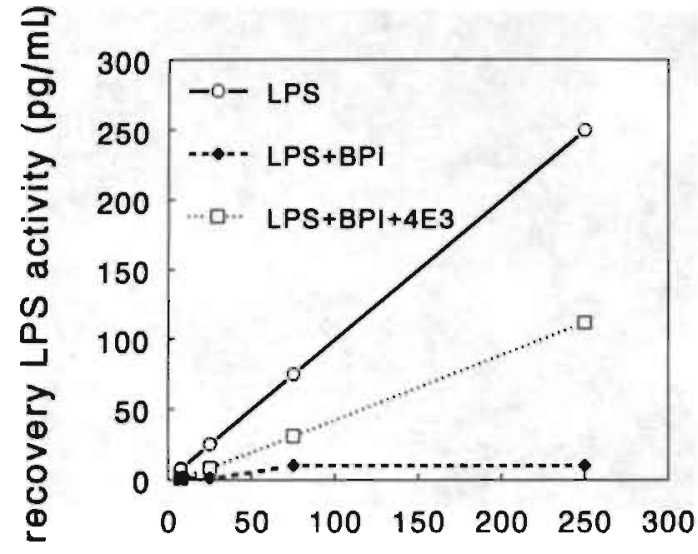

LPS (pg/ml)

Figure 4. Anti-bactericidal/permeability-increasing protein (BPI) monoclonal antibody reduces BPI inhibition of lipopolysaccharide (LPS) activity in limulus amebocyle lysate (LAL) assay. BPI (30 $\mathrm{ng} / \mathrm{mL}$ ) preincubated $\left(30 \mathrm{~min} .37^{\circ} \mathrm{C}\right.$ ) with no other reagent or with $4 \mathrm{E} 3(12.5 \mu \mathrm{g} / \mathrm{mL})$ was added to different concentrations of LPS and incubated for $30 \mathrm{~min}$ at $37^{\circ} \mathrm{C}$. after which LPS activity was determined. Data are expressed as recovery of LPS activity. expressed in amount of $\mathrm{pg} / \mathrm{mL}$ of original LPS used to obtain identical signal in LAL assay. Representative experiment from series of 4 is shown.

was confined to the granules in the cytoplasm of the PMNL. as shown by immunofluorescence studies. This corresponds to previous reports of the presence of BPI in azurophilic granules [5. 6]. In addition. PMNL showed low levels of membrane expression of BPI. Flow cytometric detection of membrane BPI has been described using polyclonal anti-BPI antiserum [7. 8]. Furthermore, in one study [7] membrane expression of BPI was delected using biotinylation of membrane proteins.

The interaction of anti-BPI MAbs with membrane BPI indicates that the epitope on BPI recognized by both MAbs is most likely exposed and not involved in the association with the PMNL membrane. It is not clear whether PMNL expressed surface BPI because of activation due to the isolation procedure or whether membrane BPI is constitutively present in vivo. It is possible that the BPI bound to the membrane of the azurophilic granule [5.28] is transported to the outer membrane through exocytosis, where it could serve as a specific L.PS receptor. This extracellular BPI might be instrumental in the internalization of LPS by PMNL. However. the physiologic function of BPI on the surface of PMNL requires further analysis.

LPS induces activation of different cells (e.g. PMNL and monocytes). After LPS stimulation. cytokines. including
TNF $\alpha$, are released: these play a key role in the biologic effects of LPS [29,30]. A standard assay for measuring L.PS activity is the LAL assay [31]. We showed that BPI blocked LPS activity in the LAL assay and LPS-induced TNFa re. lease by monocytes, as has been reported [7, 13-16, 18]. Both $4 \mathrm{E} 3$ and $5 \mathrm{D} 7$ could reduce these inhibitory activities of BPI. The effect of BPI on LPS-induced monocyte activation could be prevented completely if MAbs and BPI were at equal concentrations, whereas the inhibition by BPI of L.PSinduced LAL activation could only partly be prevented by excess MAbs. We postulate that this difference in effectiveness of MAbs can be explained by the difference in interaction between LPS and CDI 4 versus LPS and proenzyme.
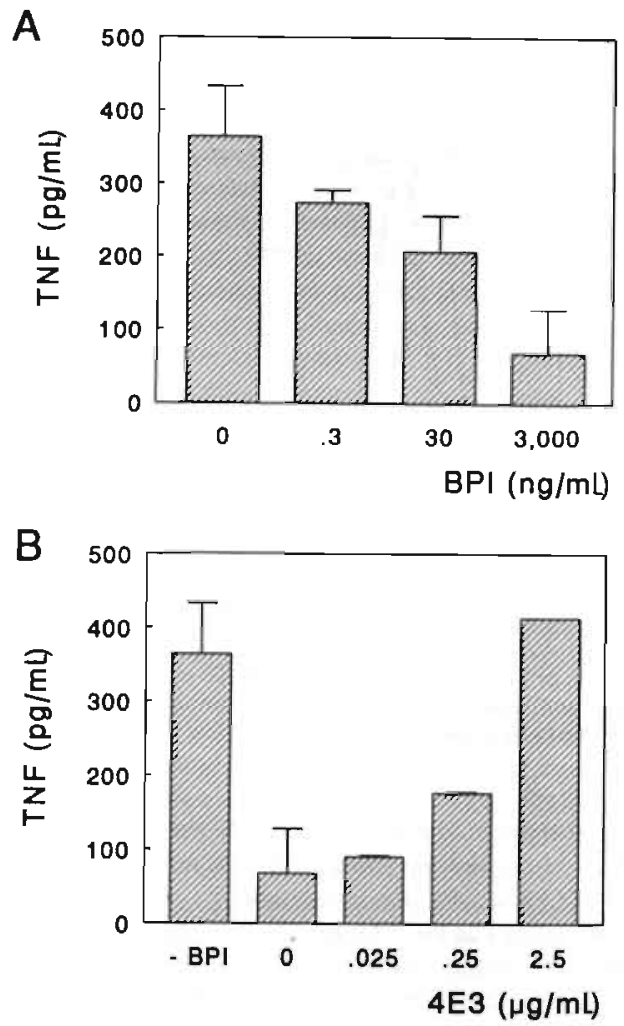

Fogure 5. Anti-bactericidal/permeability-increasing protein (BPI) monoclonat antibody abrogates BPI inhibition of lipopolysaccha. ride (LPS)-induced tumor necrosis factor (TNF)- $\alpha$ release by monocytes. A. Monocytes were incubated with LPS $(1 \mathrm{ng} / \mathrm{mL})$ with $\mathrm{n}^{-}$ treasing concentrations of BPI. B. Monocytes were incubated with LPS ( I $\mathrm{ng} / \mathrm{mL})$ and BPI $(3 \mu \mathrm{g} / \mathrm{mL})$ with increasing concentrations of 4E3. Left bar. LPS $(1 \mathrm{ng} / \mathrm{mL})$-induced TNF $\alpha$ release in absence of BPI. Data are expressed in mean \pm SD of 3 values. SD bars are omitted if they fill within symbol. Representative experiment from series of 5 is shown 
The prevention by both MAbs of the LPS-inhibiting capacity of BPI is thought to be caused by disturbance of the BPILPS interaction. In addition, we observed that LPS interfered with the interaction of anti-BPI MAbs with BPI in an ELISA. Together these data strongly suggest that both anti-BPI MAbs recognize the epitope on BPI that is involved in the BPI-LPS interaction. However, other causes for this interference, such as stearic hindrance or configurational changes. have nol been excluded.

Although we have shown that both anti-BPI MAbs can block LPS activation pathways in vitro, the activity of both MAbs in vivo has to be established. Furthermore, studies are needed to test the effect of MAbs on the bactericidal activity of BPI. Spitznagel et al. [32] have described two MAbs that recognize CAP57, a protein substantially similar to BPI [6]. One of these MAbs has been shown to block the bactericidal capacity of CAP57.

Using the anti-BPI MAbs. a sensitive sindwich ELISA has been developed that shows the presence of BPI in biologic fluids (unpublished data), indicating that these MAbs are a valuable tool for studying the regulation of BPI production and distribution in vivo. Such ELISA data could provide insight into the role of $\mathrm{BPl}$ in the defense against gram-negative microorganisms. In conclusion, two MAbs reactive with human BPI were isolated and shown to block the biologic activity of $\mathrm{BPI}$.

\section{References}

1. Martich GD, Boujoukos AJ. Suffredini AF. Response of man to endotoxin. Immunobiology 1993:187:403-16.

2. Rotrosen D. Gallin Jl. Disorders of phagocyte function. Annu Rev Immunol 1987; 5:127-50.

3. Weiss J. Elsbach P. Olsson I. Odeberg H. Purification and characterization of a potent bactericidal and membrane active protein from the granules of human polymorphonuclear leukocytes. J Biol Chem 1978:253:2664-72

4. Weiss J, Victor M. Stendhal O. Elsbach P. Killing of gram-negative bacteria by polymorphonuclear leukocytes: role of an $\mathrm{O}_{2}$-independent bactericidal system. J Clin Invest 1982:69:959-70.

5. Weiss J. Olsson I. Cellular and subcellular localization of the bactericidal/permeability-increasing protein of neutrophils. Blood 1987 69:652-9.

6. Pereira HA. Spitznagel JK. Winton EF, et al. The ontogeny of a 57-Kd cationic antimicrobial protein of human polymorphonuclear leukocytes: localization to a novel granule population. Blood 1990; $76: 825-34$

7. Marra MN. Wilde CG. Collins MS. Snable JL. Thornton MB. Scou $\mathrm{RW}$. The role of bactericidal/permeability-increasing protein as a natural inhibitor of bacterial endotoxin. J Immunol 1992:1 48:5327.

8. Weersink AJL, Kessel KPM van. Tol ME van den, et al. Human granulocyles express a 55-kDa lipopolysaccharide-binding protein on the cell surface that is identical to the bactericidal/permeability-increasing protein. J Immunol 1993: 150:253-63.

9. Weiss J, Muello K. Victor M. Elsbach P. The role of lipopolysaceharides in the action of the bactericidal/permeability-increasing neutro- phil protein on the bacterial envelope. J Immunol 1984:132:310915.

10. Mannion BA. Kalatis ES. Weiss J. Elsbach P. Preferential binding of the neutrophil cytoplasmic granule-derived bactericidal/permeability increasing protein to target bacteria: implications and use as a means of purification. J Immunol 1989:142:2807-12.

11. Gazzano-Santore H. Parent JB. Grinna L et al High-aftinity binding of the bactericidal/permeability-increasing protein and a recombinant amino-terminal fragment to the lipid A region of lipopolysaccharide. Infect Immun 1992:60:4754-61.

12. Mannion BA. Weiss J. Eisbach F. Separation of sublethal and lethal effects of the bactericidal/permeability increasing protein on Esche richia coli. J Clin Invest 1990:85:853-60

13. Marra MN, Wilde CG. Griffith JE, Snable JL. Scott RW. Bactericidal/ permeability-increasing protein has endotoxin-neutralizing activity. J Immunol 1990; 144:662-6.

14. Ooi CE. Weiss 3. Doerfler ME. Elsbach P. Endotoxin-neutralizing properties of the $25 \mathrm{kD}$ N-terminal fragment and a newly isolated $30 \mathrm{kD}$ C-terminal fragment of the 55-60 kD bactericidal/permeabilityincreasing protein of human neutrophils. J Exp Med 1991: 174:649SS.

15. Dentener MA. Asmuth EJU von. Francot GJM. Marra MN. Buurman WA. Anlagonistic effects of lipopolysaccharide binding protein and bactericidal/permeability-increasing protein on lipopolysaccharide. induced cylokine release by mononuclear phagocytes: eompetition for binding to lipopolysaccharide. J Immunol 1993:151:4258 65.

16. Mészíros K. Parent JB. Gazzano-Santoro H. et al. A recombinant amino terminal fragrnent of bactericidal/permeability-increasing protein inhibits the induction of leucocytc responses by LPS J Leukoc Biol 1993:54:558-63.

17. Betz-Cormadin S. Heumann D. Gallay P, Smith J, Mauel J, Glauser MP. Bactericidal/permeability-increasing protein inhibits induction of macrophage nitric oxide production by lipopolysaccharide. J Infect Dis 1994:165t105-11.

18. Marra MN. Thernton MB, Snable JL. Wilde CG. Scott RW. Endotoxin-binding and-neutralkzing properties of recombinant bactericidal/permeability-increasing protein and monoclonal antibodies HA-1A and ES. Cril Care Med 1994:22:559-65.

19. Opal SM. Fisher CJ, Marra MN, Scou RW. Palardy JE. Bactericidal/ permeability-increasing protein as a novel therapeutic modality in the treatment of endotoxic shock: \{abstract) Clin Res 1991:39:351.

20. Fisher CJ. Marse MN. Palandy JE, Marchbanks CR. Scotl RW. Opal SM. Human neutrophil bactericidal/permeabiltry-increasing protein reduces mortality rase from endotoxin challenge: a placebo-controlled study. Crit Care Med 1994:22:553-8.

21. Ammons WS. Kung AHC. Recombinant amino terminal fragment of bactericidal/permeability-increasing protein prevents hemodynamic responses to endotoxin. Circ Shock 1993:41:176-84.

22. Kohn FR. Ammons WS. Horwitz A, et al. Protective effect of a recombinant amino-terminal fragment of bactericidal/permeability-increasing protein in experimental endotoxernia. I Infect Dis 1993:168:1307-10.

23. Heumann D. Gallay P, Betz-Corradin S. Barras C. Baumgartner JD. Glauser MP. Competition between bactericidal/permeability-increasing protein and lipopolysaccharide-binding protein for lipopoly. saccharide binding to monocytes. I Infect Dis 1993;167:1351-7.

24. Holmes K. Fowlkes BJ. Preparation of cells and reagents for flow cytometry, In: Coligan JE. Kruisbeck AM. Margulies DH. Shevach EM. Strober W, eds. Current protocols in immunology. Vol I. New York: Gireene Publishing Associates and John Wiley \& Sons, 1994:5.3.4.

25. Graziano RF. Fanger MW. Fcy RI and FcyRII on monocytes and granulocytes are cytotoxic triger molecules for tumor cells. I Immunol 1987:139:3536-41. 
26. Engelberts I. Moller A. Schoen GJM. van der Linden CJ. Buurman WA. Evaluation of measurement of human TNF in plasma by ELISA. Lymphokine Cyiokine Res 1991:10:69-76.

27. Schumann RR. Leong SR. Flaggs GW. et al. Strueture and function of lipopolysaccharide binding protein. Science 1990:249:1429-31.

28. Gray PW. Flaggs $G$. Leong SR. et al. Cloning of the CDNA of a human neutrophil bactericidal protein: structural and functional correlations. J Biol Chem 1989:264:9505-9.

29. Beutler B. Milsark IW. Cerami AC. Passive immunization against cachectin/tumor necrosis factor protects mice from lethal effect of endotoxin. Science 1985:229:86,9-71.
30. Mathison JC. Wolfson E. Ulevitch R. Participation of tumor necrosis. factor in the mediation of gram-negative bacterial lipopolysaccharide-induced injury in rabbits. J Clin Invest 1988:81:1925-37.

31. Munson TE. FDA guideline for validation of the LAL. test as an end product endotoxin test for human and biologic drugs. In: Watswn SW, Levin J. Novitsky TJ, eds. Endotoxins and their detection with the limulus amebocyte lysate tesL. New York: AR Liss. 1982:25-32.

32. Spizznagel JK. Pereira HA. Martin LE. Guzman GS. Shafer WM. A monoclonal antibody that inhibits the antimicrobial action of a 57 . KD cationic protein of human polymorphonuclear leucocytes. $\mathrm{J} \mathrm{lm}$ munol 1987:139:1291-6. 
Chapter 8

Bactericidal/Permeability-Increasing Protein, a Lipopolysaccharide-Specific Protein on the Surface of Human Peripheral Blood Monocytes

Reprinted with permission 


\title{
Bactericidal/Permeability-Increasing Protein, a Lipopolysaccharide-Specific Protein on the Surface of Human Peripheral Blood Monocytes
}

\author{
Mieke A. Dentener, Gaby J. M. Francot, \\ and Wim A. Buurman
}

Department of Surgery, University of Limburg: Department of Pulmonology, University Hospital Maastricht, Netherlands

\begin{abstract}
Bactericidal/permeability-increasing protein (BPI), a cationic protein present in the azurophilic granule and on the surface of polymorphonuclear leukocytes, specifically interacts with lipopolysaccharide (LPS). This study demonstrates for the first time, using flow cytometry with specific antiBPI monoclonal antibody (MAb), that human peripheral blood monocytes express BPI on their cell surface. The monocyte cell surface BPI was shown to bind to LPS, because binding of anti-BPI MAb 4E3 (which is known not to react with BPI to which LPS is bound) to cell surface BPI was strongly reduced after preincubation of cells with LPS. However, cell surface BPI did not quantitatively contribute to the interaction of LPS with the monocyte cell membrane, since preincubation of cells with $4 E 3$ did not block binding of LPS-fluorescein isothiocyanate to monocytes. The origin of the monocyte cell surface BPI remains to be further elucidated.
\end{abstract}

Lipopolysaccharide (LPS), a complex glycolipid in the outer membrane of gram-negative bacteria, plays a major role in the pathophysiology of gram-negative infection. The phagocyte system, which consists of polymorphonuclear phagocytes (PMNL) and mononuclear phagocytes, belongs to the first line of defense against invading bacteria [1]. Recognition of LPS at the surface of these cells is required for LPS uptake or initiation of transmembrane signaling, leading to cell activation. Several LPS-binding proteins are present on the surface of phagocytic cells (reviewed in $[2,3]$ ). CD18 and the scavenger receptor recognize LPS and are involved in uptake and degradation of LPS. Furthermore, LPS binds to a $70-\mathrm{kDa}$ antigen that was recently demonstrated to be cell membrane-bound albumin [4]. LPS-binding protein (LBP). which is present in plasma of healthy persons, mediates binding of LPS to CD14, a 55-kDa protein present on mononuclear phagocytes and PMNL, resulting in cell activation.

Another important LPS-recognizing protein on the surface of PMNL is bactericidal/permeability-increasing protein (BPI) $(5,6]$. This protein, which is one of the microbicidal proteins present in the PMNL granule, specifically recognizes LPS, both in intact bacteria and in isolated form (reviewed in [7]). In this shidy, we investigated whether this specific L.PS-binding protein is also present on mononuclear phagocytes. As the presence of BPI on the cell surface of human peripheral blood monocytes was demonstrated, the functional activity of monocyie cell surface BPI was also investigated.

\section{Materials and Methods}

Reagents and antibodies. LPS (from Escherichia coli O55:B5), LPS-fluorescein isothiocyanate (FITC; from $E$, coli O111:B4), bo-

Received 14 June 1995; revised 17 August 1995 Blood donors gave informed consent for research

Reprints or correspondence; Mieke A. Dentener, Dept. of Surgery. University of Limburg. P.O. Box 616, 6200 MD Maastricht, Netherlands.

The Journal of Inferious Disenses 1996:173:252-5

0 1996 by The University of Chicago. All rights reșerved.

$0022-1899 / 96 / 7301-0037501.00$ vine serum albumin (BSA), and cycloheximide were purchased from Sigma ( $\mathrm{St}$. Louis). Azide ( $\mathrm{NaN}_{3}$ ), paraformaldehyde, methanol, and glycine were obtained from Merck (Darmstadt, Germany) and streptavidin-R-phycoerythrin (strep-R-PE) from Caltag (South San Francisco, CA). Human serum (HS) was obtained from healthy donors at the Red Cross Blood Bank Zuid Limburg (Maastricht). Human full-length recombinant (r)BPI was provided by M. Marra (Incyte Pharmaceuticals, Palo Alto, CA). Macrophage serum-free medium was obtained from GIBCO (Paisley, UK) and did not contain human $\mathrm{BPI}$, as determined by ELISA [8].

BPI-neutralizing monoclonal antibody (MAb) 4E3 (IgCI) and 5D7 (IgG2a) were prepared and characterized as described [9]. Neither anti-BPI MAb cross-reacted with LBP, as described [8, 9]. In short, addition of LBP ( $100 \mathrm{ng} / \mathrm{mL}$ ) to 96 -well plates coated with anti-BPI MAb and detection with biotin-labeled polyclonal rabbit anti-human LBP IgG did not yield a signal; LBP $(2.5 \mu \mathrm{g}$ $\mathrm{mL}$ ) spotted directly on a polyvinylidene difluoride membrane was not detected by MAb $4 \mathrm{E} 3$ or $5 \mathrm{D} 7$; and LBP did not inhibit BPI detection in a BPI-ELISA based on anti-BPI MAb $4 \mathrm{E} 3$ as the catching reagent, followed by biotin-labeled polyclonal rabbit antihuman BPI, since spiking of rBPI $(20 \mathrm{ng} / \mathrm{mL}$ ) in plasma (containing $\sim 10 \mu \mathrm{g} / \mathrm{mL}$. LBP) of healthy volunteers yielded a BPI recovery of $70 \%-100 \%$.

Anti-BPI MAbs 1208 (lgG2b), 1211 (IgG1), 1213 (lgGi), and 1221 (IgGI) were provided by M. Marra (Incyte Pharmaceuticals). The nonspecific myeloma protein MOPC21 (IgG1) was provided. by Celltech (Slough, UK) and anti-CDI4 MAb MEM-18 (IgGi) by V. Horejși (Institute of Molecular Genetics. Prague). MAbs. were purified from culture supernatant by affinity chromatography on a protein G-Sepharose 4 Fast Flow Gel (Pharmacia, Uppsala, Sweden). MAbs and rBPI were biotinylated as described [9], using biotin-X-NHS (Calbiochem, La Jolla, CA). The $\mathrm{F}\left(a b^{\prime}\right)_{2}$ fragment of the MAbs was prepared as described [9].

Cells. Peripheral blood monocytes were obtained either from fresh whole blood of healthy volunteers, collected in evacuated blood tubes (Sherwood Medical, St. Louis) containing $0.1 \mathrm{~mL}$ of $15 \%(\mathrm{Wt} / \mathrm{wt})$ EDTA, or from buffy coats of blood anticoagulated. with $0.4 \%(w t / v o l)$ trisodium citrate $(\mathrm{pH} 7.4)$ provided by the Red Cross Blood Bank Zuid Limburg. Monocytes were obtained as described [10]. In short, mononuclear leukocytes, obtained after 
Lymphoprep (Nycomed, Oslo) centrifugation, were allowed 10 clump by low-speed centrifugation at $4^{\circ} \mathrm{C}$. Cell clumps were separated from the rest of the cells by sedimentation through icecold HS. The cell suspensions obtained consisted of $80 \%-95 \%$ of monocytes and contained $<5 \%$ PMNL contamination.

PMNL, obtained from fresh whole blood of healthy volunteers and collected as described above, were isolated as reported [11]. In short, the mixture of PMNL and red blood cells collected after centrifugation was treated with ice-cold isotonic $\mathrm{NH}_{4} \mathrm{Cl}$ solution to lyse the erythrocytes. PMNL were $>95 \%$ pure.

Flow cytometry. For cell surface fluorescence assay, untreated cells were used. For intracellular fluorescence assay, cells were permeabilized as follows: Cells were incubated with $4 \%$ paraformaldehyde for $10 \mathrm{~min}$ at room temperature, washed, and incubated with $70 \%$ methanol for $30 \mathrm{~min}$ on ice, followed by $30 \mathrm{~min}$ of incubation with $1 \%$ glycine in PBS at room temperature. After staining, cells were analyzed with a FACSort (Becton Dickinson, Mountain View, CA). Using forward versus side scatter, cells were gated out to discriminate between cell types and to exclude aggregates and dead cells. Results are expressed as mean fluorescerce intensity (MFI) and are presented as mean \pm SE.

Analysis of B.PI expression. Aliquots of cells $\left(10^{6} / \mathrm{mL}\right)$ were incubated for $1 \mathrm{~h}$ on ice with $10 \mu \mathrm{g} / \mathrm{mL}$. biotin-conjugated control MAG MOPC21 or anti-BPI MAb 4E3, 5D7, 5D7-F(Ab') $)_{2}$ 1208, 1211,1213 , or 1221 . Wash/dilution buffer consisted of cold PBS, $0.1 \%$ BSA, and $0.1 \% \mathrm{NaN}_{3}$. Cells were stained with $1 \mu \mathrm{g} / \mathrm{mL}$ strep-R-PE for $1 \mathrm{~h}$ on ice.

To test the infuence of LPS on interaction of anti-BPI MAb with BPI present on the cell surface of monocytes, cells were preincubated for $1 \mathrm{~h}$ at $4^{\circ} \mathrm{C}$ with LPS $(25 \mu \mathrm{g} / \mathrm{mL})$ washed in cold PBS, $0.1 \% \mathrm{BSA}$, and $0.1 \% \mathrm{NaN}_{3}$ and sequentially incubated for $1 \mathrm{~h}$ on ice with $10 \mu \mathrm{g} / \mathrm{mL}$ biotin-conjugated $\mathrm{MAb} 4 \mathrm{E} 3$ and $1 \mu \mathrm{g}^{\prime}$ $\mathrm{mL}$ strep-R-PE.

Analysis of LPS-FITC binding to monocyte cell surface. Monocytes $\left(10^{6} / \mathrm{mL}\right)$ were incubated with $50 \mu \mathrm{g} / \mathrm{mL}$. LPS-FITC dissolved in wash/dilution buffer in the absence or presence of $10 \%$ HS for $l \mathrm{~h}$ on ice and sequentially analyzed with FACSort. To test the effect of anti-BPI MAb 4E3, anti-CDI4 MAb MEM-18. or control MAb MOPC21 on LPS-FITC interaction with monocyte cell surface, cells were preincubated $1 \mathrm{~h}$ on ice with one of the MAbs $(100 \mu \mathrm{g} / \mathrm{mL})$; after cells were washed, LPS-FITC $(50 \mu \mathrm{g} /$ mL.) binding to cells was analyzed.

\section{Results and Discussion}

Cell surface expression of BPI on human peripheral blood monocyles. To investigate whether peripheral blood monocytes express BPI, whole blood of healthy volunteers was collected, and freshly isolated PMNL and monocytes were examined for BPI expression by flow cytometry, using specific anti$\mathrm{BPI} \mathrm{MAb}$ [8]. In accordance with previous reports $[5,6,9$, 12], the flow cytometry with PMNL showed the presence of high levels of intracellular BPI (MFI of 5 donors, $726 \pm 368$ [4E3] vs. $43 \pm 19$ [MOPC21]) and of BPI on the PMNL cell surface (MFI of 5 donors, $35 \pm 14$ [4E3] vs. $6 \pm 1$ [MOPC21]). Data from 1 representative donor are shown in figure $1 \mathrm{~A}$.

Analysis of the monocyte fraction of whole blood revealed that both anti-BPI MAbs 4E3 and 5D7 reacted with the cell
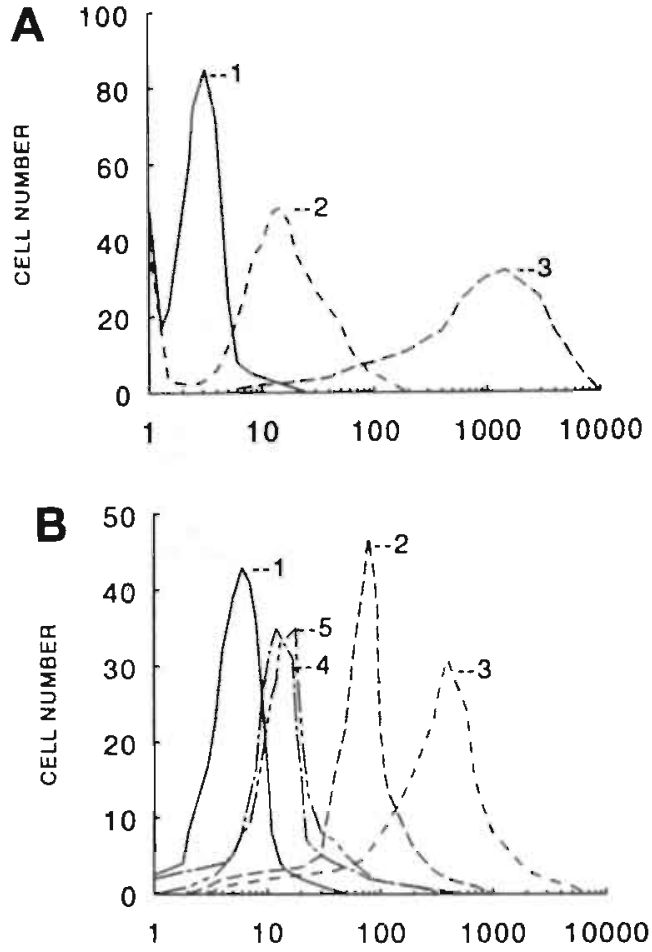

\section{FLUOARSCENCE INTENSITY}

Figure 1. Flow cytometry detection of membrane and intracellular BPI expression on peripheral blood phagocytic cells. Data are from 1 representative donor. A, Polymorphonuclear leukocytes (PMNL) were incubated with biotin-conjugated control monoclonal antibody (MAb) MOPC21 (1, nonpermeabilized PMNL) or 4E3 (2, nonpermeabilized PMNL; 3, permeabilized PMNL) followed by streptavidinR-phycoerythrin (strep-R-PE). B. Nonpermeabilized monocytes were incubated with biotin-conjugated MAbs MOPC21 (1), 5D7 (2), 4E3 (3), 1208 (4), and 1221 (5), followed by strep-R-PE incubation.

surface of all monocytes, indicating the presence of BPI. MFI of 10 donors analyzed was $667 \pm 159$ (4LE3) versus: $17 \pm 5$ (MOPC 21): data from 1 representative donor are shown in figure 1B. Permeabilization of monocytes did not enhance the MFI compared with nonpermeabilized cells (data not shown), indicating that BPI was localized only on the surface of the monocytes. Solubilization of monocytes by treatment with $1 \%$ Triton X-100 revealed that these cells, in contrast to PMNL, contained only low amounts of BPI ( $\sim 5 \mathrm{vs}, \sim 100 \mathrm{ng} / 10^{6}$ cells, respectively), further suggesting that $\mathrm{BPJ}$ is present, not inside monocytes but only on the surfaces of these celis.

The use of $F\left(a b^{\prime}\right)_{2}$ fragments of anti-BPI MAb and incubation of monocytes with anti-BPI MAb in the presence of mouse serum or human $\operatorname{IgG}$ also clearly demonstrated the presence 
Table 1. Interaction of LPS with monocyte cell surface BPI.

\begin{tabular}{lcc}
\hline Fluorescent reagent & $\begin{array}{c}\text { Mean } \\
\text { Interfering } \\
\text { reagent }\end{array}$ & $\begin{array}{c}\text { Aluorescence } \\
\text { intensity }\end{array}$ \\
\hline MOPC21-biotin + strep-R-PE & - & $16 \pm 5$ \\
4E3-biotin + strep-R-PE & - & $266 \pm 176$ \\
4E3-biotin + strep-R-PE & LPS & $43 \pm 5$ \\
None & - & $6 \pm 2$ \\
LPS-FITC & MOPC21 & $49 \pm 25$ \\
LPS-FITC & 4E3 & $43 \pm 20$ \\
LPS-FITC & MEM-18 & $52 \pm 29$ \\
LPS-FITC & $17 \pm 12$ \\
\hline
\end{tabular}

NOTE. To test interaction of LPS with monocyte cell surface BPI, influence of LPS on interaction of anti-BPI monoclonal antibody (MAB) 4E3 with cell surface BPI and effect of anti-BPI MAb on interaction of LPS with cell surface were studied. As control MAb, nonspecific myeloma protein MOPC21 and anti-CDI4 MAb MEM-18 were used. Data are mean \pm SE (3 experiments). Strep-R-PE = streptavidin-R-phycoerytherin; LFS-FITC = LPS-fluorescein isothiocyanate.

of BPI on membranes of monocytes (data not shown), indicating that the anti-BPI MAb interacted specifically with the monocyte cell surface. Extensive washing of monocytes, known to remove LBP [13], a serum protein with great sequence homology to BPI, did not reduce BPI cell surface expression, indicating that anti-BPI MAb did not cross-react with LBP. Furthermore, the observation that four independently developed anti-BPI MAbs detected BPI on the surfaces of monocytes confirmed that the antigen detected was indeed BPI. Data from tests with two MAbs are shown in figure 1B.

Comparison of BPI cell surface levels on peripheral blood phagocytes revealed that for all 6 donors tested, MFI of BPI on monocytes was higher than the MFI of BPI on PMNL. (MFI with $4 \mathrm{E} 3,424 \pm 191$ [monocytes] vs. $114 \pm 58$ [PMNL]), suggesting a more abundant presence of $\mathrm{BPI}$ on the surface of monocytes.

Monocyte cell-surface BPI interacts with LPS. Next, we investigated whether the monocyte cell-surface BPI interacts with LPS. We used the property of anti-BPI MAb $4 E 3$ not to react with BPI to which LPS is bound $[9,13]$. For these experiments, we used peripheral blood monccytes isolated from buffy coats, which were also demonstrated to express BPI on the cell surface (data not shown). Monocytes were preincubated with LPS at $4^{\circ} \mathrm{C}$ in the presence of azide to prevent cell activapresence of L.PS prevented interaction of 4E3 with the monocyte cell surface (table 1), which indicated that L.PS interacts with BPI on the surface of monocytes.

Thereafter, we investigated quantitatively the involvement of cell-surface BPI in the interaction of LPS with the cell membrane of monocytes. To this end, we used the capacity of MAb 4E3 to block BPI reactivity with LPS [9]. In accordance with other reports [2,3]. we observed that in the presence of serum, interaction of LPS-FITC with monocytes was mediated mainly via $\mathrm{CDI}$, since the LPS binding was strongly reduced by anti-
CD14 MAb MEM-18 (table 1). Preincubation of monocytes with MAb $4 E 3$ did not reduce the reactivity of LPS-FITC with the cell surface of monocytes (table 1). In the absence of serum, and therefore in the absence of LBP, binding of LPS-FITC to monocytes was strongly reduced (data not shown). Under these conditions, both MAbs 4E3 and MEM-18 did not reduce binding of LPS-FITC to the monocyte surface (data not shown). indicating that under serum-free conditions neither CD14 nor BPI mediates binding of LPS to monocytes. From these data, we conclude that LPS binds to the monocyte cell surface BPI; however, this membrane antigen does not quantitatively contribute to the interaction of LPS with the cell membrane.

The observation that LPS also disturbed the interaction of antiBPI MAb 4E3 to BPI on the PMNL cell surface (data not shown) strongly suggests that BPI is expressed in a similar functional form on the cell surface of both monocytes and PMNL.

In vitro 18-h culture of monocytes in the presence of the protein synthesis inhibitor cycloheximide did not reduce the level of BPI cell-surface expression (data not shown). The activity of cycloheximide was ascertained by inhibition of LPS. induced cytokine release in these cultures. These results suggest either that BPI is produced at a very slow rate by monocytes, with a low turnover rate on the membrane, or that BPI is adsorbed by monocytes from the environment.

Incubation of monocytes with biotin-labeled rBPI $(10 \mu \mathrm{g})$ $\mathrm{mL}$ ) for $30 \mathrm{~min}$ at $37^{\circ} \mathrm{C}$. followed by incubation with strep-R$\mathrm{PE}(1 \mu \mathrm{g} / \mathrm{mL})$ for $30 \mathrm{~min}$ at $4^{\circ} \mathrm{C}$ did not yield a signal. Furthermore, BPI cell-surface expression on monocytes cultured $18 \mathrm{~h}$ in medium containing $10 \% \mathrm{HS}$, and therefore in the presence of BPI ( 1-5 ng/mL), was not enhanced compared with expression on freshly isolated cells (data not shown). Therefore, no indications for (extra) adsorption of BPI were seen. Thesc results could indicate that the amount of BPI on the surfaces of monocytes was already saturated.

If $\mathrm{BPI}$, like the LPS-binding protein albumin [4], is adsorbed to the cell membrane, this adsorption must be a relatively specific process. since plasma of healthy volunteers (in contrass to biologic fluids of patients $[8,14\}$ ) contains low or nondetectable BPI levels [8, 15]. Furthermore, after culture of monocytes for $18 \mathrm{~h}$ in macrophage serum-free medium (and therefore in the absence of human BPI), no reduction of BPI expression was observed compared with freshly isolated cells (data not shown). This suggests that BPI is strongly anchored to the cell membrane, confirming a specific interaction with the etll membrane.

In conclusion, in this study we demonstrated for the first time that peripheral blood monocytes express (in addition to the LPS-binding proteins CD14, CD18, and albumin) the protein BPI, which specifically interacts with LPS, on the cell surface. The origin of monocyte cell-surface BPI remains to be further elucidated.

\section{References}

1. Cumunte JT, Orkin SH, Dinauer MC. Genetic disorders of plagocyte function. In: Stamatoyannopoulos $G$, Nienhuis AW, Majierus PW, Var- 
mus $\mathrm{H}$, eds. The molecular basis of blood diseases. 2nd ed. Philadelphia WE Saunders, 1994:493-540.

2. Wright SD. Muitiple receptors for endotoxin. Curr Opin Immuno 1991:3:83-90

3. Ulevitch RJ. Recognition of bacterial endotoxins by receptor-dependent mechanisms. Adv Immunol 1993;53:267-89.

4. Driarski $\mathbf{R}$ Cell-bound alhurnin is the 70-kDa peptidoglycan-, lipopolysaccharide-, and lipoteichoic acid-binding protein on lymphocytes and macrophages. J Biol Chem 1994;269:20431-6.

5. Martw MN, Wilde CG, Collins MS, Snable $\pi$, Thornton MB, Scott RW. The role of bactericidal/permeability-increasing protein as a naturad inhibitor of bacterial endotoxin. J Immunol 1992; 148:532-7.

6. Weersinik $A J L$, van Kessel KPM, van den Tol ME, et al. Human granuloevtes express a $55-\mathrm{kDa}$ lipopolysaccharide-binding protein on the cell surface that is identical to the bactericidal/permeability-increasing protein. J Immunol 1993; 150:253-63.

7. Elsbach P. Weiss J. Bactericidal/permeability increasing protein and hos defense against gram-negative bacteria and endotoxin. Curr Opin Immunol 1993; 5: 103-7

8. Dentener MA, Francot GJM, Smit FT, et al. Presence of bactericida! permeability-increasing protein in disease: detection by ELISA. I Infect Dis 1995: 171:739-43.
9. Dentener MA. Snit FT, Francot GJM, Buurman WA. Characterization of two monoclonal antibodies directed against bactericidal/permeability. increasing protein. J Infect Dis 1994: 170:1483-9.

10. Graziano RF. Fanger MW. FcyRI and FcyRII on monocytes and granulocytes are cytotoxic trigger molecules for tumor cells. J immuno 1983; 139:3536-4I

11. Kuijpers TW, Tool ATJ, van der Schoot CE, et al. Mermbrane surface amtigen expression on neutrophils: a reappraisal of the use of surface markers for neutrophil activation. Blood 1991; 78:1105-11.

12. Weiss J, Olsson I. Cellular and subcellular localization of the bactericidal permeability-increasing protein of neutrophils. Blood 1937;69:652-9.

13. Dentener MA, von Asmuth EJU, Francot GM, Marra MN, Buurman WA. Antagonistic effects of lipopolysaceharide binding protein and bactericidal/permesbility-increasing protein on lipopolysacchande-induced cytokine release by mononuclear phagocytes: competition for binding to lipopolysaccharide. J Immunol 1993; 151:4258-65.

14. Opal SM, Palardy JE, Marra MN, Fisher CJ Jr, McKelligon BM, Scon RW. Relative concentrations of endotoxin-binding proteins in body fluids during infection. Lancet 1994:344:429-31.

15. White ML, Ma JK, Birt CA, Trown PW, Canoll SF, Measurement of bactericidal/permeability-increasing protein in human body fluids by sandwich EL_ISA. I Immunol Methods 1994; 167:227-35. 
$-118-$ 


\section{Chapter 9}

Bactericidal/Permeability-Increasing Protein Release in Whole Blood Ex Vivo: Strong Induction by Lipopolysaccharide and Tumor Necrosis Factora 


\section{Bactericidal/Permeability-Increasing Protein Release in Whole Blood Ex Vivo: Strong Induction by Lipopolysaccharide and Tumor Necrosis Factor- $\alpha$}

\author{
Mieke A. Dentener, Gaby J. M. Francot, \\ Pieter S. Hiemstra, Anton T. J. Tool, Arthur J. Verhoeven, \\ Peter Vandenabeele, and Wim A. Buurman
}

\author{
Deparments of Pulmonology and Surgery: Laiversity of Limburg. \\ Maastricht and Deparment of Pulmonology. Universiny Hospital \\ Leiden, and Ceniral Laboratory of the Netherlands Red Crass Biood \\ Transfusion Senvice and Laboratory of Clinical and Experimenta! \\ Immunology. Universing of Amsterdam. Netherlands; Laboratany of \\ Molecular Biology. University of Gent. Bejgium
}

\begin{abstract}
In this study, the release of bactericidal/permeablitity-increasing protein (BPI), which is stored in polymorphonuclear leukocytes (PMNL), was analyzed In a whole blood ex vivo system. Of the microbial products tesied, lipopolysaccharide (LPS) most potently lnduced BPI release; FMLP. serum-treated zymosan (STZ), and lipoteichole acid (LTA) also Induced BPI release. In addition, the inflammatory mediator tumor necrosis factor (TNF)- $\alpha$ potently activated PMNL in whole blood, via TNF receptor p55, to release BPI, whereas interleukin $(\mathrm{L})-1, \mathrm{~L}-8$, platelet activating factor, and C5a were poor inducers of BPI release. STZ and phorbol myristate acetate, but not LPS, FMLP, or LTA, stimulated isolated PMNL to release BPI. BPI was released in comparable magnitude with the azurophllic granule protein elastase. Furthermore, both proteins were released with similar kinetics, which started within $30 \mathrm{~min}$ after onset of stimulation and lasted $1-4 \mathrm{~h}$.
\end{abstract}

Lipopolysaccharide (LPS). a glycolipid present in the cell wall of gram-negative bacteria, plays an important role in the pathophysiologic response in gram-negative bacterial infections. The response of the host to LPS is strongly affected by the interaction of endogenous components with LPS. The acule-phase reactant LPS-binding protein (LBP), which is present in plasma of healthy persons at $\sim 10 \mu \mathrm{g} / \mathrm{mL}$, is known to transfer L.PS 10 membrane CDI4 or to the soluble form of CD 14, inducing cell activation (reviewed in [1]). Furthermore, LBP catalyzes binding of LPS to lipoproteins, thus neutralizing biologic activity of L.PS [2]. Polymorphonuclear leukocyles (PMNL) contain other LPS-binding proteins, such as bactericidal/permeability-increasing protein (BPI), lysozyme, lactoferrin, and CAP-18 [3].

BPI, a cationic protein of 456 amino acids with a high binding affinity for LPS, has both strong bactericidal activity and LPS-neutralizing capacity in vitro and in vivo (reviewed in [4]). Initially, BPI was reported to exert its bactericidal activity intracellularly [5]. However, Weinrauch et al. showed that BPI, as present in glycogen-induced sterile inflammatory rabbit periconeal exudate, exhibited bactericidal activity [6], indicating that extracellular BPI has biologic capacity. Furthermore, variuss reports have described that exogenous recombinant BPI ( $\mathrm{BBPl}$ ) has protective capacity in models of experimental endo-

Recerved 17 April 1996; revised 25 July 1906

Financial support: Commission of European Communities. Biotech Project Bip2- $2702-0316$

Blood donors, gave informed sonsen for research

Reprinis or correspondence: Dr. Mieke A. Dentener. Dept. of Surgery. University of Limburg. P.O. Box 616,6200 MD Maastrichi. Nesherlands.

The Journal of Infectious Diseases 1997:175:000-000

C. 1997 by The Unwersiry of Chicago All rights reserved

$0022-1890 / 97750$ ! -000050 ! 00 toxemia and bacteremia [7,8]. These data indicate that $\mathrm{rBPI}$ can overcome the effects of other plasma proteins such as LBP. which, as we have shown, antagonizes BPI activity [9]. The release of BPl by PMNL during disease was demonstrated by the increased levels of BPI in biologic fluids of various patients groups $[10,11]$, as opposed to low or undetectable BPI levels in plasma of healthy volunteers [12.13]. Taken together, these data indicate that BPI released by activated PMNL could contribute to the protection against LPS and gram-negative bacteria.

BPI is stored in the azurophilic granules of PMNL, most probably associated with the granule membrane [14], and is present on the cell surface [15-17]. After stimulation of PMNL, granule constituents are released, with a hierarchy in the mobilization of the four types of PMNL granules: secreiory vesicles, gelatinase granules, specific granules, and azurophilic granules [18]. In vitro data indicate that BPI is released from azurophilic granules in response to stimulation with the combination of cytochalasin $B$ and FMLP [14. 15].

The present study was done to analyze $\mathrm{BPI}$ release in response to physiologic reagents, such as microbial compounds and inflammatory mediators, in a whole blood ex vivo system. Furthermore, the release of BPI was compared with the release of the well-known azurophilic granule protein, elastase.

\section{Materials and Methods}

Reagents and antibodies. Human recombinant tumor necrosis factor (TNF)- $\alpha$ was provided by BASF/Knoll (Ludwigshafen, Germany), recombinant human ( $\mathrm{r}$ ) interleukin (IL)-1B and the dimeric rh-p80:Fc construct [19] by S. Gillis (Immunex, Searle), and rhlL8 by $\mathrm{l}$. Lindley (Sandoz Forschungsinstitut, Vienna). TNF mutants specifically interacting with the TNF receptors (R) TNFR 4 ( $R 32 \mathrm{~W}$ S8ST) or TNFR $_{7}$ (DI43N A 143R) were prepared as described 
[20]. The specific interaction of these TNF- $\alpha$ mutants with either TNFR $_{4 s}$ or TNFR 75 was demonstrated by competitive binding, in solid-phase assays, and in biologic tests in which oniy one receptor type is signal transducing [20-22]. The lipid A compound monophosphoryl lipid A was provided by J. Rudbach (Ribi Immunochem Research. Hamilton, MT) [2.3] and was dissolved by preparing a stock solution of $1 \mathrm{mg} / \mathrm{mL}$ in $0.1 \%$ TEA (vol/vol), which was warmed at $45^{\circ} \mathrm{C}$ and sonicated in a water-bath sonicator for $\sim 5 \mathrm{~min}$. The lipid A analogue SDZ MRL 953 was provided by P. Stütz (Sandoz Forschungsinstitut) and was dissolved as described [24]. In shor, I mg of SDZ MRL 953 was sonicated in $10 \mu \mathrm{L}$ of ethanol for $1 \mathrm{~min}$. During further sonication for $10 \mathrm{~min}$, sterile isotonic glucose solution ( $5.4 \%)$ was added dropwise up to $1 \mathrm{~mL}$.

RPMI 1640 was obtained from GIBCO Europe (Paisley, UK). LPS (from Escherichia coli serotype O55:B5 and from Salmonella minnesolo Re 595), staphylococcal enterotoxin B (SEB), lipoteichoic acid (LTA) derived from Staphylococcus aureus, phorbol myristate acetate (PMA), FMLP, complement factor CSa, plateletactivating factor (PAF), and zymosan were all obtained from Sigma (St. Louis). Zymosan was opsonized as described previously [25] by using pooled human sera from 3 donors, provided by the Red Cross Blood Bank Zuid Limburg (Maastricht, Netherlands). in short, zymosan dissolved in distilled water was heated for i h at $100^{\circ} \mathrm{C}$ and washed with PBS. Subsequently, zymosan was incubated for $30 \mathrm{~min}$ at $37^{\circ} \mathrm{C}$ with an equal volume of untreated human serum, washed with PBS, and stored at $-20^{\circ} \mathrm{C}$. Serum-treated zymosan (STZ) contained $<1 \mathrm{pg} / \mathrm{mL}$ endotoxin, as determined in the limulus amebocyte lysate (LAL) assay (Kabi Pharmacia, Mölndal, Sweden)

The anti-TNF- $\alpha$ monoclonal antibody (MAb) 6IE71 ( $\lg G 1$ ), polyclonal rabbit anti-human TNFR antibody, and polyclonal rabbit anti-human $\mathrm{TNFR}_{75}$ antibody were prepared as described previously $[26,27] . F\left(a b^{\prime}\right)_{2}$ fragments were prepared by pepsin digestion (immobilized pepsin; Pierce, Rockford, IL). MAb IB4 ( $\lg 22 a$ ), reactive with CD18, was a gift from $M$. Daha (University Hospital Leiden).

Whole blood collection and stimulation. Blood from healthy volunteers was anticoagulated in $10-\mathrm{mL}$ blood collection vacuum tubes (Sherwood Medical, St. Louis) containing $0.1 \mathrm{~mL}$ of heparin at $500 \mathrm{JU} / \mathrm{mL}$ (Leo Pharmaceutical Products, Weesp, Netherlands). The heparin contained $<\mathrm{I} \mathrm{pg/mL}$ endotoxin, as determined in the LAL assay. Whole blood was stimulated in nonrotating polypropylene tubes (Costar. Cambridge, MA) at $37^{\circ} \mathrm{C}$. with indicated reagents for indicated time periods. Plasma was separated from blood cells by centrifugation for $5 \mathrm{~min}$ at $1500 \mathrm{~g}$ and stored at $-20^{\circ} \mathrm{C}$ until analyzed by ELISA. For differential blood cell counts, blood was anticoagulated in $3-\mathrm{mL}$ tubes containing $0.03 \mathrm{~mL}$ of $15 \%$ (wtwt) EDTA and analyzed using a MAX-M counter (Coulter, Luton, UK). The amount of BPI or elastase detected in plasma was corrected for the total PMNL present in whole blood and expressed in nanograms per $10^{\wedge} \mathrm{PMNL}$.

PMNL isolation and stimulation. PMNL were obtained either from the buffy caat of $500 \mathrm{~mL}$ of blood anticoagulated with $0.4 \%$ ( $w / v o l$ ) trisodium citrate, $\mathrm{pH} \mathrm{7.4,} \mathrm{or} \mathrm{from} \mathrm{whole} \mathrm{blood} \mathrm{of} \mathrm{healthy}$ volunteers anticoagulated with heparin as described above. PMNL were isolated using standard procedures. In short, blood cells were separated by density-gradient centrifugation over Lymphoprep (Nycomed, Oslo). The interphase, containing the mononuclear leu- kocytes, was removed, and the remaining mixture of PMNL, and red blood cells was treated for $30 \mathrm{~min}$ with ice-cold isotonic $\mathrm{NH}_{4} \mathrm{C}$ solution (155 mM NH${ }_{4} \mathrm{Cl}, 10 \mathrm{mM} \mathrm{KHCO}_{3}, 0.1 \mathrm{mM}$ EDTA, pH 7.4) to lyse the erythrocytes. The remaining PMNL were washed twice. The PMNL had a purity of $>98 \%$, and consisted mainly of neutrophils (>95\%).

Untreated PMNL were lysed in the following ways: (1) cells were dissolved in $0.5 \%$ Triton X-100 in HEPES buffer (132 $\mathrm{mm}$ $\mathrm{NaCl}, 6 \mathrm{mM} \mathrm{KCl}, 1 \mathrm{mM} \mathrm{CaCl}, 1 \mathrm{mM} \mathrm{MgSO}, 1.2 \mathrm{mM}$ potassium phosphate, $20 \mathrm{mM}$ HEPES, $5.5 \mathrm{mM}$ glucose, and $0.5 \%$ [wivol]

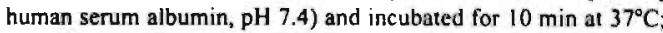
(2) cells were dissolved in HEPES buffer, followed by three freezethaw cycles; (3) cells were dissolved in $100 \mathrm{mM}$ glycine, pH 2.0 . followed by three freeze-thaw cycles: (4) cells, dissolved in HEPES buffer, were sonicated three times for $10 \mathrm{~s}, 8 \mu \mathrm{m}$ peak to peak at $4^{\circ} \mathrm{C}$. Isolated PMNL $\left(2-5 \times 10^{6} / \mathrm{mL}\right)$ were resuspended in RPMI 1640 and stimulated in nonrotating polypropylene tubes at $37^{\circ} \mathrm{C}$, with the indicated reagents. After a $\mathrm{J}-\mathrm{h}$ incubation, the supernatant was separated from PMNL by centrifugation for $5 \mathrm{~min}$ at $1500 \mathrm{~g}$ and stored at $-20^{\circ} \mathrm{C}$ until analyzed by ELISA. Cell viability during the experiment was testcd by lactate dehydrogenase release, which was $<2 \%$ under all experimental conditions. The amount of BPI detected in the supematant was corrected for the amount of PMNL present and expressed in nanograms per $10^{h}$ PMNL.

BPI ELISA. BPI concentration was determined using a sandwich ELISA as described previously [12]. In short, 96-well $1 \mathrm{~m}$ muno Maxisorp plates (Nunc, Roskilde, Denmark) were coated overnight at $4^{\circ} \mathrm{C}$ with human BPI-specific MAb 4E. The wash and dilution buffer consisted of $80 \mathrm{mM} \mathrm{MgCl}, 50 \mathrm{mM}$ TRIS- $\mathrm{HCl}$, pH $7.4,150 \mathrm{mM} \mathrm{NaCl}, 0.1 \%$ bovine senum albumin, and $0.05 \%$ Tween 20; the plates were washed five times after each incubation step. Human rBPl (provided by M. Мarra, Incyte, Palo Alto, CA) was used as the standard. Samples were diluted in buffers (resulting in final buffer composition similar to that of assay buffer), added to the plates, and incubated for $2 \mathrm{~h}$ at room temperature. Next, 5 $\mu \mathrm{g} / \mathrm{mL}$ biotinylated polyclonal rabbit anti-human $\mathrm{BPI} \mathrm{lgG}$ was incubated for $\mathrm{l} h$ at room temperature. Peroxidase-conjugated streptavidin (Dakopatts, Glostrup, Denmark) diluted in PHS-0.1\% bovine serum albumin was added, and after a $1-h$ incubation, plates were washed with distilled water containing $0.1 \%$ Tween 20 . TMB (3.3',5,5'tetramethylbenzidine; KPL. Gaithersburg, MD) was used as a substrate for peroxidase. Spectrophotometry $(450 \mathrm{~nm})$ was done using a microELISA autoreader. The detection limit of the assay was $200 \mathrm{pg} / \mathrm{mL}$.

Elaslase ELISA. Human neutrophil elastase was detected by a sandwich ELISA. Briefly, microwells (Immulon 4: Dynatech Laboratories, Chantilly, VA) were coated ovemight at room temperanure with polyclonal rabbit anti-human elastase $\operatorname{lgC}$. Both standard serial dilutions of elastase purified from purulent sputum [28] and samples were diluted in PBS containing $0.05 \%$ (vol $/ \mathrm{vol}$ ) Tween-20 and $1 \%$ (vol/vol) heat-inactivated newborn calf serum and incubated for $1 \mathrm{~h}$ at $37^{\circ} \mathrm{C}$. Bound elastase was detected using biotinylated rabbit anti-human elastase $\mathrm{lgG}$, followed by peroxidase-conjugated streptavidin, which were both incubated for $1 \mathrm{~h}$ at $37^{\circ} \mathrm{C}$. The lower detection limit of the assay was $<0.4 \mathrm{ng} / \mathrm{mL}$. Cross-reactivities of this ELISA with highly purified preparations of the PMNL proteinases, cathepsin $G$ (purified from purilent 
sputum), and proteinase 3 (gift from M. Daha), were $<0.3 \%$ and $<0.01 \%$, respectively.

Statisfics. Data are presented as mean $\pm S D$, representing interassay results. For each phase of the study, a different group of 4-6 persons was used, except for the data presented in tables 1 and 2 , which were derived from the same group of persons. Statistical analyses were performed using a one-tailed Wilcoxon signed-rank test. Each subject's whole blood or neutrophils were used as the simultaneous control for the paired statistical analysis. $P<.05$ was considered statistically significant.

\section{Results}

Total BPI content of PMNL. First, the total amount of BPI in PMNL was determined. To this end, PMNL obtained from buffy coats were lysed using different methods. Dissolving

Table 1. BPI release in whole blood induced by microbial products.

\begin{tabular}{|c|c|c|}
\hline Reagent & Concentration & $\mathrm{BPI}\left(\mathrm{ng} / 10^{*} \mathrm{PMNL}\right)$ \\
\hline None & - & $1.9 \pm 1.2$ \\
\hline \multirow[t]{5}{*}{ LPS (Escherichia coli) } & $10 \mathrm{pg} / \mathrm{mL}$ & $4.1 \pm 2.4^{*}$ \\
\hline & $100 \mathrm{pg} / \mathrm{mL}$ & $4.9 \pm 1.7^{\circ}$ \\
\hline & $1 \mathrm{ng} / \mathrm{mL}$ & $6.6 \pm 3.6^{\circ}$ \\
\hline & $10 \mathrm{ng} / \mathrm{mL}$ & $8.7 \pm 4.4^{\circ}$ \\
\hline & $100 \mathrm{ng} / \mathrm{mL}$ & $9.7 \pm 4.5^{*}$ \\
\hline \multirow[t]{5}{*}{ LPS (Salmonella minnesora) } & $10 \mathrm{pg} / \mathrm{mL}$ & $1.9=1.0$ \\
\hline & $100 \mathrm{pg} / \mathrm{mL}$ & $3.3=2.3^{\circ}$ \\
\hline & I $\mathrm{ng} / \mathrm{mL}$ & $2.9 \pm 2.0$ \\
\hline & $10 \mathrm{ng} / \mathrm{mL}$ & $4.1 \pm 2.9^{\circ}$ \\
\hline & $100 \mathrm{ng} / \mathrm{mL}$ & $7.3 \pm 4.6^{\circ}$ \\
\hline \multirow[t]{3}{*}{ MPL } & $100 \mathrm{ng} / \mathrm{mL}$ & $3.1=1.7^{\circ}$ \\
\hline & $1 \mu \mathrm{g} / \mathrm{mL}$ & $4.3 \pm 2.2^{\circ}$ \\
\hline & $10 \mu \sigma^{\mathrm{mL}}$ & $5.8 \pm 4.0^{\circ}$ \\
\hline \multirow[t]{2}{*}{ SDZ MRL 953} & $1 \mu g / m L$ & $2.0 \pm 1.0$ \\
\hline & $10 \mu \mathrm{g} / \mathrm{mL}^{2}$ & $3.1 \pm 2.0^{\circ}$ \\
\hline \multirow[t]{3}{*}{ FMLP } & $10^{-n} M$ & $3.9 \pm 2.4$ \\
\hline & $10^{-1} \mathrm{M}$ & $6.0 \pm 3.0^{\circ}$ \\
\hline & $10^{-6} M$ & $8.2 \pm 4.3^{\circ}$ \\
\hline \multirow[t]{4}{*}{ LTA } & I ng/mL & $2.4 \pm 1.7$ \\
\hline & $10 \mathrm{ng} / \mathrm{rnL}$. & $3.6 \pm 2.0^{*}$ \\
\hline & $100 \mathrm{ng} / \mathrm{mL}$. & $6.1 \pm 2.7^{\circ}$ \\
\hline & $\mu \mathrm{g} \sin \mathrm{L}$ & $8.5 \pm 3.7^{\circ}$ \\
\hline \multirow[t]{2}{*}{ SEB } & $\mu \mathrm{gmL}$ & $1.9 \pm 1.2$ \\
\hline & $10 \mu \mathrm{g} / \mathrm{mL}$ & $2.4 \pm 1.7$ \\
\hline \multirow[t]{3}{*}{ STZ } & $1 \mu g / m L$ & $2.2 \pm 1.5$ \\
\hline & $10 \mu / / \mathrm{mL}$ & $2.9 \div 1.7^{*}$ \\
\hline & $100 \mu \mathrm{g} / \mathrm{mL}$ & $8.2 \pm 3.7^{\circ}$ \\
\hline \multirow{3}{*}{ PMA } & $10^{-61} \mathrm{M}$ & $2.3 \pm 1.6$ \\
\hline & $10^{-11} M$ & $4.2 \pm 2.0^{\circ}$ \\
\hline & $10^{-7} M$ & $10.3 \pm 4.2^{*}$ \\
\hline
\end{tabular}

NOTE. Heparinized whole hlood was incubated for $1 \mathrm{~h}$ at $37^{\circ} \mathrm{C}$ with indicated reagents. BPI in plasma was detected by ELISA and is expressed in $\mathrm{ng} / 10^{\mathrm{T}} \mathrm{PMNL}$. Mean $\pm \mathrm{SD}$ of results from 5 donors is shown. BPI, bactericida/ permeabiliry-increasing prorein; PMNL., polymorphonuclear leukocyes; LPS. iipopolysaccharide: MPL. monophosphoryl lipid A: LTA. lipoteichoic acid; SEB. staphylococcal enterotoxin B: STZ, serum-rreated zymosan; PMA, phorbol myristale acetate.

$-P<.05$ vs: spontaneous BPI release. by I-tailed Wilcoxon signed-rank test.
Table 2. Effect of inflammatory mediators on BPI release in whole blood.

\begin{tabular}{lcc}
\hline Reagent & Concentration & BPI (ng/10 PMNL \\
\hline None & - & $1.9 \pm 1.2$ \\
TNF- $\alpha$ & $10 \mathrm{pg} / \mathrm{mL}$ & $2.8 \pm 1.8^{\circ}$ \\
& $1 \mathrm{ng} / \mathrm{mL}$ & $8.2 \pm 3.4^{\circ}$ \\
IL-18 & $100 \mathrm{mg} / \mathrm{mL}$ & $11.1 \pm 43^{\circ}$ \\
& $10^{\prime} \mathrm{U} / \mathrm{mL}$ & $2.3 \pm 1.7$ \\
IL-8 & $10^{\circ} \mathrm{U} / \mathrm{mL}$ & $3.9 \pm 2.7^{\circ}$ \\
& $100 \mathrm{ng} / \mathrm{mL}$ & $2.1 \pm 1.3$ \\
PAF & $1 \mu \mathrm{g} / \mathrm{mL}$ & $3.1 \pm 1.7^{\circ}$ \\
& $10 \mathrm{nM}$ & $2.7 \pm 1.7^{\circ}$ \\
& $100 \mathrm{nM}$ & $3.5 \pm 2.1^{\circ}$ \\
CS. & $1 \mu M$ & $3.8 \pm 1.7^{\circ}$ \\
& $100 \mathrm{ng} / \mathrm{mL}$ & $2.7 \pm 1.8$ \\
& $1 \mu \mathrm{g} / \mathrm{mL}$ & $2.9 \pm 1.8$ \\
\hline
\end{tabular}

NOTE. Heparinized whole blood was incubated for $1 \mathrm{~h}$ at $37^{\circ} \mathrm{C}$ with indicated reagents. BPI in plasma was detected by ELISA and is expressed in $\mathrm{ng} / 10^{6} \mathrm{PMNL}$. Mean \pm SD of resulis from 5 donors is shown. BPI, bactericidal permeability-increasing protein; PMNL. polymorphonuclear leukocytes: IL. interleukin: PAF, platelet-activating factor.

- $P<.05$ vs. spontaneous BPI release, by 1-railed Wilcoxon signed-rank test.

PMNL in either $0.5 \%$ Triton $X-100$ or in $100 \mathrm{mM}$ glycine, $\mathrm{pH}$ 2.0 , followed by three freeze-thaw cycles yielded comparable $B P I$ release. The $B P I$ content per $10^{\wedge}$ PMNL of 4 donors was $182 \pm 101 \mathrm{ng}$ (mean $\pm \mathrm{SD}$ ). Dissolving the cells in HEPES buffer followed by three freeze-thaw cycles resulted in cell destruction, as measured by release of the cytosolic protein lactate dehydrogenase (data not shown), but hardly affected azurophilic granules (only $13 \%$ of the BPI was recovered) compared with the Triton X-100 treatment. Sonication of cells in isotonic medium induced a BPI recovery of $86 \%$, compared to the Triton X-100 treatment. Measurement of BPI by ELISA was not disturbed by different lysis media because the samples were diluted at least 100 times. These data indicate that because $1 \mathrm{~mL}$ of blood from healthy individuals contains $\sim 3-8 \times 10^{\text {n }}$ PMNL, the maximal amount of BPI released after stimulation of whole blood will be $500-1500 \mathrm{ng} / \mathrm{mL}$.

Inducrion of BPI release by microbial products. First the capacity of microbial reagents to induce $\mathrm{BPI}$ release was studied. Whole blood was incubated at $37^{\circ} \mathrm{C}$ in polypropylene tubes to minimize PMNL adherence. Since minimal spontaneous BPI release was seen after $\mathrm{l} \mathrm{h}$ incubation in nonagitated tubes, whereas considerable BPI release was observed after LPS exposure (data not shown), we used a 1-h incubation period at $37^{\circ} \mathrm{C}$. Unstimulated PMNL in whole blood released $\sim 1 \%$ of their total BPI content (table 1). Products derived from gramnegative bacteria were strong inducers of BPI release. Both smooth L.PS, derived from $E$. coli $055: \mathrm{BS}$, at $\geqslant 10 \mathrm{pg} / \mathrm{mL}$, and rough LPS, derived from $S$. minnesora, at $100 \mathrm{pg} / \mathrm{mL}$, activated PMNL in whole blood 10 release BPI. In addition, two lipid A analogues were able to induce BPI release in whole blood. Monophosphoryl lipid A had to be used at $100 \mathrm{ng} / \mathrm{mL}$ and 
SDZ MRL 953 at $10 \mu \mathrm{g} / \mathrm{mL}$ to exert this effect. Furthermore, at submicromolar concentrations, FMLP strongly activated PMNL to release BPI. In addition, two products of gram-positive bacteria were tested. The cell wall component LTA induced release of BPI, although not as potently as the components of gram-negative bacteria, whereas SEB did not induce BPI release. Furthermore, STZ was found to activate PMNL, leading to the release of BPI. The anti-CD18 MAb IB4 did not affect $\mathrm{BPI}$ release as induced by microbial reagents (data not shown), indicating that CD18 is not involved in activation of PMNL to release $\mathrm{BPI}$ in these experiments. Furthermore, PMA, which directly activates protein kinase $C$, induced BPI release (table 1), indicating that one of the signal transduction pathways leading to $B P I$ release is mediated via protein kinase $C$ activation.

$T N F-\alpha$ triggers $P M N L$ to release $B P I$ via $T N F R_{5}$ whereas the inflammatory mediators IL-IB, IL-8, and PAF are weak inducers of BPI release. In response to infection with gramnegative bacteria or LPS, an array of inflammatory mediators is produced. Therefore, we analyzed several inflammatory mediators for their ability to induce BPI release in whole blood. As shown in table 2. TNF- $\alpha$ strongly induced the release of BPI, at concentrations as low as $10 \mathrm{pg} / \mathrm{mL}$. Since PMNL express two receptors for TNF- $\alpha$, a 55-kDa (TNFR $s$ ) and a 75$\mathrm{kDa}\left(\mathrm{TNFR}_{73}\right.$ ) receptor, which are both able to mediate part of TNF- $\alpha$ activities $[27,29]$. we analyzed which receptor was involved in TNF- $\alpha$-induced BPI release. To this end, whole blood was incubated with polyclonal rabbit anti-human TNFR $_{35}$ antibody or polyclonal rabbit anti-human TNFR $_{75}$ antibody, which have previously been shown to exert agonistic properties [27]. In response to polyclonal rabbit anti-human TNFR s, antibody, considerable amounts of BPI were released, whereas high concentrations of polyclonal rabbit anti-human TNFR $_{75}$ antibody were required to induce release of low amounts of BPI (table 3). To exclude activation of PMNL via Fc receptors, experiments were repeated with $F\left(a b^{\prime}\right)_{3}$ fragments of polyclonal rabbit anti-human TNFR $\$$ antibody. which yielded comparable results (table 3). In addition, the TNF mutant R32W S85T, which specifically interacts with $\mathrm{TNFR}_{33}$, strongly induced BPI release in whole blood, whereas the TNF mutant D143N A143R, specifically interacting with $T_{N F R}$, had no effect on $\mathrm{BPI}$ release (table 3 ). These data strongly indicate that TNF- $\alpha$ activates PMNL to release BPI via TNFR ss.

The other inflammatory mediators analyzed, the cytokine IL-IB, the chemokine IL-8, the lipid mediator PAF, and the activated complement component $\mathrm{C} 5 \mathrm{a}$, induced the release of none or low amounts of BPI (table 2). Even the combined exposure to PAF $(100 \mathrm{nM})$ and $\mathrm{IL}-8(1 \mu \mathrm{g} / \mathrm{mL})$, which was described to have a synergistic effect upon NADPH oxidase activation [30], hardly induced BPI release (data not shown).

Since LPS is known to induce the release of TNF- $\alpha$ by monocytes, which is (as shown in table 2) a potent inducer of $\mathrm{BPI}$ release, we analyzed whether TNF- $\alpha$ is an intermediate in LPS-induced BPI release. To this end, whole blood was activated for 1 and $4 \mathrm{~h}$ with different concentrations of LPS
Table 3. TNF- $\alpha$-induced BPI release is mediated via TNF receptor (R) TNFR :s-

\begin{tabular}{|c|c|c|}
\hline Reagent & Concentration & BPl ing $/ 10^{\circ}$ PMNL) \\
\hline None & - & $3.3 \pm 1.7$ \\
\hline \multirow[t]{4}{*}{ TNF-a } & $100 \mathrm{pg} / \mathrm{mL}$ & $4.1 \pm 2.1$ \\
\hline & I ngimL & $9.8=5.1^{\circ}$ \\
\hline & $10 \mathrm{ng} / \mathrm{mL}$ & $17.7=9.1^{\circ}$ \\
\hline & $100 \mathrm{ng} / \mathrm{mL}$ & $30.1=15.0^{\circ}$ \\
\hline \multirow[t]{3}{*}{ pAb TNFR ss } & $100 \mathrm{ng} / \mathrm{mL}$ & $8.7 \pm 6.4^{\circ}$ \\
\hline & $\mathrm{I} \mu \mathrm{g} / \mathrm{mL}$ & $24.5 \pm 21.9^{\circ}$ \\
\hline & $10 \mu \mathrm{g} / \mathrm{mL}$ & $23.4=16.1^{*}$ \\
\hline \multirow[t]{3}{*}{$F\left(a b^{\prime}\right)_{h} p A b T^{\prime} R_{93}$} & $100 \mathrm{ng} / \mathrm{mL}$ & $4.5 \div 3.2$ \\
\hline & $1 \mu \mathrm{g} / \mathrm{mL}$ & $130 \pm 18.1 *$ \\
\hline & $10 \mu \mathrm{g} / \mathrm{mL}$ & $21.4=12.6^{\circ}$ \\
\hline \multirow[t]{3}{*}{ PAb TNFR, } & $100 \mathrm{ng} / \mathrm{mL}$ & $2.8 \pm 1.2$ \\
\hline & $1 \mu \mathrm{g} / \mathrm{mL}$ & $2.9=1.4$ \\
\hline & $10 \mu \mathrm{g} / \mathrm{mL}$ & $5.0 \pm 2.7^{\circ}$ \\
\hline \multirow[t]{4}{*}{ R32W S8ST' } & $100 \mathrm{pg} / \mathrm{mL}$ & $4.3=2.4^{\circ}$ \\
\hline & $3 \mathrm{ng} / \mathrm{mL}$ & $5.7=2.6^{*}$ \\
\hline & $10 \mathrm{ng} / \mathrm{mL}$ & $12.8=4.8^{\circ}$ \\
\hline & $100 \mathrm{ng} / \mathrm{mL}$ & $2.1 .21=7.0^{\circ}$ \\
\hline \multirow[t]{4}{*}{ D143N A145R! } & $100 \mathrm{pg} / \mathrm{mL}$ & $3.0 \pm 1.1$ \\
\hline & $1 \mathrm{ng} / \mathrm{mL}$ & $3.1 \pm 1.5$ \\
\hline & $10 \mathrm{ng} / \mathrm{mL}$ & $3.0 \pm 1.8$ \\
\hline & $100 \mathrm{ng} / \mathrm{mL}$ & $4.5 \div 3.8$ \\
\hline
\end{tabular}

NOTE. Hepannized whole blood was incubaled for $1 \mathrm{~h}$ at $37^{\circ} \mathrm{C}$, with indicated reagents. BPI in plasma was detecied by ELISA and is expressed in $\mathrm{ng} / 10^{\circ}$ PMNL. Mean $\neq \mathrm{SD}$ of results from 6 donors is shown. EPI, bactericidal/ permeabiliry-increasing protein: PMNL. polymorphonuclear leukocytes; pAb, polyclonal rabbit anti-human antibedy.

- $P<.05$ vs. spontaneous BPI release, by I-tailed Wilcoxon signed-rank iest.

'R32W S85T, TNF mutant that specificaliy interacts with TNFR,y.

"D143N A 145R. TNF mulant that specifically interacts with TNFR",

in the absence or presence of anti-TNF MAb $61 E 71$ and the dimeric th-p80:Fc construct, which are both known to block. biologic effects of TNF- $\alpha[19,26]$. The presence of these TNF$\alpha$ blocking agents did not inhibit LPS-induced BPI release but did inhibit TNF- $\alpha$-induced BPI release (f̂gure 1), suggesting that LPS-induced BPI release was not mediated via TNF- $\alpha$.

Release of BPI by isolated PMNL versus by PMNL in whole blood. Next, BPI release by isolated PMNL versus PMNL in whole blood was studied. Isolated PMNL were dissolved in RPMI 1640 and stimulated, in parallel with whole blood from the same donor, for $1 \mathrm{~h}$ at $37^{\circ} \mathrm{C}$. Spontaneous BPI release by PMNL in whole blood was higher than that by isolated PMNL (table 4). This difference is partially due to a larger cellular volume of whole blood compared with that of the PMNL suspension, thus reducing the volume in which BPI is present and enhancing the BPI concentration. To compare the capacity of various reagents to induce BPI release by isolated PMNL versus by PMNL in whole blood, the stimulation index (the ratio of the amount of BPI released after stimulation to spontaneous BPI release) was calculated (table 4). Isolated PMNL were strongly activated to release BPI after stimulation with PMA and STZ, with a stimulation index comparable to that of PMNL 
A

Figure 1. Effect of anti-TNF-a monoclonal antibody (MAb) 6IE7I on A, lipopolysaccharide (LPS) and B. TNF-a-induced BPI release in whole blood. Whole blood was stimulated for $1 \mathrm{~h}$ with various concentrations of LPS or TNF- $\alpha$ in absence or presence of anti-TNF-a MAb 6IE7I. BPI was measured in plasma using specific EL.ISA and is expressed in $\mathrm{ng} / 10^{6}$ PMNL. One representative experiment of series of 3 is shown.

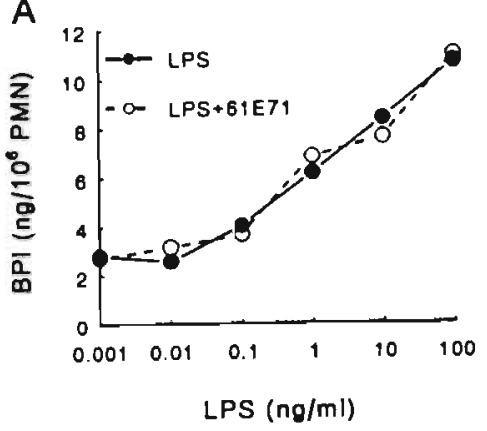

B

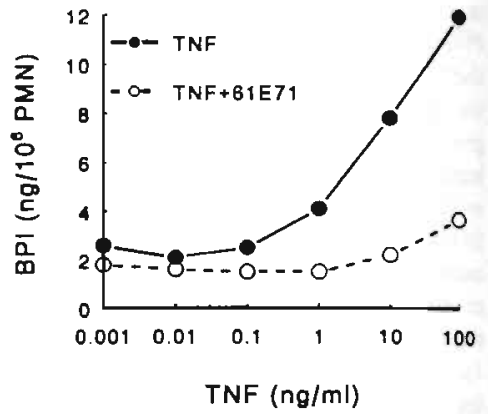

in whole blood. However, in response to LPS, LTA, and FMLP, isolated PMNL released only very low amounts of BPI, in contrast to the substantial BPI release induced by these agents in whole blood (table 4, table 1). These data suggest that phagocytosis of zymosan and activation of protein kinase $C$ directly activated PMNL to release BPI, whereas the LPS-. LTA- and FMLP-induced BPI release appeared to be dependent on other blood components.

$B P I$ release compared with elastase release. Release of elastase is often considered as a marker for the release of azurophilic granule proteins. Since several types of azurophilic granules exist in PMNL, which differ in intragranular distribution of BPI and elastase [31], we compared the release of both proteins in whole blood. First, total arnounts of elastase and BPI present in PMNL were compared. To this end. whole blood was lysed with $0.5 \%$ Triton $X-100$, and the amount of either protein was expressed per $10^{\circ} \mathrm{PMNL}$. Considerably higher amounts of elastase than BPI were present in PMNL (mean \pm SD of 6 donors was $3169 \pm 977$ vs. $150 \pm 79 \mathrm{ng} / 10^{6} \mathrm{PMNL}$, respectively). Next, whole blood was activated with a series of agents demonstrated to be either potent or low inducers of BPI release in whole blood. Table 5 shows that higher amounts of elastase than of BPI were released. However. presenting the data as percentage of total elastase or BPI content in PMNL revealed that elastase and $\mathrm{BPI}$ were released to a comparable magnitude in response to the various stimuli.

Kinetics of $B P I$ and elastase release. In the above-dzscribed experiments, BPI release was analyzed after a $1-h$ incubation. Next, we analyzed the kinetics of BPI release induced by those agents demonstrated to be potent inducers of BPI release. To this end, whole blood was stimulated. and after various time points after onset of stimulation, an aliquot was harvested and analyzed for the amount of BPI. Of the stimuli tested, STZ and FMLP most rapidly induced the release of $\mathrm{BPI}$, within $10 \mathrm{~min}$ from onset of stimulation (figure $2 \mathrm{~A}$ ). TNF$\alpha$ and PMA also induced $\mathrm{BPI}$ release within $10 \mathrm{~min}$ after activation; in contrast, the LPS- and LTA-induced $B P I$ release staned 10-30 min after stimulation (figure $2 \mathrm{~A}$ ). The release

Table 4. Release of BPI by isolated PMNL versus by PMNL in whole blood

\begin{tabular}{|c|c|c|c|c|c|}
\hline Reagent & Concentration & $\begin{array}{c}\text { Isolated PMNL (supernaunt) } \\
\text { BPI (ng/10* PMNL) }\end{array}$ & SI & $\begin{array}{l}\text { Whole blood (plasma) } \\
\text { BPI (ng/10. PMNL) }\end{array}$ & \$1 \\
\hline None & - & $1.9 \pm 1.4$ & 1.0 & $5.0 \pm 3.2$ & 1.0 \\
\hline \multirow[t]{2}{*}{ LPS (Escherichia coll) } & $1 \mathrm{ng} / \mathrm{mL}$ & $1.5 \pm 0.8$ & $0.9 \pm 0.1$ & $12.6=4.7^{\circ}$ & $2.8=0.6$ \\
\hline & $100 \mathrm{ng} / \mathrm{mL}$ & $2.4 \pm 0.9$ & $1.6 \pm 0.6$ & $24.1 \pm 5.4^{\circ}$ & $5.8 \pm 2.6$ \\
\hline FMLP & $10^{-6} \mathrm{M}$ & $2.0 \pm 1.0$ & $1.2 \pm 0.5$. & $22.8 \pm 13.3^{\circ}$ & $4.5 \pm 1.0$ \\
\hline \multirow[t]{2}{*}{ LTA } & $10 \mathrm{ng} / \mathrm{mL}$ & $1.3 \pm 0.6$ & $0.8=0.2$ & $7.3 \pm 4.9$ & $1.5 \pm 0.5$ \\
\hline & $1 \mu \mathrm{g} / \mathrm{mL}$ & $2.1 \pm 0.8$ & $1.4 \pm 0.6$ & $16.8=6.2^{\circ}$ & $4.1 \pm 2.4$ \\
\hline SIR & $100 \mu \mathrm{g} / \mathrm{mL}$ & $5.8=4.4^{\circ}$ & $3.1=0.8$ & $15.8=9.9^{\circ}$ & $3.1 \pm 0.9$ \\
\hline PMA & $10^{-7} \mathrm{M}$ & $8.2=4.2^{\circ}$ & $5.0 \pm 1.6$ & $27.5 \pm 12.9^{\circ}$ & $5.7 \pm 1.2$ \\
\hline
\end{tabular}

NOTE. PMNL were isolated from heparinized whole blood of healthy individuals and stimulated parallel with heparinized whole blood of same donor for $1 \mathrm{~h}$ at $37^{\circ} \mathrm{C}$. BP1 concentration in supernatant or plasma was determined using ELISA and is expressed in ng/10 PMNL. Dalu are mean \pm SD of 5 denors. BPI, bactericidal permeabilityincreasing protein; PMNL, polymorphonuclear leukocytes; LPS, lipopolysaccharide: LTA, Lipoteichoic acid; STZ, serum-treated zymosan. SI, stimulation index, expressed as natio of BPI released after stimulation to spontaneous BPI release:

$-P<.05$ vs. spontancous BPI release, by 1-tailed Wilcoxon signed-rank test. 
Table 5. Comparison of BPI and elastase release in whole blood.

\begin{tabular}{|c|c|c|c|c|c|}
\hline Reagent & Concentration & $\begin{array}{l}\text { Absolute amounts of } \\
\text { BPI (ng/10^ PMNL) }\end{array}$ & Elastase (ng/10 $10^{\circ} \mathrm{MNL}$ ) & $\begin{array}{l}\% \text { of total amount } \\
\text { of BPI }\end{array}$ & Elastase $(\%)$ \\
\hline None & - & $1.5=0.5$ & $56.0 \pm 10.0$ & $1.1 \pm 0.5$ & $2.1 \pm 0.6$ \\
\hline LPS $(E$. coli $)$ & $100 \mathrm{ng} / \mathrm{mL}$ & $16.4 \pm 10.1$ & $272.1 \pm 56.0$ & $10 . \overline{0} \pm 3.7$ & $10.8 \pm 3.1$ \\
\hline LPS (S. minnesola) & $100 \mathrm{ng} / \mathrm{mL}$ & $12.2 \pm 8.8$ & $199.2 \pm 45.8$ & $6.9 \pm 2.3$ & $7.8 \pm 1.9$ \\
\hline FMLP & $10^{-6} M$ & $12.8 \pm 7.4$ & $292.1 \pm 36.7$ & $7.9 \pm 3.0$ & $11.5 \pm 2.2$ \\
\hline LTA & $\mathrm{l} \mu \mathrm{g} / \mathrm{mL}$ & $18.6 \pm 7.9$ & $370.2 \pm 124.8$ & $12.8 \pm 5.6$ & $14.0 \pm 3.6$ \\
\hline SEB & $1 \mu \mathrm{g} / \mathrm{mL}$ & $2.4 \pm 1.0$ & $80.6=13.2$ & $1.8 \pm 1.2$ & $3.1 \pm 0.2$ \\
\hline STZ & $100 \mu \mathrm{g} / \mathrm{mL}$ & $19.1 \pm 10.1$ & $477.7 \pm 88.9$ & $10.7 \pm 1.5$ & $18.8 \pm 4.4$ \\
\hline PMA & $10^{-1} M$ & $13.3 \pm 8.3$ & $110.7 \pm 9.0$ & $7.8 \pm 2.4$ & $4.4 \pm 0.7$ \\
\hline$T N F-\alpha$ & $100 \mathrm{ng} / \mathrm{mL}$ & $35.2 \pm 24.8$ & $517.8 \pm 269.4$ & $20.0 \pm 8.7$ & $21.0 \pm 12.7$ \\
\hline $\mathrm{IL}-1 \beta$ & $10^{4} \mathrm{U} / \mathrm{mL}$ & $3.6 \pm 2.2$ & $102.9 \pm 9.0$ & $3.9 \pm 0.9$ & $4.0=0.1$ \\
\hline IL-8 & $1 \mu \mathrm{g} / \mathrm{mL}$ & $2.8 \pm 1.0$ & $103.1 \pm 10.4$ & $2.1 \pm 1.1$ & $4.0 \pm 0.5$ \\
\hline PAF & $1 \mu M$ & $6.6 \pm 3.6$ & $189.3 \pm 21.6$ & $3.9 \pm 0.9$ & $7.4 \pm 1.1$ \\
\hline $\mathrm{CSa}_{\mathrm{a}}$ & $\mathrm{I} \mu \mathrm{g} / \mathrm{mL}$ & $2.7 \pm 0.4$ & $124.2 \pm 41.6$ & $2.2 \pm 1.5$ & $4.8 \pm 1.5$ \\
\hline
\end{tabular}

NOTE. Heparinized whole blood was incubated for $1 \mathrm{~h}$ at $37^{\circ} \mathrm{C}$ with indicated reagents. BPI and elastace concentration in plasma were determined with specific ELISAs and are expressed in ng/10 PMNL. Data are mean \pm SD of 4 donors. Data are also expressed as \% of reiease of total BPI or elastase content of PMNL, determined for each donor by lysis of aliquol of blood immediately after collection. BPI, bactericidalipermeability-increasing protein; PMNL, polymorphonuclear leukocytes: LPS, lipopolysaccharide; $E$. coli, Escherichia coll: $S$. minnesota, Salmonella minnesola: LTA, lipoteichoic acid; SEB, staphylococcal enterotoxin B: STZ, senum-treated zymosan. IL. interleukin: PAF, platelet-activating factor.

of BPI, induced by all stimuli, continued to $1-4 \mathrm{~h}$ after stimulation. Thereafter. BPI release strongly decreased, which was reflected by a moderate increase of the BPI concentration after $24 \mathrm{~h}$ of stimulation compared with that after $4 \mathrm{~h}$ of stimulation (figure 2B). Figure 3 demonstrates that $\mathrm{BPI}$ and elastase are released with similar kinetics. further supporting the suggestion that release of both proteins is under similar regulatory control.

\section{Discussion}

A series of physiologic agents was investigated for the ability to induce BPI release in an ex vivo whole blood system. Although we have recenily demonstrated that mononuclear phagocytes express BPI on their cell surface, no indications were obtained for production of BPI by these cells [17]. Therefore, we assume, on the basis of reports by others $[4,14]$, that PMNL are the only producers of BPI. The observation that the total amount of BPI present in PMNL is $\sim 200 \mathrm{ng} / 10^{6} \mathrm{PMNL}$ is supported by data of others, who reported a BPI content of $650 \mathrm{ng} / 10^{6}$ PMNL [14] and $230 \mathrm{ng} / 10^{6}$ PMNL [32].

The four different types of PMNL granules, secretory vesicles, gelatinase granules, specific granules, and azurophilic granules, require different signals to trigger degranulation. The secretory granules are released by an increase of intracellular $\mathrm{Ca}^{++}$[18]; for the release of azurophilic granules, additional signals (e.g., preincubation of PMNL with cytochalasin B or adherence of PMNL 10 a surface) are required [33-35]. In concert with these reports, most of the physiologic agents tested in this study (LPS, FMLP, and LTA) did not activate isolated PMNL to release the azurophilic protein BPI. In contrast, PMA. a protein kinase $\mathrm{C}$ activator, induced $\mathrm{BPI}$ release, indicating that one of the signal transduction pathways leading to $\mathrm{BPI}$ release is mediated via protein kinase C. Also, strum-opsonized zymosan, a polysaccharide complex prepared from yeast cell wall, which is phagocyrized by PMNL resulting in cell activation [36], directly activated PMNL to induce BPI release.

In contrast to the results obtained with isolated PMNL. it was shown in this study that several of the microbial reagents tested potently induced BPI reicase in whole blood. L.PS, a known primer for PMNL activation but one that does not directly induce respiratory burst activity or azurophilic granule release by PMNL in suspension $[35,37]$, was the most potent inducer of BPI release in whole blood. At coneentrations of $\geqslant 10 \mathrm{pg} / \mathrm{mL}$, this glycolipid, to which the biologic activity of $\mathrm{BPI}$ is specifically directed, activated PMNL in whole blood to release BPI. Both rough and smooth LPS induced BPI releuse. Furthermore, two lipid $A$ analogues, which were described as inducing tolerance for LPS $[23,24\}$, activated PMNL to release $\mathrm{BPl}$; in agreement with other reports, high concentrations were required for cell activation $[23,24]$.

The strong induction of BPI release in whole blood, in contrast to a weak induction of BPI release by isolated PMNL, suggests that LPS activates other cellular or humoral factors present in whole blood that may modulate the activation of PMNL. The LPS-induced BPI release was not mediated via production of TNF- $\alpha$, since reagents blocking the biologic activity of TNF- $\alpha$ did not affect LPS-induced BPI release. Furthermore, although LPS is known to induce complement activation [38], no proof for the involvement of activated complement factors in BPI release in whole blond was obtained, since C5a did not induce BPI release in whole blood. In addition, there 
Figure 2. Kinetics of BPI release in whole blood. Whole blood was stimulated for indicated time periods with indicated reagents. BPI was detected in plasma using specific EL.ISA and is expressed in $n g / 10^{6} \mathrm{PMNL}$. One representative experiment of series of 6 is shown. BPI release during I st h (A) or $24 \mathrm{~h} \mathrm{(B)} \mathrm{after} \mathrm{onset} \mathrm{of} \mathrm{stimulation} \mathrm{is} \mathrm{shown.} \mathrm{LPS,}$ lipopolysaccharide; LTA, lipoteichoic acid; STZ, senumtreated zymosan; PMA, phorbol myristate acetate.

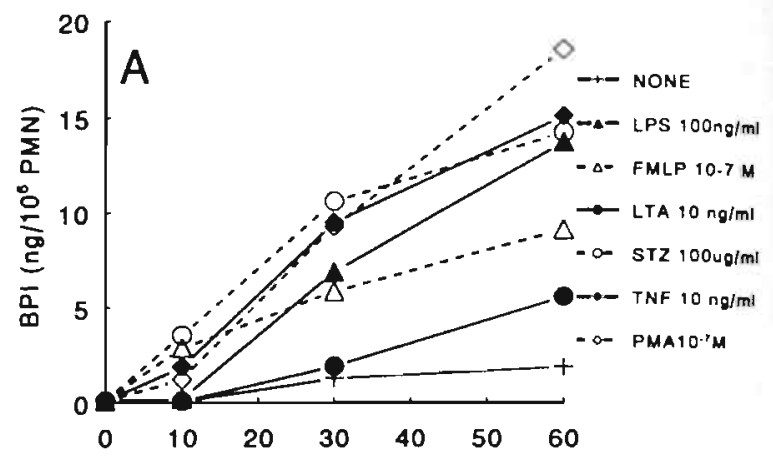

TIME (MINUTES)

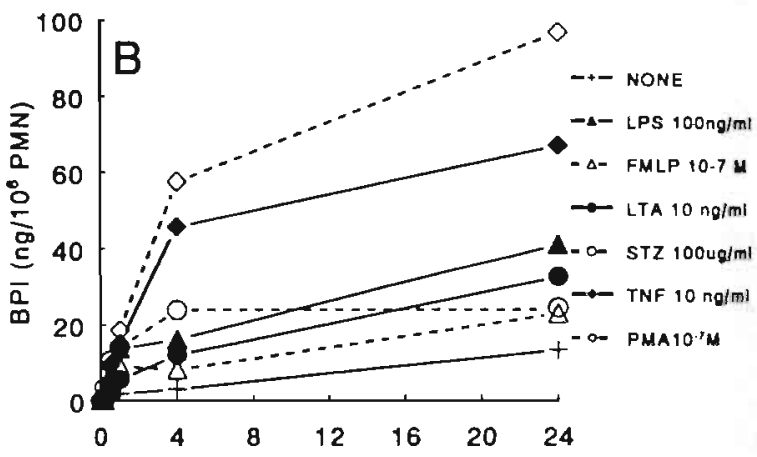

TIME (HOURS) were no indications for the involvement of acrivated platelets was found, since the addition of collagen to whole blood (leading to platelet aggregation) did not affect BPI release (data not shown). Moreover. PAF induced the release of only low amounts of BPI in whole blood. Therefore, the activation processes involved in LPS-induced BPI release in whole blood have to be further elucidated.

In addition to the potent BPI release induced by LPS, submicromolar concentrations of FMLP, the synthetic analogue of the major peptide PMNL chemotactic factor produced by $E$. coli [39], induced BPI release in whole blood. Furthermore. LTA, a cell wall product of gram-positive bacteria, which is known to have monocyte-activating capacity [40], activated PMNL to release BPI. In concert with this observation, LTA binding sites on PMNL have been reponed [4I]. In contrast, SEB, derived from $S$ aureus, which is a potent T cell stimulant and a macrophage activator $[42,43]$. hardly induced BPI release.

The inflammatory mediator TNF- $\alpha$ potently induced BPI release in whole blood, in contrast to the other inflammatory mediators tested, the monokine IL-10, the chemokine IL-8, the bioactive lipid PAF, and the activated complement factor C5a. which are all well known PMNL activators [44-47]. With use of agonistic agents. the TNF- $\alpha$ effect was shown to be mediated via TNFR 3 , whereas no direct role for $\mathrm{TNFR}_{25}$ was demonstrated. However, a potentiating role of TNFR 3 in TNFR induced BPI release, as reported for several TNFR s $_{3}$-mediated PMNL and endotheliai cell responses cannot be excluded from our data $[27,48]$.

Although a different intragranular distribution of the azurophilic proteins BPI and elastase was reported [14, 31], namely, a membrane association of BPI and cytosolic localization of elastase. in this study a comparable release of both proteins (expressed as percentage of total protein present) was observed. The total content of elastase of $\sim 3 \mu \mathrm{g} / 10^{\mathrm{h}}$ PMNL, however, which is comparable to concentrations reported previously [49]. is considerabiy higher than the BPI concentration of $200 \mathrm{ng} / 10^{6} \mathrm{PMNL}$. The observation that BPI and elastase were released with similar kinetics further indicates that the release of both these azurophilic granule proteins is under similar regulatory control. 

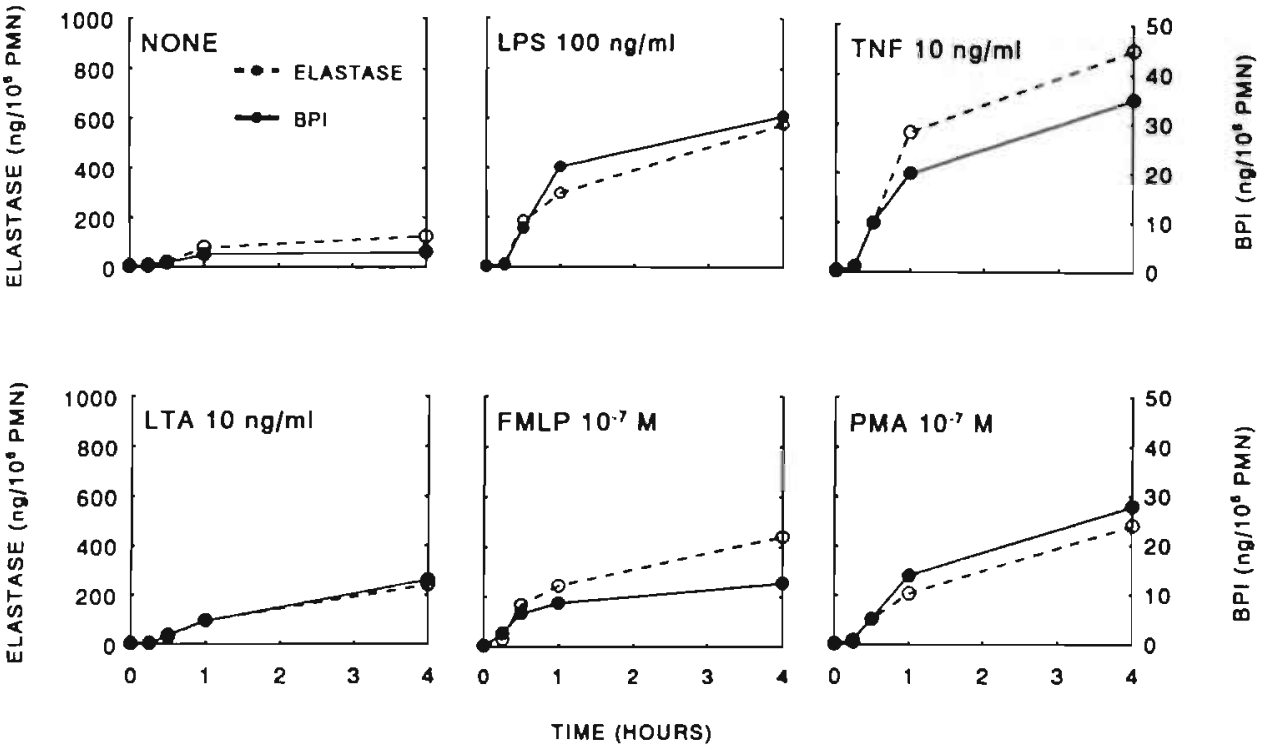

Figure 3. Comparison of kinetics of elastase and BPI release in whole blood. Whole blood was stimulated for indicated time periods with indicated reagents. Elastase and BPI were detected in plasma using specific ELISAs and are expressed in ng/10 polymorphonuclear leukncyte (PMN). One representative experiment of series of 4 is shown. LPS. lipopolysaccharide; LTA. lipoteichoic acid: PMA, phorbol myristate scetale.

BPI was released mainly between 0 and $4 \mathrm{~h}$ after onset of stimulation, in concen with the study of Calvano et al. [50]. who described peak BPI concentrations in plasma of healthy volunteers $2-10 \mathrm{~h}$ after exposure to endotoxin. However, our observations are in contrast to several in vitro studies in which a maximal release of granule components was reported to occur within seconds or minutes after stimulation [51]. This discrepancy could be due to priming of PMNL, during isolation, possibly accelerating the degranulation process.

Although we demonstrated in this study that LPS and TNF. $\alpha$. compared with other physiologic stimuli tested, potently induced release of BPI in whole blood. our data also revealed that the maximal amount of BPI released was no more than $20 \%$ of the total BPI present in PMNL. This indicates that major pan of BPI will remain intracellular and, therefore, we assume that BPI functions mainly as an intracellular bactericidal protein. However, a role for extracellular BPI in protection against LPS and gram-negative bacteria cannot be excluded. since BPI present in rabbit peritoneal exudate exhibited bactericidal activity [6]. Furthermore, under certain pathologic conditions, high levels of BPI will be released, which are expected to exen strong biologic effects. For instance, we have shown that in wound fluid of humans, BPI levels up to $15 \mu \mathrm{g} /$ $\mathrm{mL}$ were present, most probably caused by rupture of large amounts of PMNL [12].
In conclusion, in this study we demonstrated that out of a series of physiologic agents, LPS and TNF- $\alpha$ (via TNFR Ts $_{9}$ ) most potently and with high sensitivity induced the release of BPI from whole blood. The induction of BPI release by PMNL appeared to depend on the presence of other cellular and humoral factors present in whole blood. BPI release was paralleled by the release of the azurophilic granule protein elastase.

\section{References}

1. Ulevitch RJ. Tobias PS Recepror-dependen mechanisms of cell strimula. tion by bacterial endotoxin. Annu Rev Immunol 1995:13 437-57.

2. Wurfel MM, Kunitake ST, Lichenstein H. Kane JP. Wright SD. Lipopolysaccharide (LPS)-binding protein is carried: on lipoprokeins and acts as a cofactor in the neutralization of LPS. J Exp Med 1994: 180: 1025-35.

3. Ohno N. LPS binding proteins in granulocye lysosomes. In: Morrison DC; Ryan JL, eds. Bacierial endotoxic lipopolysaccharides. Vol 1. Molecular biochemistry and cellular biology. Boca Raton. FL: CRC Press, 1992 387.

4. Elsbach P, Weiss J. Bactericidal/permeatulity increasing protein and host defense againsi gram-negative bacteria and endoloxin. Curr Opin Immunol 1993; $5: 103-7$.

5. Weiss J, Kao L. Victor M. Elsbach P. Oxygen-independent intracellular and oxygen-dependent exracellular killing of Escherichio coll Sis by human polymorphonuclear leukocytes. J Clin Invest 1985,7t.206-12.

6. Weinnuch Y. Foremañ A, Shu C, et al. Extracellular accumulation of potently microbicidal bactericidal/permeability-increasing protein and 
p15s in an evolving sterile rabbit peritoneal inflammatory exudate. It Clin Invest 1995:95:1916-24.

7. Ammons WS. Kohn FR, Kung AHC. Protective effects of an $\mathrm{N}$-terminal fragment of bactericidal/permeability-increasing protein in rodent models of gram-negative sepsis: role of bactericidal properties. I Infect Dis 1994: 170:1473-82

8. Fisher CJ, Marra MN, Palardy JE, Marchbanks CR, Scot RW, Opal SW. Human neutrophil bactericidalpermeability-increasing protein reduces mortality rate from endotoxin challenge: a placebo-controlled study. Crit Care Med 1994:22:553-8.

9. Dentener MA. Von Asmuth EIU, Francol GJM, Marm MN. Buurman WA. Antagonistic ellects of lipopolysaccharide binding protein and bactericidal/permeability-increasing protein on lipopolysaccharide-induced eytokine release by mononuclear phagocytes: competition for binding to lipopolysactharide. J Immunol 1993: 151:4258-65.

10. Opal SM, Palardy JE, Marra MN, Fisher CJ Jr, McKelligon BM, Scon RW. Relative concentrations of endotoxin-binding proteins in body fluids during infection. Lancet 1994: 344:429-31.

11. Froon AHM, Dentener MA, Greve JWM, Rumsay G, Buuman WA. Lipopolysaccharide toxicity-regulating proceins in bacteremia. J Infect Dis 1995: 171:1250-7.

12. Dentener MA. Francor GJM, Smit FT. et al. Presence of bactericidal permeability-increasing protein in disease: detection by ELISA.J Infect Dis 1995: 171:739-43.

13. White ML, Ma JK, Bir CA. Trown PW, Carroll SF. Measurement of bactericida/permeability-increasing protein in human body fluids by sandwich ELISA I Immunol Methods 1994: 167:227-35.

14. Weiss J, OIsson I. Cellular and subcellular localization of the bactericidal permeability-increasing protein of neutrophils. Blood 1987;69:652-9.

15. Marra MN. Wilde CG, Collins MS, Snable JL. Thomton MB, Seon RW. The role of bactericidal/permeability-increasing procein as a natural inhibitor of bacterial endotoxin. $J$ Immunol 1992:148:532 - 7.

16. Weersink AlL. Van Kessel KPM. Van den Tol ME, et al. Human granulocytes express a $55-k \mathrm{Da}$ lipopalysaccharide-binding protein on the cell surface that is identical to the bactericidal/permeability-increasing protein. J Immunol 1993: 150:253-63.

17. Deniener MA, Francol GJM, Buurman WA. Bactericidal/permeabilityincreasing protein, a lipopolysaccharide-specific protein on the surface of human peripheral blood monocyies. J Infect Dis 1996: 173:252-5.

18 Sengetov H. Kjeldsen L. Borregaard N. Control of exocylosis in early neutrophil activation. J Immunol 1993: 150:1535-43.

19. Mohler KM. Torrance DS. Smith CA. et al. Soluble tumor necrosis factor (TNF) feceptors are effective therapeutic agents in lethal endoroxemia and function simultaneously as both TNF carriers and TNF antagonists. J Imminol 1003: 15!:1548-61.

20. Loetscher $H$, Siueber D, Banner D. Mackay $F$. Lesslauer W. Human tumor necrosis factor $\alpha$ (TNFa) mutants with exclutive specificiry for the 55 $k D a$ of $75-k D a$ TNF Receptors. J Biol Chem 1993:268:26350-7

21. Van Ostade X. Vanderabeste P. Everserdt B. et al, Human TNF mutants with selective activity on the ps5 reseptor. Nanure 1993;361:266-9

22. Van Ostade $X$, Yandenabeele $P$, Tavsmier J. Fiers $W$. Human numor necrosis factor mutants with preferential binding to and activity on either the R55 or R75 recepinr. Eur J Biochem 1994:220:771-9.

23. Rudhach JA, Myers KR, Rechtman DJ. Ulrich JT. Prophylactic use of monophosphoryl lipid A in patients at risk for sepsis. In: Levin J, Van Deventer SJH. Van der Poll T. Sturk A eds. Bactericidal endotoxins: basic science 10 anti-sepsis smategies. Proceedings of the fourth internstional conference on endotoxins. Yol 388. Progress in clinical and biological research New York: Wiley-Liss, 1994:107-24

24. Siern A, Engelhardt R, Foster $C$, et al. SDZ MRL 953, a lipid A analog as selective cytokine inducer. In: Levin J. Alving CR. Munford RS, Redl H, eds. Bacterial endotoxins: lipopalysaccharides from genes to therapy. Proceedings of the third conference of the International Endotoxin Society. Vod 392. Progress in clinical and biological research. New York: Wiley-Liss, 1995:549-65.
25. Von Asmith. EIU. Maessen JG. Van der Linden CJ. Buuman W/A. Tünwr necrosis faeior alpha (TNF $\alpha$ ) and interleukin 6 in a zymosan-induced shock model. Scand I Immunol 1990.32:313-9.

26. L.eerwenberg JFM, Van Damme J. Meager T. Jeunhomme TMAA. Buur. man WA. Effects, of tumor necrosis factor on the interferon- $y$-induced major histocompatibility complex class fll antigen expression by human endothelial cells. Eur J Immunol 1988: 18:146y-72.

27. Leeuwenberg JFM, Van Tits LJH. Jeunhomme TMAA, Buurman WA Evidence for exclusive role in signalling of rumour necrosis factor pss recepter and a porentiating function of $\mathrm{p} 75$ receptor on human endothe:liai cells. Cytokine 1995:7,457-62.

28. Feinstein $G$, Janoff A. A rapid method of purification of human granulocyte cationic neutral proteases: purification and further characterisation of human granulocyte clastase. Biochim Biophys Acta 1975; 403:493 - S05

29. Tarraglia LA, Goeddel DV, Reynolds C, et al. Stimulation of human T. cell proliferation by specific activation of the $75-\mathrm{kDa}$ tumor necresis facior receptor. J Immunol 1993:151:463?-41.

30. Sozzani S, Agwu DE, Ellenburg MD, er al. Activation of phospholipase $D$ by interleukin- 8 in human neutrophils. Blnod 1994:84:3895-901.

31. Egesten A, Breton-Gorius J, Guichard J. Gullberg U, Olsson I. The heterogeneity of azurophil granules in neutrophit promyelocytes: immunogold localization of myeloperoxidase, cathepsin $\mathrm{G}_{\text {, elastase. protenase } 3 .}$ and bactericidalpermeability-increasing protein. Blood 199.4:83 $2985-94$.

32. Van Kessel KPM, Weersink AJL, Van der Tol ME, Verhuef J. Stimulated human neutrophils release intact $\mathrm{BPI}$ withour a concomitant change in expression on the cell surface. In: Levin J. Alving CR. Munford RS, Redl H, eds. Bacterial endotoxins: lipopolysaccharides from genes to therapy. Proceedings of the third conference of the International Endoroxin Sociery. Vol 392. Progress in clinical and biological research New York: Wiley-Liss. 1995:305-15.

33. Zurier RB. Hoffstein $\mathrm{S}$. Weissmann G. Cynochalasin B: effect on lysosomal enzyme release from human leukocytes. Proc Natl Acad Sci USA 1973 70:844-8.

34. Nathan CF. Neutrophil activation on biological surfaces: massive secretion of hydrogen peroxide in response: 10 products of macrophages and $1 \mathrm{ym}$. phacyles. J Clin Invest 1987:80:1550-60.

35. Dahinden C, Fehr J. Granulocyte activation by endotoxin II. Role of granulocyce adherence. aggregation, and effecl of cyrochalas in B. and comparison with formylated chemotactic peptide-induced stimulation. $J 1 \mathrm{mmy}$ nol 1983: 130-863-8.

36. Weissmann G. Zurier RB, Spieler PJ, Goldstein IM. Mechanisms of lysosomal enzymi release from leukocytes exposed to immune complexes and other particles. J Exp Med 1971:134:149s-165.

37. Wilson ME Effects of bacterial endotoxins on neurephil function. Rev Infect Dis 1985: 7:404-8.

38. Morrison DC, Kline LF. Activation of the classicial and properdin pathways of complement by bacterial hapopolysaccharides (LPS). J Immunal 1977. 118:362-8.

39. Marasco WA, Phan SH, Krulzsch H, et al. Purification and identification of formyl-methionyl-leucyl-phenylalanine as the major peplide neutrophil chemolactic factor produced by Escherichia coli I Biol Chem 1984; 250:5430-9.

40. Wikabayashi G. Gelfand JA. Jung WK. Connolly RU, Burke JF. Dinarello CA. Siaphloceccus epidermidis induces complement activation, umer necrosis, factor and interleukin-1, a shock-like state and tissue injury in rabbits withoul endotoxemia. J Clin Invest 1991:87:1925-35.

41. Courney H. Otek 1, Simpson WA, Beachey EH. Characierization of lipoteichoic acid binding to polymorphonuclear leukocytes of human blood. Infeet Immun 1981:32:625-31.

42. White J. Herman A. Pullen AM, Kubo R, Kappler JW, Marack P. The Vp-specific superantigen staphylococcal enterotaxin $B$ stimulation of mature $T$ cells and clonal deletion in neonatal mice Cell 1989:56 $27-35$. 
43. Fleming SD, landolo JJ, Chapes SK. Murine macrophsge activation by staphylococcal exotoxins. Infect Immun 1991:59:4049-55.

44. Ferrante A. Activation of neutrophils by interteukins-I and -2 and rumor necrosis faciors. Immunol Ser 1992:57:417-36.

45. Baggiolini M, Imboden P, Detmers P. Neutrophil activation and the effects of interleukin-8/neutrophil-actuvaring peptide I (IL-8NAP-1). In: Baggiolini M. Sorg C, eds. Interleuk in 8 (NAP. 1 ) and related chemolactic cytokines. Basel, Switzerland: Karger, 1992:1-17.

46. Zimmerman GA. Prescoll SM. Mclntyre TM. Platelet-activating factor, a fluid-phase and cell-associated medistor of inflammation. In: Gallin Jl, Goldstein IM. Snyderman R. eds. Inflammation: basic principles and clinical correlates. New York: Raven Press, 1992:149-67.
47. Goldstein IM. Complement biologically attive products. In: Gallin JI. Goldsten IM, Snyderman R, eds. Inflammation basic pnncipies and clinical correlates. New Yark: Raven Press, 1992:63-80

48. Barbera JA. Smith WB. Gambie JR, el al. Disseciation of TNF-a cytotoxic and proinflammatory activities by ps5 receptor- and p75 receptorselective TNF-a mutants. EMBO J 1994; 13:843-50.

49. Janoff AJ. Elastase in tissue injury. Annu Rev Med 1985;36:207-16.

50. Calvano SE. Thompson WA. Marra MN, et al. Changes in polymorphonuclear leukocyte surface and plasma baciericidal/permeability-increasing protein and plasma lipopolysaccharide binding protein during endotoxemia or sepsis. Arch Surg 1994: 129:220 - 6 .

51. Bentwood BJ. Henson PM. The sequential release of granule constituents from human neutrophils. J Immunol 1980; 124.855. 62. 
$-130-$ 
Chapter 10

Presence of Bactericidal/Permeability-Increasing Protein in Disease: Detection by ELISA

Reprinted with permission 


\title{
Presence of Bactericidal/Permeability-Increasing Protein in Disease: Detection by ELISA
}

Mieke A. Dentener, Gaby J. M. Francot, Frederieke T. Smit, Albert H. M. Froon, Herman-Jan Pennings, Emiel F. M. Wouters, and Wim A. Buurman

\author{
Department of Surgery. University of Limburg: Depariment of \\ Pulmonology. University Hospital Maasiricht. Maastricht. Netherlands
}

\begin{abstract}
A sandwich ELISA was developed specific for human bactericidal/permeability-increasing protein (BPI), using $\mathrm{Mg}^{{ }^{*+}}$ ions to abrogate disturbance by lipopolysaccharide of BPI measurement and to prevent aspecific adherence of BPI to solid phase. In fresh EDTA or heparinized plasma of healthy volunteers BPI was not detectable, whereas in serum BPI was present, indicating that coagulation activates polymorphonuclear leukocytes to release BPI. Furthermore, BPI was present in plasma of critically ill intensive care unit (ICU) patients, in bronchoalveolar lavage fluid of patients suspected of having pneumonia, in wound fluid, and in pleural fluid. In subgroups of samples with culture-proven bacteria, mean BPI levels were increased compared with subgroups without bacteria, although the differences were only significant in EDTA plasma of ICU patients. These findings indicate the presence of BPI during pathologic conditions. The physiologic role of the released BPI has to be further elucidated.
\end{abstract}

A putent hactericidal protein produced by polymorphonuclear leukucytes (PMNL) is bactericidal/permeability-increasing protein (BPI) [1]. This 50- to 60-kDa cationic protein is stored in the azurophilic granules [2] but is also expressed on the cell surface [3-5]. Bactericidal activity of BPI is specifically directed against gram-negative bacteria. caused by the strong affinity of BPI for lipopolysaccharide (LPS) [1,6]. Besides bactericidal capacity. BPI neutralizes LPS activities in vitro and in vivo [3. 7-9].

Activation of PMNL in vitro induces the release of a part of their BPI content [2, 3]. Furthermore, membrane expression of BPI is up-regulated after stimulation [3. 4]. So far. only indications for an intracellular function of BPI have been demonstrated [10]. It is unknown whether BPI is released in vivo or whether the released BPI has biologic activity.

A sensitive sandwich ELISA for measurement of human BPI was developed. BPI levels in blood of healthy volunteers were determined and optimal conditions for measurement were established. Furthermore, biologic fluids of patients with microbial infection were screened for presence of $\mathrm{BPI}$.

\section{Materials and Methods}

Reagents. Bovine serum albumin (BSA) and LPS (Escherichia coli O55:B5) were obtained from Sigma (St. Louis). Human recombinant (r) BPI. provided by M. Marra (Incyte, Palo

Received 13 April 1994; revised I August 199.4.

Human studies were approved by the Ethical Committee of the University Hospital Maastricht.

Grant support: Netherlands Organization for Scientific Research (900562-110).

Reprints or correspondence: Mieke A. Dentener. Dept. of Surgery. Univensity of Limburg. P.O. Box 616.6200 MD Maastricht, Netherlands.

The Journal of Infections Diseases 1995;171:739-43

- 1995 by The University of Chicago. All rights reserved.

0022-1899/95/7103-0039501.00
Alto. CA), was produced by transfected $\mathrm{CHO}$ cells. Purification occurred sequentially by ion exchange and size-exclusion chromatography. BPI-specific monoclonal antibody (MAb) $4 \mathrm{E} 3$ (lgGI) was obtained and characterized as described [5]. MAb 4E 3 was purified over Sepharose G (Pharmacia. Uppsala, Sweden). Polyclonal antibodies to human rBPI were obtained by immunizing rabbits with human rBPI. After protein A (Phamacia) purification, the polyclonal $\operatorname{IgG}$ was biotinylated using biotin-X-NHS (Calbiochem, La Jolla. CA). This polyclonal antiBPl lgG did not cross-react with human rLPS-binding protein (LBP). provided by M. Marra (Incyte), as tested in ELISA.

BPI ELISA. For ELISA, 96-well plates (Immuno-Maxisorp: Nunc. Roskilde. Denmark) were coated overnight at $4^{\circ} \mathrm{C}$ with human rBPI-specific MAb 4E3, $2.5 \mu \mathrm{g} / \mathrm{mL}$ dissolved in PBS. Free sites were blocked by $1 \mathrm{~h}$ of incubation with PBS plus 18 BSA at room temperature. Wash and dilution buffer consisted of $50 \mathrm{~m} M$ TRIS (pH 7.4), $150 \mathrm{~m} M \mathrm{NaCl}, 0.1 \%$ BSA, $0.05 \%$ Tween 20. and $80 \mathrm{mM} \mathrm{MgCl}$; plates were washed five times after each incubation step. Human rBPI was used as standard, and samples were incubated for $2 \mathrm{~h}$ at room temperature. It is not known whether the affinity of $4 \mathrm{E} 3$ for natural and $\mathrm{rBPI}$ are similar. indicating that the amounts of natural BPI detected were equivalent to the described amounts of rBPI.

Next, $5 \mu \mathrm{g} / \mathrm{mL}$ biotinylated polyclonal rabbit anti-human BPI $\lg G$ was incubated for I $h$ at room temperature. Peroxidase-conjugated streptavidin (Dakopatts, Glostrup, Denmark) diluted in PBS plus 0. I\% BSA was added: after $1 \mathrm{~h}$ of incubation. plates were washed with distilled water containing $0.1 \%$ Tween 20 . The substrate for peroxidase was 3,3',5,5'-tetramethylbenzidine (Kirkegaard \& Perry Laboratories. Gaithersburg. MD). Spectrophotometry $(450 \mathrm{~nm})$ was done with a micro-ELISA autoreader.

Collection of biologic fluids. Blood was anticoagulated in evacuated blood collection tubes (Sherwood Medical, St. Louis) containing either $0.1 \mathrm{~mL}$ of $15 \%$ (wt/wt) EDTA or $0.1 \mathrm{~mL}$ of $500 \mathrm{IU} / \mathrm{mL}$ heparin (Leo Pharmaceutical Products, Weesp. Netherlands). Blood was coagulated in integrated serum separator tubes (Sherwood Medical) or in LPS-free glass tubes, prepared by heating the tubes for $3 \mathrm{~h}$ at $180^{\circ} \mathrm{C}$. After incubation 
times indicated in Results, plasma and serum were separated from blood cells by centrifugation twice for $5 \mathrm{~min}$ at $1500 \mathrm{~g}$ to prevent the presence of residual PMNL, which release BPI after freezing and thawing (unpublished data).

Freshly prepared plasma and serum collected from 32 healthy volunteers was screened for the presence of BPI. EDTA plasma was collected from critically ill patients. For 5 days, blood samples of patients newly admitted to the intensive care unit (ICU) were collected. Bronchoalveolar lavage (BAL) fluid was obtained from BAL done during diagnostic fiberoptic bronchoscopy of patients with suspected pneumonia. Physiologic fluid $(150 \mathrm{~mL})$ was instilled in three aliquots into the segment suspected for the presence of pneumonia. Each aliquot was aspirated immediately after inspiration. The third aliquot was screened for presence of BPI. Wound fluid was collected on 5 successive days from patients after surgery. This fluid was obtained either directly out of the superficial wound or from drainage of an abdominal wound. Pleural fluid from patients admitted for evaluation of pleural effusion was obtained by thoracentesis.

EDTA plasma from ICU patients, BAL fluid, wound fluid, and pleural fluid were centrifuged to remove cells and debris and stored at $-20^{\circ} \mathrm{C}$ until analyzed.

Siatistical analysis. The Mann-Whitney $U$ test was used to analyze differences between subgroups. $P<.05$ was defined as statistically significant.

\section{Results}

Human BPI ELISA. By using anti-BPI MAb 4E3 as a coating reagent in combination with biotinylated polyclonal rabbit anti-BPI IgG and peroxidase-conjugated streptavidin, a human BPI ELISA was developed. Since LPS has been shown to inhibit reactivity of $4 \mathrm{E} 3$ to $B P I[5,7]$, the effect of LPS on the measurement of BPI was analyzed. To this end, BPI was preincubated for $30 \mathrm{~min}$ at $37^{\circ} \mathrm{C}$ with LPS and subsequently added to plates coated with $4 E 3$. Data in figure IA show that presence of LPS reduced the detection of BPI in this ELISA. The LPS effect was concentration-dependent and was present even at a concentration as low as $100 \mathrm{pg} / \mathrm{mL}$ (data not shown).

Presence of high amounts of $\mathrm{Mg}^{++}$ions has been reported to prevent BPI-LPS interaction [6, 11]. Addition of $80 \mathrm{~m} M$ $\mathrm{Mg}^{*+}$ to the assay buffers abrogated the influence of LPS on BPI measurement (figure $1 \mathrm{~A}$ ). Furthermore, the aspecific adherence of BPI to solid phase, a characteristic of cationic proteins [12], was prevented by presence of $\mathrm{Mg}^{++}$(figure 1B). Optimal results were obtained when $80 \mathrm{mM} \mathrm{Mg} \mathrm{Mg}^{+++}$in assay buffers was used until peroxidase-conjugated streptavidin incubation. A sensitivity of $200 \mathrm{pg} / \mathrm{mL}$ could be reproduced.

$B P I$ content in plasma and serum of healthy subjects. BPI was not detectable in EDTA or heparinized plasma of 32 healthy persons, when plasma was separated from blood cells immediately after collection. However, in plasma of heparinized blood incubated for $0.5-1 \mathrm{~h}$ at room temperature, $1-2 \mathrm{ng} / \mathrm{mL}$ BPI was present, and the amount increased
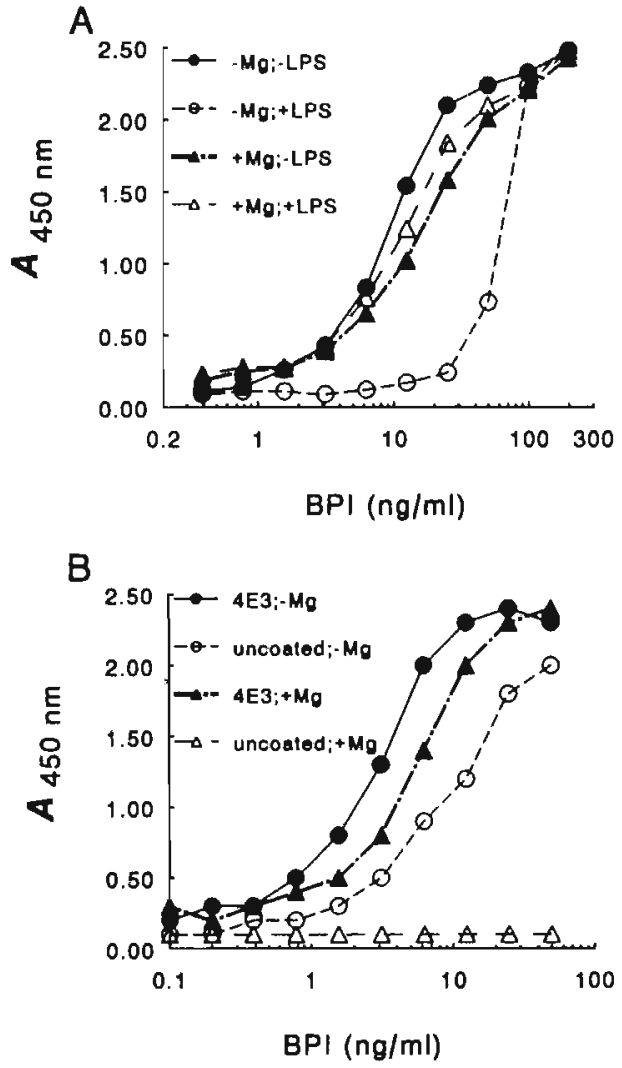

Figure 1. $\mathrm{Mg}^{++}$ions prevent disturbance by lipopolysaceharide (LPS) of BPI interaction to anti-BPI monoclonal antibody $4 \mathrm{E} .3$ (A) and inhibit aspecific adherence of BPI to solid phase (B). A, Recombinant (r) BPI was preincubated with LPS and added to plates coated with $4 E 3$. Dilution and wash buffer used included or did not include $\mathrm{Mg}^{++}$. B. rBPI was added to plates costed or not coated with $4 \mathrm{E} 3$. Dilution and wash bufler included or did not include $\mathrm{Mg}^{*+}$. Plates were developed with biotin-labeled polyclonal antiBPI IgG and peroxidase-conjugated streptavidin. One representative experiment from a series of 5 is shown.

concomitant with the length of incubation time, up to 60 $\mathrm{ng} / \mathrm{mL}$ after $24 \mathrm{~h}$. In plasma of EDTA blood incubated up to $4 \mathrm{~h}$ at room temperature. BPI was not detectable. In serum samples of whole blood coagulated for 1 h at room temperature in integrated serum separator tubes, BPI levels were 2.0 $40.1 \mathrm{ng} / \mathrm{mL}$ (mean, 11.0). In contrast, in serum from blood coagulated in LPS-free glass tubes, BPI levels were much lower (mean, $1.4 \mathrm{ng} / \mathrm{mL}$.). These data suggest that coagulation activates PMNL, although. in integrated senum separator tubes. PMNL are probably predominantly stimulated by contaminating PMNL-activating agents. These data indicate that EDTA plasma is preferred for the detection of BPI.

To investigate matrix effects on recovery of $\mathrm{BPI}, \mathrm{rBPI}(20$ 
$\mathrm{ng} / \mathrm{mL}$ ) was spiked in either pure EDTA plasma or EDTA whole blood. After I h of incubation at room temperature, samples were analyzed by ELISA. Recovery of BPI in plasma was $70 \%-100 \%$, whereas recovery in whole blood was $60 \%$ $80 \%$ (data not shown). These data indicate that detection of BPI was hardly disturbed by matrix components.

BPI content in biologic fluids of patients. Biologic fluids of several patient groups were screened for presence of BPI (figure 2). First. EDTA plasma obtained from 60 critically ill ICU patients was analyzed, and results were compared with the presence of infection proven by bacterial culture (gramnegative. gram-positive, or both). In 50 of these plasma samples, BPI was detectable. In patients suffering from infection. significantly higher BPI levels were observed than in patients with negative culture results $(P=.03)$.

Furthermore, in BAL fluid of patients suspected of having pneumonia, BPI was detectable in all but I of the 25 samples tested. Analysis of samples revealed that BPI levels were higher in samples for which bacterial culture was proven than in BAL fluid samples without bacteria, although the difference was not significant $(P=. I)$.

BPI was also detected in wound fluid of patients after sur- gery. BPI levels were very high, up to $15,900 \mathrm{ng} / \mathrm{mL}$, although in 3 of 18 samples, no BPI was detectable. BPI levels in subgroups according to the absence or presence of bacteria were not significantly different $(P=.7)$.

In 20 of 44 pleural fluid samples analyzed. BPI was detected. In only a few samples were bacteria observed, so samples were divided into exudates or transudates. BPI levels in exudates were higher than in transudates, although these differences were not significant $(P=.1)$.

\section{Discussion}

For the development of a BPI sandwich ELISA, MAb 4E3, highly specific for BPI (described in [5]), was chosen. The fact that $4 \mathrm{E} 3$ recognized an epitope on BPI involved in the functional reactivity with endotoxin and lacked interaction with either denatured BPI or L.BP was considered to enhance the value of the assay. The observation that the presence of LPS disturbed reactivity of $4 \mathrm{E} 3$ with BPI supported the specificity of the MAb but reduced the usefulness of $4 E 3$ in the ELISA, in which samples possibly contaminated with LPS had to be tested.
Figure 2. BPI levels in biologic fluids of patient groups. Plasma. wound fluid, and bronchoalveolar lavage (BAL) fluid were divided in groups according to presence or absence of bacteria in fluids. Numbers of patients in each subgroup are plasma intensive care unit patients, no bacteria, $n=30$, and bacteria present, $n=30$; wound fluid, no bacteria. $n=5$, and bacteria present, $n=13$; BAL fluid, no bacteria, $n=8$, and bacteria present. $n$ $=17$. Pleural fluid samples were divided into transudate $(n=15)$ or exudate $(n-29)$. Data are mean of 2 values; average is indicated. BPI levels below detection are indicated as $0.1 \mathrm{ng} / \mathrm{mL}$.
PLASMA ICU PATIENTS
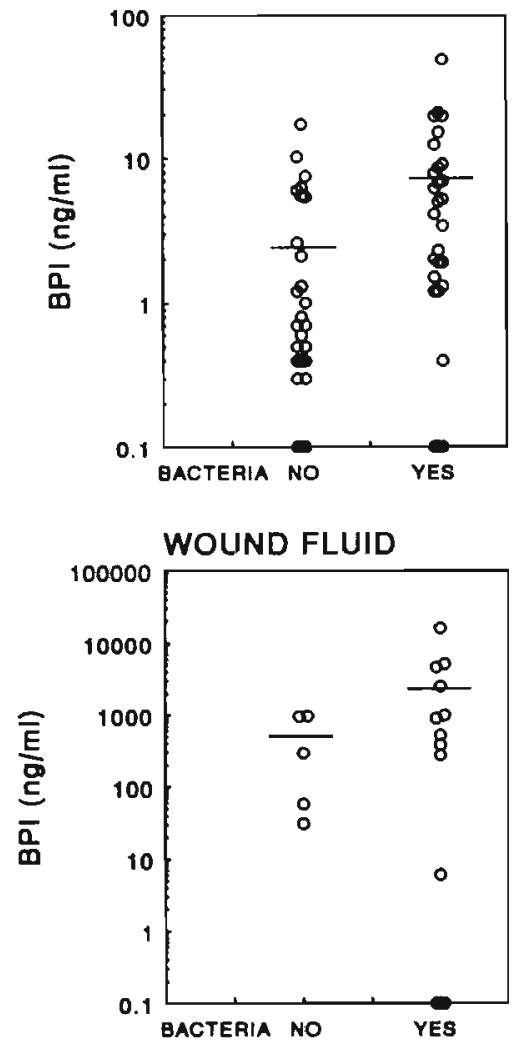

BAL FLUID
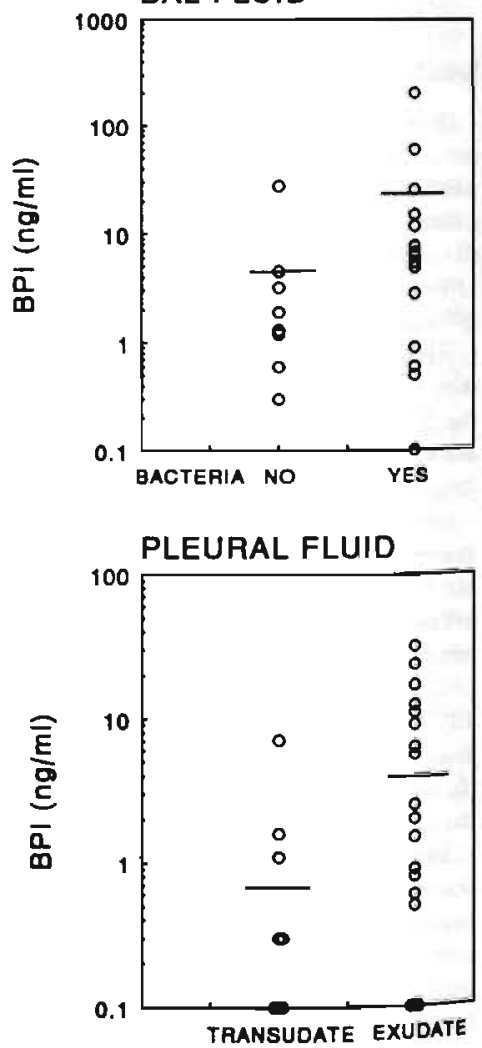
The use of $\mathrm{Mg}^{*+}$, which has been reported to disturb LPS$\mathrm{BPI}$ interaction $[6,11]$, in the assay buffers prevented the inhibition by LPS of BPI recovery in the ELISA. In addition. the aspecific adherence of BPI to the solid phase was prevented by $\mathrm{Mg}^{++}$. Recently, a sandwich BPI ELISA based on a polyclonal antibody has been described, in which the polyanion heparin was used to circumvent sticking properties of this cationic protein [12]. Using heparin in our ELISA similarly prevented aspecific adherence; however. the disturbance by LPS was less effectively prevented by heparin than by $\mathrm{Mg}^{++}$(data not shown). Thus, this newly developed sandwich ELISA with a sensitivity of $200 \mathrm{pg} / \mathrm{mL}$ appeared to be useful for measurement of BPI in biologic fluids.

BPI was not detected in fresh plasma of healthy subjects in this study. whereas White et al. [12] observed low levels of BPI in plasma. Incubation of heparinized whole blond at room temperature yielded the presence of $\mathrm{BPI}$. indicating that PMNL in collection tubes were activated. In addition. we showed that coagulation induced the release of BPI, although presence of contaminating PMNL-activating agents in coagulation tubes must be considered. The release of BPI during coagulation might prevent bacterial growth in situations of induced coagulation. EDTA treatment of whole blood did not induce BPI release and permits detection in vivo of circulating BPI.

Our study with patients showed that in various biologic fluids from different patient groups. BPI was detectable. In subgroups with culture-proven bacteria, mean BPI levels were higher than in subgroups without bacteria, although the differences were only significant in EDTA plasma of ICU patients. These results strongly suggest that high levels of $\mathrm{BPl}$ are related to inflammation. These observations are comparible with reports describing enhanced levels of the azurophilic protein elastase, found in infectious diseases [13].

Recently. BPI levels in plasma from patients with sepsis were analyzed [14]. In that study. BPI was detectable not only in plasma from patients but also in plasma from healthy volunteers. We consider that these data were obtained because of the blood collection method used. The observed differences of BPI plasma levels between patients and healthy volunteers were not significant. This is in contrast to our patient data, which show clear differences between BPI plasma levels in healthy subjects and ICU patients with bacteremia.

Until now, only indications for an intracellular function for BPI exists [10]. It is unclear if BPI present in biologic fluids contains LPS neutralizing or bactericidal capacity. For determination of biologic consequences of enhanced BPI levels, further studies are now in progress, using larger patient groups and analyzing results on a patient-by-patient basis. Furthermore, the physiologic function of BPI present on the surface of PMNL must be analyzed further.

We have recently reported that BPI and LBP have counteractive effects concerning LPS-induced cell activation [8]. In plasma of healthy volunteers, LBP levels of $7 \mu \mathrm{g} / \mathrm{mL}$ were observed [15]. Although BPI levels in biologic fluids of patients were much lower than this LBP concentration, at the site of inflammation, sufficiently high levels of BPI might overcome LBP levels and have a physiologic effect. Moreover, it has recently been shown that soluble BPI can protect against endotoxemia in experiments using systemic administration of BPI $[3,9]$.

In conclusion, a specific and sensitive ELISA for human BPI was developed. BPI was not present in plasma of healthy volunteers, but it was present in biologic fluids of patients. These data are evidence that measurement of BPI could be a valuable tool for studying in vivo the role of BPI in the defense against gram-negative microorganisms.

\section{References}

I. Weiss J. Elsbach P. Olsson I. Odeberg H. Purification and eharacterization of a potent bactencidal and membrane active protein from the granules of human polymorphonuclear leukocyles. J Biol Chem 1978:253:2664-72

2. Weiss J. Olssin I. Cellular and subcellular localization of the bactericidal/permeability-increasing protein of neutrophits. Blood 1987; 69:652-9

3. Marra MN. Wilde CG. Collins MS. Snable JL. Thomton MB. Seolt $\mathrm{RW}$. The role of bactericidal/permeabitity-increasing protein as a natural inhibitor of bacterial endotoxin. I Immunol 1992;148:5327.

4. Weersink AJL van Kessel KPM. van den Tol ME, el al. Human granulocytes express a $55-\mathrm{kDa}$ lipopolysaccharide-binding protein on the cell surface that is identical to the bactericidal/permeability-increasing protein. I Immunol 1993; 150:253-63.

5. Dentener MA. Smil FT. Francol GJM, Buurman WA. Characterization of two monoctonal antibodies directed against bactericidal/ permeability-increasing protein. J Infeet Dis 1994 (in press)

6. Weiss: J. Muello K. Victor M. Elsbach P. The role of lipopolysacchandes in the action of the bactericidal/permeability-incteasing neutrophil protein on the bacterial envelope. J Immunol 1984;132:310915 .

7. Ooi CE, Weiss J. Doerfler ME. Elsbach F. Endotoxin-neutralizing properues of the $25 \mathrm{kD} \mathrm{N}$-terminal fragment and a newly isolated $30 \mathrm{kD}$ ) C-terminal fragrnent of the 55-60 kD bactericidal/permeabilityincreasing protein of human neutrophils. J Exp Med 1991:174:64955

8. Dentener MA. von Asmuth EIU. Francol GJM. Marra MN. Buturman WA. Antagonistic effects of lipopolysaccharide binding protein and bactericidal/permeability-increasing protein on lipopolysaccharideinduced cyokine release by mononuclear phagocytes: competition for binding to lipopolysaccharnde. J Immunol i993; 151:4258-65.

9. Kohn FR. Ammons WS. Horwiz. A. el al, Protective effect of a recombinant amino-terminal fragment of bactericidal/permeability-increasing protein in experimental endotoxemia. $\mathrm{J}$ Infect Dis 1993; 168:1307-10.

10. Weiss J. Kao L. Victor M. Elsbach P. Oxygen-independent intracellular and oxygen-dependent ex tracellular killing of Excherichia coll $\$ 15$ by human poifmorphonuclear leukocytes. J Cin Invesi 1985;76:20612.

11. Mannion BA. Kafatris ES. Weiss J. Elsbach P. Preferential binding of the neutrophil cytoplasmic granule-derived bactericidal/permeability increasing protein to larget bacteria: implications and use as a means of purification. J Immunol 1989;142:2807--12

12. White ML. Ma JK. Birr CA. Trown PW. Carroll SF. Measurement of bactericidal/permeability-increasing protein in human body fluids by sandwich ELISA. I Immunol Methods 1994:167:227-35. 
13. Gardinali $M$. Padalino P. Vesconi S, et al. Cornplement activation and polymorphonuclear neutrophil leukocytc elastase in sepsis: correlation with severity of disease. Arch Surg 1992;127:12!9-24.

14. Calvano SE., Thompson WA. Marra MN, et al. Changes in polymorphonuclear leukocyle surface and plasma bactericidal/permeability- increasing protein and plasma lipopolysaccharide binding protein during endotoxemia or sepsis. Arch Surg 1994:129:220-6.

15. Letureq D. VanHook P. Smith R. Tobias P. Ulevitch R. Moriary A Generation of monoclonal antibodies to human LBP and their use in the detection of LBP protein in serum. J Cell Biochem 1992; I6(suppl C):161. 
Chapter 11

Lipopolysaccharide Toxicity-Regulating Proteins in Bacteremia

Reprinted with permission 


\title{
Lipopolysaccharide Toxicity-Regulating Proteins in Bacteremia
}

\author{
Albert H. M. Froon, Mieke A. Dentener, \\ Jan Willem M. Greve, Graham Ramsay, \\ and Wim A. Buurman
}

Department of Surgery. University Hospilal Maastricht, Uiniversily of Limburg. Netherlands

\begin{abstract}
The toxicity of lipopolysaccharide (LPS) is modified by several proteins, such as bactericidal/ permeability-increasing protein (BPI) and LPS-binding protein (LBP). BPI and LBP plasma levels were measured in patients with gram-negative $(n=36)$ or gram-positive $(n=28)$ bacteremia. Levels of BPI and LBP, which are proteins that neutralize and enhance LPS effects, respectively, were increased before bacteremia was first detected. The BPI/neutrophil ratio, reflecting neutrophil activation, was significantly associated with the presence of sepsis syndrome and death in bacteremic patients: $1.06(0.11-6.49)$ versus $0.57(0.06-3.82)$ in patients with and without sepsis syndrome $(P<.01)$, respectively, and $0.64(0.06-3.82)$ versus $1.02(0.12-6.49)$ in survivors and nonsurvivors $\left(P<.05\right.$ ), respectively (ratio in nanograms of BPI per $10^{6}$ neutrophils). High LBP peak levels were significantly associated with the presence of sepsis syndrome $(P<.01)$. No difierences in BPI and LBP levels were observed in patients with gram-negative versus gram-positive bacteremia. BPI/neutrophil ratio, as a parameter of neutrophil activation, may be useful in monitoring infectious disease.
\end{abstract}

Infections with gram-negative and gram-positive bacteria can lead to a systemic inflammatory response syndrome (SIRS). In gram-negative infections, endotoxin (lipopolysaccharide [LPS]), a component of the gram-negative bacterial cell wall, is considered the principal initiator of SIRS [1, 2]. LPS activates mononuclear phagocytes to produce inflammatory mediators, such as tumor necrosis factor and interleukin-1 and -6 . which are responsible for many of the clinical features of endotoxemia [3, 4]. The LPS-induced release of these inflammatory mediators is regulated by endogenous proteins of different origin. In this regard, $\mathrm{SCD}$ 14, the soluble form of the putative LPS receptor CD / 4 [5-9], and LPS binding protein (LBP), a carrier molecule for L,PS, are of importance [10-14]. Also. LPS inactivating factors such as bactericidal/permeability-increasing protein (BPI) are considered important in regulating LPS effects during endotoxemia [1519].

BPI, specifically cytotoxic for gram-negative bacteria [20], is a $55-\mathrm{kDa}$ cationic protein stored in the azurophilic granules [21] but also expressed on the cell surface of polymorphonuclear leukocytes (PMNL) [22, 23]. Binding of BPI to L.PS in the cell wall of gram-negative bacteria induces membrane alterations and eventually bacterial death [24]. Besides being bactericidal, BPI inhibits LPS-induced phagocyte acti-

Received 26 July 1994: revised 7 November 1994

This study was reviewed and approved by the Medical Ethical Committec of University Hospical Maastricht.

Reprints or correspondence: Dr. A. H. M. Froon. Dept. of Surgery, University Hospital Maastricht. P.O. Box 5800, 6202 AZ Masstncht. Netherlands.

The Journal of Infections Desenses 1995:171:1250-7

- 1905 by The University of Chicago. All rights resenved. $0022-1899 / 95 / 7105-0024501.00$ vation [10,22, 25-29]. In addition, BPI has been found to be protective in experimental animal studies of gram-negative infection [15-19]. Activation of PMNL induces release of a part of their BPI content in vitro [2], 22], and limited survey studies showed that BPI was present in large quantities in several body fluids during infection: however. BPI was not detectable in plasma of healthy volunteers [30].

LPS-binding protein (LBP), a $60-\mathrm{kDa}$ acute-phase protein. appears to function in an opposing fashion to BPI despite a striking homology in DNA sequence [31, 32]. LBP facilitates binding of LPS to the LPS receptor CD/4, whereas BPI prevents this interaction $[10,11,33,34]$. Specifically, in the presence of low LPS concentrations, LBP enhances LPS-induced cell activation [10-12,14]. It was recently reported that LBP also neutralizes LPS effects by transferring LPS to high-density lipoproteins [35]. However, increased LBP levels, as demonstrated after LPS administration in an animal model [36], may, as in vitro, antagonize BPI effects and enhance LPS toxicity $[10,12,37]$

The role of sCD 14, normally present in plasma, in modulating LPS toxicity seems to be twofold. For CDI4-negative cells, such as endothelial and epithelial cells, sCD 14 strongly enhances LPS-induced cell activation [5-8]. In contrast. for CD14-positive monocytes. SCDI 4 neutralizes LPS effects by competing with cell-bound $\mathrm{CD} 14$ [9].

To investigate the role of LPS activity-modulating proteins in infectious disease. BPI, LBP, and SCDI 4 plasma levels were measured in patients with culture-proven gramnegative bacteremia. These data were compared with those from bacteremic patients from whom a gram-positive. consequently L.PS lacking, microorganism was isolated. In addition, the correlation between plasma levels and clinical parameters was assessed. 


\section{Patients and Methods}

Patients. In a prospective study in which all patients admitted to the intensive care unit (ICU) were enrolled, clinical data. sepsis syndrome parameter measurements, and plasma samples were collected daily. Patients were included in the study when. while they were in the ICU. bacteremia was proven by at least I positive blood culture. Blood for culture was obtained by vein puncture. Exclusion criteria were detection of a single blood culture with Staphylococcus epidermidis (considered as contamination). presence of a mixed gram-negative/gram-positive bacteremia (to analyze differences between gram-negative vs. grampositive bacteremia), or surgical interventions within 2 weeks before bacteremia (to exclude the putative effect of surgery on the parameters studied). Patients were divided into 3 subgroups: those with or without sepsis syndrome (as a parameter of severity of disease) [38]; survivors and nonsurvivors at day 28 after first positive blood culture; and those with gram-negative versus gram-positive bacteremia.

Plasma samples obtained during the study (from 3 days before up to 3 days after first positive blood culture) were analyzed. and the data were compared with those of 49 healthy volunteers. Further, the kinetics of BPI and LBP were investigated in 10 patients selected because plasma samples from a 14-day followup were available.

Blood samples. As part of a larger surveillance study, blood samples were taken daily from each ICU patient using evacuated blood collection tubes containing EDTA. Blood samples were always collected at the first daily round of routine blood sampling at $\sim 6$ A.M. The blood samples were immediately put on ice, and plasma was prepared by centrifugation at $2200 \mathrm{~g}$ for $5 \mathrm{~min}$ at $4^{\circ} \mathrm{C}$. Care was taken to prevent contamination of the plasma samples with PMNL, which may release BPI after freezethawing. Hemolytic plasma samples were excluded from laboratory measurements; this procedure minimizes artificial BPI release [30]. Samples were stored at $-70^{\circ} \mathrm{C}$ until use. Levels of $\mathrm{BPI}$. LBP. and $\mathrm{SCD} / 4$ were determined, as described later. in plasma samples collected during the study.

Reagents and materials. Human recombinant BPI ( $\mathrm{rBPl}$ : provided by M. Marra. InCyte. Palo Alto, CA) was produced by transfected CHO cells. Puritication was done sequentially using ion-exchange and size-exclusion columns. A BPI-neutralizing monoclonal antibody (MAb) $4 E 3$ ( $\mathrm{IgGI}$ ) was developed in our laboratory and described elsewhere [10]. This antibody has been shown to react specifically with human rBPI, with no cross-reactivity with recombinant LBP (rLBP). Polyclonal antibodies to human $r B P I$ were obtained by immunizing rabbits with human rBPI. This anti-BPI antiserum did not cross-react with human rLBP as tested by ELISA. After protein A puritication. the polyilonal IgG was biotinylated.

Human rLBP was produced by the transfected human embryonic kidney cell line 293 EBNA provided by Invitrogen (San Diego). Polyclonal antibodies to human rLBP were obtained by immunizing rabbits with human rLBP. After protein A purification, the polycional $\operatorname{IgG}$ was biotinylated.

The murine anti-human $\mathrm{CDl} 4$ MAb MEM-18 ( $\operatorname{lgGl} 1$ ). sCD14. and polyclonal rabbit anti-sCD 14 antibodies were provided by Hořesji Institute of Organic Chemistry and Biochemistry (Prague) [39.40].
Peroxidase-conjugated goat anti-rabbit IgG was purchased from Jackson Immunoresearch Laboratories (Westgrove, PA). peroxidase-conjugated streptavidin from Dakopatts (Glostrup, Denmark), and TMB (3,5.5'-tetramethylbenzidine) substrate from KPL (Gaithersburg. MD). Immuno maxisorp plates (Nunc, Roskilde, Denmark) were used for ELISAs.

Immunoassays. Plasma BPI, LBP, and sCD14 levels were measured using sandwich ELISAs.

BPI was detected as deseribed elsewhere [30]. In short. 96. well plates were coated with human $\mathrm{rBPI}$-specific MAb $4 E 3$. and free sites were blocked with PBS-1\% bovine serum albumin. Washing and dilution buffers contained $80 \mathrm{mM} \mathrm{MgCl}$; the $\mathrm{Mg}^{++*}$ ions prevented disturbance of BPI measurement by LPS. Human rBPI was used for the standard titration curve. Test samples diluted in assay buffer $(1: 2)$ were incubated for $2 \mathrm{~h}$ at room temperature. Next, a biotinylated polyclonal rabbit anti-human BPI IgG was used, followed by peroxidase-labeled streptavidin. TMB was used as a substrate, and photospectometry $(450 \mathrm{~nm})$ was done using a micro ELISA autoreader. The detection limit for the BPI assay was $100 \mathrm{pg} / \mathrm{mL}$.

For LBP detection. plates were coated with polyclonal antihuman LBP antibodies. The washing and reagent dilution buffer contained $40 \mathrm{mMMgCl}$; the $\mathrm{Mg}^{++}$ions prevented disturbance of LBP recovery by LPS in the ELISA. Diluted plasma samples (1:5000) and a standard dilution series with rLBP were added to the plate. Detection occurred with a biotinylated polyclonal rabbit anti-human LBP $\mathrm{IgG}$, followed by peroxidase-conjugated streptavidin and substrate. The detection limit for the LBP assay was $200 \mathrm{pg} / \mathrm{mL}$.

Plasma sCD14 levels were measured using MEM-18 as capture reagent. Diluted plasma samples $(1: 2000)$ and a standard dilution series with $\mathrm{sCD} / 4$ were added to the plates. The amount of SCD 14 bound to the wells was quantified by sequential incubation with a polyclonal rabbit anti-sCD/4 antibody. followed by peroxidase-conjugated goat anti-rabbit antibody. The detection limil for the sCD 14 assay was $50 \mathrm{pg} / \mathrm{mL}$.

All plasma samples were analyzed in the same run. When plasma levels exceeded the detection limit of the assay, sampies were additionally diluted and analyzed in a separate run with an overlap to correct for interassay variation. The intra- and interassay coefficients of variance of the various assays were all $<10 \%$.

Sratistical analysis. To analyze differences between the subgroups studied, the Mann-Whitney test was done using the peak levels detected in each patient during the study period (day 3 before to day 3 after bacteremia was diagnosed). Correlations were analyzed by using Spearman's rank correlation test. The incidence of sepsis syndrome and mortality in the studied subgroups was assessed by $x^{2}$ test. Unless stated otherwise, plasma levels are given as median (range). Differences were considered significant at $P<05$.

\section{Results}

Paticnts. A total of 64 patients ( 36 men, 28 women) aged $29-95$ years (average $\pm \mathrm{SF}, 62+2$ ) were included in the study. The microorganism, isulated from the blood are given in table 1. The severity of clinical symptoms varied 
Table 1. Organisms isolated from the blood of bacieremic patients.

\begin{tabular}{|c|c|}
\hline Organism isolated & No. of patients \\
\hline Bacillur species & 2 \\
\hline Bacteroides species & 3 \\
\hline Enterobacter rloacus & I \\
\hline Enterococcus faecalis & 6 \\
\hline Escherichia coli & 11 \\
\hline Haemophilus influenzae & 3 \\
\hline Klebsiello pucumoniae & 6 \\
\hline Monganell's morganii & 2 \\
\hline Neisseria ineningitidis & 1 \\
\hline Proprionibucterium species & 2 \\
\hline Proteus mirabilis & 5 \\
\hline Pseudomonas aeruginosa & 4 \\
\hline Sernalia marcesiens & 1 \\
\hline Slaphwocarcus aureus & 9 \\
\hline Sraphylococcus epidennidis & 3 \\
\hline Siuphyloceccus species & 4 \\
\hline Sirepioroccus species & 7 \\
\hline
\end{tabular}

NOTE. In 58 patients, I organism was isolated: in 6.2 organisms were cultured. Patients from whom $S$. epidernidis was iscolated were included only when another gram-positive organism was detected simultaneously.

from mild fever to severe multiple organ dysfunction. According to sepsis criteria [38], 30 patients had sepsis syndrome (table 2). The incidence of sepsis syndrome was similar for patients with gram-negative and gram-positive bacteremis. On the day bacteremia was first detected (day 0 ). APACHE II scores [41] of sepsis syndrome patients were significantly higher than those of patients without sepsis syndrome $(20.0$ [11.0-36.0] vs. 14.8 [8.0-22.0]; $P<.0001)$. In addition, mortality in patients with sepsis syndrome was significantly higher $(P<.005)$ than in those without sepsis syndrome (18/30 [60\%] vs. $7 / 34$ [21\%], respectively).

$B P I$. LBP. and $s C D 14$ plasma levels in bacteremic parients. BPI, usually not detectable in plasma of healthy volunteers [30], was found in large amounts in 60 of 64 bacteremic patients (figure 1, lef). As a result, peak levels of BPI were significantly higher in patients with bacteremia (median [range], $8.39[<0.2-120.0] \mathrm{ng} / \mathrm{mL}$ ) than in healthy volunteers $(P<.0001)$. In the healthy volunteers $(57$ years old [range, 2I-82]). BPI was detectable in only 8 of 49 subjects $(0.4-0.8 \mathrm{ng} / \mathrm{mL})$.

Proteins modulating LPS toxicity are expected to be more affected in patients with gram-negative than in those with gram-positive infections. since gram-positive micruorganisms do not contain LPS. Interestingly. BPI peak levels were similar in patients with either gram-negative or gram-positive bacteremia $(7.9[<0.2-120.0]$ and $9.3[<0.2-82$. I] $\mathrm{ng} / \mathrm{mL}$. respectively).

L.BP was detectable in all blood samples from bacteremic patients and healthy volunteers. Peak levels of I.BP in bacteremic patients (figure 1, middle) were significantly higher
$(P<.0001)$ than those in healthy controls $(216.0[44.0-$ 656.0] $\mu \mathrm{g} / \mathrm{mL}$ vs. $16.2[9.1-43.2] \mu \mathrm{g} / \mathrm{mL}$ ). However. again no significant differences were observed in LBP peak levels between patients with either gram-negative (228 [44-656] $\mu \mathrm{g} / \mathrm{mL}$ ) or gram-positive $(203[68-475] \mu \mathrm{g} / \mathrm{mL}$ ) bacteremia.

For sCDI4 (figure 1, right), peak levels were significantly lower in the gram-negative subgroup (2.23 [0.82-5.30] $\mu \mathrm{g}$ $\mathrm{mL}$ ) than in either the gram-positive subgroup (2.74 [1.15$8.34] \mu \mathrm{g} / \mathrm{mL})$ or healthy controls $(2.64[1.36-6.82] \mu \mathrm{g} / \mathrm{mL})$ (gram-negative $[n=36]$ vs. gram-positive $[n=28]$ bacteremia, $P<.01$ : gram-negative bacteremia vs. controls, $P<$ $.01)$. When all 64 bacteremic patients $(2.42[0.82-8.34] \mu \mathrm{g}$ $\mathrm{mL}$ ), however, were compared with the healthy controls, differences in peak levels were not significant.

BPI. $L B P$. and sCDI4 plasma levels and clinical course. Severity of disease in bacteremic patients was assessed by the presence or absence of sepsis syndrome and mortality at day 28. For BPI, peak levels in bacteremic patients (figure 2, left) were similarly enhanced in patients with and without sepsis syndrome $(P=.19)$, and there was no correlation with outcome.

Sepsis syndrome may be accompanied by leukocytosis as well as leukopenia. Since BPI is released by peripheral blood neutrophils, the number of blood neutrophils during bacteremia was expected to affect plasma BPI levels. Therefore, the correlation between plasma BPI levels and neutrophil counts was investigated. In patients with detectable BPI levels, a significant correlation was found between neutrophil counts and BPI levels ( $r=.49 ; P<.0001$; data not shown). In accord, in patients with severe neutropenia $(n=4$ : leukocytes $\leqslant 2 \times 10^{9} / \mathrm{L}$ ) BPl was not detectable ( $\leqslant 0.2 \mathrm{ng} / \mathrm{mL}$ ). In order to consider BPI levels independently of blood neutrophil counts, the BPI/neutrophil ratio, as an indicator of neutrophil activation. was analyzed in the studied subgroups. In patients with sepsis syndrome, peak values of BPI/neutrophil ratio (figure 3. left) were significantly higher $(P<.01)$ compared with those of patients without sepsis syndrome ( 1.06 $[0.11-6.49]$ vs. $0.57[0.06-3.82] \mathrm{ng}$ of $\mathrm{BPI} / 10^{6}$ neutrophils). In addition, peak values of the BPI/neutrophil ratio were significantly higher $(P<.05)$ in nonsurvivors $(1.02[0.12-$ $6.49] \mathrm{ng}$ of $\mathrm{BPI} / 10^{6}$ neutrophils) than in survivors $(0.64$ [0.06-3.82] ng of BPI $/ 10^{6}$ neutrophils) of bacteremia.

In patients with bacteremia, LBP levels were significantly

Table 2. Blood culture data and prevalence of sepsis syndrome and mortality in the study population.

\begin{tabular}{lcc}
\hline & \multicolumn{2}{c}{ Sepsis syndrome } \\
\cline { 2 - 3 } Blond culture & $Y e s(n=30)$ & $N_{0}(n=34)$ \\
\hline Gram-negative & $20(11)$ & $16(4)$ \\
Gram-positive & $10(7)$ & $18(3)$ \\
\hline
\end{tabular}

NOTE. No. of nonsurvivors is in parentheses. 
BPI

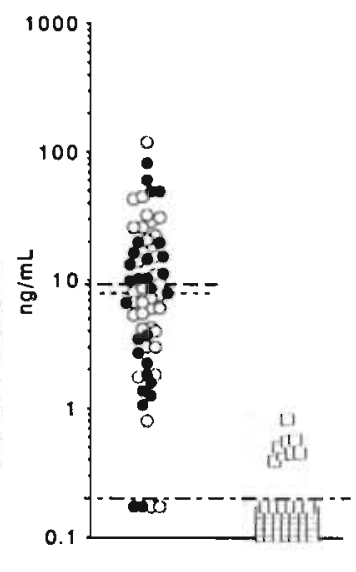

LBP

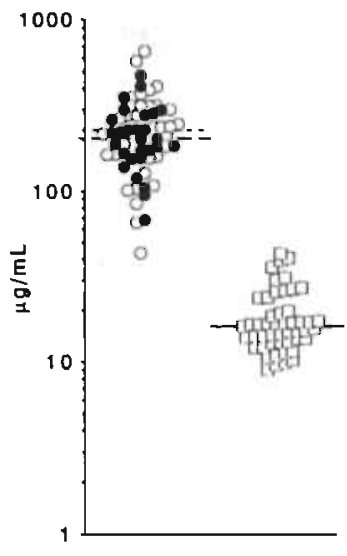

SCD14
Figare 1. Bactericidal/permeability-increasing protein (BPI). lipopolysaccharide-binding protein (LBP), and soluble CDI4 (sCDI4) levels in bacteremic patients $(n=64)$ and healthy controls $(n=49)$. Data for bacteremic patients represent peak levels.

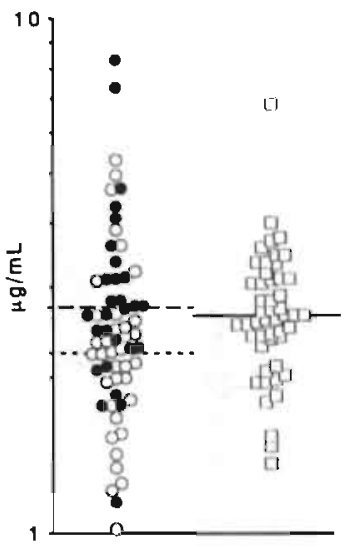

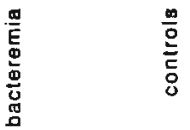

Gram-negative bacteremia o with corresponding median ......-

Gram-positive bacterenia - with corresponding median - - -

Median, heal thy controls

Detection linit of assay -....

associated with the presence of sepsis syndrome (figure 2 . middle). These patients had higher L.BP peak levels than did patients without sepsis syndrome: $256(66-656)$ versus 184 $(44-574) \mu \mathrm{g} / \mathrm{mL}$, respectively $(P<.01)$. However. LBP peak levels were not different in nonsurvivors compared with survivors of bacteremia: $223(68-475)$ versus $204(44-656) \mu g /$ $\mathrm{mL}$, respectively.

Since BPI and LBP have antagonistic properties, the ratio between these proteins may be of clinical relevance in patients with bacteremia and endotoxemia. No association between day 28 mortality and the peak values of LBP/BPI ratio was found. However, in the subgroup of patients with gramnegative bacteremia. the LBP/BPI ratio at day 0 tended to be higher in patients who died early (within 7 days after diagnosis of bacteremia) compared with survivors (69 [4-488] and $20(2-330) \times 10^{3}$, respectively: $P=.06$ ) (figure 3, right). No association between $\mathrm{LBP} / \mathrm{BPI}$ ratio and mortality rate was observed in patients with gram-positive bacteremia (34 [1$297]$ vs. 51 [2-907] $\times 10^{3}$ for nonsurvivors and survivors, respectively).

Absolute differences in SCDI4 levels between the subgroups were small (figure 2, right). No differences in $\mathrm{sCD} / 4$ peak levels were observed between nonsurvivors and survivors $(2.29[0.82-4.64]$ and $2.43[1.25-8.34] \mu \mathrm{g} / \mathrm{mL}$, respectively). However, sCDI 4 peak levels were significantly lower in patients with sepsis syndrome than in those without sepsis syndrome: $2.23(0.82-5.30)$ versus $2.56(1.76-8.34) \mu \mathrm{g} / \mathrm{mL}$. respectively $(P<.01)$.

Kinetics of $B P I$ and $L B P$ in individual patients. Kinetics of BPI and LBP were assessed in a subgroup of 10 patients. Data for 4 typical cases with either an early recovery or an early fatal course are given in figure 4 . Both plasma BPI and LBP levels were already increased in the first samples tested compared with levels in controls. Fluctuations in plasma levels. assessed during a 14-day period after bacteremia was diagnosed, were more pronounced for BPI than for LBP. The ratio between maximum and minimum levels in these 4 patients ranged from 11 to 133 for $\mathrm{BPI}$ and from 1.8 to 3.3 for LBP.

Two of 4 patients survived beyond day 28, whereas the other 2 died at day 14 and 21 , respectively. In a survivor of gram-negative pulmonary sepsis (figure $4 \mathrm{~A}$ ). a significant correlation between BPI and blood neutrophil kinelics was observed $(r=.86 ; P<.0001)$. This case demonstrates that during severe sepsis. BPI levels may normalize as a result of neutropenia complicating sepsis syndrome and not because neutrophils are not activated.

The second survivor had gram-negative bacteremia accompanying strangulation ileus (figure 4B). After surgical intervention (day 2-3), the patient recovered quickly, and BPI levels decreased rapidly (from 120.0 to $0.9 \mathrm{ng} / \mathrm{mL}$ ) with normalizing neutrophil levels, whereas LBP levels remained en- 
BP I

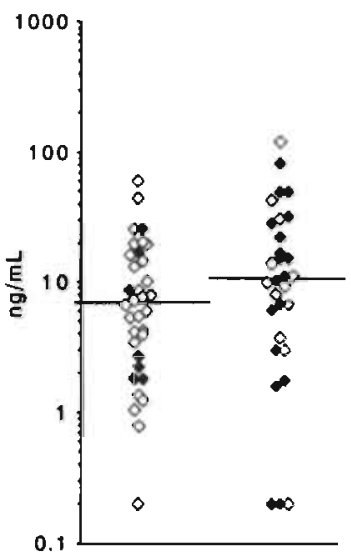

$\begin{array}{ll}\frac{n}{50} & \frac{n}{5} \\ \frac{0}{9} & \frac{0}{9} \\ 0 & \end{array}$
LBP

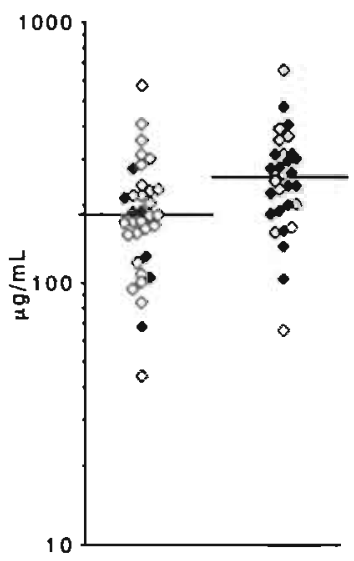

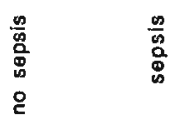

hanced (from 313 to $109 \mu \mathrm{g} / \mathrm{mL}$. maximum and day 14 value, respectively).

BPI and LBP both increased in a patient with gram-positive abdominal sepsis who died on day 14 (figure $4 C$ ). Of interest, the ratio between plasma BPI levels and blood neutrophil counts increased from 0.1 to $0.6 \mathrm{ng} \mathrm{BPl} / 10^{6}$ circulating neutrophils shortly before death. These data strongly suggest an ongoing activation of neutrophils until death due to multiple organ dysfunction.

Similarly, in a patient with osteomyelitis due to Staphylococcus aureus, both BPI level and BPI/neutrophil ratio increased shortly before death (figure 4D) due wo deterioration of sepsis syndrome complicated by multiple organ dysfunction. The increase in BPI/neutrophil ratio (from 0.5 to 63.0 ng of BPI $/ 10^{6}$ neutrophils, day 14 and 21 , respectively). however, was more pronounced compared with the increase in BPI levels (from 4.6 to $57.0 \mathrm{ng} / \mathrm{mL}$ )

\section{Discussion}

The toxicity of LPS is, at least in vitro, modulated by several proteins, including BPI, LBP. and sCD/4. Therefore. these L.PS toxicity-modulating proteins were expected to be more affected in gram-negative than in gram-positive bacteremia. Indeed, $s C D / 4$ levels were found to be decreased in the subgroup of patients in which a gram-negative microorganism uas detected. In accord, LPS was demonstrated, al-

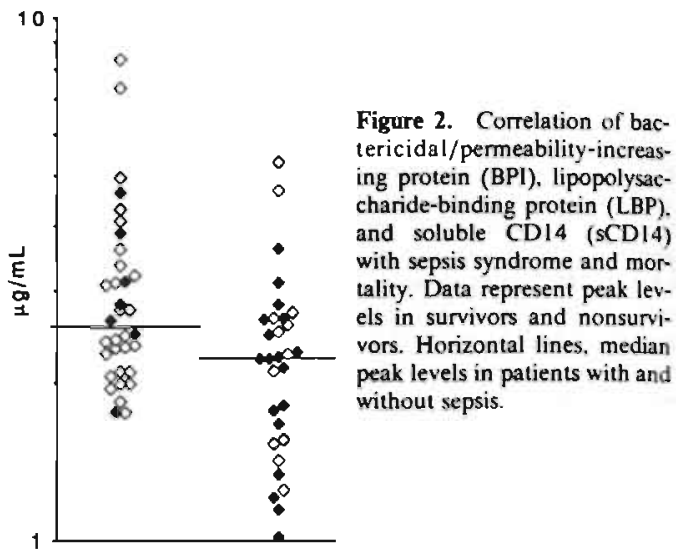

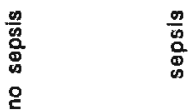

though not consistently, to lead to a decreased monocyte cell membrane expression of $\mathrm{CDI} 4$, which may lead to decreased sCDI4 levels [42, 43]. On the other hand, activation of monocytes has also been reported to lead to shedding of CDI4 [42].

In contrast to the expected differences between data in gram-negative and gram-positive bacteremia, the present study shows similarly enhanced BPI and LBP levels in both gram-negative and gram-positive bacteremia. In gram-negative bacteremia, these observations may be explained by the presence of LPS. which has been shown to induce an increase of BPI in human volunteers [44], and of LBP in an animal model [36]. During infections with gram-positive microorganisms, however. LPS may also be present and affect plasma levels of the parameters studied. The presence of endotoxemia in critically ill patients without gram-negative intection has been reported $[45,46]$. In such patients, endotoxin may leak from the gut into the circulation following failure of the gut mucosal barrier [47-49]. The presence of endotoxemia during gram-positive infections could also be explained by failure to detect gram-negative microorganisms.

In bacteremic patients, LPS levels are reported to be timedependent, usually not exceeding $100 \mathrm{pg} / \mathrm{mL}$ [46]. It remains, therefore, unclear whether LPS is the most important stimulus for the increase in BPI and LBP levels. Besides LPS, other stimuli may be responsible for the increase in BPI and 
BPI/neutrophII ratlo

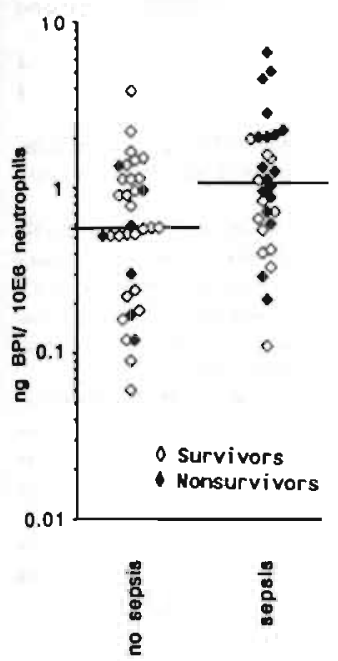

LBP/BPI

ratlo

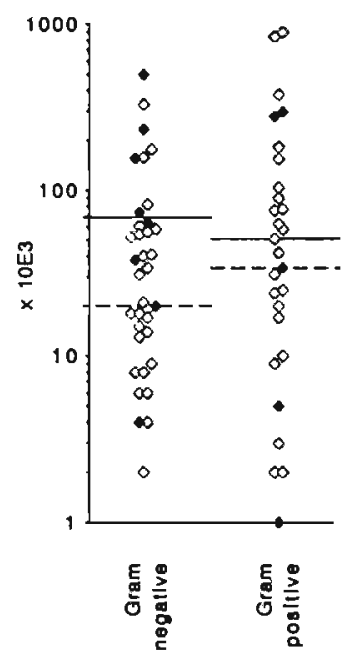

Figure 3. Prognostic value of bactericidal/permeability-increasing protein (BPI) in relation to blood neutrophil count and lipopolysaccharide-binding protein (LBP) levels. Left. peak values of BPI/ blood neutrophil ratio. Horizontal lines $=$ medians in patients with and without sepsis. Right. ratio on day bacteremia was first detected according to early mortality (day 7 ). Dashed lines = medians in survivors; solid lines = medians in nonsurvivors.

LBP levels. Nonspecific inflammatory responses clicited by, for example, extracorporeal circulation, as occurs during hemodialysis, were reported to induce a temporary $\mathrm{BPI}$ increase [50]. Furthermore, turpentine administration and gram-positive bacterial infection were accompanied by an increase of LBP levels in an animal model [36].

In most of the patients. BPI and LBP levels were increased in the first samples studied, indicating that the inflammatory response had been triggered before bacteremia was detected. Fluctuations of plasma levels with time were more pronounced for BPI than for LBP, whereas changes in SCDI4 levels (data not shown) were minimal.

BPI levels were remarkably enhanced in patients with hacteremia. but no correlation with the presence of sepsis syndrome or mortality was observed. Our data are supported by a recent report describing high BPI levels in sepsis syndrome patients [44]. These authors also reported, however, high BPI levels in healthy controls: in controls. these levels may be due to the artificial release of BPI after blowd sampling. which occurs if BPI release is not prevented, as we have recently shown [30]. The low BPI levels detected in a minority of the controls in the present study suggest that only minimal neutrophil activation occurred during blood sampling and processing. leading to minimal BPI release. The high BPI levels in our patients, therefore. reflect BPI levels present in plasma at the time of blood drawing.

The release of the neutrophil product BPI is considered to depend on the extent of neutrophil activation. We therefore hypothesized that BPI levels depend on the extent of neutrophil activation as well as the number of activated neutrophils. In this light, the BPI/neutrophil ratio represents the degree of neutrophil activation: this ratio was positively correlated with the presence of sepsis syndrome as well as death. In accord, in the selected cases presented, an increase in the BPI/neutrophil ratio was associated with subsequent death. These data are in line with other reports on parameters of neutrophil activation in infectious disease. Enhanced levels of elastase, stored in the same granules as BPI. were detected in sepsis syndrome patients [51-53]. A correlation between enhanced elastase levels and mortality was. however, not found consistently. This inconsistency may be the result of the influence of blood neutrophil count on these levels as we demonstrated for BPI.

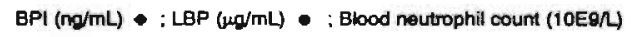
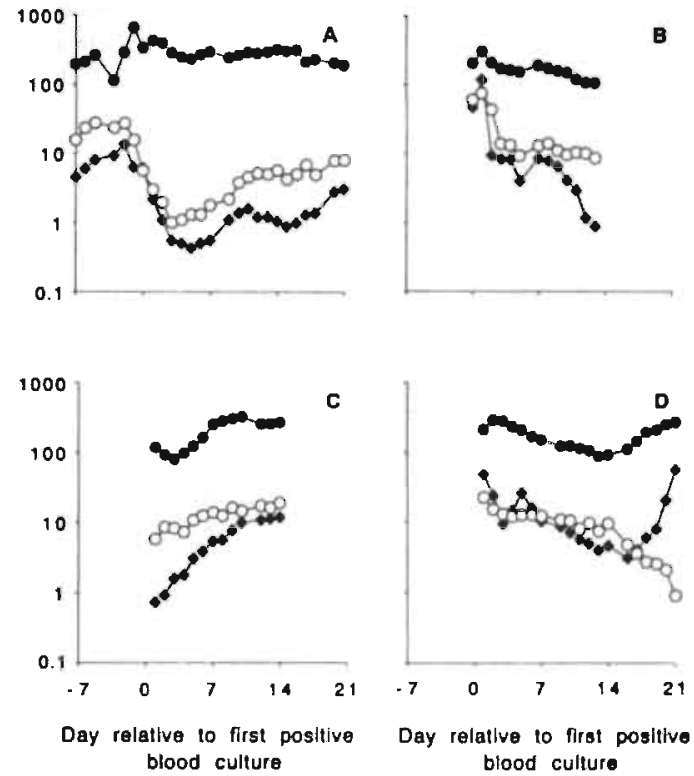

Figure 4. Kinetics of bactericidal/permeability-increasing protein (BPI) and lipopolysatcharide-binding protein (LBP) in individual patients. Data represent survivor of grami-negative: pulmonary sepsis (A), patient who recovered from gram-negative bacteremia accompanying sirangulation ileus (B), nonsurvivor of gram-positive abdominal sepsis $(\mathbf{C})$, and nonsurvivor with gram-positive osteomyelitis (D). 
Increased LBP levels were, as with the BPI/neutrophil ratio, associated with the presence of sepsis syndrome. The highest levels were detected 24-48 h after onset of bacteremia, confirming the acute-phase nature of LBP. whereas the $\mathrm{BPI} /$ neutrophil ratio reached highest values within the first $24 \mathrm{~h}$ (data not shown). The results presented are in line with those concerning C-reactive protein (CRP) [54]. Increased plasma levels of CRP, also an acute-phase protein, were associated with the presence of bacteremia and severity of infection. whereas no correlation was found with causative microorganisms.

On the basis of in vitro data, LBP appears to enhance LPS toxicity and antagonize the effects of BPI. which is considered to be protective by inactivation of LPS. Therefore, we investigated the ratio between LBP and BPI levels. This parameter may reflect the net result of these proteins on LPS effects. Only in a subgroup of patients with gram-negative bacteremia was an enhanced LBP/BPI ratio on the day of detection of bacteremia associated with poor outcome. suggesting that this ratio may be of value in gram-negative infections. The exact role of enhanced circulating BPI and LBP levels remains unclear, since BPI and LBP probably exert their main functions locally at the site of infection.

The present study shows that decreased sCDI 4 levels were associated with gram-negative bacteremia and the presence of sepsis syndrome. However, differences between the subgroups were not substantial: therefore. monitoring sCDI4 levels seems to be of limited value.

In conclusion, enhanced levels of BPI and LBP characterized the inflammatory response during bacteremia. An increased BPI/neutrophil ratio, as a parameter of neutrophil activation, and increased L.BP levels correlated positively with the presence of sepsis syndrome. In addition, an enhanced $\mathrm{BPI} /$ neutrophil ratio was associated with a fatal clinical course. Further studies on BPI and LBP will be required to elucidate the exact role of these LPS toxicity modulating proteins in infectious disease.

\section{Acknowledgments}

We thank H. Schouten (Department of Medical Statistics) for statistical advice and the nursing staff of the ICU for assistance in blood sampling.

\section{Refereaces}

I. Morrison DC. Ryan JL. Endotoxins and disease mechanisms. Annu Rev Med 1987:38:417-32.

2. Martich GD. Boujoukos AJ. Suffredini AF. Response of man to endotoxin. Immunobiology 1993:187:403-16.

3. Tracey KJ. Beutler B. Lown SF, et al. Shock and tissue injury induced by rcombinant human cachectin. Science 1986:234:470-4

4. Akin S, Hirano T, Taga $T$, Kishimoto $T$. Biology of multifunctional cytokines: 1L-6 and related molecules (IL-I and TNF). FASEB J 1990:4:2860-7.
S. Pugin J. Schurer-Mally CC. Leturca D. Moriary A. Ulevitch RJ. To bias. PS. Lipopolysaccharide activation of human endothelial and ep: thelial cells is rnediated by lipopolysaccharide-binding protein and soluble CD|4. Proc Natl Acad Sci USA 1993:90:2744-8.

6. Haziot A, Rong GW. Silver J. Goyert SM. Recombinan soluble CDIA mediates the activation of endothelial cells by lipopolysaccharide. J Immunol 1993:151:1500-7.

7. Frey EA. Milter DS. Jahr TG. et al. Soluble CDI4 participales in the response of cells to lipopolysaccharide. I Exp Med 1992:1 76:166571.

8. von Asrauth EJ. Dentener MA, Bazil V. Bouma MG. Leeuwenberg JF. Buurman WA. Anti-CDI4 antibodies reduce responses of cultured human endothelial cells to endotoxin. Immunology 1993:80:78-81.

9. Haziol A. Rong GW. Bazil V. Silver J, Goyert SM. Recombinant soluble CD 4 inhibits LPS-induced tumor necrosis factor-a production by cells in whole blood. J Immunol 1994;152:5868-76.

10. Dentener MA, von Asmuth EJ. Francot GJ, Marra MN. Burman WA Antagonistic effects of lipopolysaccharide binding protein and bacte ricidal/permeability-increasing protein on lipopolysaccharide-induced cytokine release by mononuclear phagocyles. Competition for binding to lipopolysuccharide. J Immunol 1993; IS1:4258-65.

11. Wright SD. Ramos RA. Tobias PS. Ulevitch RJ. Mathison JC. CDI4, a receptor for complexes of lipopolysaccharide (LPS) and I.PS binding protein. Science 1990;249:1431-3.

12. Heumann D. Gallay P. Barras C. et al. Control of lipopolysaccharide (LPS) binding and LPS-induced tumor necrosis factor secretion in human peripheral blood monocytes. J Immunol 1992; 148:3505-12.

13. Gallay P. Heumann D. Le Roy D. Barras C, Gleuser MP. Lipopolysaccharide-binding protein as a major plasma protein responsible for endotoxemic shock. Proc Nall Acad Sci USA 1993:90:9935-8.

14. Mathison JC, Tobias PS, Wolfson E. Ulevitch RU. Plasma lipopolysaccharide (LPS)-binding protein. A key component in macrophage recagnition of gram-negative LPS. J Immunol 1992: 149:200-6.

15. Fisher CJ, Marra MN. Palardy JE. Marchbanks CR, Scoit RW, Opal SM. Human neutrophil bactericidal/permeability-increasing protein reduces mortality rate from endotoxin challenge: a placebu-controlled study. Crit Care Med 1994;22:553-8

16. Kelly CJ. Cech AC. Argenteanu M. et al. Role of bactericidal permea bility-increasing protein in the treatment of grnm-negative pneumonia. Surgery 1993; 1 14: 140-6.

17. Kohn FR. Ammons WS. Horwitz A. et al. Protective effect of a recombinant amino-terminal fragment of bactericidal/permeability-increas ing protein in experimental endotoxemia. I Infect Dis 1993:168 1307-10.

18. Lin Y. Kohn FR. Kung AH. Ammons WS. Protective effect of a recombinant fragment of bactericidal/permeability increasing protein against carthohydrate dyshomeostasis and tumor necrosis factor-alpha elevation in rat endotoxemis. Biochem Pharmacol 1994;47 $1553-9$.

19. Ammons WS. Kung AHC. Recombinant amino terminal fragment of bactericidal/permeability-increasing protein prevents hemodynamic responses to endotoxin. Circ Shock 1993;41:176-84

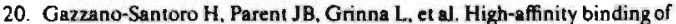
the bactericidal/permeability-increasing protein and a recombinant amino-terminal fragment to the lipid A region of lipopolysaccharide. Infect Immun 1992;60:4754-6I

21. Weiss J. Otsson 1. Cellular and subcellular localization of the bactericidal/permeability-increasing protein of neutrophils. Blood 1987: 69:652-9

22. Marra MN. Wilde CG. Collins MS. Snable JL. Thomton MB, Scoll RW. The role of bactericidal/permeability-increasing protein as a natural inhibitor of bacterial endotoxin. I Immunol 1992:148: 532-7.

23. Weersink AJ van Kessel KP, van den Tol ME, et al. Human granulo- 
cytes express a S5-kDa lipopolysaccharide-binding protein on the cell surface that is identical to the bactericidal/permeability-increasing protein. J Immunol 1993:150:253-63.

24. Weiss J. Elsbach P. Olsson I. Oderberg H. Purification and characterization of a potent bactericidal/permeability-increasing protein from the granules of human polymorphonuclear leukocytes. I Biol Chem 1978:253:2664-72.

25. Marra MN, Wilde CG, Griffith JE. Snable JL. Scott RW. Bactericidal/ permeability-increasing protein has endotoxin-neutralizing activity. J Immunol 1990: 144:662-6.

26. Ooi CE. Weiss J. Doerfler ME. Elshach P. Endotoxin-neutralizing properties of the $25 \mathrm{kD} \mathrm{N}$-serminal fragment and a newly isolated $30 \mathrm{kD}$ C-terminal fragment of the 55-60 kD bactericidal/permeabilityincreasing protein of human neutrophils. J Exp Med 1991:174:64955.

27. Weiss J. Elsbach P. Shu C. et al. Human bactericidal/permeabilityincreasing protein and a recombinant $\mathrm{NH}_{2}$-terminal fragment cause killing of serum-resistant gram-negative bacteria in whole blood and inhibit tumor necrosis factor release induced by the bacteria. J Clin Invest 1992:90: 1122-30.

28. Corradin SB. Heumann D. Gallay P. Smith J. Mauel J, Glauser MP. Bactericidal/permeability-incressing protein inhibits induction of macrophage nitric oxide production by lipopolysaccharide. J Infect Dis 1994:169:105-11.

29. Meszaros K. Parent JB, Gazzano SH, et al. A recombinant amino terminal fragment of bactericidal/permeability-increasing protein inhibits the induction of leukocyte responses by LPS. J Leukoc Biol 1993:54:558-63.

30. Dentener MA. Francot GJM. Smit FT, et al. Presence of bactericidal/ permeability-increasing protein in disease: detection by ELISA. J Infect Dis 1995:171 (in press).

31. Schumann RR. Leong SR. Flaggs GW. et al. Structure and function of lipopolysaccharide binding protein. Science 1990:249:1429-31.

32. Gray PW. Flaggs G. Leong SR. et al. Cloning of the CDNA of a human neutrophil bactericidal protein. Structural and functional correlations. J Biol Chem 1989:264:9505-9.

33. Tobias PS. Soldau K. Ulevitch RJ. Isolation of a lipopolysaccharidebinding acute phase reactant from rabbit serum. I Exp Med 1986: $164: 777-93$

34. Hailman E, Lichenstein HS. Wurfel MM. et al. Lipopolysaccharide (L.PS)-binding prote in accelerates the binding of LPS 10 CD 14 . J Exp Med 1994:179:269-77.

35. Wurfel MM. Kunilake ST. Lichtenstein H. Kane JP. Wrighı SD. Lipur polysaccharide (LPS)-binding protein is carried on lipoproteins and acts as a cofactor in the neutratization of LPS. J Exp Med 1994:180:1025-35.

36. Geller DA. Kispen PH. Su GL. el al. Induction of hepatocyte lipopolysaccharide binding protein in models of sepsis and the acute-phase response. Arch Surg 1993:128:22-7.

37. Gazzano-Santoro H. Meszaros K. Birr C. et al. Competition between rBPI23. a recombinant fragment of bactericidal/permeability-increasing protein. and lipopolysaccharide (LPS)-binding protein for binding to LFS and gram-negative bacteria. Infect Immun 1994:62:1185-91

38. Bone RiC. Sepsis, the sepsis syndrome. multi-organ failure: a plea for comparable definitions [editorial]. Ann Intern Med 1991:114: $332-3$.

39. Buzil V. Horejsi V. Baudys $M$. et al. Biochemical chancterization of a soluble form of the $53 \cdot \mathrm{kDa}$ monocyte surface antigen. Eur $\mathrm{J} \mathrm{m}$ munol 1986:16:1583-9.

40. Bazil V. Baudys M. Hilgert I, et al. Structural relationship between the soluble and membrane-bound forms of human monocyte surface glycoprotein CD14. Mol Immunol 1989:26:657-62.

41. Knaus WA, Draper EA, Wagner DP. Zimmerman JE. APACHE Il: a severily of disease classification system. Crit Care Med 1985:13:81829

42. Bazil V. Strominger IL. Shedding as a mechanism of down-modulation of CDI4 on stimulated human monocytes. J Immunol 1991:147: 1567-74.

43. Payne JB. Nichols FC. Peluso JF. The effects of interferon- $\gamma$ and bacterial lipopolysaccharide on CDIA expression in human monocytes. J Interferon Res 1992:12:307-10.

44. Calvane SE. Thompson WA. Marra MN, et al. Changes in polymorphonuctear surface and plasma bactericidal/permeability-increasing protein and plasma lipopolysaceharide binding protein during endotoxernia or sepsis. Arch Surg, 1994:129:220-6.

45. Rush BF. Sori A. Murphy TF. Endotoxemia and bacteremia during hemorrhagic shock. Ann Surg 1988:207:549-54.

46. Boom SJ. Reidy J. Ramsay G. Endotoxemia in severe staphylococcal intection. Surg Res Comm 1992:12:25-31.

47. Ryan CM. Yarmush ML. Burke JF. Tompkins RG. Increased gut permeability early after burns correlates with the extent of tiurn injury. Crit Care Med 1992:20: 1508-12.

48. Sori AJ. Rush BJ. Lyse TW, Smith S, Machiedo GW. The gut as source of sepsis after hemorthagic shock. Am J Surg, 1988:155:187-92.

49. Herndon DN. Zeigler ST. Bacterial translocation after thermal injury. Crit Care Med 1993:21:S50-4.

50. Schindler R. Marra MN, Mckelligon BM. e1 al. Plasma Levels of bactericidal permeability-increasing protein (BPI) and lipopolysaccharidebinding protein (LBP) during hemodialysis. Clin Nephrol 1993. 40:346-51.

51. Gardinali M. Padalino P. Vesconi S, et al, Complement activation and polymorphonuclear neutrophil leukocyte elastase in sepsis. Correla. tion with severity of disease. Arch Surg 1992:127:1219-24

52. Nuijens JH. Abbink JJ. Wachtfogel YT. el al. Plasme elastase alpha l-antitrypsin and lactoferrin in sepsis: evidence for neutrophils as mediators in fatal sepsis. J Lab Clin Med 1992:119:159-68

53. Pacher R. Redl H. Frass M. Petzl DH. Schuster E. Woloszczuk W. Relat tioniship between neopterin and granulocyte elastase plasma lev. els and the severity of multiple organ faulure. Crit Care Med 1989:17:221-6.

54. Liggenberg PC. Hoepelman IM. Oude Sogtoen GA, et al. C-reaciive protein in the dagnosis and management of infections in granulocy. Ioperic and non-granulocytopernic patients. Eur J Clin Microbiol Infect Dis 1991:10:25-31. 
Chapter 12

\section{Discussion and Summary}




\section{DISCUSSION AND SUMMARY}

Endotoxin or LPS comprises the major component of the outer membrane of all gram-negative bacteria. Therefore, the recognition of and response against this glycolipid by the host will provide protection against a wide range of microorganisms. The host can be exposed to LPS due to translocation of gut bacteria into the circulation, as a result of mucosal epithelium dysfunction or due to severe trauma, whereas another route of exposure is the inhalation of air-borne LPS (Chapter 1).

LPS interacts with a broad range of humoral and cellular systems of the host. After entering the circulation, LPS binds to lipoproteins in plasma, resulting in a reduction of its biological activity. Furthermore, LPS activates the complement system, and induces coagulation, whereas also the liver and the neuro-endocrine system are also activated, resulting into metabolic alterations. In parallel, cells of the immune system, like monocytes and PMN, but also endothelial and epithelial cells, which perform besides their barrier function also an immune function, are activated. These cellular activation processes are mediated via LBP and CD14. The diversity of physiological responses act in concert and are directed at the elimination of free LPS and gram-negative bacteria, and subsequently at the repair of damaged tissues.

However, under certain conditions, like the continuous presence of high concentrations of LPS, or as a result of enhanced sensitivity for LPS, the actions of these normally well regulated defense systems, become noncontrollable. As a consequence, instead of contributing to protection against microorganisms, these responses will be detrimental for the host. More insight in the pathways of LPS action will help to develop therapeutic strategies to intervene in LPS-mediated pathology. To this end, a series of studies was performed analyzing several aspects of host response to LPS.

The sensitivity for LPS, which varies considerably across species (1), is strongly increased due to exposure to environmental agents, like lead (2). The mechanisms which underlie this phenomenon are not yet fully understood. Since TNF $\alpha$ is an important mediator of LPS effects (3), the role of this pro-inflammatory cytokine in this phenomenon was investigated (Chapter 2).

In this study evidence was provided that TNF $\alpha$ plays an important role in the mechanism of the enhanced sensitivity of animals to endotoxin after exposure to lead. It was shown that mice after exposure to lead become more sensitive to TNF $\alpha$, in a similar way as to LPS. Furthermore, lead treated mice had lower serum TNF $\alpha$ levels two hours after LPS exposure, whereas serum TNF $\alpha$ levels at six and eight hours after LPS were enhanced as compared to mice not exposed to lead. Finally, a monoclonal antibody (mAb) directed against mouse TNF $\alpha$ prevented lethality induced by the combined administration of lead and LPS.

Other studies confirmed the central role of TNF $\alpha$ in the enhanced susceptibility for LPS, after exposure to hepatotoxic agents like lead and D-galactosamine $(4,5)$. Recently, it was demonstrated that the enhanced sensitivity to LPS induced by Dgalactosamine is caused by TNF $\alpha$-induced apoptosis in hepatocytes with transcriptional arrest (6). This indicates that lead most probably induces sensitization 
via a similat pathway, although this had not yet been confirmed.

Furthermore, a series of studies was preformed to analyze the regulation of cellular responses to LPS. Studies by Wright et al. demonstrated that CD14, an antigen present on monocytes but also at low levels at the surface of PMN (7), functions as a receptor for LPS. LPS was shown to bind to CDI4, a process mediated by the plasma protein LBP, whereas blockade of CDI4 prevented LPS-induced TNF $\alpha$ release by monocytes $(8,9)$. Next to TNF $\alpha$, the pro-inflammatory cytokine IL- 6 and the chemokine IL-8 are important mediators of LPS-induced biological effects $(10,11)$. Therefore, it was analyzed whether the release of these cytokines was also mediated via CDI4 (Chapter 3).

First, a series of anti-CDI4 mAb were tested for their ability to block LPSinduced TNF $\alpha$ release. Two out of the five anti-CD14 mAb tested, namely MEM18 and Cris 6 which recognize the same epitope (7) inhibited LPS-induced TNF $\alpha$ release by monocytes, indicating that a specific CD14 epitope is involved in CD14LPS recognition. Evidence that CD14 is also involved in the LPS-induced IL-6 and IL-8 release was obtained from the observation that anti-CD14 mAb MEM-18 blocked the LPS-induced, TNF $\alpha$ independent, release of IL- 6 and IL-8. This inhibition was most pronounced at low LPS concentrations, and only partial at higher LPS concentrations. A possible explanation for this observation is that at high LPS concentrations cytokine release is induced via both CD14-dependent and independent pathway.

Furthermore, MEM-18 also blocked cytokine release by monocytes stimulated under serum-free conditions, indicating that LPS is able to interact directly with $\mathrm{CD} 14$, as was confirmed in other studies $(12,13)$. However, as the production of cytokines induced by LPS via CD14 is generally higher in the presence of serum as compared to serum-free conditions, serum factors like LBP, seem to enhance the affinity of LPS to membrane CD14.

In addition, the LPS-induced cytokine release by alveolar macrophages was also blocked by MEM-18. This indicates that on these differentiated mononuclear phagocytes CD14 also functions as a receptor for LPS. From this study was concluded that CD14 is involved in the LPS-induced release of TNF $\alpha$, IL-6 and IL8 by monocytes and alveolar macrophages.

Besides monocytes, endothelial cells function as immunologically active cells and respond strongly to LPS (14). Whereas, as described in chapter $3, \mathrm{CD} 14$ is involved in LPS-induced monocyte activation, the mechanisms of LPS-induced endothelial cell activation were not elucidated. This prompted us to analyze the role of CD14 in LPS-induced endothelial cell activation (Chapter 4).

This study demonstrated that, comparable to monocytes, CDI4 is involved in LPS-induced endothelial activation. The anti-CD14 mAb MEM-18 blocked the LPSinduced human endothelial cell (HUVEC) activation, as measured by the novo expression of the adhesion molecule E-selectin, and the release of IL-6. This inhibition was most pronounced at low LPS concentrations. Messenger RNA encoding E-selectin and IL-6 was reduced in parallel, indicating that MEM-18 blocked these LPS effects at the pretranscriptional level. MEM-18 did not affect 
endothelial cell activation induced by IL-1 $\beta$, TNF $\alpha$, and phorbol myristate acetate (PMA), indicating that anti-CD14 mAb specifically inhibited HUVEC responses to LPS.

Since IL-6 release and E-selectin expression on HUVEC were strongly reduced when LPS activation was performed in the absence of serum, the involvement of serum components in LPS activation of HUVEC was indicated. Nevertheless, MEM18 also blocked LPS-induced HUVEC activation under serum-free conditions, suggesting that LPS is able to interact directly with the endothelial cell membrane associated CD14. This hypothesis however, could not be confirmed, since no indications for expression of CD14 on endothelial cell surface were obtained, neither by flow cytometry, nor by surface labeling.

Although the involvement of CD14 in LPS-induced endothelial cell activation was clearly shown, the role of serum components was not completely elucidated. Further studies by others showed that the plasma protein LBP mediates binding of LPS to sCD14, also present in plasma. The LPS-sCD14 complex activates cells that do not express membrane CD14, like endothelial cells, epithelial cells, and astrocytes, most probably via an yet unidentified receptor on these cells $(15,16)$.

The pro-inflammatory cytokine TNF $\alpha$, mediating many LPS effects, activates cells via interaction with membrane receptors. Most cells express two types of TNF $\alpha$ receptors namely $\mathrm{TNFR}_{55}$ and $\mathrm{TNFR}_{75}$, which can be shed from the cell surface after activation, resulting into soluble forms (17-19). sTNFR probably play a role in inactivation of circulating $T N F \alpha$, by preventing the interaction with membrane TNFR, although low STNFR concentrations were reported to stabilize the trimeric structure of TNF $\alpha$, so reducing its decay of activity $(20,21)$. Since monocytes are a primary target for LPS, it was investigated whether LPS also affected TNFR shedding or expression, whereas also the role of CD14 in this process was analyzed (Chapter 5).

LPS was shown to induce release of $s T N R_{75}$, but not of sTNFR 5 , reaching plateau levels after approximately 48 hours. The induction of $T_{N F R}$ release was mediated via LBP and CD14, since anti-CD14 mAb inhibited LPS-induced TNFR $_{75}$ shedding, whereas the LPS-induced $T_{N F R}$ shedding, which was strongly reduced under serum-free conditions could be restored by addition of LBP. Furthermore, BPI, a PMN protein known to possess LPS neutralizing capacity (22), blocked LPSinduced $\mathrm{TNFR}_{75}$ shedding.

Also the cell surface expression of both TNFR was affected by LPS. On freshly isolated monocytes the expression of both TNFR was similar, which increased gradually during culture of monocytes. In contrast, after 1 hour exposure to LPS, the expression of both receptors was completely reduced, followed by enhanced reexpression after 24 hours of stimulation. This LPS effect was enhanced by LBP, and blocked by BPI.

LPS thus not only activates monocytes to release TNF $\alpha$, but also controls the TNF $\alpha$ effects by inducing shedding of TNFR $_{75}$, possibly inhibiting TNF $\alpha$ effects, and by temporary downregulation the expression of both $\mathrm{TNFR}_{55}$ and $\mathrm{TNFR}_{75}$. Moreover, both the release of TNF $\alpha$ and the LPS-induced TNFR shedding are mediated via a similar pathway mediated by LBP and CD14, and blocked by BPI. 
Studies described in chapter 2 to 5 showed that endogenous proteins strongly affect LPS-induced cell activation, as is confirmed in other studies $(11,23,24)$. LBP and BPI, two proteins with opposing effects, have considerable sequence homology (9), and both bind to the lipid A part of LPS $(25,26)$. This urged us to study the functional relationship between these two proteins (Chapter 6). To this end, the effect of both proteins on LPS-induced cytokine release by monocytes was analyzed.

LBP was demonstrated to enhance not only the LPS-induced TNF $\alpha$ release (as reported previous:9,12), but also the IL-6 and IL-8 release by monocytes stimulated under serum-free conditions. In contrast to the enhancing effect of LBP, BPI inhibited the release of all these three cytokines. Furthermore, it was demonstrated that the effects of LBP and BPI on LPS-induced cytokine release by monocytes were counteractive. BPI interfered with the enhancing effect of LBP on the LPSinduced cytokine release. At high LBP to BPI ratios, BPI could no longer inhibit LBP-induced enhancement. In accordance, increasing concentrations of BPI abrogated the LBP effects.

In order to analyze the mechanism of these antagonistic activities, it was studied whether LBP and BPI compete for binding to LPS. To this end, an assay was used that detects binding of free BPI to an anti-BPI $\mathrm{mAb}$, which will be further described below. Presence of LPS prevented binding of BPI to anti-BPI mAb, whereas preincubation of LPS with LBP prevented this inhibition, indicating that LBP and BPI bind on the same site of LPS.

It was therefore concluded that the antagonistic effects of LBP and BPI are due to competition for binding to LPS (Figure 1), as was confirmed by other reports $(27,28)$. These data indicate that the balance between BPI and LBP levels determines LPS activity under physiologic conditions. Although BPI, in contrast to LBP, is not present in blood of healthy individuals, levels can be enhanced during disease, as will be discussed below.

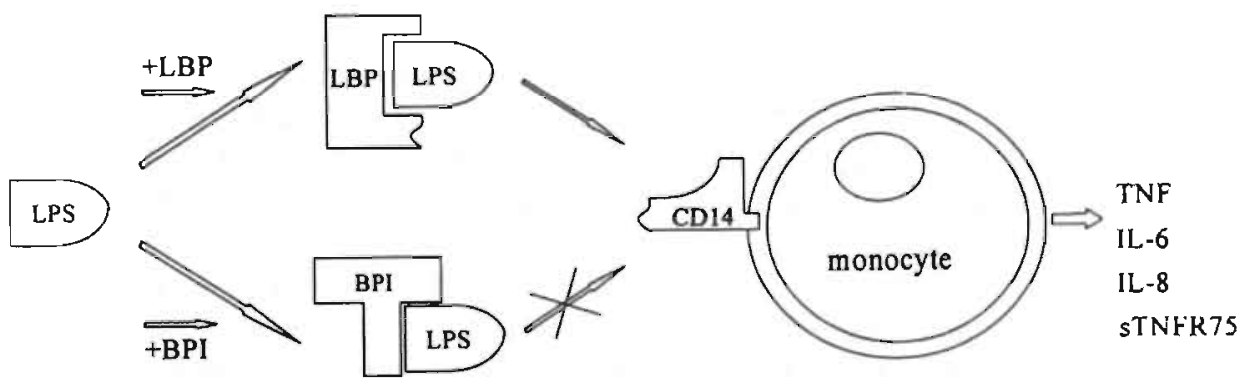

Figure 1. LBP and BPI have antagonistic effects upon LPS-induced monocyte activation. This antagonistic effects are due to competion for interaction with LPS. Whereas the interaction of LPS with LBP results in CD14 mediated monocyte activation, BPI binding blocks LPS interaction with CD14 and, thus prevents cell activation.

The PMN protein BPI, which was originally characterized as a potent bactericidal protein (29), thus appears to be a very important protein neutralizing LPS-induced 
cell activation. Next, the presence of this protein in health and disease was investigated. Firstly, mAb directed against BPI were developed and characterized (Chapter 7).

Two BPI-specific mAb, named $4 \mathrm{E} 3\left(\mathrm{IgG}_{1}\right)$ and $5 \mathrm{D} 7\left(\mathrm{IgG}_{2 \mathrm{a}}\right)$ were generated. The specificity of these mAb was shown in several ways. Both mAb reacted with BPI coated on immuno-plates, in a BPI concentration dependent manner. In addition, the anti-BPI $\mathrm{mAb}$ coated in wells captured biotinylated BPI. These $\mathrm{mAb}$ recognized native $B P I$, but not BPI denatured by sodium dodecyl sulfate. Furthermore, the antiBPI mAb did not cross-react with LBP, a protein with high sequence homology to BPI (9).

The use of 4E3 and 5D7 in flow cytometry revealed that PMN contained intracellular BPI, which was confined to the granules in the cytoplasm, as shown by immunofluorescence. These data correspond to previous reports of the presence of BPI in azurophilic granules $(30,31)$. Furthermore, also low PMN surface expression of BPI was detected, in accordance with other studies $(32,33)$.

In addition, both anti-BPI mAb were able to block biological activity of BPI. The inhibition by BPI of LPS-induced limulus amebocyte lysate activation, and of LPSinduced TNF $\alpha$ release by monocytes, was prevented by $4 \mathrm{E} 3$ and by 5D7. Moreover, LPS was shown to interfere with the interaction of anti-BPI $\mathrm{mAb}$ with BPI in an enzyme linked immunosorbent assay (ELISA) system. Together, these data strongly suggest that both mAb recognize an epitope on BPI involved in the BPI-LPS interaction.

In chapter 7 it was described that BPI is present not only inside PMN, but also on the cell surface of PMN. Next it was investigated whether monocytes, which are extremely sensitive for LPS, also express the specifically LPS-binding protein BPI on their cell surface (Chapter 8). Flow cytometric analysis, using anti-BPI mAb $4 \mathrm{E} 3$ and 5D7, and anti-BPI mAb kindly provided by M. Marra (Incyte, Palo Alto, Ca) revealed that monocytes, express BPI on their cell surface. However, no indications for intracellular presence of BPI were obtained.

Furthermore, it was demonstrated that monocyte cell surface BPI binds LPS, because binding of anti-BPI mAb 4E3 (which, as described above, does not react with BPI to which LPS is bound) to cell surface BPI was strongly reduced after preincubation of cells with LPS. However, cell surface BPI did not contribute quantitatively to the interaction of LPS with the monocyte cell membrane, since preincubation of cells with 4E3 did not block binding of LPS to monocytes.

Although we assume that BPI is adsorbed by monocytes from the environment, no indications for this hypothesis were obtained, since incubation of monocytes with biotin labeled BPI, or with human serum, known to contain BPI, did not enhance the cell surface expression of BPI as compared to untreated cells. The origin and the function of BPI present on the surface of monocytes and PMN have therefore to be further elucidated. In a recent report it was shown that the monocytic cell line THP1 is able to adsorb exogenous BPI, which still exerted biological activity (34).

BPI which was originally shown to exert its bactericidal activity intracellularly (35), was recently shown to be released during pathological conditions and to perform 
biological activity under these conditions (36). These data indicate that BPI released by activated PMN can contribute to the protection against LPS and gram-negative bacteria. Therefore, the release of BPI induced by physiological agents was studied, using a human whole blood system (Chapter 9). BPI levels as present in plasma were detected using a BPI specific ELISA, which is described in more detail in the next study.

Out of a series of microbial agents tested LPS most potently induced BPI release. Exposure of whole blood to FMLP, serum treated zymosan (STZ) and Lipoteichoic acid (LTA) also lead to BPI release. In contrast, Staphylococcal enterotoxin B did not induce BPI release.

In addition, the inflammatory mediator $\mathrm{TNF} \alpha$ potently activated $\mathrm{PMN}$, via $\mathrm{TNFR}_{S 5}$, in whole blood to release BPI, whereas $\mathrm{IL}-1, \mathrm{IL}-8, \mathrm{PAF}$ and complement factor C5a hardly induced the release of BPI. The LPS-induced BPI release was not mediated via production of TNF $\alpha$, since agents blocking biological activity of TNF $\alpha$ did not affect LPS-induced BPI release.

Whereas LPS, FMLP and LTA potently induced BPI release in whole blood these stimuli hardly activated isolated PMN to release BPI. This is in agreement with other reports showing that for release of azurophilic granules additional stimulation is required, like adherence to solid phase or stimulation with cytochalasin $\beta(37,38)$. These data further indicate that in whole blood other cellular or humoral factors are stimulated that are involved in the activation of PMN. In contrast, STZ and PMA a protein kinase $\mathrm{C}$ activator, seemed to activate PMN directly, since isolated PMN were stimulated to a similar magnitude as PMN in whole blood.

Also, BPI release was compared with release of the well studied azurophilic granule protein elastase (39). Elastase was shown to be present in PMN in considerable higher amount than BPI (approximately $3 \mu \mathrm{g}$ versus $200 / 10^{6} \mathrm{PMN}$ ). Expressing the amount of either protein released as percentage of total amount present, revealed that both proteins were released with similar magnitude. Furthermore, both BPI and elastase were released with similar kinetics, which started within 30 minutes after onset of stimulation and lasted up to 1 or 4 hours, suggesting that the release of both proteins is under similar regulatory control.

Although we demonstrated that LPS and TNF $\alpha$ are relatively potent inducers of BPI release, the maximal amount of BPI released was maximally $20 \%$ of total BPI content present in PMN. This indicates that major part of BPI will remain intracellular, and confirms other studies that under non-vigorously conditions BPI functions mainly intracellularly (35).

In order to further study the role of extracellular BPI and its impact on disease, BPI levels present in healthy volunteers and in patients with microbial infection were analyzed (Chapter 10). To this end, an ELISA for measurement of human BPI was developed, by using anti-BPI $\mathrm{mAb} 4 \mathrm{E} 3$ as catching reagent, and biotinylated polyclonal rabbit anti BPI IgG as detector. Since the presence of LPS disturbed detection of BPI in this ELISA, $80 \mathrm{mM} \mathrm{Mg} \mathrm{Mg}^{2+}$, known to prevent BPI-LPS interaction (40), was used in assay buffers. Furthermore, the use of $\mathrm{Mg}^{2+}$ in assay buffers also prevented aspecific adherence of the cationic BPI to solid phase. This newly developed specific BPI ELISA could be used for detection of BPI in 
biological samples and had a lower detection level of $200 \mathrm{pg} / \mathrm{ml}$.

In plasma of healthy volunteers no BPI was detectable. It was shown that PMN can be activated in collection tubes, indicating that proper collection is required, including the use of EDTA as anticoagulant as well as rapid handling of bloodsamples. In contrast to absence of BPI in healthy volunteers, in biological fluids of patients BPI was detected. BPI was present in plasma of critically ill intensive care unit patients $(\mathrm{n}=60$; mean $4,8 \mathrm{ng} / \mathrm{ml})$, in bronchoalveolar lavage fluid of patients suspected for pneumonia $(\mathrm{n}=25$; mean $16,2 \mathrm{ng} / \mathrm{ml})$, in wound fluid $(\mathrm{n}=18$; mean $1860 \mathrm{ng} / \mathrm{ml}$ ) and in pleural fluid ( $\mathrm{n}=44$; mean $3,1 \mathrm{ng} / \mathrm{ml}$ ). In subgroups of patients with culture proven bacteria mean BPI levels were enhanced compared with subgroups without bacteria, although the differences were only significant in plasma of intensive care unit patients.

Although it was shown in chapter 10 that BPI is released during pathological conditions, the biological effects of BPI will be affected by the presence of other endogenous LPS binding proteins like LBP and SCD14 $(15,41)$. Therefore, next the levels of all three of these LPS-activity modulating proteins were analyzed in bacteremic patients, and correlated with clinical parameters (Chapter 11).

BPI and LBP levels were significantly enhanced in bacteremic patients $(n=64)$ as compared to healthy controls ( $\mathrm{n}=49$ ) (mean, $8.4 \mathrm{ng} / \mathrm{ml}$ versus $<.2 \mathrm{ng} / \mathrm{ml} ; 216 \mu \mathrm{g} / \mathrm{ml}$ versus $16 \mu \mathrm{g} / \mathrm{ml}$ ), in accordance with other study $(42,43)$. sCD14 levels in bacteremic patients were not changed as compared to healthy controls, although in a subgroup of patients with gram-positive bacteria significantly higher sCD14 levels were detected as compared to a subgroup of patients with gram-negative infections $(2.7 \mu \mathrm{g} / \mathrm{ml}$ versus $2.2 \mu \mathrm{g} / \mathrm{ml})$.

The BPI/neutrophil ratio, which is used as an indicator for neutrophil activation, was significantly associated with the presence of sepsis syndrome and death in bacteremic patients. Furthermore, high peak LBP levels were significantly correlated with sepsis, but not with mortality. On the contrary. patients with sepsis syndrome were observed to have reduced sCD14 levels, as opposed to another study (44).

Analyzing the kinetics of BPI and LBP levels in a subgroup of patients revealed that levels of both proteins were already enhanced before demonstration of positive blood culture. Since LBP and BPI exert antagonistic effects concerning LPS-induced cell activation, the ratio of these proteins was also analyzed, which did not correlate with mortality.

BPI and LBP probably exert their main functions locally at the site of infection, therefore the exact role of enhanced circulating BPI and LBP levels as detected in bacteremic patients remains unclear. It can be speculated that, due to leakage, circulating levels reflect levels locally present. Indications that at site of infection BPI can be present at greater concentrations than LBP, thus able to exert its biological function were provided by studies of Opal et al. showing a BPI/LBP ratio $>1$ in abscess fluid (45). 
In conclusion, a series of studies was performed to obtain more insight in the pathways of LPS action. First, it was demonstrated that TNF $\alpha$ is an important intermediate in the phenomenon of the enhanced sensitivity for LPS obtained after exposure to lead. Furthermore, it was shown that monocyte membrane CD14 is a general 'LPS-receptor' since this antigen is involved not only in the LPS-induced release of pro-inflammatory cytokines but also in the LPS-induced shedding and downregulation of TNFR. These LPS activities were enhanced by LBP, facilitating the binding of LPS to CDI4, and blocked by the PMN protein BPI. Furthermore, both proteins were demonstrated to have antagonistic effects, due to competition for binding to LPS. Besides, it was revealed that CD14 is also involved in LPS-induced endothelial cell activation.

In addition, studies on the potent LPS neutralizing protein BPI were performed, using newly developed antibodies. It was shown that monocytes, like PMN, express BPI on their cell surface. Furthermore, analysis of BPI release in whole blood revealed that LPS and TNF $\alpha$ are relatively potent inducers of BPI release. However, major part of BPI remained inside PMN, indicating that BPI functions mainly intracellularly. In blood of healthy volunteers no BPI was detectable, whereas in biological fluids of several patient groups BPI was present. The biological function of extracellular BPI will depend on the levels of other endogenous LPS binding proteins. It was observed that in infectious lesions like wound fluid, high BPI levels were present, and it can be expected that under these conditions BPI will contribute to fluid phase protection against LPS. However, under less rigid conditions, BPI most probably mainly contributes to LPS defense as an intracellular protein. Further studies are required on the function of this protein, which could possibly serve as therapeutic agent in protection against LPS and gram-negative bacteria. 


\section{REFERENCES}

1. Berczi I, Bertók L, Bereznai T. Comparative studies on the toxicity of Escherichia coli lipopolysaccharide endotoxin in vartous animal species. Can J Microbiol 1966;12:1070-1.

2. Seyle H, Tuchweber B, Bertók L. Effect of lead acetate on the susceptibility of rats to bacterial endotoxins. J Bacteriol 1966;91:884-90.

3. Tracey KJ, Cerami A. Tumor necrosis factor: a pleiotropic cytokine and therapeutic target. Annu Rev Med 1994:45:491-503.

4. Honchel R, Marsano L, Cohen D, Shedlofsky S, McClain JC. Lead enhances lipopolysaccharide and tumor necrosis factor liver injury. J Lab Clin Med 1991;117:202-8.

5. Lehmann V, Freudenberg MA, Galanos C. Lethal toxicity of lipopolysaccharide and tumor necrosis factor in normal and D-galactosamine-treated mice. J Exp Med 1987;165:657-63.

6. Leist M, Gantner F, Bohlinger I, Tiegs G, Germann PG, Wendel A. Tumor necrosis factorinduced hepatocyte apoptosis precedes liver failure in experimental murine shock models. Am J Pathol 1995; 146:1220-34.

7. Goyert SM, Haziot A, Jiao D, Katz IR, Kruger C, Ross J, Schütt C. CDI4 cluster workshop report. In: Schlossman SF, Boumsell L, Gilks W. et al. Leucocyte typing V: white cell differentiation antigens. Oxford: Oxford University Press, 1995:778-90.

8. Wright SD, Ramos RA, Tobias PS, Ulevitch RJ, Mathison JC. CD14, a receptor for complexes of lipopolysaccharide (LPS) and LPS binding protein. Science 1990;249:1431-3.

9. Schumann RR, Leong SR, Flaggs GW, et al. Structure and function of lipopolysaccharide binding protein. Science 1990;249:1429-31.

10. Baggiolini $M$, Dewald $B$, Walz A. Interleukin-8 and related chemotactic cytokines. In: Gallin J, Goldstein IM, Snyderman R. Inflammation: basic principles and clinical correlates. 2nd ed. New York: Raven Press, 1992:247-63.

11. Hirano T, Akira S, Taga T, Kishimoto T. Biological and clinical aspects of interleukin 6 . Immunol Today 1990;11:443-9.

12. Heumann D, Gallay P, Barras C, et al. Control of lipopolysaccharide (LPS) binding and LPSinduced tumor necrosis factor secretion in human peripheral blood monocytes. $\mathrm{J}$ Immunol 1992;148:3505-12.

13. Lee J-D, Kato K, Tobias PS, Kirkland TN, Ulevitch RJ Transfection of CD14 into 70Z/3 cells dramatically enhances the sensitivity to complexes of lipopolysaccharide (LPS) and LPS binding protein. J Exp Med 1992;175:1697-1705.

14. Pohlman TH, Harlan JM. Endotoxin-endothelial cell interactions. In: Morrison DC, Ryan JR. Bacterial endotoxic lipopolysaccharides vol 1: Molecular biochemistry and cellular biology. Boca Raton: CRC Press, 1992:347-71.

15. Frey EA, Miller DS, Jahr TG, Sundan A, Bažil V, Espevik T, Finlay BB, Wright SD. Soluble CDI4 participates in the response of cells to lipopolysaccharide. J Exp Med 1992;176:1665-71.

16. Haziot A, Rong G-W, Silver J, Goyert SM. Recombinant soluble CD14 mediates the activation of endothelial cells by lipopolysaccharide. J Immunol 1993;151:1500-1507.

17. Tartaglia LA, Goeddel DV. Two TNF receptors. Immunol Today 1992;13:151-3.

18. Porteu F, Nathan C. Shedding of tumor necrosis factor receptors by activated human neutrophils. J Exp Med 1990;172:599-607.

19. Van Der Poll, Jansen J, Van Leenen M, et al. Release of soluble receptors for tumor necrosis factor in clinical sepsis and experimental endotoxemia. J Infect Dis 1993;168:955-60.

20. Burger D, Dayer J-M. Inhibitory cytokines and cytokine inhibitors. Neurology 1995;45(suppl 6):S39-S43.

21. Mohler KM, Torrance DS, Smith CA. et al. Soluble tumor necrois factor (TNF) receptors are effective therapeutic agents in lethal endotoxemia and function simultaneously as both TNF carriers and TNF antagonists. J Immunol 1993;151:1548-61.

22. Elsbach $\mathbf{P}$, Weiss $\mathbf{J}$. Bactericidal/permeability increasing protein and host defense against gramnegative bacteria and endotoxin. Curr Opin Immunol 1993;5:103-7.

23. Tobias PS, Mathison JC, Ulevitch RJ. A family of lipopolysaccharide binding proteins 
involved in the responses to gram-negative sepsis. J Biol Chem 1988;263:13479-81.

24. Marra MN, Wilde CG, Griffith JE, Snable JL, Scott RW. Bactericidal/permeability-increasing protein has endotoxin-neutralizing activity. J Immunol 1990;144:662-6.

25. Tobias PS, Soldau K, Ulevitch RJ. Identification of a lipid A binding site in the acute phase reactant lipopolysaccharide binding protein. J Biol Chem 1989;264:10867-71.

26. Gazzano-Santoro H, Parent JB, Grinna L, et al. High-affinity binding of the bactericidal/permeability-increasing protein and a recombinant amino-terminal fragment to the lipid A region of lipopolysaccharide. Infect Immun 1992;60:4754-61.

27. Heumann D, Gallay P, Betz-Corradin S, Barras C, Baumgartner J-D, Glauser MP. Competition between bactericidal/permeability-increasing protein and lipopolysaccharide-binding protein for lipopolysaccharide binding to monocytes. J Infect Dis 1993;167:1351-7.

28. Gazzano-Santoro $\mathrm{H}$, Mészáros $\mathrm{K}$, Birr $\mathrm{C}$, et al. Competition between $\mathrm{rBPI}_{23}$, a recombinant fragment of bactericidal/permeability-increasing protein, and lipopolysaccharide (LPS)-binding protein for binding to LPS and gram-negative bacteria. Infect Immun 1994;62:1185-91.

29. Weiss J, Elsbach P, Olsson I, Odeberg H. Purification and characterization of a potent bactericidal and membrane active protein from the granules of human polymorphonuclear leukocytes. J Biol Chem 1978;253:2664-72.

30. Weiss J, Olsson I. Cellular and subcellular localization of the bactericidal/penneabilityincreasing protein of neutrophils. Blood 1987;69:652-9.

31. Egesten A, Breton-Gorius J, Guichard J, Gullberg U, Olsson I. The heterogeneity of azurophil granules in neutrophil promyelocytes: immunogold localization of myeloperoxidase, cathepsin G, elastase, proteinase 3, and bactericidal/permeability-increasing protein. Blood 1994;83:298594.

32. Marra MN, Wilde $\mathrm{CG}_{2}$ Collins MS, Snable JL, Thomton MB, Scott RW. The role of bactericidal/permeability-increasing protein as a natural inhibitor of bacterial endotoxin. J Immunol 1992;148:532-7.

33. Weersink A.J, Van Kessel KPM, Van den Tol ME, et al. Human granulocytes express a 55 $\mathrm{kDa}$ lipopolysaccharide-binding protein on the cell surface that is identical to the bactericidal/permeability-increasing protein. J Immunol 1993;150:253-63.

34. Bumett RJ, Lyden CA, Tindal CJ, Marra MN, Neely AN, Solomkin JS. Effects of bactericidal permeability-increasing protein upon mononuclear cell interactions with endotoxin-evidence for cell binding. J Endotox Res 1995;2:349-57.

35. Weiss J, Kao L, Victor M, Elsbach P. Oxygen-independent intracellular and oxygen-dependent extracellular killing of Escherichia coli S15 by human polymorphonuclear leukocytes. I Clin Invest 1985:76:206-12.

36. Weinrauch Y, Foreman A, Shu C, Zarember K, Levy O, Elsbach P. Weiss J. Extracellular accumulation of potently microbicidal bactericidal/permeability-increasing protein and pi $5 \mathrm{~s}$ in an evolving sterile rabbit peritoneal inflammatory exudate. J Clin lnvest 1995:95:1916-24.

37. Nathan CF. Neutrophil activation on biological surfaces: massive secretion of hydrogen peroxide in response to products of macrophages and lymphocytes. J Clin Invest 1987;80:1550-60.

38. Zurier RB, Hoffstein S, Weissmann G. Cytochalasin B: efect on lysosomal enzyme release from human leukocytes. Proc Natl Acad Sci U S A 1973;70:844-8.

39. Janoff AJ. Elastase in tissue injury. Annu Rev Med 1985;36:207-16.

40. Mannion BA, Kalatzis ES, Weiss J, Elsbach P. Preferential binding of the neutrophil cytoplasmic granule-derived bactericidal/permeability increasing protein to target bacteria: implications and use as a means of purification. J Immunol 1989;142:2807-12.

41. Marra MN, Thomton MB, Snable JL, Leong S, Lane J, Wilde CG, Scott RW. Regulation of the response to bacterial lipopolysaccharide by endogenous and exogenous lipopolysaccharide binding proteins. Blood Purif 1993;11:134-40.

42. Calvano SE, Thompson WA, Marra MN, et al. Changes in polymorphonuclear leukocyte surface and plasma bactericidal/ permeability-increasing protein and plasma lipopolysaccharide binding protein during endotoxemia or sepsis. Arch Surg 1994;129:220-6.

43. Gallay P, Barras C, Tobias PS, Calandra T, Glauser MP, Heumann D. Lipopolysaccharide 
(LPS)-binding protein in human serum determines the tumor necrosis factor response of monocytes to LPS. J Infect Dis 1994;170:1319-22.

44. Landmann R, Zimmerli W, Sansano S, Link S, Hahn A, Glauser MP, Calandra T. Increased circulating soluble CD14 is associated with high mortality in gram-negative septic shock. J Infect Dis 1995;171:639-44.

45. Opal SM, Palardy JE, Marra MN, Fisher Jr CJ, McKelligon BM,Scott RW. Relative concentrations of endotoxin-binding proteins in body fluids during infection. Lancet 1994;344:429-31. 
$-159-$ 


\section{DE AFWEER TEGEN BACTERIËLE ENDOTOXINE: DE ROL HIERIN VAN CD14, LBP EN BPI}

Infectie met ziekteverwekkende bacteriën, of de verplaatsing van bacteriën, zoals Escherichia coli, vanuit de darmholte het lichaam in, kan schadelijke gevolgen hebben voor de mens. Deze bacteriën dringen in weefsels binnen waar ze zich kunnen vermenigvuldigen, terwijl ze daarnaast giftige stoffen (toxinen) produceren.

De mens bezit een uitgebreid afweersysteem tegen bacteriën. Een grote groep van bactcriën, namelijk de gram-negatieve bacteriën, wordt door het afweersysteem herkend via een specifiek bestanddeel van de bacterie wand, het endotoxine (beschreven in hoofdstuk 1). De naam endotoxine is afgeleid van 'endogeen toxine', oftewel toxine van binnen uit. Endotoxine is opgebouwd uit een vet gedeelte (lipide) en een suiker gedeelte (poly-saccharide) en wordt om die reden ook aangeduid als lipopolysaccharide of LPS. Door de interactie van het afweersysteem met endotoxine wordt een reeks van processen geactiveerd die allen bijdragen aan de bescherming tegen gram-negatieve bacteriën. Het endotoxine is dus een unieke herkenningsstructuur voor het afweersysteem waardoor dit systeem tegen de grote groep van gram-negatieve bacteriën kan reageren. Een aantal facetten van de verschillende onderdelen van het afweer systeem op endotoxine, worden hier kort beschreven.

De aanwezigheid van endotoxine in het bloed leidt tot de activatie van zogeheten complement eiwitten, die samen het complement systeem vormen. Het complement systeem draagt op meerdere manieren bij aan de verdediging tegen bacteriën. De geactiveerde complement eiwitten tasten de membraan van de bacterie aan, hetgeen leidt tot sterfte van de bacterie. Ook activeren complement eiwitten de cellen van de afweer die betrokken zijn bij het opruimen van vreemde deeltjes zoals bacteriën. Daarnaast binden complement eiwitten het endotoxine, en in deze complexe vorm wordt het endotoxine gemakkelijker herkend door de cellen van de afweer, en vervolgens onschadelijk gemaakt.

Een ander systeem dat door endotoxine wordt geactiveerd is het stollings systeem. De interactie van endotoxine met stollingsfactoren in het bloed leidt tot de vorming van een bloedstolsel. Dit draagt bij aan de bescherming tegen bacteriën, omdat de bacteriën die worden gevangen in het bloedstolsel zich niet verder kunnen verspreiden in het lichaam. Een andere reactie van het lichaam op endotoxine is de inductie van koorts, hetgeen wordt veroorzaakt door activatie van de hypothalamus, een zenuwcentrum in de hersenen. De verhoogde lichaamstemperatuur remt de deling van micro-organismen en activeert de verdediging van de gastheer.

Naast de reacties van eiwitten in het bloed spelen ook cellen, en in het bijzonder die van het afvecrsysteem, een belangrijke rol in de verdediging tegen endotoxine/gram-negatieve bacteriën. Twee belangrijke cellen van de afweer zijn de granulocyt en de monocyt. Granulocyten vormen 60-70\% van de cellen die in het bloed circuleren, en zijn gespecialiseerd in het opruimen van vreemde deeltjes/bacteriën. Na specifieke interactie van de bacterie met de celwand (de 
celmembraan) van de granulocyt wordt de bacterie door een deel van de wand omstulpt en als een zakje naar binnen gehaald. In de granulocyt zijn verscheidene blaasjes (granules) met toxische eiwitten aanwezig, die versmelten met het blaasje waarin de opgenomen bacterie zit en deze onschadelijk maken.

De monocyt vormt ongeveer $5 \%$ van de totale hoeveelheid circulerende cellen in de bloedbaan, en kan net als de granulocyt, bacteriën opnemen en onschadelijk maken. Daarnaast zijn monocyten in staat om na prikkeling door endotoxine, hormoon-achtige stoffen, de zogenaamde cytokinen te produceren en af te geven. Cytokinen zijn boodschapper moleculen met vele functies waaronder het activeren van andere cellen van de afweer en het aantrekken van deze cellen naar de plaats van de ontsteking. Ten gevolge van deze activiteiten ontstaat een versterkte afweer.

De gastheer heeft dus een aantal mogelijkheden om te reageren op, en zich te verdedigen tegen, endotoxines en dus tegen gram-negatieve bacteriën. Echter, het is belangrijk dat de activiteiten van deze verdedigingsmechanismen goed gereguleerd worden. Immers een té sterke activiteit, die voor kan komen indien er zeer grote hoeveelheden bacteriën aanwezig zijn, of indien er een overgevoeligheid voor endotoxine bestaat, zoals beschreven bij astma patiënten, is schadelijk is voor de gastheer. Bijvoorbeeld, een niet goed gecontroleerde stolling kan ertoe leiden dat vaten dicht komen te zitten, terwijl het vrijkomen van eiwitten die bacteriën kapot knippen ook schadelijk kan zijn voor het eigen weefsel. Veel van de schadelijke effecten die optreden ten gevolge van een infectie met bacteriën blijken dan ook te worden veroorzaakt door de reactie van de gastheer op het endotoxine van gramnegatieve bacteriën.

In dit proefschrift staan een aantal onderzoeken beschreven die verricht zijn om meer inzicht te verkrijgen in de reacties van de gastheer op endotoxine. Dit inzicht draagt bij aan het ontwikkelen van therapieën waarmee overmatige reakties op, en dus schadelijke effecten van endotoxine voorkómen kunnen worden.

De gevoeligheid voor endotoxine van mens en verschillende diersoorten is niet gelijk. De mens reageert b.v. al op veel kleinere hoeveclheden endotoxine dan de muis en de rat, terwijl het konijn ook erg gevoelig is voor endotoxine. De gevoeligheid voor endotoxine kan onder bepaalde omstandigheden veranderen. $\mathrm{Na}$ blootstelling aan lood worden muizen veel gevoeliger voor endotoxine. In hoofdstuk 2 hebben we onderzoek gedaan naar het mechanisme dat hieraan ten grondslag ligt. Een belangrijk cytokine dat gevormd wordt door endotoxine geactiveerde monocyten is het TNF (Tumor Necrosis Factor). TNF speelt een essentiële rol in de ontstekingsreacties die veroorzaakt worden door bacteriën en endotoxine, terwijl grote hoeveelheden TNF toxisch zijn. Wij toonden aan dat het TNF belangrijk is in de verhoging van de gevoeligheid van muizen voor endotoxine na blootstelling aan lood. Ten eerste bleek dat lood óók de gevoeligheid van muizen voor TNF verhoogde. Ten tweede, na de blokkade van de biologische activiteiten van TNF was de sterfte ten gevolge van blootstelling aan lood en endotoxine sterk verminderd. Het cytokine TNF dat wordt geproduceerd na blootstelling aan endotoxine is dus bepalend voor de mate van gevoeligheid voor endotoxine. 
Vervolgens zijn studies uitgevoerd om na te gaan op welke manier het endotoxine de verschillende cellen van het afweer systeem activeert. Om op endotoxine te kunnen reageren moet er een specifieke herkenning van endotoxine met de cellen plaatsvinden. Deze interactie verloopt via bepaalde eiwitten gelokaliseerd op de membraan van de cellen, die het endotoxine herkennen en vervolgens een signaal de cel in sturen, hetgeen leidt tot celactivatie. Deze ontvanger-eiwitten worden ook receptoren genoemd.

Een membraaneiwit op monocyten waarvan bekend is dat het als receptor voor endotoxine functioneert is het CD14 eiwit. CDI4 bindt endotoxine en geeft signalen door die resulteren in de produktie van het cytokine TNF. Echter, in respons op endotoxine wordt door monocyten behalve TNF ook de cytokinen IL-6 en IL-8 geproduceerd. De studie beschreven in hoofdstuk 3 laat zien dat het CD14 eiwit eveneens betrokken is bij de door endotoxine veroorzaakte produktie van IL-6 en IL8. Dit werd aangetoond in monocyten van het bloed, en in alveolaire macrofagen, een monocyt-achtige cel die in de longen aanwezig is.

Endotheelcellen vormen de binnenbekleding van de bloedvaten. Deze cellen zijn ook in staat om op endotoxine te reageren. Het resultaat hiervan is ondermeer dat cellen van de afweer makkelijker naar het gebied van de infectie kunnen migreren. Aangezien het onbekend was via welk membraaneiwit de endotheel-cellen het endotoxine specifiek herkennen, hebben we onderzocht of CD14 hier eveneens een rol in speelt. In de studie beschreven in hoofdstuk 4 toonden we aan dat in de aanwezigheid van antistoffen (Y-vormige bloedciwitten die zeer specifiek een bepaald eiwit binden) die de biologische activiteit van CD14 blokkeerden, de endotheelcel activatie door endotoxine geremd was. Dit suggereert zeer sterk dat het CD14 eiwit betrokken is bij de endotheelcel activatie door endotoxine. Echter, omdat het niet lukte om het CD14 eiwit aan te tonen op de membraan van de endotheelcellen, was het onduidelijk op welke manier dit proces plaats vond. Verdere studies van andere onderzoeksgroepen hebben aangetoond dat het CD14 niet alleen voorkomt als membraan-gebonden eiwit, maar ook in een losse vorm, het soluble CDI4 (sCD14), circulerend in het bloed. Het sCDI4 bindt endotoxine en dit complex gaat een interactie aan met een onbekend eiwit op endotheelcellen, hetgeen resulteert in endotheelcel activatie.

TNF is in staat om andere cellen te activeren, hetgeen leidt tot een ontstekingsreactie. TNF interacteert met cellen via 2 specifieke membraaneiwitten, de TNF receptoren genaamd TNF receptor 1 (TNFR1) en TNFR2. Na activatie van cellen kunnen deze TNF-receptoren van de membraan afgesplitst worden, waardoor losse oftewel soluble TNF-receptoren (sTNFR) ontstaan. Deze sTNFR kunnen TNF binden, en op deze wijze de activatie van cellen door TNF beïnvloeden. In hoofdstuk 5 tonen we aan dat na de blootstelling aan endotoxine monocyten TNFR2 afsplitsen, volgens een proces dat plaats vindt via het membraan gebonden CD14 eiwit.

Eerdere studies hebben aangetoond dat in het lichaam verschillende eiwitten aanwezig zijn die de effecten van endotoxine kunnen beïnvloeden. Een van deze eiwitten is het LPS bindende proteïne (LBP), welke in het bloed circuleert en 
endotoxine bindt. Het complex van endotoxine en LBP kan veel gemakkelijker aan het membraan CD14 binden dan het losse endotoxine. Dit betekent dat in de aanwezigheid van LBP veel minder endotoxine nodig is voor binding aan membraan CD14, en dus voor cel activatie. In de studie beschreven in hoofdstuk 5 is verder aangetoond dat in de aanwezigheid van LBP veel minder endotoxine nodig was om het afsplitsen van de TNFR2 te induceren.

Een ander eiwit dat endotoxine bindt is het BPI (bactericidal/permeabilityincreasing protein), een eiwit aanwezig in de granule van de granulocyt. Van dit eiwit is bekend dat het de effecten van endotoxine kan remmen. In overeenstemming hiermee zagen wij dat het BPI de endotoxine geïnduceerde afsplitsing van de TNF receptor sterk verminderde.

De lichaamseigen, endotoxine bindende eiwitten LBP en BPI oefenen dus een tegengesteld effect uit met betrekking tot de endotoxine geïnduceerde monocyten activatie. LBP vergemakkelijkt de binding van endotoxine aan CD14 waardoor de monocyt bij een lagere endotoxine hoeveelheid geactiveerd wordt en de cel dus gevoeliger is voor endotoxine. Het BPI daarentegen remt de activatie van monocyten door endotoxine en maakt de cel ongevoeliger voor endotoxine. Bovendien is bekend dat de structuur van LBP en BPI veel overeenkomsten vertonen. In hoofdstuk 6 is de werking van beide eiwitten nader bekeken. We toonden aan dat LBP en BPI elkaars functie remmen. Indien een hoge LBP concentratie aanwezig was kon BPI de endotoxine geïnduceerde cytokine produktie door monocyten niet meer remmen, terwijl bij een hoge BPI concentratie LBP geen effect meer had op endotoxine. Deze tegenwerking bleek veroorzaakt te worden doordat LBP en BPI met elkaar competeren voor binding aan het endotoxine. Deze resultaten betekenen dat de verhouding tussen de hoeveelheid LBP en BPI bepaalt in welke mate endotoxine monocyten kan activeren.

Van het BPI eiwit was oorspronkelijk bekend dat het een bacterie dodend eiwit is. Aangezien BPI bovendien de biologische activiteiten van endotoxine kan remmen, zijn meerdere studies verricht naar dit granulocyt eiwit. Hiertoe zijn twee antistoffen, die specifiek het BPI herkennen, ontwikkeld en gekarakteriseerd, als beschreven in hoofdstuk 7. Met deze antistoffen werd de aanwezigheid van BPI in de granule van de granulocyt aangetoond, terwijl BPI ook aanwezig bleek te zijn op de celmembraan van de granulocyt. Daamaast waren beide antistoffen in staat de biologische activiteit van BPI te remmen.

Gebruik makend van deze anti-BPI antistoffen hebben we laten zien dat BPI niet alleen aanwezig is in de granulocyten, maar óók op de celmembraan van monocyten, hoofdstuk 8. Het BPI op de monocyt membraan was in staat om endotoxine te binden. Aangezien er geen aanwijzingen waren dat de monocyten zelf BPi produceren vermoeden we dat het BPI door de monocyten wordt opgenomen uit hun omgeving.

Vervolgens is nagegaan onder welke condities de granulocyten het BPI vrijmaken uit de granule in de cel en vervolgens afgeven in de omgeving. Hiertoe werd bloed (met 
de daarin aanwezige granulocyten) gestimuleerd met een aantal bestanddelen afkomstig van verschillende micro-organismen waaronder gram-negatieve bacteriën, alsook met cytokinen, hoofdstuk 9. Het bleek dat met name endotoxine, waartegen BPI specifiek gericht is, en TNF de afgifte van BPI het meest stimuleerden. Echter, de hoeveelheid BPI die uitgescheiden werd was nooit meer dan $20 \%$ van de totale hoeveelheid BPI aanwezig in de granulocyt. Dit betekent dat het grootste deel van BPI in de cel blijft. Deze resultaten suggereren dat de belangrijkste taak van BPI is om in de granulocyt de opgenomen bacterie te doden, of het binnengehaalde endotoxine te neutraliseren.

Ook is geanalyseerd of BPl aanwezig is in bloed van gezonde individuen en/of in verschillende lichaamsvloeistofien van patiënten, hoofdstuk 10. In bloed van gezonde personen was geen BPI aantoonbaar, terwijl in bloed van emstig zieke patiënten, in vocht afkomstig uit wonden, in pleuravocht en in vocht uit de longen van patiënten, wel BPI aanwezig was. Dit duidt erop dat de granulocyten van deze patiënten geactiveerd waren, of kapot waren gegaan, waardoor BPI was vrijgekomen.

Alhoewel het BPI aanwezig is in biologische vloeistoffen van patiënten (hoofdstuk 10), zal het biologisch effect van BPI op endotoxine mede worden bepaald door de aanwezigheid van andere endotoxine bindende eiwitten zoals LBP en sCDl4. Daarom zijn de hoeveelheden van deze drie eiwitten gemeten in een groep patiënten met een bacteriële infectie, hoofdstuk 11. In het bloed van deze patiënten waren, in vergelijk met gezonde personen, sterk verhoogde concentraties van LBP en BPI aanwezig, terwijl de hoeveelheid $\mathrm{SCD} 14$ niet was veranderd. De hoeveelheid LBP was gerelateerd aan het verergeren van het ziektebeeld, namelijk het optreden van een sepsis syndroom. De BPI/granulocyt ratio was ook gecorreleerd met het ontstaan van een sepsis syndroom, alsook met het overlijden van de patiënten. Deze data geven aan dat de hoeveelheden LBP en BPI in het bloed de ernst van de ziekte weerspiegelen.

Concluderend: In dit proefschrift zijn verschillende onderdelen van de gastheer respons op endotoxine geanalyseerd. We hebben aangetoond dat het cytokine TNF een belangrijke rol speelt in de verhoogde gevoeligheid voor endotoxine, die ontstaat na de blootstelling aan lood. Verder is duidelijk geworden dat membraan CD14 betrokken is bij vele effecten die endotoxine uitoefent op monocyten, namelijk de produktie van TNF, IL-6 en IL-8, maar ook de afsplitsing van één TNF-receptor (TNFR2). Deze effecten van endotoxine worden versterkt door LBP en geremd door BPI. LBP en BPI blijken elkaars werking op te heffen, doordat ze met elkaar concurreren voor binding op het endotoxine. Daarnaast is aangetoond dat het CDI4 eveneens een belangrijke rol speelt in de endotheelcel activatie door het endotoxine.

Verder zijn studies verricht met betrekking tot BPI. een endotoxine neutraliserend granulocyt eiwit. Antistoffen tegen BPI zijn ontwikkeld. Met deze stoffen kon worden aangetoond dat BPI ook op de membraan van monocyten voorkomt. Endotoxine en TNF blijken de meest sterke stimulatoren te zijn van BPI afgifte door granulocyten. Echter, omdat het grootste deel van BPI intracellulair blijft 
concluderen wij dat het de belangrijkste taak van BPI is om in de granulocyt, de opgenomen bacteriën/endotoxine te doden $\mathrm{cq}$ te neutraliseren. In het bloed van gezonde personen kon geen BPI aangetoond worden terwijl in vloeistoffen van patiënten wel BPI aanwezig was. De werking van dit extracellulaire BPI hangt af van de aanwezigheid van andere endotoxine bindende eiwitten. De hoeveelheden LBP en BPI aanwezig in het bloed van ernstig zieke patiënten bleken een maat te zijn voor de ernst van de ziekte. 


\section{PUBLICATIONS}

Dentener MA, Greve JW, Maessen JG, Buurman WA. Role of tumour necrosis factor in the enhanced sensitivity of mice to endotoxin after exposure to lead. Immunopharmacol Immunotoxicol 1989;11:321-34.

Dentener MA, Bažil V, Von Asmuth EJU, Ceska M, Buurman WA. Involvement of CD14 in lipopolysaccharide-induced tumor necrosis factor- $\alpha$, IL- 6 and IL-8 release by human monocytes and alveolar macrophages. $J$ Immunol $1993 ; 150: 2885-91$.

Dentener MA, Von Asmuth EJU, Francot GJM, Marra MN, Buurman WA. Antagonistic effects of lipopolysaccharide binding protein and bactericidal/permeability-increasing protein on lipopolysaccharide-induced cytokine relcase by mononuclear phagocytes; competition for binding to lipopolysaccharide. J Immunol 1993;151:4258-65.

Von Asmuth EJU, Dentener MA, Bažil V, Bouma MG, Leeuwenberg JFM, Buurman WA. Anti-CD14 antibodies reduce responses of cultured human endothelial cells to endotoxin. Immunology 1993;80:78-83.

Bažil V, Dentener MA, Buurman WA. CDI4 - myeloid cell surface receptor involved in bacterial lipopolysaccharide recognition. In: Levin J, Alving CR, Munford RS, Stütz PL. Bacterial endotoxin: Recognition and effector mechanisms. Elsevier Science Publishers, 1993:167-75.

Leeuwenberg JFM, Dentener MA, Buurman WA. Lipopolysaccharide LPS-mediated soluble TNF receptor release and TNF receptor expression by monocytes; role of CD14, L.PS binding protein and bactericidal/permeability-increasing protein. $J$ Immunol 1994;153:5070-6.

Dentener MA, Smit FT, Francot GJM, Buurman WA. Characterization of two monoclonal antibodies directed against bactericidal/permeability-increasing protein. J Infect Dis 1994;170:1483-9.

Dentener MA, Von Asmuth EJU, Francot GJM, Buurman WA. Interaction between $\mathrm{CD} 14$, lipopolysaccharide binding protein and bactericidal/permeability-increasing protein during lipopolysaccharide-induced cell activation. Prog Clin Biol Res 1994:388:59-70.

Von Asmuth EJU, Dentener MA, Ceska M, Buurman WA. IL-6, IL-8, and TNF production by cytokine and lipopolysaccharide-stimulated human renal cortical epithelial cells in vitro. Eur Cytokine Netw 1994;5:301-10. 
Dentener MA, Francot GJM, Smit FT, Froon AHM, Pennings H-J, Wouters EFM, Buurman WA. Presence of bactericidal/permeability-increasing protein in disease: detection by ELISA. J Infect Dis 1995:171:739-43.

Froon AHM, Dentener MA, Greve JWM, Ramsay G, Buurman WA. LPS toxicityregulating proteins in bacteremia. J Infect Dis 1995:171;1250-7.

Staal-van den Brekel AJ, Dentener MA, Schols AMWJ, Buurman WA, Wouters EFM. Increased resting energy expenditure and weight loss are related to a systemic inflammatory response in lung cancer patients. $J$ Clin Oncol 1995; 13:2600-5.

Dentener MA, Francot GJM, Buurman WA. Bactericidal/permeability-increasing protein, a lipopolysaccharide-specific protein on the surface of human peripheral blood monocytes. J Infect Dis 1996; 173:252-5.

Schols AMWJ, Buurman WA. Staal-van den Brekel AJ, Dentener MA, Wouters EFM. Evidence for a relationship between metabolic derangements and increased levels of inflammatory mediators in a subgroup of patients with chronic obstructive pulmonary disease. Thorax 1996;51:819-24.

Dentener MA, Francot GJM, Hiemstra PS, Tool ATJ, Verhoeven AJ, Vandenabeele $\mathrm{P}$. Buurman WA. Bactericidal/perneability-increasing protein release in whole blood ex vivo: strong induction by lipopolysaccharide and Tumor Necrosis Factor- $\alpha$. J Infect Dis 1997;175:108-17.

Bouma MG, Laan MP, Dentener MA, Buurman WA. Analysis of soluble adhesion molecules. In: Johnstone AP, Turner MW. Immunochemistry 2: A practical approach. Oxford: Oxford University Press, 1997; in press.

Bouma MG, Maessen JG, Weerwind PW, Dentener MA, Fransen EJ, De Jong DS, Buurman WA. Release of LPS toxicity-modulating proteins in patients undergoing cardiopulmonary bypass using non-coated and heparin-coated extracorporeal circuits. Chest 1997; in press.

Staal-van den Brekel AJ, Dentener MA, Drent M, Ten Velde GPM, Buurman WA, Wouters EFM. The enhanced inflammatory response in non small cell lung carcinoma is not reflected in the alveolar compartment. Respiratory Medicine 1997; in press. 


\section{NAWOORD}

Dat de bundeling van een aantal wetenschappelijke artikelen, samen met een inleiding en discussie, een 'boek' vormt, stelt mij in de gelegenheid een nawoord te schrijven, waar ik dankbaar gebruik van wil maken. Alhoewel alleen de naam van ondergetekende op de omslag van dit proefschrift prijkt, zou dit niet tot stand zijn gekomen zonder de bijdrage van velen. Graag wil ik een aantal personen met name noemen.

Als eerste natuurlijk mijn co-promotor Wim Buurman. Nadat ik via een stage vanuit de studie Gezondheidswetenschappen, kennis had gemaakt met het onderzoeks laboratorium van Algemene Heelkunde onder zijn leiding, zou ik 7 maanden op dit lab komen werken om enkele nieuwe technieken op te starten. Nu zijn we heel wat jaren en een promotie verder. Wim, dat het onderzoek van de afgelopen jaren heeft geresulteerd in dit proefschrift is in belangrijke mate te danken aan jouw enthousiasme, je scherpe blik en je motiveringsvermogen. Mijn (blijvende) stationering binnen de vakgroep Heelkunde nadat $i k$ binnen de vakgroep Pulmonologie was aangesteld, heeft mij in de gelegenheid gesteld om optimaal gebruik te maken van de binnen de Heelkunde aanwezige kennis en mogelijkheden.

Mijn promotor. prof.dr. Wouters. wil ik graag bedanken voor de, vanuit de vakgroep Pulmonologie, geboden mogelijkheden om aan het in dit proefschrift beschreven onderzoek te werken, en dit af te ronden met een promotie.

Dan mijn paranimphen: Gaby, je hebt een aanzienlijke bijdrage geleverd aan het onderzoek beschreven in dit proefschrift. Je praktische vaardigheden, kritische houding en grote betrokkenheid maakte de samenwerking erg prettig alsook zeer productief. Trudi, vanaf het aller-begin toen ik stage kwam lopen (en ver daarvoor) was jij aanwezig. Je bent een vast anker binnen de sterk wisselende groep van onderzoekersisters en je vriendelijke behulpzaamheid en je warme belangstelling maken je tot een zeer gewaardeerd anker/medewerkster.

De (oud)-medewerkers van het lab Algemene Heelkunde onder leiding van Win Buurman: Jet, Eckhardt, Ingeborg en Marc B, toen ik (geheel onervaren) binnenkwam was ik erg onder de indruk van jullie wetenschappelijke discussies. Gelukkig doet goed voorbeeld volgen. Albert Froon, als er monsters nodig waren van patiënten op de intensive care unit, kon ik altijd op jou rekenen. Maarten, Robbert-Kees, en Berry, het was erg gezellig om met jullie samen te werken. Marjan, en later Shirley, bedankt voor de ondersteunende secretariële werkzaamheden. Monique, Jessica, Nicole, en Marc D, naast het (harde) werk(en) staan ook gezelligheid en betrokkenheid hoog in het vaandel, hetgeen een zeer prettige werksfeer creert!

Medewerkers van het metabole lab Algemene Heelkunde, Ivo, Carlo, Dennis, Hans, Gabrie, Marcella, Maaike en Mick, alsook Bas, Mart-Jan, Vincent, en Stephen: de pauzes met vlaai (al blokkeren we dan de gang) en de gezamelijke labuitjes zijn altijd een aangename ontspanning.

Ook de aanwezigheid van student(-assistent)en brengt veel gezelligheid met zich mee. Graag wil de studenten noemen die een steentje hebben bijgedragen aan het onderzoek, te weten: Frieke Smit, Marika Laan, Sandra Verploegen, Joffrey KleinOvink, en Renske Bun. Verder natuurlijk Anita Vreugdenhil, naast een prettige 
samenwerking ontwierp je ook de omslag van dit proefschrift!

De vele bloeddonoren (en prikkers) waren essentieel voor de uitvoer van een groot deel van het onderzoek, mijn dank hiervoor.

Ook een aantal medewerkers van de vakgroep Pulmonologie wil ik met name noemen. Jeske, je bracht altijd leven in het lab van Heelkunde; het was erg gezellig om met je samen te werken. Herman-Jan, voor pleuravocht, BAL-vloeistof of longgerelateerde vragen kon ik bij jou aankloppen; op naar jouw proefschrift. Daarnaast wil ik waardering uitspreken voor de prettig samenwerken met Annemie Schols en Marjolein Drent, alsook voor de behulpzaamheid van de secretaresses.

De samenwerking met Anton Tool, Arthur Verhoeven (CLB, Amsterdam), Pieter Hiemstra (afdeling longziekten, AZL) en Peter Vandenaabele (Rijksuniversteit Gent, België) heeft geresulteerd in de data zoals beschreven in hoofdstuk 9, waarvan hier akte.

De leden van de beoordelingscommissie te weten, prof.dr. C.A.M.V.A. Bruggeman (voorzitter) prof.dr. M.P. van Dieijen-Visser, prof.dr. J. Kips, dr. G. Ramsay, prof.dr. E.Th. Rietschel, dank ik voor hun bereidheid het manuscript te willen beoordelen. Prof.dr. E.Th. Rietschel, thank you very much for critically reading this manuscript.

Dan als laatste degenen aan wie ik dit boekje heb opgedragen: pa en ma bedankt voor de ruimte en steun die jullie me gegeven hebben, tijdens mijn eerdere opleidingen van zeer dichtbij en tijdens dit onderzoek van wat grotere afstand. Johan, jij weet als geen ander wat het doen van onderzoek inhoudt. Je stond altijd voor me klaar, hielp me te relativeren en vierde met mij de (wetenschappelijke) successen.

Allemaal zeer hartelijk bedankt.

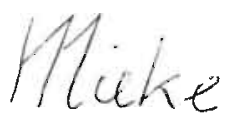


$-170-$ 


\section{CURRICULUM VITAE}

Maria Anna Dentener

7 oktober 1965

Geboren te Mierlo

aug 1978- juni 1984

Gymnasium $\beta$ : Gymnasium Beekvliet te StMichielsgestel

sept 1984- juni 1989

Studie Gezondheidswetenschappen. afstudecrrichting Biologische Gezondheidskunde. Universiteit Maastricht

sept 1989- sept 1991

Onderzoeksmedewerker bij de vakgroep Algemene Heelkunde, Universiteit Maastricht

okt 1991- maart 1995

Onderzoeksmedewerker bij NWO, ten behoeve van de vakgroep Pulmonologie, Universiteit Maastricht

aug 1994

'Young Investigators Award' van de '3 $3^{\text {th }}$ International Conference of the International Endotoxin Society', te Helsinki

april 1995 - sept 1996

Assistent in Opleiding bij de vakgroep Pulmonologie, Universiteit Maastricht

vanaf okt 1996

Post-doc aanstelling bij de vakgroep Pulmonologie, Universiteit Maastricht 
